\title{
Sound Maps and the Representation of Audible Space
}

\author{
Peter Louis Tschirhart
}

Houston, Texas

Bachelor of Music, Rice University, 2005

A Dissertation presented to the Graduate Faculty

of the University of Virginia in Candidacy for the Degree of

Doctor of Philosophy

Department of Music

University of Virginia

May, 2013

Michael J. Puri, Ph.D.

Fred E. Maus, Ph.D.

Edward J. Coffey, Ph.D.

Daniel Bluestone, Ph.D.

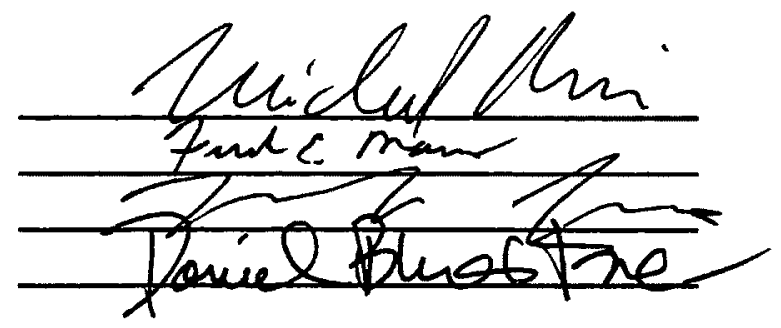


(C) Copyright by

Peter Louis Tschirhart

All Rights Reserved

May 2013 


\title{
Table of Contents
}

\author{
Abstract - iv \\ Acknowledgments - v \\ Introduction - 1
}

Chapter 1: Theorizing the Sound Map - 20

Chapter 2: A Typology for Environmental Sound Maps - 73

Chapter 3: Analyzing a "Territory" Sound Map - 123

Chapter 4: Sound Maps in Music Notation - 146

Chapter 5: Sound Mapping the Utopian City - 198

Conclusion - 254

Appendix: Figures -260

Bibliography - 309 


\section{Abstract}

This dissertation constructs a critical and cultural history of the "sound map," a notational practice that can be defined in two ways: first, as diagrams, spatial graphics, or geophysical representations that adopt sound as their thematic object; second, as a way of thinking, a specifically sonic consciousness, that situates the interaction between sound and space as co-productive. Acting as a conceptual bridge, sound maps link the idea for a "soundscape" back to the complex realities of sound's transience: its weather-like properties, which make sound difficult to study and impossible to root. Each chapter links sound maps to a particular theoretical or cultural moment. The first locates the conceptual development of the sound map among the work of Harvard physicist Wallace Sabine, whose acoustical research yielded not only useful quantitative models, but provocative visual demonstrations of sound's tendency to change as it moves through and interacts with the physical environment. The second and third chapters conduct a critical analysis of urban and environmental sound maps —from the publications of the World Soundscape Project, to "Noise Exposure Maps" overseen by the Federal Aviation Administration. In addition to proposing a broad typology, these chapters work to disentangle the visual form of sound maps from the methodologies used to construct them. The fourth chapter studies how composers during the mid- and latetwentieth century utilize sound maps as a discrete notational element, one that opens new possibilites for creative action and embodied performance. The fifth chapter traces the influence of sound maps onto the work of utopian cyberneticist Nicolas Schöffer, whose provocative vision for the city of the future asks us to consider how sonic indeterminacies might be re-composed dynamically, and in real time, to make urban life sound more pleasing. 


\section{Acknowledgements}

Seven years ago, when I arrived on the grounds of the University of Virginia as an eager (perhaps idealistic) and confident (perhaps buoyant) graduate student, there was no way I could have foreseen what an incredible experience I was about to have: the fascinating people I would meet, the ideas and philosophies that would challenge my worldview, the brilliant students I would teach, and the high-level expectations I would have to satisfy. Today, as I write this passage in the spring of 2013, I find myself remarkably changed, enlightened, and inspired-even as I admire the many (newly!) gray hairs I earned along the way. Suffice it to say, there are more people to thank than I could possibly name in just a few pages; but it would be unconscionable for me not to try.

I am profoundly indebted to Michael Puri, an incredible advisor and scholar, for his tireless and thoughtful feedback on my work. His mentorship from my earliest days at the university were formative, and his guidance gave shape to this dissertation in more ways than can be counted. I will be forever grateful for his willingness to engage with even the most extravagant and difficult of ideas (literally, from Adorno to Žižek), and to approach them with the seriousness and respect they deserve. I am also incredibly thankful for Ted Coffey, whose wonderful courses and brilliant compositions have served as a constant source of inspiration. I am especially grateful for Ted's sensitivity to issues of ethics and the environment-concerns which have greatly influenced and inspired my own work. I would also like to express tremendous gratitude to Fred Maus, a rigorous thinker and elegant writer whose work I greatly admire, and whose thoughtful mentorship I deeply appreciate. I am particularly glad that Fred introduced me to somatic and 
postmodern philosophies, including the work of Richard Shusterman and Richard Rorty, and that he served in an official capacity as my teaching mentor during much of my time at U.Va.

I am also profoundly grateful for my many friends and colleagues-from music and architecture; at U.Va. and Rice - who have encouraged me to think critically and creatively about sound, music, notation, power, the environment, and "everyday life." Special thanks to Vilde Aaslid, Bridger Bell, Erik DeLuca, Kirstin Ek, Emily Gale, Liz Markon, Marilyn Moedinger, Davis Niendorff, Shana Goldin-Perschbacher, Matt Jones, Chris Peck, Allison Robbins, Mary Simonson, Peter Traub, and Jonathan Zorn. Each of them, at one point or another, was gracious enough to read my work, provide comments, offer advice, participate in a survey, or more simply discuss music, critical theory, or the history of ideas over a cup of coffee. These interactions are what, for me, made graduate school such a rich and meaningful experience. I would also be remiss without thanking a few "instrumental" teachers from years past, all of whom provided countless moments of inspiration and encouragement: percussionist Doug Dement—an accomplished Deleuzian; organists Carol Nave and Linton Powell; harpsichordists Jane Clark and Matthew Dirst. Their guidance has been essential. Thanks also to the many librarians from across the university who assisted me with research over the past seven years. Erin Mayhood, Winston Barham, and so many others were always enthusiastic and supportive of my work.

Tremendous thanks are due also to Nancy Takahashi, Principal of Hereford College, who gave me the opportunity to do something tangible with my life when not 
writing, editing, deleting, re-writing, trashing, re-editing, and otherwise finishing my dissertation. From managing the Hereford Undergraduate Research Scholars, to chaperoning trips to New York City: Hereford gave me invaluable professional experience and allowed me to make many wonderful new friends among the students, faculty, and staff at U.Va. I value tremendously the friendship of my fellow Coordinators of Study, past and present: Renee Gondek, Bob Tappan, Elizabeth Molacek, and Petra Turner. But it has been a special pleasure getting to know many of the fellows and students, too. I can imagine few better ways to spend an afternoon than conversing with such brilliant and engaging colleagues as John Alexander, Bill Anderson, Raf Alveredo, Nancy Damon, Rich Gregory, Paul Harris, Steve Macko, David Morris, Diana Morris, Lisa Shutt, Karl Shuve, Jeanne Siler, Winston Lung, and many, many others. Thanks to them.

Needless to say, there is also a long list of friends and family whose constant support and encouragement made this dissertation possible. Special thanks to George Padaroff and Dorothea Muller, both of Charlottesville, Virginia, for their incredible friendship, and for many wonderful evenings spent drinking wine and discussing music, politics, world affairs, and the future of human civilization. I am also greatly indebted to Ellen and Peter Wolf in Crailsheim, Germany, whose constant and enthusiastic support, even from another continent, reminded me I was never alone. I truly cannot thank them enough. I am also grateful for my grandmother, Audrey Tschirhart of San Antonio, Texas, for her optimism, open-mindedness, and enthusiastic encouragement. Thanks also to my cousin, Beth Shelby of Bakersfield, California, for sticking with me through thick and 
thin. Her eagerness to engage with deep and challenging ideas is truly inspirational. I am also thankful beyond words for my brother, Stephen Tschirhart of Houston, Texas, for his enduring friendship, and for his willingness to discuss any topic under the sun-even when it seemed far too specialized to be of any interest.

I would also like to acknowledge the constant presence of Simon and Lucy, both of whom found many novel ways to be "helpful" over the years: chasing string, hunting bugs, and sitting on loose paper, wool blankets, and laps.

Most importantly of all, however, I wish to thank Brian Smith for being my best friend, companion, and true life partner. This dissertation would not have been possible without you. 


\section{Introduction}

It is the very structure of cartographic reason that - far from inscribing a single determinate line-draws and redraws our world, erases and inscribes again, decodes and recodes, in a ceaseless and complex array of forms of deterritorialization and reterritorialization producing the multiple and shifting identities (or assemblages) we take as ourselves.

—John Pickles, A History of Spaces

Put the tracings back into the map, connect the roots or trees back up with a rhizome. -Gilles Deleuze and Félix Guattari, $A$ Thousand Plateaus

\section{Scaping Sound}

The goal of this dissertation is to sketch a critical and cultural history of the sound map-a notational practice that developed alongside acoustical science at the end of the $19^{\text {th }}$ century, and that proliferated throughout the arts, cultural geography, and urban studies during the middle of the $20^{\text {th }}$. In the following chapters, I will scrutinize four interrelated subjects: the advent of sound maps as a critical-theoretical practice; the use of sound maps as a tool in environmental, cultural, and urban sound analysis; the appearance of sound maps in musical notation and their reciprocal influence on the perceived boundaries of notation as such; and the consequent utopian efforts to re-map urban space as both a site and source of musical interest. To grasp why an analysis of sound maps is needed, however, it is important to first understand something of the historical and discursive context surrounding them.

Over the past 50 years, a growing chorus of scholars and artists has questioned how sound intersects with everyday life. Of course, the very modality of that question-how -suggests an underlying concern for methodology: the tools and assumptions we use to develop answers will inevitably inform the kind of information we gather, the conclusions we draw, and more importantly, the general nature of the interactions we 
observe. And in fact, from Marxist theory to music, the methodologies used to-date have proven quite diverse. Where spatial theorist Henri Lefebvre asked us to analyze the "rhythms" of everyday life, ${ }^{1}$ composer John Cage encouraged us to appreciate sounds "just as they are, apart from psychology about them."

Perhaps the most powerful and influential framing device to have developed, though, is the idea that there exists a "scape" of sound -an equivalent to a "landscape" or "streetscape"--some thing that can be studied aurally in the way others scapes are studied visually and materially. The concept of "soundscape" was articulated with particular clarity by the aptly named World Soundscape Project (WSP). At its height during the 1970s, the WSP included a number of influential music, sound, and communications scholars as members, including R. Murray Schafer, Barry Truax, and Hildegard Westerkamp. ${ }^{3}$ While their broad goal was to observe the balance among human, animal, natural and mechanical sounds, an important premise of their work is that many sounds-especially those of the factory, the car, and the airplane-have for decades seeped unchecked into everyday life, the aural equivalent of industrial runoff and chemical waste. In the process, these sounds have made scarce what the WSP called "hi-

\footnotetext{
1 Henri Lefebvre, Rhythmanalysis: Space, Time and Everyday Life (New York: Continuum International, 2004), 76-81.

2 John Cage, Silence (Middletown, CT: Wesleyan University Press, 1939), 83.

${ }^{3}$ R. Murray Schafer, The Tuning of the World, New York: Knopf, 1977; Westerkamp in particular has recently been highlighted as the subject of a doctoral dissertation. See: Andrea Shirley Jean McCartney, Sounding Places: Situated Conversations Through the Soundscape Compositions of Hildegard Westerkamp, Ph.D. Diss, York University (Toronto, Ontario), 1999.; Truax, Acoustic Communication.
} 
fi" listening environments, ${ }^{4}$ places of relative quiet which allow us to hear and appreciate the intricate and easily masked sonic textures of more pleasant sounds, including those of chirping birds and rustling trees. Many of these same acoustic pollutants, they said, have also dirtied our "clean ears"-in part by creating a culture of omnipresent sound, where the whooshing of traffic or the "moozak" of shopping malls surrounds us constantly. 5

Emerging at a time of great concern about industrial pollution, human health, and the future of Earth, it is difficult to view the WSP too far removed from the modern environmental movement. Rachel Carson's influential book Silent Spring, published in 1962 , is commonly credited for being one (if not the) spark igniting the movement; and while there does not appear to be any direct connection between her ideas and WSP research - at least, none is directly credited - it is worth noting some of the philosophical and methodological synergies between them. One especially clear example can be seen in the title of Carson's book, which referenced the medium she believed would first alert us to impending environmental collapse:

There was a strange stillness. The birds, for example-where had they gone? ... It was a spring without voices. On the mornings that had once throbbed with the dawn chorus of robins, catbirds, doves, jays, wrens, and scores of other bird voices there was now no sound; only silence lay over the fields and woods and marsh ... No

${ }^{4}$ R. Murray Schafer, ed., The Vancouver Soundscape (Vancouver: A.R.C. Publications, 1978), 48; Schafer explains: "The hi-fi soundscape is one in which discrete sounds can be heard clearly because of the low ambient noise level. The country is generally more hi-fi than the city; night more than day; ancient more than modern .... The lo-fi soundscape results when accidental, trivial, or boring sounds are allowed to proliferate unchecked." (48)

$5 \mathrm{lbid}$., 54. Schafer not only identifies omnipresent music as a problem, but suggests a solution: "Throughout history music has existed as figure-a desirable collection of sounds to which the listener gives special attention. Moozak reduces music to ground. It is a deliberate concession to lo-fi-ism. It multiplies sounds. It reduces a sacred art to a slobber. Moozak is music that is not to be listened to. By creating a fuss about sounds we snap them back into focus as figures. The way to defeat Moozak is, therefore, quite simple: listen to it." (54) 
witchcraft, no enemy action had silenced the rebirth of new life in this stricken world. The people had done it themselves. ${ }^{6}$

Sound, or the lack of it, was for Carson the proverbial "canary in a coal mine"-the way we would finally come to realize we have passed the point of no return, the point at which the chemical sprays of modern agriculture and the mystery emissions of modern industry had yielded far more than record crop yields and consumer goods on a gigantic scale.

The shared sonic terminology here is deceptive, though, because there is a crucial distinction between how the WSP defines "silence" and how Carson does. For her, it is a natural (or rather, unnatural) silence that is to be feared, one where everything except humans has gone quiet. A silent world for Carson is a dead world, or one very near to it. But the WSP explains silence altogether differently. Their usual focus is "human silence"- the kind where cars, busses, and trucks disappear, leaving behind only the preindustrial sounds of a world where people have a limited acoustical impact. Silence, from this point of view, is not to be totally avoided; in fact, it would be necessary for Carson's model of "listening for collapse" to ever work.

Other scholars during this period began from a different starting point but reached quite similar conclusions. For instance, during the mid 1960s, Michael Southworth and a small team of researchers at MIT undertook a survey of Boston. ${ }^{7}$ Their "exploratory study" emerged from concern not about audible pollution as such, but rather the city's

${ }^{6}$ Rachel Carson, Silent Spring, 40 ${ }^{\text {th }}$ Anniversary Edition (New York: Houghton Mifflin Harcourt, 2002), 2-3.

7 Michael Southworth, "The Sonic Environment of Cities," Environment and Behavior 1, no. 1 (June 1969): 49-70. 
aural structure, which they believed had become confused and distorted. Interesting is that Southworth's team approached this problem from what might be called a prototypical form of disability studies. "Blind persons," they wrote "rarely develop stable images of cities or other large and complex environments but at best have images of common trips." 8 The picture he paints is especially bleak for people who have suddenly become deaf: they risk living a life of "ceaseless pantomime," distanced and detached from the world, plagued by "depression ... feelings of loss, lack of alertness, sadness, loneliness, and paranoid tendencies." As a "link to reality," sound allows people to grasp how the city functions, how different neighborhoods and areas are stitched together. ${ }^{10}$ So to analyze this web of relations, Southworth's team enrolled willing participants in a wheelchair tour of the city of Boston. Their goal was to observe how sound influences our sense of place, how it gives shape to the environment as we experience it. Paying more attention to these considerations, they suggested, "would not only enhance city life by helping to overcome the stress and anonymity of today's visual city, but would be one measure for developing the sensory awareness of city residents and would provide an environment more responsive to human action and purpose."11

Many principles of "soundscape" analysis have since been adopted by scholars in other fields. Following closely on WSP ideals, anthropologist Steven Feld approached his work with the Bosavi people in Papua New Guinea with a decidedly aural focus. In

\footnotetext{
8 Ibid., 50.

9 lbid., 51.

10 lbid., 52.

11 Ibid., 70.
} 
studying "sound as a cultural system," the aim of his influential book Sound and Sentiment was to show how "modes and codes of sound" can lead us to a greater understanding not only of a society's internal or political structure, but of the quality of life its people experience. ${ }^{12}$ During the early 2000 s, Feld developed his work into a number of CD releases, which function, as Sarah Pink has written, "as invitations to listen in a particular embodied way ... [offering] listeners a route through which to hear as others might."'13

\section{Sound Fixed and Unfixed}

Not all scholars have jumped on the bandwagon of soundscape analysis or soundscape composition—or even agree such a thing as a "soundscape" exists. In 2007, British anthropologist Tim Ingold penned a clear and compelling essay expressing his belief that the attempt to "scape" sound is altogether problematic. To scape, he writes, is to make stable; and this makes the notion of a soundscape inherently incompatible with sound, which "is neither mental nor material, but a phenomenon of experience, that is, of our immersion in, and commingling with, the world in which we find ourselves."14 From Ingold's point of view, it is wrong to suppose "that the power of hearing inheres in recordings." 15 Sound cannot be subject to taxidermy: it cannot simply be extracted from the field, removed from active engagement, understood in the abstract "head space" of

\footnotetext{
12 Steven Feld, Sound and Sentiment: Birds, Weeping, Poetics, and Song in Kaluli Expression (Philadelphia: University of Pennsylvania Press, 1990), 3.

13 Sarah Pink, Doing Sensory Ethnography (Los Angeles and London: Sage, 2009), 143.

14 Tim Ingold, "Against Soundscape," in Autumn Leaves: Sound and the Environment in Artistic Practice, ed. Angus Carlyle, (Paris: Double Entendre, 2007), 11.

15 Ibid., 11.
} 
another person while maintaining cohesion. Neither is sound a thing, strictly speaking: it is compression waves moving through air. As a result, Ingold argues, we should not think of sound as something that we hear; instead, we should think of it as a medium we hear in. He writes:

Sound flows, as wind blows, along irregular, winding paths, and the places it describes are like eddies, formed by a circular movement around rather than a fixed location within. To follow sound, that is to listen, is to wander the same paths. Attentive listening, as opposed to passive hearing, surely entails the very opposite of emplacement. We may, in practice be anchored to the ground, but it is not sound that provides the anchor ... the sweep of sound continually endeavors to tear listeners away, causing them to surrender to its movement. It requires effort to stay in place. And this effort pulls against sound rather than harmonizing with it. Place confinement, in short, is a form of deafness. ${ }^{16}$

The ultimate risk is in positing the existence of an audible space that is falsely tangible, one where "persons and objects [have been] already precipitated out, or solidified, from these fluxes." ${ }^{17}$ Even still, Ingold argues most anthropologists and sound scholars today remain focused on what is stable about sound, the "fixities of surface conformation," rather than its changes, "the fluxes of the medium."18

An alternative, he suggests, is to think of sound as always-already in motion, as a phenomenon that cannot possibly be rooted. Rather than vision and sight, a better analogy for sound he suggests can be found with weather: "[w]e do not touch the wind," he writes, "but touch in it; we do not see sunshine, but see in it; we do not hear rain, but hear in it." 19 Sound, from this point of view, must not be reified. While certainly temporal, sound only becomes audible before quickly fading; while certainly structural,

\footnotetext{
16 lbid., 12.

17 lbid.

$18 \mathrm{lbid}$.

19 Ibid.
} 
its exact form slips away before it can be fixed. Because sound is difficult to "scape," Ingold explains, "our metaphors for describing auditory space ... should be derived not from landscape studies but from meteorology."20

While the sudden rise in soundscape research on its own might present reasonable cause for concern, Ingold's critique is arguably unfair, since some parts of this scholarship already does what he proposes: to treat sound as a kind of weather. Indeed, a "minor" practice visible even among WSP scholarship is maps meant to place sound among a constantly shifting field of audition, of culture, of weather-all designed to show movement, change, and evolution. ${ }^{21}$ These maps show sound as well as any weather map can: as a phenomenon passing through a city, noticed or unnoticed. Sound, through a kind of metaphorical exchange, becomes visible as lines, dots, scribbles, or icons: present visually, but not audibly.

As Valérie Maffiolo has written, maps of sound have clear methodological advantages. Unlike recordings, which risk essentializing a journey through sound technologically, the "graphic mode" she writes, "allows us to stress the diversity of levels

20 Ibid.

21 The "minor" as I use it here is a concept developed by Gilles Deleuze and Félix Guattari to describe the transfer of power back-and-forth among symbolic forms of authority, including language and other representational systems. As Verena Conley explains, Deleuze's argument, which is commonly used by postcolonial theorists, is that "we need to distinguish between major and minor language, that is, between a power (pouvoir) of constants and a power (puissance) of variables. In the political sphere where a 'major' language is seen and heard, there also inheres in its form a 'minor' element that does not exist independently or outside of its expression and statements. The more a language has or acquires the characteristics of a major form, the more likely it is to be affected by continuous variations that can transpose it into a minor language." (Verena Conley, "Minoritarian," in The Deleuze Dictionary, ed. Adrian Parr [Edinburgh: Edinburgh University Press, 2005], 164.) The concept of the "minor" has resonance here because of the way sound maps act within the dominant discourse of soundscapes. See also: Gilles Deleuze and Félix Guattari, Kafka: Toward a Minor Literature, trans. Dana Polan (Minneapolis: University of Minnesota Press, 1986). 
of abstraction for sound representations in human memory." 22 Maps, though, are not just useful in showing what people perceive or recall from past experience. They can also be used to track and locate sound empirically, much as weather maps track the approach of cold fronts and storm cells. This has been proven especially appealing to scholars seeking to study how sound shapes the formation of community identity. Moreover, as Olivier Balaÿ has written, "ready-made" maps, including those backed by interactive GIS software, could become a site of interactive place-based engagement with sound. Drawing on his work at the Centre de recherche sur l'espace sonore et l'environnement urbain (CRESSON), Balaÿ argues sound maps, much like online weather maps, could provide "new ways of exploring and organising auditory journeys for its users." 23 Maps and mappings have emerged, if not as an alternative to film- or recordingbased analysis, then certainly as a way to supplement it. But perhaps also, and more importantly, they stand to enrich the continued development of critical spatial theory. As Edward Soja has explained, the failure of Marxist theory to fully develop a broad theory of space can be understood as a failure to appreciate how "[t]he structure of organized space is not a separate structure with its own autonomous laws of construction and transformation, nor is it simply an expression of the class structures emerging from the social ... relations of production. ${ }^{24}$ Where theorists including Lefebvre and David Harvey have sought causal relationships- -whether the production of space drives

\footnotetext{
22 Valérie Maffiolo, et al, "Sound Characterization of Urban Environment," Inter-noise 3 (1997), 1242.

23 Olivier Balaÿ, "Discrete mapping of urban soundscapes," translated by Harry Forster, Soundscape: The Journal of Acoustic Ecology 5, no. 1 (Spring/Summer 2004): 14.

${ }^{24}$ Edward Soja, "The Socio-Spatial Dialectic," Annals of the Association of American Geographers 70, no. 2 (June 1980), 208.
} 
economic relations (or vice versa), and furthermore, whether that relationship manifests in the physical structure of the city-Soja proposes something more extensive. He writes, "the two sets of relations are not only homologous, in that they arise from the same origins in the mode of production, but also dialectically intertwined and inseparable."25

The appearance of sound as a domain of inquiry, and sound maps as a modality of inquiry, suggests further ways to enrich the development of Marxist spatial discourse. Attempts to link sound with participatory action mean what Soja has sketched as a socialspatial dialectic might be expanded with a third term: social-sonic-spatial. In the same way "the urban" is homologous with relations of production, it may well be that sound is, too. Like tracking "economic weather," sound maps could be used to facilitate this kind of critique: tracing fluctuations in sound, linking them to the activities and behaviors of everyday life, connecting them back to economic and state interests. They could furthermore add a potentially complementary trajectory to the study of power, one that can enrich (when not more simply complicate) our understanding of the political economy. ${ }^{26}$

\section{Exchanging Metaphors}

An obvious question remains why a music scholar would be interested or qualified to analyze sound maps - not only their visual aspects, but the power operations they conceal. Apart from the obvious involvement of sound, and in some cases the organization of sound-both of which are particular areas of expertise for musicians-a more specific answer is that the kind of metaphorical exchange sound maps perform - the

25 Ibid., 209.

26 Some of these issues will be addressed in Chapter 3 of this dissertation. 
transformation of lines, dots, fields, arrows, gradients, and numbers into representations of sound, action, direction, and movement-is one that scholars of notation are already familiar with. Similar exchanges are common among works of music and performance art from the mid $20^{\text {th }}$ century. In many of them, artists challenge not only what a symbol means, but how and on what terms the notation implicates sound in the first place.

This kind of exchange is modeled with particular clarity in two works. One is Composition 1960, \#10 by american composer La Monte Young. The score itself consists of nothing more than a simple, unadorned text: "Draw a straight line and follow it." The use of a simple, enigmatic text as a performance instruction was, of course, commonplace among experimental art and music during the $1960 \mathrm{~s}$ and $70 \mathrm{~s}-$ especially among a casual group of artists associated with Fluxus, including George Maciunas, Ben Patterson, Alison Knowles, Dick Higgins, and others. Playing with language, as Young does here, raises important questions about the relationship between text, score, and implied action, questions, ultimately, about the capacity of language to function instrumentally. As art historian Liz Kotz has argued, works like \#10 suggest the appearance of an "alternate poetics," one that "[emerged] in the postwar era as a counter-model to the earlier avantgarde practices of asyntacticality, musicality, and semiotic disruption."27

If this alternate poetics can be understood as an attempt at counterposing the deconstructionist idea of the text as performative, \#10 takes a step back from the precipice of disintegrating language and, instead, asks us to view the instructions naively: first, as simply what they are and what they say; and second, as the object of exploration,

27 Liz Kotz, Words to Be Looked At: Language in 1960 s Art (Cambridge, MA: The MIT Press, 2007), 64. 
not merely performance. But it is at this point-where language seems momentarily to reacquire meaning and become actionable, where poetic simplicity becomes its most disruptive-complexity and contradiction return. Whatever clarity there was in the beginning evaporates quickly once words become not just objects of contemplation but of performance. Beginning the process requires us to approach the line as fundamentally relational - much as Ingold has written: "any history of the line has to start with the relations between lines and surfaces. ${ }^{28}$

Young's text asks us not only to read between the line, as it were, but in a literal sense to question the ontology of line-ness. What is the relationship between a drawn line and the act of following it? What line? How can it be "followed?" One paradoxical possibility Young's piece suggests is that, by trying to draw a straight line, we find we cannot: we can only produced curved, wiggly, or disjointed lines. But even if we accept the idea of a compromise, of drawing a "relatively straight line," there remains the problem of how to "follow" it. Also possible, perhaps even likely, is that we might "draw" a line entirely in the metaphorical sense-as in the colloquial expression to make a "bee-line." And this suggests another possible paradox: we draw the line by following it first. The line becomes, almost immediately, a representation of something else: the representation of a path already walked.

It is here that a second work becomes important. Among the voluminous score for Song Books by John Cage are three relevant songs: numbers 3, 4, and $25 . .^{29}$ In each of

\footnotetext{
28 Ingold, Against Soundscape, 38.

29 John Cage, Song Books, Volume I: Solos for Voice: 3-58 (New York and London: C.F. Peters, 1970).
} 
these pieces, the performer is instructed to travel a map of Concord, Massachusetts by drawing an uninterrupted line between two points. (Figure 0-1) While the starting and ending points are determined in advance by the I-Ching, and further written into the instructions, the indeterminate route between them must conform to the shape, contour, and limitations of the represented space: foot paths, bridges, walkways, and so on. In "Solo No. 3," for instance, Cage instructs: "[g]o from Fair Haven Hill down the river by boat and then inland to the house beyond Blood's. Turn the map so that the path you take suggests a melodic line." 30

Somewhat like \#10, the line here appears first as a site and object of a performance, since in Cage's instructions, drawing it becomes equivalent to actually traveling a path. But, in being traveled, the path acquires another layer of meaning: it becomes a continuous melodic glissando, whose cartographically determined twists and turns imply changes in pitch, and whose length implies general duration. The line is not only "followed" in a more standardly "musical" sense, but in fact is connected to indeterminate movement and (relatively) indeterminate pitch. The line and map together function doubly: as already-sonic representations of space-as-sound; and conversely, as already-spatial representations of sound-as-movement.

Cage's songs and map of Concord make literal what in Young's enigmatic instructions is merely implied. That is to say, if in \#10 the line becomes the performance, in Cage's Song Book, the map becomes a site where lines acquire specific spatial and sonic meaning. Indeed, in a more conventional sense, if lines are not thought to be

30 Ibid., 2. 
performative, and if cartographic space is presumed to be silent, then these two works together challenge our assumptions about both drawing and cartography. Together, they encourage us not simply to locate sound by "tracing" it, but to view those tracings as themselves performing sound; they ask us to rethink not just the nature of the line, but to reconsider as already-musical the space it is drawn through. And as the "glue" in these visual and sonic metaphors becomes unstuck, they make conceptual space for the analysis not only of the superficial structure and technical operations of notation, but the relational implications beneath the surface.

While the notion of a "musical line" itself has a complex history, and in fact Ingold himself has written on the subject, ${ }^{31}$ lines here become not just the object and medium of notation, but metaphorical lines of demarcation: signaling the point at which the surface of the map becomes sonically "charged," the moment when graphical marks - dots, dashes, icons, symbols, speckles, or flags embedded on a digital surface-acquire specifically sonic implication. Context is everything; and despite what we might be tempted to think simply by looking at them, no such notational construct is ever entirely innocent - they conceal almost by design the choices that were made about their construction. The need for critique therefore appears with special urgency.

\section{Plan of the Current Work}

Jacqueline Waldock has recently described sound maps as "a new interactive, publicly engaging medium," one that "has emerged in sonic studies over the last decade" while capturing "the imagination of acoustic societies, libraries, universities, and tourist

31 Tim Ingold, Lines: A Brief History (London and New York: Routledge, 2007), 18-24. 
organisations alike." ${ }^{\prime 32}$ Similarly, Balay observed in the journal Soundscape that "[n]ever before have we devoted so much energy to mapping physical measurements of urban sound environments." ${ }^{33}$ Against the grain, one overarching claim of this dissertation is that sound maps are not "new" in either conception or practice; and moreover, as the work of Maffiolo and others have suggested, their usefulness is not limited simply to the representation of physical sound measurements. Indeed, while sound maps have great promise as an analytical tool, they can also be found today in a number of diverse contexts, including subjective sound surveys, online crowd sourcing projects, and even visual art. Inadvertently but necessarily, however, sound maps function also as instruments of power, capable of advancing discourse or closing it off. This dissertation aims, therefore, to study sound maps as objects and tools of power, as a creative and potentially worrisome form of notation.

In Chapter one, I locate the conceptual emergence of the sound map among the work of acoustics pioneer Wallace Sabine. His work at Harvard University at the turn of the $20^{\text {th }}$ century is often thought to mark the foundational moment for modern acoustical science. This well-known story takes as its starting point the discovery of scientific formulas capable of predicting and controlling certain "spatial" properties of sound, like reverberation; but in doing so, this genealogy encourages us to overlook a counterbalancing development: maps and diagrams that, far from showing space as stable

\footnotetext{
32 Jacqueline Waldock, "Soundmapping: Critiques and Reflections on this New Publicly Engaging Medium," Journal of Sonic Studies 1, no. 1 (October 2011), http://journal.sonicstudies.org/vol01/ nr01/a08 (accessed 23 April 2012), np.
}

33 Balaÿ, “Discrete mapping," 13. 
and unchanging, depict sonic environments as fluid and inconsistent, changing from moment to moment and place to place.

In concept, sound maps appear among Sabine's work as photographs and other novel diagrams showing the fluctuation and movement of sound even within a highly controlled laboratory setting. And because these images emerge alongside acoustical science as it is traditionally understood, I suggest they perform a needed act of critique by making difficult the desire to control space, to render it homogeneous and stable. These images, I suggest, more accurately follow a model proposed by Fredric Jameson (the "cognitive" map) and Gilles Deleuze and Félix Guattari (the map as "rhizome"). From these maps, a kind of critical-dialectical practice emerges from within the very heart of scientific efforts to manipulate the environment as stable; and in chasing what I call the "sonic Real," they make other incarnations of the sound map conceptually possible.

In the second chapter, I study sound maps as they are used in environmental and urban sound studies: from the World Soundscape Project, to digital/online collaborative sound maps, and government sound surveys. But it is crucial not to be distracted by surface appearance. As historians like Brian Harley and John Pickles have explained, maps are never what they appear to be. Like other kinds of "thematic cartography," constructing a sound map necessarily involves making careful decisions about what to show and how to show it. Consequently, the bulk of Chapter 2 is dedicated to sketching a broad sound map typology. Although some general similarities exist between them, I propose that five types can be identified, defined according to a mixture of visual, technical, sonic, and methodological details: grid maps are defined by their visual texture; 
field maps can be distinguished by reflecting sites of sonic interest to a community; soundwalk maps guide us between or among specific sounds, much like musical notation; territory maps acquire instrumental and regulatory functions; dynamic maps become objects of community engagement at the (sometimes high) price of a confused and complicated ontology of sound.

While parsing each type necessarily involves highlighting salient features, then connecting them back to actual practice, I continue in Chapter 3 by conducting a brief case study of one particular sound map: a "territory" map, called Part 150 "Noise Exposure Maps" (NEMs), made through a voluntary noise program managed by the Federal Aviation Administration. Quite apart from the emancipatory rhetoric often surrounding sound maps, these maps in particular provide some cause for concern. I draw on the recent work of Michael Hardt and Antonio Negri to argue that, by serving as instruments of political authority, and through their interactions with the neoliberal economy, NEMs perform an act of "positive" enclosure-bracketing sound, placing it off limits - by dictating which sounds people must be willing to tolerate, and at what price.

In Chapter 4, I locate sound maps in creative and artistic practice, where they are used as a form of music notation. Unlike Cage and Young, whose works merely model the exchange and recombination of spatial and sonic metaphors, in this chapter, I explore compositions where sound maps are written-in to the score. I suggest this becomes visible in two contexts: first, in musical compositions supplemented by work-specific spatial graphics; second, in music where all aspects of conventional notation are abandoned, 
replaced by maps, photographs, or collages that seem otherwise hardly related to the production of sound or music at all.

Indeed, while there is nothing particularly unusual about a simple staging diagram, I argue here that sound maps are neither simple nor staging diagrams as such. More like older forms of so-called spatial music, including polyphonic choral music, these diagrams are designed to implicate space to produce selective effects. Unlike earlier forms, however, sound maps are quite explicit in how spatial indeterminacies are to be used: where the polyphonic works of Telemann leave space unnotated, the scores discussed in this chapter often leave no contingency unplanned, and yet, they hold short of becoming "universal" or "universalizing." Finally, while the spatial and representational mechanisms used in these works often resemble those of other place-based sound and performance artists-including Richard Long, Max Neuhaus, or even Guy Debord-I suggest sound maps are significant for being both explicitly spatial and focused openly on the production, audition, or movement of the performer through sound.

In Chapter 5, I again pick up the thread of environmental sound mapping, except this time, I connect it to a looming problem soundscape scholars have so far dealt with unsuccessfully: how to design the sounds of everyday life. I turn here in particular to the work of utopian cyberneticist and sculptor Nicolas Schöffer, who presented a thorough and ambitious plan in his 1969 book La Ville Cybernétique. Returning a sense of consistency and clarity to the city, he believed, would require implementing five topologies, one of which, sound, entailed broadcasting dynamically-processed musique concrète from giant cybernetic towers. In Schöffer's work, the city itself becomes the site 
and source of a large, interactive, and indeterminate musical composition. While Schöffer's work is often discussed in literature on sculpture and architecture, his ambitious proposal to re-map the city sonically has yet to be analyzed by scholars in either music or sound studies. In this chapter, then, I not only explain how Schöffer understood sound and planned to make use of it, but why he thought re-imagining the urban environment was necessary to begin with. I conclude by locating La Ville Cybernétique among extant critical literature, which, though dismissive, often fails to consider its positive philosophical and practical dimensions. I also briefly highlight how Schöffer's vision conforms to what theorist Jacques Attali called the "future of music:" a collaborative process of community music making he called "composing."

Acting as a conceptual bridge, sound maps link the idea for a "soundscape" back to the complex realities of sound's transience: its weather-like properties, which make sound difficult to study and impossible to root. As contemporary research grapples with questions no single discipline can answer alone, I believe sound maps in their many varieties will continue to emerge both as useful tools in our interdisciplinary toolbox, and as insightful subjects for critical and cultural analysis. While much remains to be written on the subject of sound maps, I hope this dissertation will open fruitful new areas of collaborative inquiry—especially for scholars working in music, sound studies, the digital humanities, urban studies, cultural geography, and sound art. 


\section{Chapter 1: Theorizing the Sound Map}

The map is open and connectable in all its dimensions; it is detachable, reversible, susceptible to constant modification. It can be torn, reversed, adapted to any kind of mounting, reworked by an individual, group, or social formation. It can be drawn on a wall, conceived of as a work of art, constructed as a political action or as a mediation.

-Gilles Deleuze and Félix Guattari, $A$ Thousand Plateaus

\section{Introduction}

Given the relatively unfamiliar subject of this dissertation, it seems appropriate to begin with a definition. Sound maps are spatial diagrams or cartographic representations that adopt sound as their thematic object. How exactly this theme manifests-for instance, the kind, type, quality, or moment of sound the maps show-varies greatly depending on context and use; and indeed, disentangling this complexity will become a central focus of later chapters. But it is important to realize that sound maps are not just visual objects. They also, and perhaps more significantly, exemplify a certain way of thinking about the world, a way that gestures toward bridging material and experiential forms of analysis. This conceptual groundwork is important for understanding the more practical and tangible aspects of sound maps; and for that reason, I wish to begin this dissertation by addressing questions of thought, culture, and theory: How do we think about the relationship between sound and space?

To search for an answer, I will turn first to the development of acoustical science. Extant historical literature paints a predictable picture: sound appeared first as a mysterious and slippery object of analysis, a seemingly amorphous non-thing, which, to be understood, had to be quantified and transformed into general principles and stable laws. This narrative is crystalized in the familiar work of Wallace Sabine, whose research at Harvard University during the late $19^{\text {th }}$ and early $20^{\text {th }}$ centuries is often thought to mark 
the foundation of modern acoustical science-the moment when, as Emily Thompson has written, the "soundscape of modernity" was born.' I will therefore begin by narrating this story, except with an important difference. Here, I draw Sabine's work into dialogue with earlier research on sound and acoustics. My goal is to explain how his experiments, as they are understood today, can be said to draw on the Cartesian matrix of "matter and motion." Although a detailed critique of this idealogical, historical, and scientific complex deserves to be fully mounted, what I suggest warrants specific scrutiny here is not Sabine's empirical methodology, or indeed his specific conclusions, but rather the underlying cultural and environmental impulses it articulates: the desire both to exert mastery over the environment and to discipline the bodies inhabiting it.

I continue by proposing an alternate sonic consciousness, a different way to think about the relationship between sound and space, one comparably less concerned with exerting control. I do this, however, by returning to Sabine's work, by re-reading it, paying special attention to a series of visual diagrams scattered throughout his collected papers-images I call "sound maps." While seldom discussed and usually treated as selfexplanatory, a closer analysis highlights the important way these diagrams differ from other, more idealized and idealizing forms of analysis. In showing a complex, temporally constrained, and otherwise "messy" reality, sound maps empower us to study and appreciate the aural environment without the corresponding need to fabricate what Fredric Jameson calls a "totalizing discourse."

\footnotetext{
1 Emily Thompson, The Soundscape of Modernity: Architectural Acoustics and the Culture of Listening in America, 1900-1933 (Cambridge, MA: MIT Press, 2002), 107-13.
} 
It is important also to be aware of the way sound maps function: theoretically how, and philosophically why, they perform such a vital, if under-appreciated role in the study of the audible everyday. As I will suggest, sound maps are difficult to describe and explain, at least initially, because of our tendency to seek absolutes. I will therefore turn briefly to the ontology of Gilles Deleuze, whose notion of "univocity" provides a way for us to think about ordinary experience as singular and yet highly textured. That is to say, rather than being strictly physical- $\mathrm{a}$ (abstract) space into which (an abstract notion of) sound is later injected—sound maps allow us to analyze the environment as already and richly filled with sound. As hybrid visual-sonic representations, they encourage us to embrace this apparent messiness rather than flatten, simplify, or overgeneralize it.

In the end, I address a looming question: What is to stop sound maps from becoming precisely the form of "ideal discourse" I have suggested they resist? To answer, I explain how sound maps function as part of what Lacan called the Symbolic-Real. These images are inherently impossible to complete-technically, physically, acoustically, and representationally. There are simply too many variables and too many contingencies that would change, in a meaningful way, what the map is designed to show. As a result, the final image we call "a map" becomes the implicit object of repetition; and at that very moment, the map is itself transformed: from an object of vision, to an object of desire. As common, familiar, or self-explanatory as they may seem, sound maps bring not just a new awareness of the world, but a new kind of awareness - one where complexity, rather than stability, where maps and mappings, rather than laws and truths, emerge as a legitimate area of interest. 


\section{Part I: From Speculation to Certainty}

In 1895, Wallace Sabine was contacted by Charles Eliot, the President of the Corporation of Harvard University. As a physics professor, Sabine was asked to apply his knowledge of electricity and the properties of electromagnetic waves to a somewhat more tangible problem. ${ }^{2} \mathrm{~A}$ lecture hall inside the newly completed Fogg Art Museum was thought to be far too resonant for ordinary usage, distorting the spoken word to the point of unintelligibility. Sabine was therefore asked to analyze the space while holding three specific tasks in mind: the first was to uncover the material and acoustical faults of the hall itself; the second was to devise an effective strategy to remedy these faults; the third, and most challenging, was to develop general principles that could be used to assess and evaluate other spaces, and to prevent similarly unwanted outcomes in the future. ${ }^{3}$

As straightforward as these tasks might seem, there was no existing methodology, no research procedure, and no general principles of acoustics on which Sabine could rely. Indeed, the extent to which acoustical science lagged behind other fields of inquiry is perhaps surprising. Even at the turn of the $20^{\text {th }}$ century, long after comparable laws of gravity and electricity had been established, sound remained a slippery and difficult object of study. Beliefs about sound - what it was, how it moved and behaved, the way it managed to stir the passions-remained rooted in an almost anxious uncertainty, and it was certainly not unusual to find apparently sober acoustical wisdom tinged with mysticism. A common belief during the end of the $19^{\text {th }}$ century, for instance, was that

\footnotetext{
2 Wallace Sabine, Collected Papers on Acoustics (Cambridge, MA: Harvard University Press, 1922), 3.

3 Ibid., 34.
} 
twice-built blueprints would yield spaces with different acoustical profiles. ${ }^{4}$ Retrofits were likewise dubious. One frequent fix entailed suspending long lengths of metal wire parallel to the floor, just below the ceiling. ${ }^{5}$ (Figure 1-1) The wire, it was believed, would absorb excess vibrations sympathetically, thereby mitigating excessive reverberation. ${ }^{6}$ Other remedies were meant to have the opposite effect. It was thought, for example, that placing vases of different sizes and shapes throughout a room would help to make it more resonant-a solution, which, Sabine writes, was "wrongly supposed to have been the object of the vases in Greek theatres."

The uncertainty surrounding acoustics was by no means new, however, and in fact could be said to have quite deep historical roots. As far back as the $16^{\text {th }}$ century, sound research often seemed to be balanced precariously between the domains of the natural and the supernatural, and only seldom could any distinction be drawn between speculative and operative modes of inquiry. Where, as science historian Penelope Gouk has explained, the "speculative side is concerned with the underlying causes of things and providing explanations for particular phenomena," the operative is more concerned with expanding the bounds of human understanding, demystifying the nature of universal

4 Ibid., 62. Sabine dispatches this myth quickly:

The oft-repeated statement that a copy of an auditorium does not necessarily possess the same acoustical qualities is not justified, and invests the subject with an unwarranted mysticism. The fact is that exact copies have rarely been made and can hardly be expected ... Our increasing demands in regard to heat and ventilation, the restriction of the dimensions enforced by location, the changes in size imposed by the demands for seating capacity, have prevented, in different degrees, copies from being copies, and models from successfully serving as models.

5 Ibid., 4, 132.

6 Ibid., 4.

7 Ibid., 4. 
truths, perhaps even decoding the mind of an all-knowing and rational creator. ${ }^{8}$ Indeed, scientific investigations during this period often more closely resembled magic shows than careful and controlled laboratory experiments. Francis Bacon, for one, "proposed a whole series of experiments to see how the materials used in the construction of instruments ... determined qualities such as pitch and timbre." Moreover, his observational reports, though quite detailed, often touch on the occult. ${ }^{9}$ In his book Sylva, which contains some of his most important work on sound and hearing, Bacon explained how

if a Lute, or Viall, bee layed uppn the back with a small Straw upon one of the Strings; and another Lute or Viall bee laid by it; And in the other Lute or Viall, the Unison to that String bee strucken; it will make the String move...10

In Bacon's estimation, the most "interesting types of sound were those which seemed marvelous or unusual"- - those which seemed to defy immediate explanation, or which were too cumbersome or impossible to subject to staged investigation. ${ }^{11}$ This category included a number of otherwise spatial and architectural sound effects, such as strange echos resulting from peculiar geological formations. It also included

a church at Gloucester where 'if you speak against a Wall, softly, another shall hear your Voice better a good Way off, than neere hand,' a phenomenon which Bacon though merited further enquiry. ${ }^{12}$

\footnotetext{
8 Penelope Gouk, Music, Science and Natural Magic in Seventeenth-Century England(New Haven and London: Yale University Press, 1999), 93.

9 Francis Bacon, Sylva, quoted in Gouk, Music, Science, and Natural Magic, 169.

10 Ibid., 169.

11 Gouk, Music, Science, and Natural Magic, 161.

12 Bacon, quoted in Gouk, Music, Science and Natural Magic, 161-62.
} 
Public demonstrations, too, had more than purely scientific aims; they also played an important social and cultural role. In making the quirks of the natural world not only visible but, at times, audible, they helped generate common enthusiasm for the very field of empirical inquiry that scientists themselves hoped to advance.

\section{Making Math Work}

There nonetheless remained several important barriers to acoustical research.

Foremost among them was how to mediate experimental results. Despite that most aural phenomena "could not be quantified or expressed in mathematical formulae, and even those that seemed amenable to this process were still far from being fully understood,"13 mathematics still offered the most promising path forward. It was appealing primarily because of the way it functioned as an abstract instrument—one that, much like Bacon's lutes and viols, occupied

an intermediary position between knowledge of natural things, which rely on sense perception and conjecture, and knowledge of supernatural things, which are apprehended directly by the mind and produce certainty. ${ }^{14}$

Math, in that sense, was a somewhat modest tool that could be used to expose sound's tricks-to disempower it, even if only momentarily, so that the "strange participation among things" could be unearthed. ${ }^{15}$ To some scientists, however, math was thought to conceal a much deeper truth, one articulated by John Dee as early as 1570: that nature was itself regular and predictable. Following from this, as Gouk explains, math could function as an "intermediary" discipline operating "between the material and intellectual

\footnotetext{
13 Gouk, Music, Science, and Natural Magic, 158.

14 lbid., 86.

15 Ibid., 86-87.
} 
realms"16 - not only because math, itself, is internally coherent, but because beneath the observable surface, nature is constructed similarly. The underlying premises here-that sound can be accurately quantified, and that it behaves according to immutable, mathematical laws-consequently entail seeking vicarious access to something else, something more profound: a cosmic fabric whose threads were woven together in a regular and predictable way.

Indeed, as science philosopher Ronald Giere has written, it was widely believed that mathematics and similar rational systems were capable not only of exposing the hidden threads of the universe, but of granting us access to the loom. He explains:

The notion of a law of nature did not arise out of the practice of science itself. Sometime in the seventeenth century, it was imported into discourse about science from Christian theology, both directly, and indirectly through mathematics. Originally, laws of nature were understood as God's laws for nature. Thus, behind the laws of nature was a lawgiver, from whence came the universality and necessity of such laws. It is still common for scientists and commentators on science to speak of nature as being 'governed' by laws of nature, which suggest that somewhere there might be a 'governor.' It also seems pretty clear that this theological notion of laws of nature became prominent through the writings of Descartes. ${ }^{17}$

The notion of a rational and stable universe was indeed powerful and attractive. And as Giere suggests, it was taken in a new direction beginning in the mid $17^{\text {th }}$ century, when René Descartes presented his argument that the universe could be understood "as a plenum filled with infinitely divisible matter, which was effectively made up of three types."'18 Gouk clarifies:

16 Ibid., 86, 88.

${ }_{17}$ Ronald Giere, Scientific Perspectivism (Chicago: University of Chicago Press, 2006), 70.

18 Penelope Gouk, "Some English Theories of Hearing in the Seventeenth Century Before and After Descartes," in The Second Sense: Studies in Hearing and Musical Judgement from Antiquity to the Seventeenth Century, eds. Charles Burnett, Michael Fend, and Penelope Gouk (London: The Warburg Institute, University of London, 1991), 104. 
The first of these comprised large, irregular particles of 'gross matter' which formed solid bodies; the second consisted of smaller but still coarse spherical particles of air (which provided, among other things, the medium of sound); the third was made up of extremely fine particles which filled the spaces between the first and second types and was called 'subtle matter.' 19

This tripartite division provided a fundamental framework for analyzing the world as though it were configured mechanically. And indeed, the harmony Descartes observed among different materials suggested that sound, too, could be understood in terms both physical and physiological: as a series of vibrations, proceeding through one kind of matter to the next, from a vibrating string, through "subtle matter," until it influences human nerves. ${ }^{20}$ As Descartes saw it, this was a purely material relationship whose corresponding machinations were observable, measurable, and very probably controllable.

This belief consequently gave renewed importance to the study of "musical sound," which, as Gouk writes, "seemed to provide a perfect demonstration of the real, mathematical correspondence between the external world of particulate motion and the mind, which can grasp abstract relationships." ${ }^{\text {21 }}$ Much more than a useful and helpful way to explain the world, math, it seemed, was the way in which nature operated—it was how the world was knit together. Expressing sound and music mathematically-as simply and elegantly as possible - was tantamount to exposing the inner workings of the universe on its own terms. The power of this idea, what is called "Cartesian synthesis," was its palpable totality. ${ }^{22}$ As Gouk writes, "it explained everything at once--in
19 Ibid., 104.
20 Ibid., 105.
21 Ibid., 106.
22 Ibid., 106. 
twentieth-century terms, it was a 'grand unified theory." 23 Although it was not without its detractors, the underlying idea was, in the end, so compelling that even people who disagreed with various details "accepted its fundamental premise that matter and motion are the basis of explanation." 24 The rise to prominence of a mathematical and mechanistic world view was in itself an important indicator of the way in which we, as a society, would come to understand the world. It simultaneously set a standard for how future scientific observations would be expressed: by the numbers.

By the end end of the $19^{\text {th }}$ century, increasingly throughout the $20^{\text {th }}$, and well into the $21^{\text {st }}$, mathematical and quantitative explanations are valued because of their tantalizing promise of completeness. ${ }^{25}$ But, in the process of establishing empirical hegemony, the opposite has also been widely accepted: that anything can be expressed mathematically, because everything contains math — from particle physics to modern manufacturing techniques; from voting behavior to the logic of consumer demand; from Einstein's General Theory of Relativity to Corbusier's "Modulor."

23 Ibid., 106.

24 Ibid., 106-109. Gouk names Kenelm Digby, Robert Hooke, and Thomas Willis.

25 Examples can be found even in "popular" science literature. A book recently published by Cambridge physicist Stephen Hawking contains an entire chapter dedicated to "The Theory of Everything." It begins by explaining that "[t]he universe is comprehensible because it is governed by scientific laws; that is to say, its behavior can be modeled." (87) After a broad overview of scientific theories developed over the past several hundred years, it concludes with a significant hedge on the initial claim:

Then came quantum uncertainty, curved space, quarks, strings, and extra dimensions, and the net result of their labor is 10500 universes, each with different laws, only one of which corresponds to the universe as we know it. The original hope of physicists to produce a single theory explaining the apparent laws of our universe as the unique possible consequences of a few simple assumptions may have to be abandoned. (119)

The promise of a simple and explainable universe still holds a certain appeal-although the truth, as Hawking acknowledges, is perhaps more complex and messy. See: Stephen Hawking, The Grand Design (New York: Bantam Books, 2010). 
Little surprise, then, that the acoustical problems with the lecture hall at Harvard were framed as one of missing math. Sabine consequently interpreted his three central tasks - those of analysis, the development of a remedy, and the establishment of general acoustical principles-as a challenge not just to follow, but in fact create, entirely new categories of numbers. But because he lacked a preexisting methodology, he would have to find new things to quantify, new relationships to measure. And to do this, he would have to perform his own kind of magic: he would have to create the "right" conditions under which the acoustical relationships bridging sound with space could be coaxed and teased into the light.

Environmental mastery was central to many of Sabine's most crucial experiments. His early research, for instance, relied on custom made instruments whose functions included the dispassionate production, isolation, and analysis of sound. Accordingly, these instruments exemplified the very kind of stability and regularity Sabine expected to observe about sound in general. One such instrument, a chronograph, was used in many of his experiments. As Sabine describes, it was

of special design, and answered well the requirements of the work-perfect noiselessness, portability, and capacity to measure intervals of time from a half second to ten seconds with considerable accuracy ... the only duty of the observer was to [mark] the record when the sound ceased to be audible. ${ }^{26}$

But it was not just the measurement of time that would have to be predictable and stable. ${ }^{27}$ The instruments he designed to introduce sound would likewise need to emit a clear, dependable, and regular tone. To accomplish this, Sabine used several unique

26 W. Sabine, Collected Papers on Acoustics, 14.

27 Paul E. Sabine, Acoustics and Architecture (New York and London: McGraw-Hill Book Company, 1932), 43-44. 
pieces of equipment, some of which relied on mechanically governed organ pipes capable of generating precisely the steady flow of compression waves his research required. In one case, a machine was fabricated by connecting a Gemshorn pipe to an elaborate control system:

The wind supply from a double tank, water-sealed and noiseless, was turned on and off the organ pipe by an electro-pneumatic valve, designed by Mr. George S. Hutchings, and similar to that used in his large church organs. The electric current controlling the valve also controlled the chronograph, and was made and broken by a key in the hands of the observer from any part of the room. ${ }^{28}$

The need for regularity and consistency emerges as a recurring theme throughout Sabine's experiments. Indeed, as Sabine himself wrote, "the supreme test of the investigation lies in the consistency and simplicity of the whole solution." 29 Consequently, when sound was to be introduced, it had to be done carefully and in a controlled manner; when it was to be measured and analyzed, it had to be done dispassionately.

At the same time, Sabine's need for always greater and more extensive forms of mastery—sonic, temporal, and otherwise —extended well beyond his technical equipment. It touched also his human research subjects, whose bodies had to be properly disciplined to listen with stable consistency. In several of his experiments, auditors were situated throughout a test space and asked to record their impressions. The goal was, in essence, to triangulate sound: to verify test data by ensuring that different listeners, with only slight variations in their physical ability to hear, reached nearly identical conclusions about the quality and nature of the sound they heard. In one such instance, the process

28 Ibid., 14.

29 P. Sabine, Acoustics and Architecture, 14. 
had three stages. The first was limited to the observations of a single person (Sabine himself), sitting in a single space, on a single day. ${ }^{30}$ The second stage would repeat this experiment at varying intervals-days, weeks, years. ${ }^{31}$ The third would involve evaluations made by independent and otherwise untrained observers, each of whom would record their own impressions separately:

Two gentlemen, who were already somewhat skilled in physical observation, Mr. Gifford LeClear and Mr. E. D. Densmore, gave the necessary time to test the third point. After several nights' practice their results differed but slightly, being .08 seconds and .10 seconds longer than those obtained by the writer, the total duration of the sounds being 4 seconds. This agreement, showing that the results are probably very nearly those that would be obtained by any auditor of normal hearing, gives to them additional interest. It should be stated however, that the final development of the subject will adapt it with perfect generality to either normal or abnormal acuteness of hearing. ${ }^{32}$

Fundamental here was not the perceptual gaps, the differences in what people heard, but the question of how to establish an objective norm. While leaving no room for any meaningful hearing disability, or more simply, differences in opinion, it seems that, in Sabine's experiments, the presence of acoustical consensus at times preceded its actual observation.

Along with the lecture hall in the Fogg Museum, other spaces at Harvard and throughout the northeastern United States soon became "living" laboratories-though ideally lifeless and silent, both inside and out, except under the permitted, controlled conditions. ${ }^{33}$ Each observed space was to be carefully insulated from even the most ordinary of sounds - that is, the very kind of sounds that would be audible during

\footnotetext{
30 lbid., 14.

31 Ibid., 15.

32 Ibid., 15-16.

33 Thompson, The Soundscape of Modernity, 36.
} 
ordinary use. In practice, this often meant experiments could only be conducted at night. In one case, Sabine explains, "[i]t was necessary to suspend work on the approach of a street car within two blocks, or on the passing of a train a mile distant ... in Boston and in New York it was necessary to snatch observations in very brief intervals of quiet." 34 In equating noise with uncertainty, the ultimate goal was to establish a definite and stable sonic profile for each space. ${ }^{35}$

Nearly three years after his experiments began, Sabine achieved a breakthrough. Once he stepped back to observe his data, he noticed an emerging pattern. For any given space, with all other conditions held constant, the exposed surface area of absorbent material, plotted against the audible reverberation time for the space, yielded a consistent curve. The equation he used to describe it was:

$$
t=\frac{164 V}{\sum\left(a_{n} S_{n}\right)}
$$

where:

$\mathrm{t}=$ reverberation time

$V=$ the volume of the room

$a_{n}=$ absorption coefficient of material $n$

$s_{n}=$ surface area of material $n$

34 W. Sabine, Collected Papers on Acoustics, 14.

35 Michael Forsyth argues convincingly that the primary impetus for consistency and predictability in the design of concert halls was the changing economic structure of the societies surrounding them. He writes:

[B]y the early twentieth century, with the demand for increasingly large concert halls and opera house facilities, architects could not afford to trust to luck for the success of their auditoria; still less could they, like [Hans] Poelzig in his design for the Salzburg Festival auditorium, take flight toward a dreamlike and unsystematic world of total imagination. With the rationalist dogma, Form Follows Function, the concert hall architect began to tread the path of empirical science... (Michael Forsyth, Buildings for Music: The Architect, the Musician, and the Listener from the Seventeenth Century to the Present Day [Cambridge, MA: The MIT Press, 1985], 231.) 
Even in this somewhat crude form, Sabine's results seemed to expose a kind of latent acoustical rationality. What had previously seemed capricious suddenly appeared predictable; what seemed shadowy and unknowable became as simple and straightforward as solving for $t$. There was, in the end, a simple and unambiguously mathematical way to express the relationship between a given space, sound, and the resulting reverberation time.

The impact of Sabine's discovery was almost immediately felt. Fixing an overly resonant hall—as in the Fogg Museum—meant stabilizing it, bringing each relevant variable into proper alignment. And since the total volume of a room is the one variable that cannot be easily modified, this would mean, in practice, making modifications to the others. "To adjust, in original design, the reverberation of a hall to a particular and approved value" he wrote, "requires a study of conditions, of materials, and of arrangement..."36 For the lecture hall, this meant suspending several yards of highly absorbent fabric from the walls, which would reduce unwanted reverberation immediately. But the implication of Sabine's material and mathematical fix extended well beyond the Fogg Museum. As Emily Thompson has explained, Sabine's formula meant that

[if] the reverberation time that resulted from such a calculation [was] deemed unsatisfactory, an architect needed only to modify his design-changing the overall volume of the room, or the type or proportion of materials employed within it-until a satisfactory result was achieved. With this equation, Sabine had finally achieved the fundamental, quantitative understanding of reverberation time that he had long sought...37

\footnotetext{
36 W. Sabine, Collected Papers on Acoustics, 61.

37 Thompson, The Soundscape of Modernity, 42.
} 


\section{Boston and Beyond}

Outside the Fogg Museum, Symphony Hall in Boston is perhaps the most well-

known place where Sabine's formula was put to use. The ideal, expressed throughout the design process, was to create an acoustical environment with about two seconds of reverberation time. ${ }^{38}$ Sabine's formula seemed to all but guarantee that result-though implementing it would require proper management and oversight, since the casual neglect of even one element could have a cascading, negative effect on the final outcome. And indeed, there was ample reason to be cautious. The design of concert halls and theaters until this point had not been guided by specialized scientific knowledge, since no such knowledge existed. ${ }^{39}$ The common attitude among architects - in fact, the only empirically valid attitude they could have-is best exemplified by Charles Garnier, who designed the Théâtre National de l'Opéra in Paris. In discussing the final outcome,

Garnier explained something of his methodology:

I gave myself pains to master this bizarre science [of acoustics] but ... nowhere did I find a positive rule to guide me; on the contrary, nothing but contradictory statements .... I must explain that I have adopted no principle, that my plan is based on no theory, and that I leave success or failure to chance alone ... like an acrobat who closes his eyes and clings to the ropes of an ascending balloon. 40

Before Sabine's formula, chance was as reliable at predicting an acoustical outcome as careful planning. So, while Sabine is known to have greatly admired other halls-notably

38 Thompson, The Soundscape of Modernity, $42-44$.

39 While Sabine greatly admired the Gewandhaus, he was very clear that Boston's new hall was not a copy. He wrote:

Assuming perfect reproduction of all proportions with like materials," he explained, "the volume would have been 25,300 cubic meters, and the absorbing power 1,370, resulting in the value, $T=3.02$. This would have differed from the chosen result by an amount that would have been very noticeable. The new Boston Music Hall is, therefore, not a copy of the Gewandhaus, but the desired results have been attained in a very different way. (W. Sabine, Collected Papers on Acoustics, 67.)

40 Michael Forsyth, Buildings for Music, 179. 
the Neue Gewandhaus in Leipzig, which he used as a model for the hall in Boston-his interest was not to recreate these halls, but to reverse engineer them-to learn why they succeeded, however unknowingly.

Symphony Hall, then, would be different from the very beginning. Unlike the Neue Gewandhaus or the Théâtre National de l'Opéra, both of which succeeded essentially by luck, Boston's hall would be created in full view of the newly-discovered and mathematically-defined properties of sound. It would succeed, in effect, by design. Except, like the material composition of the hall itself, and like Sabine's earlier human test subjects - who not only had to be trained to hear a certain way, but whose conclusions were normalized - the wider listening public also had to be disciplined. For Symphony Hall to be "heard" in the "right" way, audiences would have to be trained how to listen; for its sound "to work," for the technically specified outcome to be deemed a success, a consensus would have to be built around the idea that the "designed" criteria were, in fact, the "correct" ones to notice. In effect, this would mean teaching the wider public both how to hear and which characteristics and qualities of sounds should be heard. But there was a reciprocal effect as well: in defining which sounds were important, the remains would have to be suppressed, labeled implicitly as noise. ${ }^{41}$

41 For the most part, Sabine's research interests were far more concerned with learning to actively control sound (e.g. reverberation and reflection) as opposed to suppressing it. He did nonetheless publish one article, called "The Insulation of Sound," which explores the problem of inadequate sound insulation at the New England Conservatory and the Institute of Musical Art in New York. As before, he explains, there was "no experimental data on which an architect could rely" to predict how the various attempts at sound suppression would work. In one instance, the director of the institute "tried the experiment of covering the walls of one of the rooms to a depth of two inches with standard hair felt, with some, but almost negligible, effect on the transmission of sound." Although Sabine's empirical investigations continued, "noise" suppression emerged as an entirely different form of problem, one requiring an entirely new experimental inquiry. See: Karin Bijsterveld, Mechanical Sound: Technology, Culture, and Public Problems of Noise in the Twentieth Century (Cambridge, MA: MIT Press, 2008). 
After it was completed, Symphony Hall received a decidedly mixed reception.

Critics, for one, were hesitant. To their ears, the hall had an unfamiliar sound: certainly it was resonant, but somehow, it was also "empty." This reaction can be seen in published reviews, including one in the Boston Transcript, where William Apthorp explained his impressions of the hall. It had "no body, no fullness," he wrote, it sounded "thin and ineffectual."

Moreover, the hall itself seems perfectly dead to it, it does not awake to the orchestra's call and vibrate with it. Things that should sound heroic and awakening, seem merely polite and irreproachable. 42

In time, however, as popular sentiment took a positive turn, a few of the much earlier mystical beliefs about sound seemed to reemerge. At least one musician thought changing attitudes were in fact evidence of the hall itself changing. Its apparently "evolving" acoustics were attributed to the "general drying out of the materials" used in construction. ${ }^{43}$ And though Sabine prepared himself to defend the hall's (and his own) reputation, public consensus soon settled: the hall was a success.

Still today, contemporary music critics consider Symphony Hall among the best spaces for the performance of music anywhere in the world - an evaluation that seems to legitimize both Sabine's science and his effort to discipline listeners. Simultaneously, and arguably incorrectly, these same critics lament that Symphony Hall was the last of its kind, that its construction marked the end of an era. As Edward Rothstein, a writer for the New York Times, explained in 2004:

Symphony Hall was the last great concert hall of the $19^{\text {th }}$ century rather than the first of the $20^{\text {th }}$. It was unaffected by Modernism. It had a single dedicated function: to

\footnotetext{
42 William Foster Apthorp, “Opening of Symphony Hall," Boston Transcript (16 October 1900).

43 Thompson, The Soundscape of Modernity, 56.
} 
serve orchestral sound. Sabine was trying to discover the nature of acoustic success, not reinvent it.

Afterward, as Emily Thompson shows ... acoustics took on a life of its own ... Increasingly, electrical tools were used not just in analyzing sound but also in reproducing sound, both in the halls and the home. The sonic frame of reference shifted.

This means that the hall is no longer a force that inspires particular styles of music and forms particular communities. It is instead meant to give way before their varied demands. It serves; it does not shape. So the hall has less of a focus. Instead of serving one ideal well-the ideal embodied in a $19^{\text {th }}$ century orchestral hall-it serves all ideals with compromise. ${ }^{44}$

Nonetheless, Rothstein's analysis—of Symphony Hall in Boston on one hand, of Emily Thompson's work on the other-seems terribly wrong. Symphony Hall was not even close to the last space designed to serve the performance ideal of $19^{\text {th }}$-century music. There have been countless examples built during the last few decades alone. From the Walt Disney Concert Hall to the Berlin Philharmonie: all are meant to "serve orchestral sound," rather than be suitable for church music, rock music, or installation sound art.

In the same sense, it is difficult to view (or hear) Symphony Hall as emblematic of an earlier age, as somehow "sonically" pre-Modern. Indeed, Symphony Hall is in many respects profoundly Modern, a direct cultural and scientific beneficiary of post-Cartesian scientific rationalism, an exuberant adherent to the principles of empirical rigor. As a physical environment, the hall fits easily within a narrative that continued to unfold throughout the $20^{\text {th }}$ century: of products and consumer goods, from kitchen appliances to suburban tract homes, that simultaneously create and satisfy a specific desire. Just like the multifunction spaces critics like Rothstein lament, Symphony Hall was constructed as a well-honed machine. It was planned and monitored from every angle, visually and

44 Edward Rothstein, "If Music is the Architect...", New York Times, Arts, May 22, 2004. 
sonically, theoretically and practically, from idea to implementation. It was an ideal container, one designed to produce, as efficiently as possible, and with as few variations as possible, a prescribed acoustical outcome-a space not to be performed with, but performed in.

At the same time, while Symphony Hall was certainly Modern, it reflected also a much older belief about the regularity of the universe. Like so many other acoustical experiments, the hall seemed to demonstrate that the relationship between sound and space was not an exception to the material order modeled by Cartesian synthesis. And in that sense, too, Symphony Hall can be said to resemble the very spaces Rothstein deplores, those that serve "all ideals with compromise." Modern performance spaceswhether extremely "dry" recording studios, or practice modules with adaptable acoustical environments-share one important thing in common: unlike their antecedents, all are designed. Beyond their functional differences, what sets them apart from earlier examples is the material and generative processes that gave rise to them. And indeed, as Rothstein himself recognizes, there is inside Boston Symphony Hall a well known plaque proclaiming the space to be "the first auditorium in the world built in known conformity with acoustical laws."

If Sabine's formula marked the foundational moment of modern acoustics, then perhaps the final, public acceptance of Symphony Hall marked the moment when an aural habitus began literally to re-sound the world. As Emily Thompson writes, Sabine's research

succeeded in many different ways, for many different groups of people. For architects, he provided the 'fixed rule' and the scientific expertise that they had long sought to guide and inform their acoustical designs. For audiences, his work 
endowed the spaces in which they gathered to listen with what most listeners considered to be a satisfying sense of control. And, for scientists, [Sabine's] method established a research agenda and it identified new problems that now required solution. 45

While Sabine himself recognized the way his discovery opened "a wide field" of investigation, it was nonetheless quickly circumscribed. ${ }^{46}$ Perhaps not surprisingly, the primary focus of acoustical research soon became quantification and control. To begin with, the absorption coefficient of various building materials had to be determined in all of their possible variations: plaster covering tile, plaster covering wood, tile without plaster, untreated wood, brick by itself. And to market the results, entire industries were devised — some of which adopted a deceptively academic guise. ${ }^{47}$ The full significance of Sabine's work, then, lies not solely in the way it aided the development of modern acoustics, but in how it created a form of consciousness, a way of thinking, which brought with it new economies, new forms of discipline, and new ways to establish value. It idealized the control not only of space, its physical shape and materiality, but of people, too.

\section{Part II: Gaps and Alternatives}

The history of acoustical science as I have re-presented it here tells of the progressive demystification and control of sound. It begins with the articulation of a

\footnotetext{
45 Thompson, The Soundscape of Modernity, 57.

$46 \mathrm{~W}$. Sabine, quoted in Thompson, The Soundscape of Modernity, 39.

47 One of the most interesting examples is a publication called Sound Control in Design. It contains both detailed descriptions of various acoustical principles, including reverberation and sound absorption, and solutions to problem areas. "Does the sound level seem to be very high in only one area? ... If so, look for concave curved surfaces. Break them up or load them with acoustical tile." (68) Except, what seems to be helpful advice is actually cleverly concealed marketing material, published by "United States Gypsum," targeted at consumers with limited expertise. See: United States Gypsum, Sound Control in Design, 1959.
} 
belief, that beneath the surface of observable reality there lies a simple and elegant truth, an equation, capable of explaining how space and sound relate. It concludes once that truth is known and widely recognized. It is, in many respects, a teleological and deterministic story, one in which the fruits of scientific inquiry are used to re-make the world, slowly but unavoidably, into something better. Uncertainty appears only as a form of technical noise to be systematically excluded, or an externality to be carefully avoided. Both are exemplified, for instance, in the way Sabine isolated the spaces he wanted to examine by excluding extraneous sounds from the world outside.

Science philosopher Ronald Giere has called this approach objective realism. This, he explains, is a more "sophisticated version of common-sense realism," the kind of realism we take for granted as children and that allows us to distinguish between "ordinary things," like "trees, dogs, and other people." "48 In a more sophisticated form, however, objective realism consists of three interlocking and co-dependent parts. The first "emphasizes the discovery of truths and the permanence of scientific knowledge;" the second "adds the idea that the truth to be discovered take the form of laws;" while the third "emphasizes a sense of progress toward truth." explanations are too simple to be believed. As more critical technological and scientific methodologies have shown, objective-realist truth often depends on unchallenged assumptions and convenient exclusions.

Two critical models become relevant here, both of which encourage the construction of more subtle and complex stories about scientific discovery, technological

\footnotetext{
48 Giere, Scientific Perspectivism, 4.

49 lbid., 4.
} 
development, and human achievement. The first is Actor Network Theory (ANT). Developed by a range of scholars-including John Law, Bruno Latour and Michel Callon, each coming from different backgrounds-this theory seeks to re-contextualize scientific investigation as a process of connection and collaboration. ${ }^{50}$ In particular, ANT asks us to refocus our attention on the consent and enrollment of different actors: ordinary citizens, perhaps, who observe a problem; scientists who agree to investigate it, or otherwise abandon their research if it proves fruitless; non-sentient/non-human actors, who may or may not "cooperate" in the research. This re-modeling of traditional scientific analysis, which is usually thought to be disinterested, is important in part because it challenges us to rethink our assumptions about the role of the non-human environment—and more generally, about what we exclude and why. No longer merely a passive substance, a plane to be acted upon, both "nature" and complex human and political networks are allowed to emerge as participants-willing or unwilling-in scientific discovery, actors whose voices can be both powerful and informative should we choose to listen.

A second important critical model is the Social Construction of Technology (SCOT). Developed by Trevor Pinch and Wiebe Bijker among others, SCOT challenges the sense of inevitability that seems often to accompany scientific breakthroughs. Their work on diverse subjects--from bicycles to the Moog synthesizer and player pianos-

50 John Law, "Monsters, machines and sociotechnical relations," in A Sociology of Monsters: Essays on Power, Technology and Domination, ed. John Law (London: Routledge, 1991); Bruno Latour, Science in Action: How to Follow Scientists and Engineers through Society (Cambridge, MA: Harvard University Press, 1987); Michel Callon, "Some Elements of a Sociology of Translation: Domestication of the Scallops and the Fisherman of St. Brieuc Bay," in Power, Action, and Belief: A New Sociology of Knowledge? ed. J. Law (London: Routledge, 1986). 
foregrounds the importance of trial and error, the often constructive role of false starts, market competition, failed experiments, and above all, the powerful role of cultural norms and (already operative) consumer expectations. In demonstrating that technological "closure" is achieved only through a long process of negotiation and compromise, and by challenging our tendency to focus only on "great men" and "unforeseeable" inventions, SCOT asks us to consider the possibility that scientific and technological advancement is itself a participant in, rather than the driver of, social and cultural change.

Even still, "great men" and "great buildings" remain the implicit center of acoustics criticism today. There are perhaps a few reasons why: one is that, because the history of acoustics follows the development of Modernism almost synchronically, any critique of the latter can be extended analogically to include the former - and thereby preempt the need to develop a specifically acoustical-critical discourse. Another possible reason is more complex. That is, because the study of acoustics is often framed as concerning the establishment of physical absolutes, it is subject neither to cultural negotiation, nor to influence by non-human actors. By this view, as a form of pure science, acoustics is able to plausibly avoid critique for the same reason that corresponding laws and theories of 
gravity or evolution do- except, perhaps, from a few denialists, or scientific

constructivists..$^{51}$

Not surprisingly, the few attempts that have been made to critique acoustics are

largely ineffectual. One such gesture can be found in the "popular" analysis of

architectural and acoustical failure-the study of spaces whose careful design nonetheless

yielded unwanted results, despite having been constructed in the post-Sabine era. This

approach is nowhere more clearly exemplified than in the intermittent discussion of

Avery Fisher Hall in New York. Harold Schonberg, a critic for The New York Times,

wrote it "has had its share of troubles from the beginning."

It was supposed to be a concert hall with flawless sound, offering in addition the kinds of amenities and creature comforts that the venerable Carnegie Hall could not begin to match..

The opening on Sept. 23, 1962, was one that nobody present will ever forget. The $\$ 21$ million building was not yet finished, and the distinguished audience had to pick its way through wet concrete. ... As the concert went on, there was the horrid realization that acoustically the hall was a mess.

Certainly the hall was unconventional in shape-much longer in relation to its width than most other concert halls. Dr. [Leo] Beranek [the acoustical designer] had installed coffin-like acoustic 'clouds.' These were supposed to take care of all acoustic contingencies. But, at opening night at any rate, they didn't. The hall had an antiseptic sound, very weak in the bass, with little color and presence. ${ }^{52}$

51 Giere's book provides a clear account of how scientific perspectivists explain the process of experimentation and discovery:

[Andy] Pickering [author of Constructing Quarks: A Sociological History of Particle Physics] claims that the scientist's account [of old High Energy Particle (HEP) physics] is really a retrospective rationalization based on the independent judgment that the new HEP provides the better account of reality. On Pickering's own account, experiments were not decisive. Rather, interpreting an experimental result requires professional judgment that is subject to many influences. In particular, judgment is subject to what he calls 'opportunism in context.' Scientists interpret results partly in terms of their own expertise, the available instrumentation, and their judgment as to which approaches provide the most opportunity for doing new work, whether experimental or theoretical. For Pickering, then, adopting a new theoretical approach involves creating a new research tradition. And, finally, if the social and materials conditions had been different, the conclusion could have been different. (Giere, Scientific Perspectivism, 8-9.)

52 Harold Schonberg, "The Curse Of Fisher Hall's Acoustics," Oct 13, 1974, Sec 2 P. 21, Col 1. 
The hall's problems did not begin at its opening 1962 , though. Its flaws are thought to be related to a series of compromises made during the initial design process. Most significant among them was the decision to increase substantially the number of seats in the hall, a decision which necessarily forced two further compromises: a change to the hall's shape, and an increase to its total volume. Experts and critics alike consider these technical errors. And because of them, the interior of Fisher Hall was rebuilt barely a decade after it opened to poor reviews. But, once finished, these later renovations, lead by renowned architect Philip Johnson, also received a tepid response, prompting critics, including Schonberg, to later equivocate on their initially unfriendly remarks. "It could very well be," he wrote, "that the critics of the hall are overreacting."

[I]n all truth Fisher Hall is a perfectly adequate installation. And, in the shadowy realm of ear testing and psychoacoustics, there is some evidence that the highly trained ears of musicians are not necessarily the best ears for judging sound. Musicians have a tendency to listen with their brains instead of their ears; they know the music so well that listening often becomes an intellectual rather than an aural experience. ${ }^{54}$

Again here, like in Boston nearly a century earlier, untrained bodies become part of the problem: it is not just that the hall's design is flawed, but that the ears of musicians were "not the best" for making acoustical judgements. And again, a general consensus seemed to persist: the repairs had not been extensive enough, and many of the initial acoustical problems remained. In the decades since then, the hall developed an unwelcome reputation for being unsuitable for the performance of classical music. Indeed, writes Rothstein, "[t]he problems didn't end" with those repairs. "And so, after decades of

$53 \mathrm{lbid}$.

54 Ibid. 
tinkering, Lincoln Center announced ... that sometime after 2009, the hall would be gutted again." 55 These secondary renovations are slated to be even more extreme. In addition to increasing the total volume of the space (presumably, in order to bring its physical dimensions into alignment with Sabine's equation), it is hoped the hall will be altered in other, more dramatic ways, such as changing its footprint.

While the final and literal shape these latest renovations will take remains unclear, it is difficult to see how the story of Fisher Hall, and others like it, can be said to function critically. Focusing on the many ways the hall "failed" does not complicate the underlying assumptions that have guided the study of sound, nor does it situate acoustics within a larger process of cultural, political, and economic negotiation. Rather more modestly, it casts doubt upon our own technical ability to execute what are widely accepted acoustical truths, and indeed, draws into question our practical understanding of how those truths should be implemented. What emerges from a study of Fisher Hall is almost the opposite of critique: a strange form of legitimation. The hall "failed" not because the underlying theories were wrong, or because our expectations were misguided, but because the plans were applied inadequately, or because the hall was being listened to with flawed ears. Consequently, the reason we can (and continually do) label Fisher Hall a "failure" is the same reason that we believe its problems can be repaired: because of our dual impulses to regularize and control the environment, and to force our perceptions to align with aesthetic values that have been scientifically

55 Rothstein, "If Music is the Architect..." 
determined-both of which correspond to a belief that control is possible, necessary, and desirable.

\section{A 'Failing' Model}

My emphasis on the need for critique should not be taken as nihilistic, as though to imply there are no physical or measurable properties of sound, or that those properties cannot be explained empirically. Sound does travel at a certain speed, it does move like a wave (and not a ray), it does reflect and respond to different materials and textures differently - as researchers from Bacon to Helmholtz and Bell have shown. Indeed, as science philosopher Ronald Giere explains, even from a perspectivist point of view, there is room for functional and "workable" empirical models. Developing them requires "bringing together two perspectives,"

one observational and one theoretical, in order to decide whether the model fits the world as well as desired. The initial presumption is that the observational perspective has priority. The models of data generated within the observational perspective are to be used to decide on the fit of the model generated by theoretical principles; not the other way around. 56

At the heart of the matter is the direction of fit. Neither fully constructivist nor objectivist, a perspectivist approach situates both observation and the observer within an inclusive context, one where the empirical act, the progressive sifting of observational data, remains contextualized. As Giere explains, this approach leaves the model itself open, so that testing it becomes

an activity in which agents use experiments to decide whether or not to regard a model as providing a good fit to the objects of inquiry. This involves, among many things, deciding how probable results in the region $R$ should be, and thus how wide $R$ should be. This in turn requires trading off risks for two possible mistakes, namely, concluding there is a good fit when there is not and concluding there is not a good fit

56 Giere, Scientific Perspectivism, 89. 
when there is. There are no general rules for making these trade-offs. That depends on the context. ${ }^{57}$

From a perspectivist point of view, what needs critique is not acoustical models per se, but rather the cultural, aesthetic, and evaluative mechanisms underlying them. Doing this requires returning to examine the desires which have lead the practice of acoustical research to its current point: the desire to control space by simplifying it; the desire to assemble a comprehensive picture of acoustical "reality"-an image that can be copied, adapted, and applied wherever we see (and hear) fit; the desire to construct a model of the universe that conforms to our most reduced and simplified experience; the desire to express sound (and in the process, some parts of human experience) simply, elegantly, and mathematically, rather than in a way that embraces complexity, diversity, and experienced difference.

Mounting a sufficient critique requires, from the beginning, a different view of Sabine's discovery. For instance, what is commonly understood as his "breakthrough moment," the discovery of the acoustical formula, can be viewed, from a Lacanian point of view, as a kind of "lack" filling a pure void. The lack does not itself consist of sound or even mathematics, but the quest to uncover a universal constant, a bridge binding sound and space together inextricably, a tool that could be manipulated and controlled. In this way, the presence of some fixed, foundational acoustical property was anticipated from the start-only its particular configuration was unknown. And it was on account of this that Sabine spent so much time working to create improbable acoustical environments: silent, laboratory-like spaces, without much resemblance to the conditions of ordinary 57 Ibid., 90. 
use, filled with carefully initiated listeners. Sabine's discovery, in a way, made sense because it was assumed to be there. It seemed simple, because simplicity was already part of the solution. It was compelling, not just because it was verified empirically, but because it articulated a collection of expectations for what would be found. And by confirming that sound and space did, in fact, relate predictably and controllably, it confirmed also long-held assumptions about the configuration of the natural world.

The formula, the numerous technical and practical applications to which it has been put, and the listening bodies that have been trained to hear the results all undoubtedly "work." They are part of a vertically-integrated network, an effective (though not necessarily sinister) collusion of science and culture. But it is important to understand what these formulas, equations, and theories are not: a decryption, an exposition of the reality of everyday life. Critique, in a much broader sense, therefore means developing an alternate and more inclusive "image," one that challenges our desire to master and control sound while leaving room for the emergence of difference, the unfolding of progressive change.

\section{Critical Imagery}

There is, indeed, another story to be told here. While it is not one that fits neatly into either an objectivist or deterministic narrative, it does offer an alternate way to understand the relationship between sound and space. And it begins, again, with the work of Wallace Sabine - viewed this time from a completely different perspective. Not all of Sabine's research was focused on the problem of reverberation. Some of his work, arguably the less frequently celebrated parts, was concerned with understanding the 
variable intensities of sound, the way in which sound moves through and saturates space, and the emergent sonic effects such movement generates. Sabine observed, for instance, that the physical shape of a space can greatly influence the way sound behaves within it. While the ultimate purpose of this research was to examine the emergence of secondary and ternary reflections, important here are the tools and techniques he used along the way.

Often enough, Sabine used an unusual medium to display his results: graphical representations that make visible in an almost uncanny way the physical interaction between space and sound. These representations are what I call sound maps - contextual and relational images showing the movement of sound as it changes in response to the lived-configuration of space. They resist our tendency to draw broad and universalizing conclusions. Instead, more modestly, sound maps have an illustrative function. Their purpose is to make plain the audible complexities within space, to help us document the behavior of sound as it can be actually observed. They are constrained images; and while not particularly amenable to either extrapolation or generalization, their purpose nonetheless gestures toward bringing into dialogue ordinarily incompatible domains: the spatial and sonic; the measurable and experiential; the visible and audible.

Many such maps can be found published throughout Sabine's papers. Significant examples can be found in his article "Architectural Acoustics," 58 where Sabine also takes some time to explain how and why they were made. In one particular instance, while studying a rectangular room with a vaulted ceiling at the Naugatuck Congregational

58 W. Sabine, Collected Papers on Acoustics, 219-236. 
Church in Connecticut, Sabine took note of audible variations in the intensity of sound, as they could be observed at various points throughout the room. The image did not show a smooth or sound-saturated field, but neither were the results unnoticeable or insignificant.

As Sabine describes, "[t]he phenomenon indicated in these diagrams," was not ephemeral, but was constant so long as the source of the sound continued,
and repeated itself with almost perfect accuracy day after day. Nor was the
phenomenon one which could be observed merely instrumentally. To an observer
moving about in the room it was quite as striking a phenomenon as the diagram
suggest. 59 The accompanying map shows an almost incredible aural topology. (Figure 1-2) Space and sound, even under highly controlled conditions, are shown together producing peaks and valleys, points of quiet and points of intensity, pockets where sound snags and gathers. But the results were not just visible; they were audible, too. Sabine explained that

[a]t the points in the room indicated as high maxima of intensity in the diagram, the sound was so loud as to be disagreeable, at other points so low as to be scarcely audible ... ${ }^{50}$

But the results were not universally applicable either. A simple change in position, the introduction of a new wall or partition, a change in the intensity of sound, could have a noticeable effect on the shape and contour of the resulting image. Sabine writes,

[h] ad the source of sound been at one end and on the axis of the cylindrical ceiling, the distribution of intensity would still have been bilaterally symmetrical but not symmetrical about the transverse axis. ${ }^{61}$

The effect represented on the map was audibly inconsistent, contingent on special conditions, but clear enough so the variations themselves could be easily noticed.

\footnotetext{
59 W. Sabine, Collected Papers on Architectural Acoustics, 234.

60 lbid., 234-35.

61 Ibid., 234-35.
} 
Nor is this image unique within Sabine's work. In another instance, Sabine undertook research inside a temperature controlled space in Harvard's physics building. During the resulting experiments, Sabine ran a film-operated recording device along a string-guided path. When pulled, the recorder spiraled toward the center of the space. By connecting relative intensity readings plotted on a spatial diagram, he discovered remarkable but symmetrical variations in the intensity of sound. The resulting contours underscored the way even a single, sustained tone could yield quite unequal results, even within the rigid confines and apparent consistency of a tightly regulated environment.

Sabine believed diagrams like these had a practical use beyond their informational applications in research. They could help provide, for instance, "a partial explanation of the so-called deaf regions in an auditorium"- -a demonstration of which can be found in his study of the New Theatre in New York. ${ }^{62}$ To study why the sound of the hall unfolded as it did, Sabine created a series of scale models, each showing a slightly different view of the hall-for instance, its footprint, viewed from directly above; or a cross section, viewed from the side. Later, "the sides of a model are taken off and, as the sound is passing through it, it is illuminated instantaneously by the light from a very fine and somewhat distant electric spark." ${ }^{33}$ This photographic technique, called schlierenMethode, shows how a single, pulsed wave interacts with the permanent, physical structure of the hall. (Figure 1-3) Enough photographs taken in quick, film-like succession can reveal useful insight into how sound waves change as they move through the full-sized hall.

62 Ibid., 232.

63 Ibid., 236. 
For the New Theatre specifically, Sabine explained "the present case ... would have predicted almost perfect acoustics in the boxes and on the main floor." 64 What the images showed, instead, was that:

[t]he wave $c_{1}$ has advanced and is reaching the front row of seats in the gallery, producing the effect of an echo. A little later it will enter the balcony, producing there an echo greater in intensity, more delayed, and affecting more than half the seats in the balcony, for it will curve under the gallery, in the manner just explained, and disturb seats which geometrically would be protected. Still later it will enter the foyer seats and the boxes. But the main disturbance in these seats and the boxes, as is well shown by the photograph, arises from the wave $c_{2}$, and in the orchestra seats on the floor from the wave $c_{3} .{ }^{65}$

Indeed, while Sabine seldom comments on visual diagrams like these-as if to suggest what they show is self-evident—he does at times overstate their importance. Despite what he suggests above, for instance, it is not clear these images explain anything, partially or otherwise. Rather, they function diagrammatically to exemplify how sound intersects with space. In depicting movement and change, they show how audible differences, heard even within the confines of a single space, are not merely figments of our perception, but emergent, material fluctuations that appear as sound itself moves through and interacts with the environment. Space and sound, these images suggest, are not purely or independently manipulable in an abstract sense. They are co-dependent, or rather, co-productive, forces that change depending on the material circumstances, the sometimes literal shape and context of observation.

Sabine was not the only scientifically-minded person during the early $20^{\text {th }}$ century to develop new ways to "visualize" sound. Another person perhaps even more famous than Sabine was Dayton Miller, whose Phonodeik, invented in 1908, was designed to

\footnotetext{
64 Ibid., 184. 65 Ibid., 184.
} 
create "photographic images of sound vibrations." "66 In some respects, the Phonodeik's technical operations more resembled a phonograph than Sabine's spiraling sound machines: sound entered a large horn causing a diaphragm to vibrate; simultaneously, light was projected toward a small mirror, connected to the diaphragm using a small string. The image reflected from the mirror would shake and vibrate according to the frequency of sound entering the horn—and the result caused a popular sensation.

Thompson explains:

Miller became known as 'The Wizard of Visible Sound' as he traveled across the country demonstrating his device. In 1914, Wallace Sabine invited Miller to give a series of public lectures ... and the Boston Evening Transcript reported that the audience was 'fascinated' by his graphic representations of music and noise. Miller's sound images were seen by millions more when they appeared in newspaper advertisements for the Aeolian-Vocalion phonograph. ${ }^{67}$

Miller's images share at least one important similarity with Sabine's maps: their attempt to translate something audible into something visible, to show sound as a moving and changing, even when apparently held constant. But there are even more significant differences between them. For one, Miller's images are not "spatial" in the same sense as Sabine's. While the final image certainly occupies space-the abstract frame-space of the projection itself-Sabine's images operate by locating sound within the physical environment, an environment that is already occupied by a listener (or perhaps a "listening" machine). In that sense, it might be that Sabine's images do not so much spatialize sound as sonicize space: they "charge" the diagrammatic image by finding it already audible.

66 Thompson, The Soundscape of Modernity, 86.

67 Ibid., 87. 
A photograph made using schlieren-Methode might not fit our immediate conception of a sound map in the same way that Sabine's hand-drawn schematic of the church in Naugatuck does, but sound maps are not limited to any one particular medium $;{ }^{68}$ instead, they construct a sensory and conceptual bridge, one that links abstract notions of sound and space to the fluid impermanence of experience. What matters, then, is the way these maps help us to picture space as "textured," rather than more simply "filled;" what matters is how they function and the relationships they mediate. Sound maps encourage us to re-imagine the everyday environment as determined by audible differences - differences which are themselves shaped by where one sits, or how one moves. They provide justification for us to hear space as constantly in motion and filled with sound-sound which itself moves, collects, and gathers unevenly in response to the changing material circumstances of space.

Maps like these are important, then, not just because they create a new way to study sound-namely, by representing it graphically and spatially—but because they encourage us to develop an entirely new conception of it: a new "sonic consciousness" that allows us to think, view, and listen to the world as defined already by difference.

\section{Sound Maps In Theory}

Sound maps are unusual because they provide insight into what I have referred to as the acoustical textures of space. But in many ways, the idea of a sound map-the simple representation of sound existing in space-might be said to be very old indeed. A

\footnotetext{
68 In the past, a clearer distinction was drawn between (what was considered to be) a map and a photograph. But these distinctions have become increasingly blurred, however, as cartographic representations have become intertwined with photography. While the details of this topic are best left to historians in art history and cartography to parse, it is a subject that does obliquely concern urban and environmental sound maps, and will therefore be addressed in Chapter 2.
} 
primitive sound map, for instance, can be found in the work of Athanasius Kircher, who not only described but illustrated any number of peculiar sonic effects, including the mysterious way that sound, under the right conditions, could be observed to bounce from one point to another-a phenomenon Sabine would later explore in his writing on "Whispering Galleries." ${ }^{99}$ Kircher suggested this peculiar, almost playful property of sound could be used to create covert eavesdropping systems, the illusion of speaking statues, or multiple echoes. Indeed, in two of Kircher's key texts, Musurgia Universalis and Phonurgia Nova, he illustrates these effects not simply by showing the underlying architectural feature, he also (and literally) draws sound into the image-though technically incorrectly, as a ray - to demonstrate how it can be heard bouncing from place to place. (Figure 1-4)

Certainly Sabine's and Kircher's visual diagrams do bear some resemblance, since both represent sound, its movement through space, and its interaction with the physical environment. But there are also important differences between them. Ultimately, Kircher's diagrams were meant to explain how a specific acoustical phenomenon could be observed and manipulated, while the images themselves show little more than speculative detail. ${ }^{70}$ Sabine's maps, by comparison, take a more rigorous approach to the idea of "mapping" sound. Whether photographic or drawn by hand, they are meant to explain not only that acoustic tricks exist, but to demonstrate in detail how they were observed on a specific occasion. They function instrumentally to help us see how space

69 W. Sabine, 255-276.

70 I mean "speculative" here in the technical sense explained by Gouk: as a form of investigation aimed at producing certain effects. See: Gouk, Music, Science, and Natural Magic, 93. 
and sound interact, how they are mutually articulated, and how we might find ourselves caught in between.

Sound maps like Sabine's are not merely locational, however; they are also orientational. That is to say, it is not their sole function to help us identify where something is in space (e.g. the location of a whispering gallery), or to help us find better ways to make use of a particular effect. Also, and more significantly, these maps help us locate ourselves in relation to change itself. They stand to help us better appreciate our relationship to and dependence on sound, its movement and its variation. In articulating a series of important relationships—both spatial and sonic_-sound maps become a critical mechanism, one that can help us re-inject listening subjects and a sense of everyday experience back into an otherwise distanced and disinterested analytical frame. ${ }^{71}$

In that sense, sound maps are important for reasons Fredric Jameson would later identify in his work on "cognitive mapping." He writes:

\begin{abstract}
...we have this split between ideology in the Althusserian sense -that is, how you map your relation as an individual subject to the social and economic organization of global capitalism - and the discourse of science, which I understand to be a discourse (which is ultimately impossible) without a subject. In this ideal discourse, like a mathematical equation, you model the real independent of its relations to individual subjects, including your own. Now I think that you can teach people how this or that view of the world is to be thought or conceptualized, but the real problem is that it is increasingly hard for people to put that together with their own experience as individual psychological subjects, in daily life. 72
\end{abstract}

Jameson's ultimate point here was made, in a much more technical sense, by Giere earlier in this chapter: that there exists a division between the world as it can be seen, measured,

71 At least one of Kircher's diagrams also pulls in this direction. The image in Fig. 6, from Phonurgia Nova, is accompanied by a text that speculates how sound might be used as a weapon, capable of spreading disinformation among an invading army.

72 Fredric Jameson, "Cognitive Mapping," in Marxism and Interpretation of Culture, eds. Cary Nelson and Lawrence Grossberg (Urbana, IL: University of Illinois Press, 1988), 358. 
and objectified, and how it is experienced subjectively. As the former, what Jameson calls an "ideal discourse," develops and increases in complexity over time, it simultaneously becomes difficult for ordinary people, "individual subjects," to locate themselves in relation to it - that is, to make sense of the world in terms the ideal discourse itself provides.

The result, Jameson suggests, is that people must be taught how they fit as pieces into a larger puzzle of ontology - what we might call the social, scientific, and political real. Cognitive mapping, as Jameson describes it, offers an alternative. Without resorting to reduction, it empowers people to go out into the world, to observe it as complex and contradictory, to examine "their own experience as individual psychological subjects, in daily life." It provides a different way to study the world as dynamic and relational, rather than a collection of idealized facts, divorced from time, experience, and change, or even more ominously, defined from the "outside."

Like maps of weather, maps of sound are not strictly cognitive; there is usually an external, sensorial, and material dimension to them. Nonetheless, as I have worked to define them here, their development and critical usefulness very much follows the pattern Jameson outlines. It is certainly true they emerged alongside an "ideal discourse"-the development of acoustical science. They are, in that sense, a byproduct of our search for an abstract model of reality. Sound maps retain also some practical and scientific utility, for instance, in the study of sound reflections in the modern concert hall; but in a broader sense, sound maps themselves can also be studied, placed in the context of our own 
theoretical efforts to understand the experience of sound, its movement and fluctuations over time and space.

In that sense, maps of sound nudge us, even if only slightly, towards a greater appreciation of space as someplace internally differentiated. They furthermore suggest what we commonly identify as "a space"-defined, perhaps, by a shared material context ("four walls and a roof"), or a rough set of geo-spatial coordinates ("second floor, first room on the left")—is not, in the final analysis, completely uniform. To the extent that "a space" is singular, it might in fact be defined by its differences. Philosopher Gilles Deleuze has explained this notion more generally in terms of "formal" and "modal" distinctions. He writes:

Formal distinction is, in effect, a real distinction, since it is grounded in being or in the object; but it is not necessarily a numerical distinction because it is established between essences or senses, between 'formal reasons' which may allow the persistence of the unity of the subject to which they are attributed ... [M]odal distinction, is established between being or the attributes on the one hand, and the intensive variations of which these are capable on the other. These variations, like degrees of whiteness, are individuating modalities of which the finite and the infinite constitute precisely singular intensities. ${ }^{73}$

By this reckoning, a "formal" distinction allows us to implicate space as singularsomething we can talk about as distinct or contained. Similarly, a "modal" distinction concerns the textural dimensions that differentiate space from itself. But the underlying ontological plane upon which modal distinctions are drawn lies elsewhere, in the concept of "univocity." He explains:

[T]he essential in univocity is not that Being is said in a single and same sense, but that it is said, in a single and same sense, of all its individuating differences or intrinsic modalities ... The essence of univocal being is to include individuating differences, while these differences do not have the same essence and do not

73 Gilles Deleuze, Difference and Repetition, trans. Paul Patton (New York: Columbia University Press, 1994), 39. 
change the essence of being - just as white includes various intensities, while remaining essentially the same white. ${ }^{74}$

This definition can be extended almost directly onto sound maps. In them, we see how space is composed of "individuating differences"-places where the material environment, for instance, effects change in the intensity of sound, forcing it to gather, snag, or bunch together in response to the surrounding space. While identifying these tendencies does not, on its own, "change the essence" of a space, it is by locating them that we are all but compelled to acknowledge what space is not: uniform, easy to simplify, fully consistent, or perceptually smooth throughout. Just as the color we casually call "white" is composed of many different frequencies of light—and yet appears coherent-what we might commonly call "space" is, in effect, internally differentiated, shaping and shaped by what happens and how. ${ }^{75}$

As maps, these images foster a spirit of experimentalism (rather than simply experiments); they encourage us to experience the world (rather than remove experience from it). Deleuze explains:

... [the map is] entirely oriented toward an experimentation in contact with the real. The map does not reproduce an unconscious closed in upon itself; it constructs the unconscious. It fosters connections between fields ... The map is open and connectible in all of its dimensions; it is detachable, reversible, susceptible to constant modification. It can be torn, reversed, adapted to any kind of mounting,

74 Ibid., 36.

75 Another of Deleuze's ideas is relevant here: deterritorialization. That is because there is an inherent irony in Deleuze's choice of examples. Isaac Newton, of course, is widely recognized as the first scientist to split light into a spectrum of color. And yet, for Newton, the fact that light could be split into so many parts was not evidence of internal difference, the univocity of whiteness, but rather an explanation of what white-ness was. Like Deleuze, I am suggesting that the history of science might be read differently, and that the products and outcomes of scientific research suggest a much more complicated version of "reality" than we ordinarily see. 
reworked by an individual, group, or social formation. It can be drawn on a wall, conceived of as a work of art, constructed as a political action or as a meditation. ${ }^{76}$

Sound maps allow us to perform a "deep" analysis-not one with clearly identifiable or fixed endpoints, but one that seems ongoing, unfinished, or un-finishable. They function as a counterweight to more common analytical modes, especially those driven toward fixity and stability. Sound maps instead ask us to think about space differently by taking the logic of acoustical trick spaces-the logic of whispering walls and parabolas (the kind of spaces admired by Wren, Bacon, and even Sabine) - and multiplying it. They suggest all spaces, vaulted or not, designed specifically as "musical" or "sonic" or not, are worth listening to. And in doing so, they make possible different forms of engagement where space, sound, and our experience can "be torn, reversed ... reworked by an individual, group, or social formation."77

\section{The 'Real' of Sound}

Sound maps are very limited, at least in a representational sense. For instance, Sabine's most commonly reprinted sound map, the isobel shown in Figure 1-2, depicts sound only at a very generic "head" level. Other maps have an uneasy relationship with time. Some are quite specific about the "moment" they show: photographs made using schlieren-Methode, for instance, are quite clear in mapping not only a narrow "slice" of space, but a very brief instant of time. Other maps, however-especially the types I will discuss in Chapter 2-adopt a more vague approach to temporality, perhaps by showing

\footnotetext{
76 Gilles Deleuze and Félix Guattari, $A$ Thousand Plateaus: Capitalism and Schizophrenia, trans. Brian Massumi (Minneapolis and London: University of Minnesota Press, 1987), 12. 77 lbid.
} 
an extended moment during which many sounds, heard by many different people and at many different "head" levels, are condensed into a single frame. Attempts to map more complex forms of experience render these limitations especially acute. A musical performance; the sounds of a city; sounds made at different volumes and durations; sounds projected at different angles and heard at different "head" levels: the process of mapping, at some point, becomes so complex that it careens toward overdetermination. It would seem, quite simply, that there is too much to hear, and too much space to hear it in.

This paradox is a familiar one: the more we hope to represent something accurately, the less we seem able to do it. Neither is there an easy escape. Creating "better" images, using more compelling and comprehensive forms of representation-moving images, 3D images, virtual realities with interactive graphics and embedded sound samples—does nothing but defer the problem, principally by relocating the phenomenological gap between represented and representation. ${ }^{78}$ More information, even finely grained and compellingly presented, will not provide any more certain, fixed, or stable access to the sonic indeterminacies of space. The alternative notion, that of a totally-mapped environment, one so complete that it becomes indistinguishable from reality, has been parodied and critiqued extensively, from Borges to Baudrillard. ${ }^{79}$ But perhaps no parody is as compelling as Lewis Carrol's, found in his 1893 novel, Sylvie and Bruno Concluded:

"That's another thing we've learned from your Nation," said Mein Herr, "map-making.

78 This issue will be revisited extensively in Chapter 2.

79 Jorge Luis Borges, "On Exactitude in Science," in Collected Fictions, trans. Andrew Hurley (New York: Viking, 1998); Jean Baudrillard, Simulacra and Simulation, trans. Sheila Faria Glaser (Ann Arbor, MI: The University of Michigan Press, 1994). 
But we've carried it much further than you. What do you consider the largest map that would be really useful?"

"About six inches to the mile."

"Only six inches!" exclaimed Mein Herr. "We very soon got to six yards to the mile. Then we tried a hundred yards to the mile. And then came the grandest idea of all! We actually made a map of the country, on the scale of a mile to the mile!"

"Have you used it much?" I enquired.

"It has never been spread out, yet," said Mein Herr: "the farmers objected: they said it would cover the whole county and shut out the sunlight. So we now use the country itself, as its own map..." 80

Sound maps, like maps of any other kind, are formally incomplete-not out of weakness, but necessity. The alternative, a "fully complete" sound map, one claiming to be the precise or exact translation of what it shows, borders the absurd.

And yet, there remains at least one important question. Aside from the inherent limitations and partiality of representation, what is to prevent sound maps from becoming a "totalizing image"? Maps, indeed, are not usually valued for being "detachable, reversible, and subject to constant modification," as Gilles Deleuze and Félix Guattari explain. Nor are mapped inaccuracies and inconsistencies usually celebrated as such. Maps, instead, are usually valued for being accurate and authoritative, for helping us from location-A to location-B without getting lost. And in that sense, as will be discussed in Chapter 2, maps are instruments of power and control. So what, then, prevents sound maps in particular from exemplifying the very form of objective realism they otherwise serve to critique?

Perhaps the shortest way to respond is by saying that sound maps operate in the Symbolic domain. But to explain what this means-generally, in terms of Lacan, and

80 Lewis Carrol, Sylvie and Bruno Concluded (New York: MacMillan and Co., 1893), 169. 
specifically in terms of the sound map - it is necessary to dip into psychoanalytic theory. As Stephen Friedlander defines it, "[t]he Symbolic is, properly speaking, not an element of experience but a constraint on experience." ${ }^{\text {81 }}$ As a category, it encompasses most representational and communicative codes, including language, which funnel what we think, and what we hope to say, through a series of filters. But the Symbolic is more than just a filter. As work in linguistics and deconstructionist philosophy has shown, once these filters become engrained both within individuals and the broader culture, they begin to shape and direct our thoughts and desires from the start. It is at this point that constraints themselves become formative, even productive-and consequently, worthy of analysis.

This process functions similarly with sound maps. Not only do they have the potential to communicate and represent experiences that have already been had, they stand to shape and filter those that might occur in the future. To examine a sound map means, on some level, appreciating its potential to function critically, to investigate the relationship between sound and space, not just as "truthful" or "accurate," but as a lens that focuses (and subsequently distorts) the world as we experience it. That lens, in turn, imposes its own constraints. Sound maps cannot be totally comprehensive, even when limited to a single observational category like "loudness," because as Carroll's earlier parody suggested, even condensing all of the information ever collected about sound, made to represent every possible loudness measurement, would still not provide a "totally mapped" image-since, at the very least, the image would be "out of time." Holes, then,

81 Stephen Friedlander, "Glossary of Lacanian Terms," in The Subject of Lacan: A Lacanian Reader for Psychologists, eds. Kareen Ror Malone and Stephen R. Friedlander (Albany, NY: State University of New York Press, 2000), 366. 
are both inevitable and necessary, but not necessarily detrimental. If anything, these shortcomings are productive, principally because they open the map to new kinds of contributions.

So, the reason sound maps do not function as a hard constraint--the reason, that is, they do not idealize the control and domination of the audible environment-is the nature of their subject, what might be called the "sonic Real." As philosopher Slavoj Žižek writes, it is precisely when we believe we have captured the Real that we are forced to confront a deeper, more complex truth; "[i]t is not that reality entered our image: the image entered and shattered our reality (i.e. the symbolic coordinates which determine what we experience as reality)." ${ }^{\prime 2}$ Sound maps are important, in this sense, because of the way they change both what is possible to be viewed and how we view it. It is not that the Real of sound is captured by the map; it is rather that maps have been caught in a swirling vortex of sound's Real.

To some extent, this is due to the nature of the Real itself. To begin with, the Real refers not to some knowable, objective, or material configuration of the world. Its essence, to the extent it has one, cannot be known or seen directly, neither can it be expressed abstractly as a number, a property, a painting, or in a musical composition. As a category, the Real includes both material states and immaterial properties, conscious and subconscious experiences. This, by nature, makes it difficult to grasp since, in nearly any circumstance, approaching it, triangulating it, requires the passage or mediation of information through successive layers of observation. Studying the Real requires

82 Slavoj Žižek, "Welcome to the Desert of the Real," in The Symptom 2 (Spring 2002), http:/l www.lacan.com/desertsymt.htm (accessed 27 September 2011). 
excavating and observing what bubbles up from beneath our most immediate analysis of the world and ourselves-accessing it, even obliquely, requires probing surface-level observations in pursuit of something beneath. The result consequently entails the passage of information through the Symbolic domain, which as mentioned above, includes both cultural and communicative codes, such as language, speech-and arguably sound maps, too- which add further layers of meaning and complexity.

Neither is pursuing the Real necessarily a linear and straightforward process. Ordinarily, it is one that requires repetition and deep (self) investigation. Each layer, each peeling back of the observable surface, reveals rich complexity, a kind and diversity of experience filled with deep signification that may, on its own, require yet further investigation. The difficulty inherent to this process has been explained by Mark Bracher, an English professor and expert on psychoanalytic theory, as rooted in the "radical incommensurability between system and non-system." 83

On the one hand, subjectivity is a function of systems - Symbolic and Imaginary, or verbal and imagistic-that organize different perceptions, memories, thoughts, feelings, desires, and enjoyments in relation to each other. On the other hand, however, there are also present within subjectivity 'impressions without memory,' which constitute what Lacan calls the Real. Lacan defines the Real as that which resists symbolization absolutely... [The Real] includes intense events (or aspects of events) of our later life that cannot be fully grasped by our perceptual or cognitive structure and categories. ${ }^{84}$

Because the Real "resists symbolization," even when we think we have accessed or contained some part of it, we can never be quite sure we have succeeded. Žižek, for instance, situates this uncertainty within a three-staged encounter.

83 Mark Bracher, "How Analysis Cures According to Lacan," in The Subject of Lacan: A Lacanian Reader for Psychologists, eds. Kareen Ror Malone and Stephen R. Friedlander (Albany, NY: State University of New York Press, 2000), 191.

84 Ibid., 191-92. 
The Real is first there as the anamorphic stain, the anamorphic distortion of the direct image of reality-as a distorted image, a pure semblance that 'subjectivizes' objective reality. Then the Real is there as the empty place, as a structure, a construction that is never actual or experienced as such but can only be retroactively constructed and has to be presupposed as such - the Real as symbolic construction. Finally, the Real is the obscene, excremental Object out of place, the Real 'itself.' 85

These three dimensions of the Real result from the three modes by which one can distance oneself from 'ordinary' reality: one submits this reality to anamorphic distortion; one introduces an object that has no place in it; and one subtracts or erases all content (objects) of reality, so that all that remains is the very empty place that these objects were filling. ${ }^{86}$

The underlying problem, the reason this encounter takes place in phases rather than all at once, is that " $[t]$ he core of our being is partially obscured, and this is why we very often cannot decide what it is we really wish, $" 87$ and furthermore that "meaning and truth escape representation, partially or in toto." 88

This encounter with the Real is mirrored also in areas other than psychoanalysis.

Lacan himself located both the structure of the Real and the necessity for a multi-phased encounter among scientific inquiry generally, the work of mathematician Kurt Gödel specifically. The reason, as theorist Alexandre Leupin has explained, is that

[t]here is an infinite number of theorems whose validity cannot be proven or disproven. In order to validate [a fundamental] theorem, which often constitutes the basis of reasoning, the scientist has to resort either to an arbitrary decision (to transform the theorem into an aporia) or to another scientific system (which puts into question the rational unity of his own field and shows that this field cannot aspire to a totalization) ${ }^{89}$

85 Slavoj Žižek, "The Real of Sexual Difference," in Interrogating the Real, eds. Rex Butler and Scott Stephens (London and New York: Continuum, 2005), 339-340.

86 Ibid., 340.

87 Alexandre Leupin, Lacan Today: Psychoanalysis, Science, Religion (New York: Other Press, 2004), 47.

88 Ibid., 48.

89 Lacan "Radiophonie," quoted in Leupin, Lacan Today, 53. 
The attempt to "close" science, to create all-encompassing explanations becomes, if not self-referential, at least self-concerned. The ultimate outcome is incommensurate with what we experience, and therefore ultimately impossible to reconcile with empiricallydetermined fact. All of the images and models science produces are bound to be distorted —and by relying on a recursive justification, they permit the Real-Real to continually slip by or stay hidden. Leupin comments:

Such interventions demonstrate that the subject of science cannot be envisioned as complete or whole but is open to an arbitrary decision or divided by the ultimate nonunity of its field. In other words, the impossibility of completeness underlines the fact that the subject of science cannot be 'sutured' (that is, be determined, and thus closed, in an entirely rational fashion. $)^{90}$

We cannot, practically or literally, have all of the facts about everything. It is therefore important to distinguish the Real from what we commonly call "reality." The latter, as Žižek explains, "is always a fictional image," a figment of the imaginary rather than the Real proper, one where "[i]dealism and nominalism are both trapped ... in thinking that the reality of signification is indeed equal to the Real order of meaning."91 The Real functions, then, not as an absolute collection of facts, but as a kind of trauma -one that is subsequently buried or coded, always beyond reach, capable of being understood only by analyzing the peculiar shadows it casts, unraveling the strange, stained, or stretched representations, like sound maps, that result. Paradoxically, then, it is by trying to represent reality that we find it absent; and it is precisely in finding it absent that we return to (re)represent it. Bruce Fink writes,

[i]t is the non-representational nature of the real that brings on repetition, requiring the subject to return to that place of the lost object, the lost satisfaction. Every other

\footnotetext{
90 Leupin, Lacan Today, 53.

91 Ibid., 47.
} 
satisfaction pales in comparison with the one that was lost, and the subject repeatedly returns to the site of that absence in the hope of obtaining the real Thing, and yet forever missing it. 92

To synthesize Žižek and Fink's analysis, then, we can say that the Real appears first as a shadow, a "stain" for which no explanation seems possible, but which, at the same time, seems to influence everything surrounding it. It appears next as a Symbolic construction, as an image: a form of representational power that is never directly experienced and, if too strongly believed, whose effectiveness easily evaporates. Finally, the Real is rendered an elusive, even obsessive and rhythmical repetition: a place-literal or metaphorical - to which we return again and again in the hope of finally understanding. And yet, it continually evades us. Each view we construct of it results in yet another stretched image, another partial glimpse, requiring yet further investigation, further participation, more insight from more people.

It remains to be clarified how this Lacanian model rescues sound maps from becoming a totalizing force - the kind of grand, unifying explanation I have suggested they serve to critique. The answer begins by noticing the way sound maps first appear, as a kind of distortion. They emerged even within acoustical research as images out of place, as representations that stretch or challenge our sense of sonic awareness. By highlighting the way space is not uniform or smooth, but rather textured and differentiated even within itself, they can, if we allow them, be analyzed critically as a form of representation that helps to "determine what we experience as reality." 93

\footnotetext{
92 Bruce Fink, "The Real Cause of Repetition," in Reading Seminar XI: Lacan's Four Fundamental Concepts of Psychoanalysis, eds. Richard Feldstein, Bruce Fink, and Maire Jaanus (Albany, NY: State University of New York Press, 1995), 228.
}

93 Žižek, "Welcome to the Desert" 16. 
Despite appearing both clear and complete, sound maps nonetheless have important limits and should not be confused with purporting to represent the "sonic Real" itself. Sound maps, instead, open up the possibility of mappings and re-mappings. They gesture toward circumscription but, because of their nature as maps, can never fully fix or define the Real itself. Instead, sound maps initiate a cycle of repetition grounded in a persistent sense of incompleteness, driven by an impossible or "lost thing." In the end, they are not designed —and arguably cannot be designed — to solidify our relationship to space, to decode it "once and for all." Rather more modestly, as will be explored throughout the remaining chapters of this dissertation, they enable us to observe the way in which space and sound interact co-productively while disempowering any further attempt to universalize the outcome as necessary or absolute.

\section{Conclusion}

I began this chapter by exploring the history of sound research at a time when experimental methods blurred the boundary between "magic" and "science." The field we recognize today as architectural acoustics emerged only much later, with the work of Harvard physicist Wallace Sabine. It was he who made a key discovery at the turn of the $20^{\text {th }}$ century: a simple and elegant mathematical equation that could be used to control reverberation. Sound, in the end, appeared not as some mysterious force, but one that is knowable and predictable — and whose behavior can be understood and explained, literally, by the numbers. Sabine's discovery had a profound effect, not only on the way we analyze and design space, but on how we conceive of ourselves in relation to it. And yet, in becoming idealized, it had the effect of creating what Fredric Jameson calls a 
"discourse without a subject:" a conceptual framework that is, if not beyond experience, then removed from it.

This realization highlights the need for an acoustical-critical discourse, one that makes difficult our cultural and scientific desire to study sound only in order to better control it. The limited form of critique that does exist is exemplified in the discussion of "failed" acoustical spaces; but this leads down a paradoxical and unhelpful path of negative legitimation. In many respects, the study of acoustical failure is used to highlight our own human inadequacies: our inability to actualize plans with precision, our tendency to hear spaces in ways not approved by the numbers. Missing, then, is a mode of critique that stops short of outright scientific denialism, but that resonates with contemporary methodologies such as Actor Network Theory (ANT) and the Social Construction of Technology (SCOT) — both of which view scientific discovery and technological development as an uneven and fundamentally cooperative process.

Constructing this kind of critique remains possible; and one way to do it, I propose, is by re-directing our focus within the already extant narrative of the development of acoustical architecture. Except, rather than studying the relationship between space and sound as fixed and stable, we can foreground its dynamic elements, re-contextualizing them as (what Deleuze and Guattari called) "univocal." Surprisingly, the published papers of Wallace Sabine again provide a compelling starting point. Included among them are numerous schematics, photographs, and diagrams made to show how sound moves and flows, gathers and collects, in uneven and sometimes unforeseen ways. These images-a form of visualization I call the "sound map"-highlight a different way of 
thinking about sound-space relationships. While they do not necessarily oppose the more conventional model of acoustical research—and indeed, in a historical sense, developed alongside it-sound maps are important for entirely different reasons. Most immediately, they empower an approach to the study of environmental sound that is based on experience and perception, one that resists being "closed" either to further analysis or to the insights of subjective experience.

With this theoretical framework in place, the remaining chapters of this dissertation turn to more tangible analysis. In the next chapter, I will explore some of the problems inherent to visualizing the urban sound environment. As government regulators, artists, scholars, and the wider public have come to appreciate the constructive role that sound plays in everyday life, they have increasingly relied on spatial graphics purporting to "show" sound: perhaps by circumscribing a sonic territory, or by identifying points of specifically sonic interest. In addition to proposing a general typology that can be used to study environmental sound maps, I will work to disentangle some of their visual elements from the design and analytical methodologies used to construct them. 


\section{Chapter 2: A Typology for Environmental Sound Maps}

To give a totally convincing image of a soundscape would involve extraordinary skill and patience: thousands of recordings would have to be made; tens of thousands of measurements would have to be taken; and a new notation would have to be devised.

-R. Murray Schafer, The Vancouver Soundscape

\section{Introduction}

In the first chapter of this dissertation, I worked to theorize the development of the sound map. I suggested its conceptual roots can be found among the work of Wallace Sabine, a physicist at Harvard, who made use of visual representations to demonstrate the movement and flow of sound, its fluctuations and variations, even within a single and highly controlled environment. I further proposed that these images suggest a different way of engaging with the world: a new sonic consciousness, where sound is valued not for its ability to be contained-or in fact, to exert control over us—but rather for its tendency to change as it moves and flows, decays or intensifies, through space.

Since the early days of the $20^{\text {th }}$ century, sound maps like these have found their way into a number of different fields of inquiry. Indeed, as scientists, sound studies scholars, government regulators, musicians, and even visual artists have developed an interest in the dynamic, sensorial textures of daily life, maps have increasingly become a representational medium of choice. Convenient and often visually compelling, sound maps can be found with regularity throughout both academic publications and regulatory documents today. And yet, very little has been written about them. Of the small number of articles dedicated to their study, none shed critical or analytical light on what sound 
maps show and how. ${ }^{1}$ The purpose of this chapter, then, is to expand the potential for academic dialogue by sketching a general sound map typology, one that can be used to disentangle the image of the map from the underlying methodology used to construct it

The typology outlined here is meant to help clarify how the "texture" of audible space is both presented and represented, transformed and transferred, into a medium that, in other contexts, might not seem suitable. Each section below, except "Thematic Words," will therefore define and discuss a particular sound map type: the first section explores grid maps; the second explores field maps; the third section explores soundwalk maps; the fourth explores territory maps; and the fifth and final section explores dynamic, internet-based maps. While each type can be distinguished based on several key methodological and visual considerations, there are nonetheless a few shared technical and optical similarities among them. For this reason, they will be sub-labeled according to the other types which bear some resemblance.

\section{Thematic Words}

Before delving too deeply into the sound map typology, it is perhaps worth explaining why this kind of typology is useful in the first place. Despite their relative historical newness, there is nothing particularly "new" in the conceptual or visual operations of a sound map. As cartographer and historian Arthur H. Robinson has written, where "general cartography" describes maps meant to "locate and identify geographical

\footnotetext{
1 Jacqueline Waldock, "Soundmapping: Critiques and Reflections on this New Publicly Engaging Medium," Journal of Sonic Studies 1, no. 1 (October 2011), http://journal.sonicstudies.org/vol01/ nr01/a08 (accessed 23 April 2012); Solène Marry, "Assessment of Urban Soundscapes," Organised Sound 16, no. 3 (2011): 245-255; Olivier Balaÿ, "Discrete mapping of urban soundscapes," translated by Harry Forster, Soundscape: The Journal of Acoustic Ecology 5 , no. 1 (Spring/Summer 2004): 13-14.
} 
features,"2 maps of sound belong to a derivative practice known as "thematic cartography." Robinson finds thematic cartography expressed with particular clarity in maps

showing the geographical occurrence and variation of a single phenomenon, or at most a very few. Instead of having as its primary function the display of the relative locations of a variety of different features, the pure thematic map focuses on the differences from place to place of one class of feature ... The number of possible themes is nearly unlimited and ranges over the whole gamut of man's interests in the present and past physical, social, and economic world, from geology to religion, and from population to disease. ${ }^{3}$

In more general terms, thematic cartography has a relatively simple function: to transform a set of (often empirical) information—about population or poverty, precipitation or the position of armies-into a series of graphical marks, whose variations in size, shape, contour, quantity, or color correspond with a perceived or material change in the represented theme. Ultimately, this is done with the "hope of discovering meaningful correlations among the regional variations." ${ }^{.4}$ Thematic maps can therefore be understood as heuristics of a sort, useful because they help us discover new and different ways to sort through what may otherwise seem like random or unrelated observations about the world.

Thematic cartography initially came to prominence during the early $19^{\text {th }}$ century coincident with the rise of strong imperial governments-a consequence of the practical need to study the languages, activities, and movements of diverse peoples. But it was industrialism, the rise of capitalism, and rapid population growth in industrialized

\footnotetext{
${ }^{2}$ Arthur $\mathrm{H}$. Robinson, Early Thematic Mapping in the History of Cartography (Chicago and London: University of Chicago Press, 1982), 16.

3 lbid.

4 lbid., 155.
} 
countries that lent these maps sudden importance. ${ }^{5}$ They were tools that could be used to study people: the health of their bodies, the movement of the goods sustaining them, and the spread of the maladies afflicting them. According to Robinson, "[t]he sharp rise" in the use of thematic cartography during the first half of the $19^{\text {th }}$ century represents "the combined effects of greatly increased curiosity about the earth and man and numerous innovations in the techniques and conceptual aspects of mapping." It was also during this time that "almost all the symbolism used in thematic mapping today was devised and put to use."

Since representing abstract topics such as the spread of urban disease was beyond the technical limits of "general" cartography, it is perhaps not surprising to find that new and different kinds of representational media developed alongside thematic maps. Where contours (also called isolines) have very early origins, dating to the work of Pieter Bruinsz in the late 16 th century, ${ }^{7}$ dots and points were not used in thematic contexts until much later, in 1837, when they were shown the relative population size of cities and towns in Ireland. ${ }^{8}$ Other maps-like flow maps, which use lines or arrows of varying length and thickness to show the intensity or volume of movement from place to placedid not appear until the early 19 th century, when they were used in maps by Henry

\footnotetext{
5 lbid., 155.

6 Ibid., 219.

7 Ibid., 210-11.

8 lbid., 199.
} 
Harness (UK), Charles Minard (France), and Alphonse Belbair (Belgium) to compare economic data and the flow of goods in Europe. ${ }^{9}$

But behind each development in representation lie also advancements in technology, especially printing and engraving. Robinson explains how "the proliferation of duplicating methods in the nineteenth century, especially lithography, had a great influence" on what themes could be shown and how. ${ }^{10}$ Lithography, of course, was itself developed in the late 18 th century as a relatively quick and cost-effective printing method. It involves using hydrophilic and hydrophobic substances to mediate the transfer of ink from one surface (historically limestone) to another (paper). Lithography was especially appealing to thematic mapmakers because it provided an efficient means to layer topical content on top of an already-extant map. Alternative approaches, conversely, were seen as risky and potentially expensive by comparison since a single mistake in a single thematic detail might require making an entirely new die. With copper engraving, for instance, thematic information could only be introduced on the original surface with "numerous flicks with a sharp tool, by using a punch and hammer to make dots, or by using a variety of rough-surfaced rollers, rockers, and roulettes which would produce a pattern of indentations." " Given the ease with which printed maps could be edited and corrected, the likelihood of error meant copper engraving was ultimately abandoned in favor of the simpler and less costly methods like lithography.

\footnotetext{
9 Ibid., 147.

10 Ibid., 193.

11 Ibid., 194.
} 
It is important to remember, however, that as soon as the process of selecting thematic information for display begins, we have already done much more than present "an innocent 'reality', somehow dictated by the intrinsic 'truth' or by 'facts' in the data."12 From Google maps to weather maps, viewers are conditioned to see the image as itself a true depiction - a representation of the world "as it is." Indeed, a naive approach to cartographic analysis would have us accept that a map, thematic or not, shows exactly what it claims. Cartographic historian J.B. Harley goes so far as to call this the "uncritical adoption" of thematic cartography and suggests that its prevailing impact can be "linked to two main sets of influences."

The first is the belief that mapping is merely a technical or methodological strategy rather than a discourse ... The second is that the sometimes strident claim by cartographers, that they had devised a technical solution to the representation of data, was taken at face value. The result was an elevation of the map so that we were often mesmerized by its mimetic powers. ${ }^{13}$

Of course, in some respects, the introduction of thematic material may seem to mitigate the need for critical analysis, since it goes almost without saying that giant isolines or arrows do not actually exist and are merely visual and conceptual abstractions. But Harley and fellow historian John Pickles suggest the opposite is true. All maps, even thematic varieties, must be seen and read as culturally, historically, and even politically determined. It is their very nature to conceal that choices were made about what to show and how-choices which can, in turn, shape and influence how we understand the world they are supposed represent. Echoing Foucault, Pickles explains how maps are

\footnotetext{
12 J.B. Harley, "Historical geography and the cartographic illusion," Journal of Historical Geography 15, no. 1 (January 1989), 86.

$13 \mathrm{lbid}$., 83.
} 
always an argument ... and it is patently wrong to present them as a hard 'truth', or to deny their indeterminacy of meaning. In historical geography they force a particular reading of reality by suppressing other aspects of the past. They are full of silences. ${ }^{14}$

Whether designed as wartime propaganda or as an aid to navigation, ${ }^{15}$ maps always do more than merely represent simple reality—or, as Žižek more accurately explains, "the symbolic coordinates which determine what we experience as reality." 16 Maps, that is to say, represent and reproduce a network of power relations, social tensions, and cultural norms. ${ }^{17}$ And as Pickles explains,

[b]y not paying sufficient attention to their own crafty skills of transmutation and by tirelessly seeking to turn away from the interpretative nature of their Merlinesque constructions, scientific cartographers have found it very difficult to explain the difference between their own magic and the conjuring tricks of those who would use this magic for militaristic, propagandistic, or commercial ends. By making scientific cartography into a technical enterprise and rejecting (or overlooking) its magical and hermeneutical practices, cartographers have grappled with the error and distortion in only technical terms. ${ }^{18}$

And yet, the "Merlinesque constructions" of sound maps--where spatial and sonic representations merge into a single frame- have not received any serious critical attention. Nowhere in the scholarly literature today is there any meaningful discussion of what they show and why: which sounds have been chosen for representation, and which, as Pickles suggests, have become "silences." Because they are more than merely a

${ }^{14}$ John Pickles, A History of Spaces: Cartographic reason, mapping and the geo-coded world (London and New York: Routledge, 2004), 86.

15 Pickles, 37-38.

${ }^{16}$ Slavoj Žižek, "Welcome to the Desert of the Real," in The Symptom 2 (Spring 2002), http:/l www.lacan.com/desertsymf.htm (accessed 27 September 2011).

$17 \mathrm{lbid} ., 37-47$. Additionally, Pickles asks "[w]hat ... can we say about maps such as those that represent the 'earth from the South' or 'the Australian's view of the world'? In such maps, the techniques of modern cartography ... are used to dislodge a particular hegemonic orientation that has been standardized historically." (Pickles, $A$ History of Spaces, 45.)

18 Ibid., 45-46. 
"technical enterprise," it is my contention that sound maps should be scrutinized in more detail, paying special attention to the relationships that bridge their methodological and visual form to the surrounding cultural and political milieu. The remainder of this chapter will therefore define five sound map types whose characteristics are designed to facilitate further critique.

\section{Type One: Grid maps, becoming fields}

The first sound map type is the grid. Though comparatively rare, grid maps can be defined as those which emplace empirically-derived sound observations, acquired either by human or mechanical means, in a regular pattern across the surface of a base map. ${ }^{19}$ These maps depend on the careful observation of sound at specifically-designated points, but what makes them distinctive is the textural consistency of the final result. In these maps, the grid rules: rather than being guided by sites deemed important or meaningful to acculturated listeners, the grid provides an indifferent framework upon which the final (though not always literal) image is assembled.

London and its boroughs provide an interesting opportunity to observe the origins of the grid map. Its developmental roots can be traced to a report published in 1968 , titled The London Noise Survey (LNS), which set out to "sample noise in as representative a way as possible."20 It consequently consisted of two discrete but interlocking parts, distinguished principally by methodology. The first was an "objective survey" carried out

\footnotetext{
${ }^{19}$ A "base map" refers to a spatial diagram onto which thematic content is layered. For a brief discussion, see: Robinson, Early Thematic Mapping, 17-22. For more recent developments, see: Alison Sant, "Redefining the Basemap," Intelligent Agent 6, no. 2 (2006) http:ll www.intelligentagent.com/archive/Nol6 No2 interactive city sant.htm (accessed 16 January 2010).

20 Building Research Station, Ministry of Public Building and Works, London Noise Survey (Her Majesty's Stationery Office: London, 1968), 3.
} 
by the Building Research Station (BRS). ${ }^{21}$ Their task was to record, catalog, measure, and graph the sounds that can be heard throughout the city_- "to assess noise of all kinds present"22 -without regard for whether these sounds are heard. ${ }^{23}$ The second part, executed by Government Social Survey (GSS), was a "subjective survey" meant to "set noise in perspective with other factors, and to ascertain the relative effects on daily living of indoor and outdoor noise." ${ }^{24}$ Because the GSS component was conducted in the abstract-drawing on statistical and demographic surveys, not addressing spatial location or the direct observation of sound-it is perhaps unsurprising their report made no use of maps at all. The BRS team did, however, and quite extensively.

Mapping sound at the urban scale presents some obvious, if not forbidding, challenges; and indeed, it became clear early on that there were very real limitations on what the BRS team could hope to accomplish. There arose, then, a need to understand precisely how much sonic information would need to be collected, and to what extent statistical samples could be used to fill in the gaps. For this, they arranged to conduct a pilot survey in the London borough of Watford, where they experimented with any number of equipment settings and orientations: different microphones, different ways of

\footnotetext{
21 Ibid., 1.

22 Ibid., 3. The word "assess" here seems somewhat inaccurate, because it seems to imply "valuation." In all, their project seemed much less interested in labeling sounds as good or bad, but simply observing them, trying to understand how they influenced various parts of the city.

23 This phraseology may coy, but it is important. Barry Truax has written that overlooking un-heard sounds is a crucial error - a syndrome he calls the "ear versus the body syndrome." $\mathrm{He}$ explains how "this syndrome ignores the fundamental fact that sound is first and foremost a physical vibration that affects the whole body. For instance, the body contains many enclosed spaces or cavities that can resonate sympathetically to vibration, each at its own frequency." See: Barry Truax, Acoustic Communication (Westport, CT: Ablex Publishing, 2001), 98.

24 Ibid., 1, 59.
} 
connecting microphones to (one or more) tape reels, different ways to calculate the loudness of sound, different heights and directions to place microphones, the usefulness and accuracy of different recording profiles (e.g. dBA, dBC), different sampling techniques, and so forth. ${ }^{25}$

After a careful review, the BRS team determined that recording for 24 continuous hours was both impractical and unnecessary; strategically acquired samples were deemed equally sufficient. Specifically, they determined a two-minute sound recording, captured once every hour for twenty four continuous hours, provided a representative cross-section of the kinds, qualities, and intensities of sound heard at each location. In addition, they narrowed the scope of the survey to the traditional workweek, since it was observed that the disruptive capacity of "unwanted sound" was most acute on weekdays when both economic and travel activity is highest. ${ }^{26}$ While the "method of sampling" the BRS proposed was novel and "had not been used in previous surveys," they nonetheless determined it would be the "least biased" approach to studying urban noise. ${ }^{27}$

The decision to structure the survey around strategic samples meant the LNS team had at least two crucial decisions to make: the first was to determine where to place the recording equipment; the second was to determine how many sites would need to be surveyed. They explained:

25 Ibid., 3.

26 Ibid.

${ }^{27} \mathrm{Ibid}$. It is important to mention that the BRS found recording sound for more than a 45-50 minute period was difficult for "practical reasons." Although they do not specify what these reasons were, it is reasonable to assume the sheer quantity of tape reel required for that duration presented some obstacles, as did the number of man hours required to analyze them. 
On practical grounds it was thought that a representative survey of this nature would take about a year, and with two sets of measuring apparatus, either about 500 points could be sampled for one complete day each, or a lesser number for a proportionately longer period of time. ${ }^{28}$

The pilot survey in Watford suggested something else. On one hand, a close spacing of microphones, at 250 yards, gave a "relatively accurate picture" of the sounds in any particular place; but since noise levels, especially those in residential areas, tend to be lower overall, the BRS team determined microphones could be spaced at twice that distance..$^{29}$ As a result, the survey was quite literally framed by an abstract grid, one with lines spaced at 500 yards apart. A recording van containing all the necessary equipment (microphone, tape reel, etc.) was then parked at each of the 540 points in real space where grid lines intersected. (Figure 2-1) Once in place, a pair of microphones would be deployed—usually on top of the recording van, or otherwise on a microphone stand raised to the equivalent height. ${ }^{30}$ Where the presence of water, train tracks, or some other obstruction meant a particular point could not be reached, the survey equipment was positioned nearby, perhaps on a bridge or riverbank. ${ }^{31}$ All of the relevant information-

28 Ibid.

$29 \mathrm{lbid} ., 3-4$. Further technical accommodations were made for the microphones. They explain: "[T] We Watford pilot survey had shown that the range of noise levels to be expected was greater than the dynamic range of any of the normal tape recorders used for recording. The full pass noise levels were likely to range from $30 \mathrm{~dB}$ in a quiet location at night to over $90 \mathrm{~dB}$ adjacent to a particularly noisy vehicle. To deal with this range of noise levels the signal from the amplifier was split to feed both channels of the tape recorder which had amplifications set to differing by $20 \mathrm{~dB}$. [sic] Since the crosstalk between adjacent channels was better than $30 \mathrm{~dB}$ and the dynamic range of each channel $50 \mathrm{~dB}$, the quieter noises, from 30 to $80 \mathrm{~dB}$ could be recorded on one channel and the louder 50-100dB, on the other."

30 Ibid., 4.

$31 \mathrm{lbid}$. 
including the location of the van, tape reference numbers, and the address of the person providing access to electricity - was later copied onto a simple report form. (Figure 2-2)

After a recording cycle was completed, all of the results would be analyzed and subsequently transferred onto a separate report form featuring a selection of qualitative (e.g. "people talking") and quantitative (e.g. " $40 \mathrm{~dB}$ ") information. (Figure 2-3) The final LNS report, published in 1968 , included 54 of these forms, $10 \%$ of the total number. Each entry shows a small street map on one side and a 24 hour graph on the other, the latter showing both the average "high" and the average "low" decibel reading for each area at any given hour of the day. It is important to note, however, that there was no incremental decibel penalty for sounds produced at night— justified in more recent surveys because the lack of ambient background sound makes even moderately disruptive noise seem more intense at night than an empirical reading might suggest.$^{32}$ Here, instead, decibel levels were graphed exactly as they were recorded; and what emerged was a striking (though not surprising) rhythm: decibel readings are uniformly higher during the morning and evening rush hours, with the deepest lull occurring just before dawn.

Many such small decisions made by the LNS team were formative. For instance, the grid, whose structure was shaped by technical or human limitations-the capabilities of a pair of microphones or the capacity of a careful listener, for example-quickly

\footnotetext{
32 In acoustics research, this statistical model is called Lon. It is designed to show the average decibel reading for a given location, with a $10 \mathrm{~dB}$ penalty for nighttime sounds. The results are calculated according to the formula $L_{d n}=10 \log \left\{1 / 24\left[15\left(10 L_{d} / 10\right)+9\left(10 L_{n}+10\right) 10\right]\right\}$ where $L_{d}$ is the equivalent noise level during the day, and $L_{n}$ is the equivalent noise level during the night. Of course, this is one of a number of different statistical models-others include perceived noise level (PNL), noise exposure forecast (NEF) - which do not usually include such penalties.
} 
became much more: a literal, methodological construct. (Fig. 2-1) That is to say, not only did the grid help narrow the ambitious breadth of the study, but the sampling method, which informed the grid's size, meant sonic noise could be studied without an excess of data noise. But the grid had other impacts, too. As the BRS team was aware, it also limited the kind of maps they could hope to make. They wrote, for instance:

it is obvious that measurements at points spaced 500 yards apart do not enable noise contours to be drawn on a map. A very much closer spacing of the points would have been necessary for this, resulting in a smaller area or a number of smaller areas being surveyed in greater detail. The results ... would not be representative of other positions except where these were virtually identical with regard to the noise sources, distances, and size of adjacent buildings. ${ }^{33}$

This process-observing sound, collating, then generalizing the results-almost precisely explains how the LNS report forms interact with the underlying grid. Each point contributes more to the study than what might seem obvious: rather than simply locating where a sound recording was taken, it links or embeds a specific sonic rhythm to a specific point. Sound, as a result, becomes deeply implicated within the frame and, furthermore, begins to spread and proliferate across the surface of the map. Indeed, the LNS even anticipated the possibility that readers would sift through each diagram to find one whose mix of housing, park, office, and industrial use is "virtually identical" to their own —and from there, extrapolate conclusions about the local soundscape. So, what seem like isolated dots on narrowly-contained maps begin to spread; and as a result, cartographic space is transformed: rather than being implicitly silent, the map comes to represent a place already woven-through with sound, though articulated only at a few key points.

33 Ibid., 11. 
This is an unusual thing for a grid to do. After all, grids are most commonly used to impose a stable and rational framework: in perspective drawing, to create a series of smaller, contained areas that can each be studied manageably; in mathematics, the Cartesian grid is used to articulate points only when underlying data calls for it. ${ }^{34}$ The transformation and development of the grid in the LNS is therefore significant in itself. Here, however, the grid functions as an implicit set of instructions: each point has to be visited, listened-to, measured, and analyzed, then spread and proliferated across the surface. If not, the sonic fabric would lack crucial threads, the image would be incomplete. Still, the LNS grid only achieves this effect through implication. There is no large-scale map published where all of the data is recombined, collaged into a single frame. That work, instead, is left for the viewer or analyst to perform. It is by making connections between and among measured locations, by noticing patterns, that the broader image of the survey begins to emerge.

Not all grid maps leave open this act of recombination. A quite sophisticated example can be found decades after the LNS was completed. The Twin Cities Design Festival in 2003 saw the release of nine innovative "knowledge maps." Each was designed to challenge the viewer to think about the city of Minneapolis differently-to help us better understand what transforms "space," its physical dimensions and material parts, into "place," a living, breathing environment, filled with meaning. Some maps did this by focusing on what was tangible and useful in the city, though perhaps underutilized, like the location of urban gardens. One map, though, took a completely

\footnotetext{
34 Hannah Higgins, The Grid Book (Cambridge, MA: The MIT Press, 2009).
} 
different approach. Rather than showing the city as someplace physical, a space filled with "things" that could be used or had, it showed Minneapolis as a sonic space, one that had been already-sounded.

This map, titled "466 Decibel Readings," was designed by a group of music students and graphic designers, lead by Rachel Thompson and Jonathan Zorn. It was made by transposing a series of small icons onto a minimalist rendering of the city's most well-known geographical features: the highway system, the airport, and the Mississippi river-all unlabeled. The result took the form of a grid, articulated by a small image, located at each point of intersection. (Figure 2-4) While Zorn explains that the idea to map Minneapolis using the grid came early in the design process, actually collecting the measurements at each point posed a number of significant challenges. After all, the location where each grid line intersected was determined ostensibly externallyregardless of how difficult that point would be to reach and without any consideration for the kinds and types of sound that would be heard there. Zorn recalls:

\begin{abstract}
We all ended up in places that we had never been before, situations where we weren't sure just how much we should follow the grid. Is it trespassing? How do you measure the $\mathrm{db}$ in the middle of the interstate? Are the giant carp going to jump out the river and attack me, and so on. It was a fun way to get to know the city. ... Often people would come up and ask what we were doing. We would explain the project and encourage them to submit stories of sonic experiences in the cities. Sometimes people would just assume that we were up to no good. I overheard one father daughter interaction after they walked by me. "Daddy what are they doing?" "Asking for money, fucking canvasers." ${ }^{35}$
\end{abstract}

The grid itself, though, was planned quite casually. Zorn joked that the design team used "something really scientific, like putting a ruler on a big map and checking off every inch

35 Jonathan Zorn, interview by author, questionnaire sent and received by email, Charlottesville, VA, 11 August 2010. 
or so." 36 The measurements they collected, on the other hand, were taken with a great deal of care. For each location, a line on a report form was completed, featuring: the date of observation, the corresponding (mapped) reference point, a geographic description of the location (e.g. " $35^{\text {th }}$ Ave + Senbury Ave"), and six discrete decibel readings acquired using low-tech hand-held equipment. This data was later averaged, and the result formed the basis for a small circular icon-showing a decibel reading in the center and a corresponding number of thin, concentric circles surrounding it. (Figure 2-5) After all of the readings had been taken, and all of the icons constructed, each of the final 466 readings was returned to the surface of the base map, superimposed on top of the unlabeled city in a way that preserved the grid's original form.

What emerges, visually, is akin to a sonic fabric knitted across the surface, an experiential and sonic topography that would be otherwise difficult to imagine. But there is also a more superficial element to this map. Not only does it open sounded-space for the imagination to dwell in, it is, more simply, interesting and compelling to look at. " 466 Decibel Readings" deftly balances abstraction with familiarity, detail with imprecision, regularity with apparent randomness. The simplicity of each icon is complicated by their subtle differences: the lines surrounding each number are easy to miscount; the increase or decrease in the number itself is easy to overlook; sudden changes in the decibel reading sometimes occur without any indication as to the cause. The result, textured but still clearly articulated, reveals a kind of aural regularity that exists both in spite and because of the sonic variations observed at each point.

36 Ibid. 
This fascinating perspective on life in Minneapolis-a textured sound gridseemed to momentarily capture the imagination of the general public, museum curators, and the news media alike. ${ }^{37}$ During a 2003 interview on National Public Radio, Rachel Thompson speculated about some of the aims and intentions behind making it:

Perhaps what we were trying to do with the project is suggest a different point of entry for visitors to the city, or a different way for residents of the cities to reconsider how they navigate or how they experience their city on a daily basis. ${ }^{38}$

What Thompson says here is crucial, because even though " 466 Decibel Readings" typifies an advanced and certainly visually compelling grid, it highlights the vague and slippery point at which the grid itself begins to dissolve: the point at which we, as auditors, begin to notice that what we hear "on a daily basis" shapes the content of our lives and the identity of our community. What begins, then, as a tightly-woven and clearly-structured frame becomes an object intertwined with ordinary life-one sensitive to an experience of place, the sounds (present and past, audible and remembered) understood to define it.

\section{Type Two: Field maps, becoming walks and territories}

A second type of sound map is the field map. Generally quite common, especially in disciplines like acoustic ecology and anthropology, field maps can be defined as those which link either subjective or empirical sound data to the life and activities of a

\footnotetext{
37 "466 Decibel Readings" was featured prominently in art exhibit, "Sense of the City," held in 2005 at the Canadian Centre for Architecture in Montreal, Canada. Photographs of the exhibit, along with reflective and analytical essays, are featured in the published guide. See: Mirko Zardini, Sense of the City: An Alternate Approach to Urbanism Montréal: Canadian Centre for Architecture, 2005).

38 "Map Marks Hot Spots in Twin Cities," interview with Robert Siegal and Rachel Thompson, All Things Considered, National Public Radio, 3 September 2003.
} 
particular community. As a result, field maps take any number of visual forms: they might have arrows, representing the approach of incoming sounds; they might include sound contours, suggesting different thresholds of perception; they might also locate a significant sound within a community, identifying where it can be heard or the object making it.

A wealth of field maps can be found in the published work of the World Soundscape Project (WSP), a consortium of scholars and sound artists based at Simon Fraser University whose work was discussed in the introduction to this dissertation. Specifically, this is where maps-what Schafer refers to as "notation"-become important. "To give a totally convincing image of a soundscape," he wrote "would involve extraordinary skill and patience: thousands of recordings would have to be made; tens of thousands of measurements would have to be taken; and a new notation would have to be devised."39 The first WSP publication to make use of this "new notation"which included maps-was The Vancouver Soundscape (TVS), published in 1978. Compared to the BRS component of the LNS, or even "466 Decibel Readings," this study approached environmental sound in a far more supple way. The WSP did not, for instance, have a uniform plan for stationing recording vans throughout the city, nor did they have a rigorous scientific approach aimed at creating statistical models. Instead, their analysis was grounded both in their own experience, living, moving, and listening to Vancouver, and the experience of other residents. To aid their study, the team developed three broad categories of ambient sound: "keynote" sounds, those that compose the city's

39 lbid., 28. 
background structure—-the hum or buzz of ambient space; "signals" sounds, usually instructional or performative, like a bell that calls people to church, or a whistle that calls them back from lunch break; and "sound marks," sounds which are in some way unique to the community and help to define its character-though in a more literal sense, they may be "signals," too: a particular church bell, a specific factory whistle.

While the WSP mapped many sounds in all three categories, relevant here is less what they mapped than how they mapped it. On one map, for instance, the WSP identifies a number of significant sounds throughout Vancouver harbor: foghorns, the time gun, church bells at the Holy Rosary Cathedral. (Figure 2-6) Not only is the spatial location of each sound identified, but the sound is itself represented iconographically, by a small image representing the thing producing it. This is a metaphorical, almost hieroglyphic form of notation, one where the sound of horns becomes horns; the sound of bells becomes a bell. And in this respect, something relatively complex happens here; the map allows Vancouver to be literally seen in terms of the complexity and richness of sound experienced there.

Of course, transforming a thing or place into a small graphic is not uncommon in thematic cartography. Similar examples can be found on tourist maps of London or Washington, D.C., where monuments and museums are turned into small symbols. Maps like these, however, are important beyond their simple transformations. In choosing to show some places rather than others-and indeed, using one symbol rather than another - they can provide insight into what a community deems valuable: perhaps what it needs to find (e.g. a train), whom it chooses to memorialize (e.g. a great person), or what 
aspects of a particular location are worth noting (e.g. an important building, a government ministry). But the harbor map of Vancouver adds an extra layer of complexity to this calculus, since what is being located is not a service or a thing, but rather an event or experience-a sound - whose conscious hearing depends on an interdependent network of actors: human operator + fog horn + foggy weather + wind direction + shipping traffic + free trade agreements, etc. Without each fully in place, there would be no horn sound, no horn, and no map. The image we see, then, does more than simply show a "sound mark." It shows a whole field of relations.

Another important development in TVS is the use of maps that locate non-audible sounds: sounds, in other words, that require some form of technological mediation in order to become audible. One memorable example identifies the varying pitch level of telephone dial tones found throughout the Vancouver metropolitan area. (Figure 2-7) This map was composed using a peculiar mix of notational schemes including traditional musical staff. While the map does not delineate clear boundaries for each pitch community, it nonetheless suggests that, if a telephone user somewhere in North Vancouver hears an "f" when they pick up the phone, someone to the southwest, perhaps in Kitsilano, will hear a flat "a," and someone calling from the east, somewhere in Port Moody, will hear a "g\#."40

A similarly imaginative map is constructed to show the broadcast range of local radio stations. (Figure 2-8) Of course, radio signals are not themselves sound but more exactly electromagnetic waves operating in the sub-visual spectrum. These waves can be

40 lbid., 41-42. 
transmitted in one of two ways-by varying amplitude (AM), or by varying frequency (FM); but in either case, the result cannot be heard without the assistance of a receiver and amplifier. The WSP ordinarily calls these sounds "schizophonic"41 — sounds transmitted away from their source by electronic means. Nevertheless, in this map, they are treated as any other ordinarily-audible sound: one that builds and reinforces a sense of community, and at the same time, one that is highly contingent and variable from place to place. ${ }^{42}$ The resulting map becomes a peculiar kind of Venn diagram—one showing how small variations in position, elevation, or location can make the difference between being included or excluded from the sonic field.

A similarly rich and diverse cache of field maps can be found in another significant WSP publication, Five Village Soundscapes (FVS). Here, the WSP team traveled to Europe to "enquire into the different types, quantities and rhythms of sound heard in five villages in five countries, and to show the relationship of these sounds to the structure of each village and its life." ${ }^{13}$ One of their principal goals was to understand how the sonic environment worked before now-familiar sounds — especially those of aircraft and carscame to dominate urban life. For that reason, it was necessary to study towns and villages whose economic and social structures more closely resembled those common during the $19^{\text {th }}$ century: each had fewer than 3,000 residents, and each had a defined economic and

\footnotetext{
$41 \mathrm{Jbid} ., 41$. "We call telephones and radios schizophonic, meaning that they split sounds apart from their original sources to transmit elsewhere. Like the related word 'schizophrenia,' we want schizophonia to have a nervous ring, for while the benefits such developments bestow are well enough known, we do not want to forget that they are contributing to the overpopulation of the soundscape." (41)

42 Ibid., 44-46.

43 R. Murray Schafer, ed. Five Village Soundscapes (Vancouver: A.R.C. Publications, 1977), 1.
} 
social framework. Dollar, Scotland, for instance, is known for its primary school, while Bissingen, Germany is known for its rich agricultural life, and Lesconil, France for its fishing economy.

While each soundscape was just as intricate and complex as Vancouver's, the relatively small size of each village meant it could be studied in more depth and detail.

The WSP team was able to investigate, for instance, how different groups of people living in each area understood and experienced their local soundscape. One important observation they made was that a village's identity is often shaped by "old" sounds—not in the sense of decayed or inaudible, but sounds that were long associated with a particular place, even if that sound has long since been "masked"44 by a general rise in ambient noise..$^{45}$ In Bissingen, they observed that the church bell, which in previous years had been considered a community sound mark, had lost much of its meaning for younger residents. This, they speculated, "may be explicable as a function of the rise of ambient noise."

As the countryside becomes noisier ... sounds do not travel as far ... as they cease, [the younger generations] no longer hear the bells, or, as we were informed in

44 In the Handbook for Acoustic Ecology, Barry Truax defines masking as "[t]he effect one sound has on another by making it harder to impossible to hear. The level of masking can be defined in decibels as the threshold shift necessary to restore a masked sound to audibility in the presence of a masking sound." See: Barry Truax, Handbook for Acoustic Ecology [CD-ROM] (Vancouver: Cambridge Street Publishing, 1999).

Jean-François Augoyard and Henry Torgue add that "[t]he mask (masque) effect ... implies a subjective psychophysiological reaction: the masking sound can be judged as either parasitic or favourable, depending on whether or not the masked sound is perceived as pleasant." See: Jean-François Augoyard and Henry Torgue, eds. Sonic Experience: A Guide to Everyday Sounds, translated by Andra McCartney and David Paquette (Montreal and London: McGillQueen's University Press, 2006), 66.

45 Schafer, Five Village Soundscapes, 15. 
several German cities, they begin to experience them as a source of irritation or noise. 46

The sound map they used to demonstrate this shrinking sense of community is a fascinating mishmash of remembered and empirically-observed sound, of conceived space and built space. It treats physical objects, like the autobahn and village borders, as constant, while the bell profile is shown quite tentatively-receding behind other objects at various points for no apparent reason. (Figure 2-9)

Other maps in FVS are somewhat more ambitious in their representational aimsand consequently, are not always convincing. One map, for instance, shows the dispersion profile of important sounds in Dollar, including the church bell and the summertime pipe band, while simultaneously showing the movement of external sounds into the village, like the train whistles from Dunfermline and the Old Caledonian Line, or the bleeding of the steam tubes at the power station on Frith of Forth. (Figure 2-10) While this map appears straightforward, the information it presents is actually quite multifaceted. Some of these sounds can be heard in the present, while others are not only inaudible, but figments of psychoacoustic memory; some sounds are part of everyday life, while others were jarring, one-time events (e.g. "Quarry Explosion 1951"); some sounds are shown circumscribed, as if contained, while others are shown advancing, moving-in on the village and its residents. Sound, or things that make it, are shown variously as sustained or intermittent, predictable or unpredictable, enjoyable or bothersome, informative, instructive, or deadly. The criss-crossing of lines and contours

46 Ibid. 
furthermore lend this map a sense of dynamism and motion, reflecting the complex interaction among sounds produced both by the community and the world outside.

A similarly complicated map from Skruv "shows the different physical areas encompassed by the signal sounds of Skruv."47 (Figure 2-11) But this map is also used by the WSP to expose some rather odd disjunctions in the way local residents perceive their environment. They explain how

[t] largest profile, yet the acoustically less powerful church bells are defined by the villagers as spreading over a greater area. They think the bells reach farther, based presumably on what they have 'noticed,' but in fact this reach of the bells is probably largely a mental process that reflects the cultural values associated with the sound. Another factor could be that the church bells have a more complex pattern: they ring repeatedly and have more internal structure than does the single blast of the shift whistle. Also, the bells ring only once a week, on Sunday, when it is quieter. ${ }^{48}$

Perhaps nowhere else in the WSP literature does the gap between sound as it is perceived and measured come into such sharp relief. And the map plays a crucial role in doing it, by showing how drastically out of sync these assessments are. While an accompanying graph provides extra empirical detail, the lines on the map do not themselves represent decibel contours. They are instead "estimates" of each sound's profile—a phrasing which highlights, if nothing else, the contingency both of the map and of memory. ${ }^{49}$

Not all of the WSP maps are quite so compelling; indeed, if one principle of thematic cartography is that "more" information is not necessarily "better," then the "Solar Wind Cycle and Sound" map of Lesconil, France is a case study in how much is too much. Arguably the most baffling map published in FVS, it commingles temporal,

$$
\begin{aligned}
& 47 \text { Ibid., } 50 . \\
& 48 \text { Ibid. } \\
& 49 \text { Ibid., } 51 .
\end{aligned}
$$


spatial, and sonic information within a single diagram. (Figure 2-12) Not only is the periodic time guide unequal, but the arrows-do they represent wind? do they represent movement?-are left unlabeled.

Overall, however, the WSP maps must be counted among the most significant collection of sound maps anywhere in published literature. They furthermore constitute an especially important group of field maps, defined by the way in which they embrace experienced and represented complexity, the ambivalence of symbols, the depth and diversity of everyday life. Very often, something is left incomplete-a strange symbol, a partial contour line, an unexpected reference, an unexpected disclaimer. These gestures seem to be self-conscious admissions of what Harley and Pickles argued earlier: that sound can never be fully, completely, or finally "mapped." Just as the larger sound community is living and changing - composed of memories and experiences with sound, and objects and places that produce sound-the map's surface becomes a site where complexity and contradiction are constantly negotiated. Instead of proposing a methodologically stable texture, as in grid maps, field maps expose a more messy truth: that beneath the surface, people are to be met, sounds are to be heard, and experiences are to be had.

\section{Type Three: (Sound)walk maps, becoming dynamic}

Observing the way field maps create tension between what is heard and experienced leads to a third type of sound map, perhaps the most specialized. The distinguishing characteristic of walk maps, or alternatively "soundwalk" maps, is the way in which they coordinate the movement of people between and among sounds of special 
interest. So, rather than simply showing the placement of foghorns, bells, or telephone dial tones, these maps verge on becoming musical notation: they select particular sounds for audition, and furthermore prescribe a sequence of encounter. They direct us-perhaps even intend us-toward a specific place. At the same time, soundwalk maps ask us to engage closely with the city, and to listen to its sounds on a deep and conscious level.

To understand what a soundwalk map shows, however, it is important first to understand what a soundwalk itself is. Though still relatively recent in its development, soundwalking emerged with special clarity among the writing of WSP scholar and composer Hildegard Westerkamp. As she explains, soundwalking can be defined as any activity whose main purpose "is listening to the environment." ${ }^{50}$ But here is no specific requirement that a listener travel to an exotic location to hear something unusual.

We may be at home, we may be walking across a downtown street, through a park, along the beach; we may be sitting in a doctor's office, in a hotel lobby, in a bank; we may be shopping in a supermarket, a department store, or a Chinese grocery store; we may be standing at the airport, the train station, the bus-stop. Wherever we go we will give our ears priority. ${ }^{51}$

Indeed, while this description suggests even walking is optional, should it be included in the activity, the walk has no particular requirements. Soundwalks can therefore be taken ...alone or with a friend (in the latter case the listening experience is more intense and can be a lot of fun when one person wears a blindfold and is led by the other). It can also be done in small groups, in which case it is always interesting to explore the interplay between group listening and individual listening by alternating between walking at a distance from or right in the middle of the group. A soundwalk can furthermore cover a wide area or it can just centre around one particular place. 52

\footnotetext{
50 Hildegard Westerkamp, "Soundwalking," Sound Heritage 3, no. 4 (1974), http://www.sfu.cal \%7Ewesterka/writings\%20page/articles\%20pages/soundwalking.html (accessed 12 May 2010). 51 Ibid.

52 lbid.
} 
A soundwalk map, then, would seem logically to come later-after some preliminary observations have been made, some experimentation and listening activities already completed. Soundwalk maps involve directed walking, not aimless wandering. Most, in fact, are quite clear about where to go, and often the path to take in order to get there. The fact a soundwalk map is made at all, however, suggests that not all sounds or places are worth hearing; inherently, there must have been some exclusions, some silencing, in the process of making it.

One good example of a soundwalk map can be found in TVS. (Figure 2-13) The base map frames a five-block area between Hastings and Alexander Streets, near downtown Vancouver, on top of which is labeled a series of places (and associated sounds) in the neighborhood nearby. For example, where point number three is clearly marked "Young Iron Works," others are left unlabeled—suggesting, rather than indicating, that something, or perhaps nothing, in that location is worth hearing. What is most crucial about this map, however, is that it provides a specific sequence, a pathway, connecting each point together. An auditor beginning at Main St. and Hastings would proceed on Main toward Alexander St., make a slight detour toward the iron works, double back towards point number two, then turn on Main St. toward the "C.N.R. Station" and the harbor docks. What matters here is not just that a certain sound or collection of sounds are important to a community, but that these sounds can, might, or must be heard in a particular order. Soundwalk maps, then-quite unlike grid maps or field maps-are designed to be performed. 
Another interesting example, one with quite detailed and vivid instructions, can be found in Westerkamp's own work. Titled "A Soundwalk in Queen Elizabeth Park in Vancouver," this map follows the pattern discussed above: it shows specific sites in the park, numbered according to the sequence of encounter. (Figure 2-14) The explanation she includes is unusual, however, because it further demonstrates how actualizing the map must be an active rather than passive process-not only in the sense of the walk, but in the sounds produced and heard along the way. For example, she writes:

3) Close to the fountains you will find a metal sculpture ("Knife Edge" by Henry Moore). Explore it visually as well as acoustically. It consists of two pieces both of which have a different structure. Do they also differ in their sounds? What other relationships can you find between its form and its sounds?

Produce a wide variety of sounds and - among others-try to find a low-pitched rumble, a high-pitched clang, and a swish. You may even like to join together a series of sounds and create a composition (called "Knife Edge ?") Put your ear against the surface and listen to the inside.

4) When you walk into the conservatory, you are entering an artificially created, tropical environment. Take your time and experience it with all your senses. Does it look and smell and feel tropical? Does it sound tropical? What kinds of birds do you hear? Can you strike up a conversation with some of them? Can you hear the sound of the air-conditioning system?

When you walk across the bamboo-bridge explore it as if it was a sound sculpture. It creates a unique sound which is not generally heard in northern countries. Once you have passed the bamboo bridge listen for the sound of a small waterwheel. In the early days, when the conservatory first opened, it was always running and created a most interesting water soundscape in its vicinity. It is not always audible now and seems to have been neglected as a sound source. 53

That soundwalk maps would require active engagement in addition to active listening should not come as a terrible surprise. As a form of spatial-sonic activity, soundwalking has been described as a creative act in its own right. As Kenny Cuper has written, walking "transforms the discreteness and separateness of the city into a fluid

$53 \mathrm{lbid}$. 
landscape: the city becomes landscape through the walk." 54 The soundwalk, he says, "is not merely goal-oriented and breaks with the automatic pilot mode of perception." It allows the walker "to transform the city into a field of game and chance. By giving over to the city, this city becomes another world." 55 Sound maps mediate this experience by encouraging us to become more aware of the world, teaching us how to listen to it.

The necessity and strictness of the path-how closely it should or must be followed —ften remains undetermined on soundwalk maps. So, where the map in TVS recommends both a sequence of sounds and a route to follow, Westerkamp's provides an ordered sequence but no specific path. Both, however, face lingering questions: whether the walker will follow the instructions, whether the instructions can be followed, or indeed, whether anything will be heard if they are. As notation usually goes, there are no absolute guarantees. While it is possible everything notated on the map will be heard, it is equally possible that, through a series of mistakes or wrong turns, nothing will. A soundwalk map followed at midnight, for instance, is unlikely to encounter a working blacksmith.

Recently, however, scholars and artists have taken the idea for a soundwalk in a different direction entirely, transforming it from an active process into an "art piece." One web-based "soundwalk map" made by students at Concordia University in Montréal traces a walking path digitally while an embedded audio track plays a recording of sounds heard along the way. (Figure 2-15) Meanwhile, a slideshow displays photographs

\footnotetext{
54 Kenny Cuper, "Walking as Do-It-Yourself Urbanism," Goldsmiths Sociology Research Papers (London: University of London and Kenny Cupers, 2004), 7. 55 Ibid., 7.
} 
of significant buildings-making the final result something of a "virtual" soundwalk. ${ }^{56} \mathrm{~A}$ related example, though one without the latest digital trappings, is Annea Lockwood's "A Sound Map of the Hudson River," $" 57$ a musical composition which provides "an aural journey" from Lake Tear of the Clouds to Long Island. As Lockwood herself explains, because "[e]ach stretch of the Hudson has its own sonic texture," the work performs a guided tour through and among the various stretches of riverbank. The CD liner notes feature a map that identifies points of significance along the way. In the end, both projects articulate the idea for a "soundwalk" or "soundwalk map" in a completely different way than I mean to discuss it here. Though not always walked-perhaps drifted or paddled - they are, strictly speaking, representations of a soundwalk already walked. Rather than being active and interactive, the map becomes fixed-technically, if only technologically, repeatable.

\section{Type Four: Territory maps, becoming dynamic}

Territory maps, the fourth type, find sound maps within an institutional or regulatory environment. As a result, they are concerned, not with the location of sounds deemed meaningful to a particular community, but rather with the construction of a standardized view of sounds perceived commonly as unwanted. While the intent of territory maps is not always misplaced, what makes them worth bracketing as a unique type is both the legal machinations that surround them and their frequent dependence on "projected" observation. In Chapter 3, I will critique one particular kind of territory map

\footnotetext{
56 "Montréal Sound Map," http://cessa.music.concordia.ca/soundmap/en/ (accessed 1 February 2010).
}

${ }^{57}$ Annea Lockwood, Sound Map of the Hudson River, Lovely Music, audio compact disc, 1989. 
in detail: Part 150 "Noise Exposure Maps," which function as part of an aviation noise program managed by the Federal Aviation Administration. For now, though, it is worth examining the characteristics that define territory maps in general.

A straightforward example of a territory mapping practice can be found in Europe. With the approval of the Fifth Action Programme in February of 1993, the European Community reaffirmed the importance of monitoring and limiting human exposure to noise-defined here as "harmful" rather than merely "unwanted" sound. ${ }^{58}$ But this time, the issue was broached not from the perspective of noise as such, but from that of environmental sustainability. Here, "natural resources" were defined in the broadest possible terms to include air; and since noise is, in a strict sense, nothing more than compression waves moving through air, it was decided that noise could, in fact, be regulated as a kind of air pollution. Which is to say: if noise had been understood earlier in the century only metaphorically as a kind of dirt, it here became dirt by law. ${ }^{59}$

A more detailed statement, the Green Paper on Noise Policy (COM(96) 540), was approved just over three years later, in November of $1996 .{ }^{60}$ But this document had no specific regulatory provisions. As elsewhere, Green Papers in the EU are designed primarily to facilitate a public discussion; and this one in particular presented some startling facts that clarified why a conversation about noise was needed:

80 million people suffer from noise levels that scientists and health experts consider to be unacceptable ... an additional 170 million citizens are living in so-called 'gray

\footnotetext{
58 "Towards Sustainability," Fifth Action Programme, O.J. C 138/5 1993.

59 Karin Bijsterveld, Mechanical Sound: Technology, Culture and Public Problems of Noise in the Twentieth Century (Cambridge, MA: The MIT Press, 2008).

60 European Commission, Green Paper on Noise Policy, COM(96) 540, 1996.
} 
areas' where the noise levels are such to cause serious annoyance during the daytime. ${ }^{61}$

Although no specific remedies or sanctions were proposed, the report did identify what it called the leading causes of noise pollution: transportation infrastructure, specifically cars, trains, and aircraft. ${ }^{62}$ It furthermore expressed optimism that tangible results, aimed at reducing noise and mitigating its negative impact on the human population, could be reasonably achieved. It notes with praise, for instance, how over the previous twenty years

noise from individual cars has been reduced by $85 \% \ldots$ and the noise from lorries by $90 \%$. Likewise for aircraft footprint around an airport made by a modern jet has been reduced by a factor of 9 compared to an aircraft with 1970 s technology. ${ }^{63}$

While it acknowledged some consensus antinoise remedies can be found throughout the EU already, the Green Paper suggested that continued success depends on a sense of "shared responsibility"- defined here as a uniform system for monitoring and ultimately mitigating the negative impact of noise. ${ }^{64}$

Specific provisos came a few years later in the form of 2002/49/EC, an international directive requiring local governments serving populations greater than

61 lbid.

62 It is interesting to note how the primary culprits of antinoise policy changed over the intervening 60 years: from gramophones and radios, to public transportation. While the "class bias" Bijsterveld observes in Amsterdam seems less obvious on the surface, and while it is no doubt true that transportation systems are responsible for generating a significant quantity of "unwanted" sound, it is also true that busses and trains are most often used by members of the lower- and middle-classes.

63 European Commission, Green Paper on Noise Policy, COM(96) 540, 1996.

64 lbid. 
250,000 people to implement ongoing noise surveys. ${ }^{65}$ And perhaps the most visible part of this program was the mandate for all such urban areas to construct "strategic noise maps" to show which parts of the city are most at risk of excessive noise exposure, and furthermore, to identify which sources are most likely responsible. In the United Kingdom, these monitoring and mapping duties were delegated to the Department of Environment, Food, and Rural Affairs (DEFRA), the governing body which remains responsible for studying and regulating pollution of all kinds today. Their first strategic noise map of London was completed in 2006, and in accordance with the EU mandate, was updated beginning in 2011. (Figure 2-16)

The maps created by DEFRA differ in some significant ways from sound map types discussed previously - certainly those of the LNS. For instance, where the BRS team had the power to determine both how and how much information to collect, DEFRA's maps are required to conform to a common set of international standards. While this leaves little room for local ears and preferences-for instance, all of DEFRA's maps concern loudness without providing for the possibility that some "loud" sounds may actually be appreciated or enjoyed - the result has been the birth of an international sound map "semiotics:" a common visual and methodological standard for collecting, studying, and mapping sound. As a result, a map of Glasgow might be quickly and easily compared to one of Munich. Another crucial difference between DEFRA's maps and those of the LNS is accessibility. Where the original LNS study was otherwise a specialist affair, known mostly to scientists, scholars, and government officials, DEFRA's maps of London are

65 Commission Directive No. 2002/49, O.J. L 182/12. The European Parliament and the Council of the European Union, Directive 2002/49/EC, relating to the assessment and management of environmental noise, L. 189/12. 
meant to be easy to find, easy to read, and easy to understand. They can, in many respects, be seen as an extension of the Green Paper's initial purpose: to facilitate a broad public discussion on questions of noise, the city, and everyday life. Consequently, the maps are widely available on the internet today, viewable from anywhere in the world, searchable by post code. ${ }^{66}$ The results can even be filtered to show different aspects or sound, or even to show sound made only by a single source: railway, car, or aviation. A more significant difference with the LNS, and perhaps a more ominous one, is how the underlying noise information was collected: it wasn't. Presently, all of DEFRA's noise data is derived from statistical models. As a nondescript disclaimer on their website makes clear, no actual sound measurements were made of any location, nor were any decibel measurements taken at any particular place.$^{67}$ All of the information used to construct the maps is generated by computer models, which can estimate noise levels by considering the material construction of the surrounding city, nearby transportation activities, the proximity of airports, and so forth.

Computer models like this are commonly used by acoustical engineers, and not without good reason. Roads of a certain size, composed of a certain material, carrying traffic of a certain volume, tend to be associated with decibels levels within a predictable range; neighborhoods located a certain distance away from an airport, whose landing patterns pass within a certain lateral distance and altitude, tend to be subject to a predictable range of aircraft noise. Sound maps created using these techniques are made

66 Department for Environment, Food, and Rural Affairs, "Noise Mapping England," http:// services.defra.gov.uk/wps/portal/noise (accessed 18 January 2013).

67 Department for Environment, Food, and Rural Affairs, "Noise Mapping England: Frequently Asked Questions," http://services.defra.gov.uk (accessed 2 November 2010). 
more by "coding" the city than by "measuring" it: roads, according to the material type and traffic volume; neighborhoods, by their proximity to highways, factories, and waterways. Afterward, the requisite decibel level is applied-without ever having to set foot in any park or sidewalk, for any reason other than to observe the physical materials used in construction, or to count the number of cars and trains passing by.

In a way, this approach shares basic similarities with other, more familiar kinds of thematic mapping, especially maps of weather. Where information such as temperature, humidity, precipitation, and barometric pressure is concerned, meteorologists routinely depend on strategic samples: measurements taken in places where it has special relevance (airports), or which are common points of community reference (city halls or schools). Though certainly not "complete" in the most literal sense, the sampled data points are understood to reflect something of the conditions in the surrounding area. Temperature data, for instance, is not thought to be confined to the precise point in real space where the thermometer was placed, but a somewhat larger area whose geography and form resembles the recording position (e.g. urban, rural, suburban, residential, etc). It is only when results from many different measurement locations are combined systematically that it becomes possible to assemble, literally and metaphorically, a broad if only provisional picture of weather.

The image DEFRA's maps present, consequently, is not of a "sometime, someplace," but a "no-time, no-where." That is to say, while the maps do present a clear, compelling, and easy-to-read image-one that conforms to EU directives-it is one, at root, that disregards anything more than a very narrow definition of what "noise" is, what 
a sound survey ought to reveal, and what our experience of that place could possibly be. It reflects an almost exact reversal of the idea of sonic engagement, since the image presented by the map does not depend on sound at all, but rather, the precise measurement, documentation, and projection of the physical environment.

These problems and compromises can be seen clearly in how DEFRA's maps use color. Here, they borrow conceptually from other, more familiar forms of thematic cartography, like traffic maps. Red, commonly used to signal warning, danger, or the need for caution, is on DEFRA's maps used to identify areas of extreme loudness. Areas marked green or yellow, on the other hand, imply relative safety and quietude. But adding this extra layer of information has an important side effect. However apparently detached or objective they may appear, this familiar color scheme suggests sound has not been simply evaluated strategically, but indeed valued. The maps do not simply "show noise," but implicitly warn us about it.

Color coding also, perhaps unintentionally, helps expose other peculiarities. Human pathways, for instance, like those through Hyde Park, have no sound data attached to them at all and are colored gray as a result. (Figure 2-17A) The same holds true for ponds or waterways, which are colored a neutral blue. This suggests by implication that sound somehow stops at the edge of the pathway, going no further than the curb on the nearby road. The flaw in this assumption should be obvious to anyone who has found themselves in a noisy urban park: lived experience tells us that sound observes no such boundaries. Like weather, it flows through space, blurring the distinction between roads and sidewalks, ponds and highways. Alas, these maps provide nothing more than a 
reductionist image of environmental sound, one based fundamentally on a "projection" determined by computer models.

Such obvious flaws, however, have not stifled creative adaptation. One fascinating artistic treatment of DEFRA's maps can be found in the work of English graphic designer and artist Simon Elvins. ${ }^{68}$ In 2006, Elvins inverted DEFRA's data to create a map exposing not London's noisiest areas, but its most silent. He did it by transforming all of the color information on DEFRA's maps into grayscale, so that red became dark gray, and green or yellow lighter shades. This data was then inverted - dark to light, light to darkwhich allowed the "silent" areas of London to emerge in the foreground. But this had an unusual consequence: foot paths, even those in parks, are rendered the same tone as busy streets. (Figure 2-16B) Rather than being subversive—by suggesting, somehow, a different way to engage with or value the city's sounds-the end result further confuses what were purely data-driven oversights in the first place. Elvin's map-as compelling and provocative as it appears-is nonetheless inextricably bound to the very same technical and conceptual flaws as DEFRA's.

To be fair, many of the objections and limitations I have raised here are acknowledged even by DEFRA. One prominent disclaimer located on their website explains how

the maps are only intended to be used for strategic assessment of noise levels in any given area. They should not be used to attempt to determine, represent or imply precisely the noise levels at individual locations (e.g. individual houses, windows). It should also be borne in mind that the noise levels shown are for an average day in

68 Simon Elvins, "Silent London," http://www.simonelvins.com/silent london.html (accessed 13 January 2010). Elvins' map is also available in a compilation of London Maps. See: Simon Foxell, Mapping London: Making Sense of the City, London: Black Dog Publishing, 2007. 
the year, and therefore do not show the specific noise from individual vehicles, trains, or aircraft or from discrete industrial activities. 69

But in acknowledging these shortcomings, the map arguably becomes even less meaningful than it was before. Indeed, to say its use should be limited to "strategic assessment" is to add vagary on top of the already vague. If they cannot be used to "determine, represent or imply" the sound levels at a particular area, one might rightly wonder what a "strategic assessment" would allow us to assess.

Admittedly, DEFRA's statement is probably meant as a legal disclaimer-and with good reason. Scholars from fields like economics and sociology have for the last several decades worked to quantify the measurable impact of noise-for instance, by studying its adverse effect on housing prices and minority groups. ${ }^{70}$ Any tool able to tangibly link noise to a specific location, especially one created by a recognized governmental body, could easily become useful in a legal struggle waged by property owners looking to recoup lost value, or by noise-afflicted populations seeking some relief. In effect, then, DEFRA's disclaimer extinguishes the usefulness of their maps--suggesting the EU directive is itself the only reason for their construction.

The need to map environmental sound, articulated at nearly every institutional level —international, national, and local—highlights some uncomfortable associations with

69 Department for Environment, Food, and Rural Affairs, "Noise Mapping England: Frequently Asked Questions," http://services.defra.gov.uk (accessed 2 November 2010).

70 Andrea Baranzini and José V. Ramirez, "Paying for Quietness: The Impact of Noise on Geneva Rents," Urban Studies 42, no. 4 (April 2005): 633-646; Jon P. Nelson, "Meta-Analysis of Airport Noise and Hedonic Property Values: Problems and Prospects," Journal of Transport Economics and Policy 38, no. 1 (January 2004): 1-27; G. Pennington, N. Topham, and R. Ward, "Aircraft Noise and Residential Property Values Adjacent to Manchester International Airport," Journal of Transport Economics and Policy 24, no. 1 (January 1990): 49-59; Julii S. Brainard et al., "Exposure to Environmental Urban Noise Pollution in Birmingham, UK," Urban Studies 41, no. 13 (December 2004): 2581-2600. 
Foucault's notion of "biopower." The state, these maps suggest, is not only concerned with the health of our ears (and by extension, our physical and psychological wellbeing), but it has the right to measure, enforce, and change what they hear. Indeed, as will be discussed at length in Chapter 3, not only is it possible to monitor and control physical space- the flow of traffic, the gathering of crowds or mobs-but also the more ephemeral dimensions of everyday life: the sound of traffic; perhaps even the sound of crowds and mobs. ${ }^{71}$ Alternatively, it becomes possible for the state to mandate what sounds must be tolerated, a process I will discuss later as "positive" enclosure. In any case, the image presented by territory maps is potentially an ominous one-where sound has been narrowly defined and space totally controlled.

The need to acquire an increasingly complete understanding of sound -or, more accurately, to estimate it "strategically"-also suggests close associations with neoliberal power structures, which themselves emerged during the late 1970 s and early 80 s. As governments became increasingly aware of the power of the market, entranced with the idea that choice, desire, and cultural values could be reduced neatly into data points, territory maps offer a convincing way to do the same: to condense even the most slippery and ephemeral dimensions of everyday life into an easy-to-understand form. But in doing so, in creating an image of the sound environment that, in reality, is little more than an extrapolation of computer models, territory maps arguably dis-place the very communities they are supposed to represent.

71 Michel Foucault, Discipline and Punish: The Birth of the Prison, translated by Alan Sheridan (New York: Vintage Books, 1977). 


\section{Type Five: Dynamic maps, becoming fields and grids}

In contrast with territory maps, the fifth and final type, dynamic maps, can be

characterized by their dependence on active and ongoing community participation.

Unlike field and grid maps, which, though participatory, are ultimately constructed by

trained specialists, dynamic maps return the process of constructing the map to ordinary

people —or at least claim to. By definition, then, they are impossible to complete:

dynamic maps are fueled by sonic crowd-sourcing; they are "open" forms meant to be

continually expanded, refined, and improved upon with the addition of new information.

Dependent as they are on digital and interactive media environments, dynamic

maps are clear beneficiaries of the internet age. Online maps permit, even encourage, the

constant adjustment, re-scaling, tagging, and modification of represented space. Indeed,

as internet maps first began to emerge during the late 1990 s and early 2000 s, they

promised a remarkable array of advancements. Not only would they allow us to see Earth

in new and compelling ways, and with incredible precision and detail, they would help

create "immersive" experiences. ${ }^{72}$ As John Pickles wrote,

[a]s the hard work of imaging the earth in this way continues, a broad cultural economy of vision in depth may be being constructed. ... Full-immersion environments and VR simulations push these ontologies of transparency to their full extension and ... invest their subjects in depth. Gone are ontologies of nonpenetrable surfaces and objects. Now all objects are bundles of information that can be imaged in as many ways as they can be imagined. ${ }^{73}$

72 See: Alan M. Maceachren and D. R. Fraser Taylor, eds. Visualization in Modern Cartography, New York: Elsevier Science, 1994. This collection of essays does an excellent job surveying the developments in cartographic visualization, but has become somewhat dated given the rapid pace of technological change over the past 15 years. It nevertheless contains some early glimpses at how the arrival of digital mapping changed how we think about and practice cartography -- and in that sense, is an important source.

73 Pickles, A History of Spaces, 170. 
With satellite imagery and 3D modeling, dynamic maps today allow other kinds of information-including sound files - to be embedded beneath the virtual surface. Space, then, becomes not just manipulable, but potentially audible as well.

One notable example of a dynamic sound map is "Sounds Around You," a website operated by the Acoustic Research Centre at the University of Salford in Manchester. (Figure 2-18) Although not explicitly stated, this project seems to adopt something of the "ear cleaning" activism of the WSP. Their project, as they explain it, is designed to "raise awareness of how our soundscape influences us and could have far reaching implications for professions and social groups ranging from urban planners to house buyers." ${ }^{14}$ They continue:

We're calling people across the world to use their mobile phones (or another audio recording device if their phone is not compatible) to record 10-15 second clips from different sound environments, or 'soundscapes' from a family car journey to a busy shopping centre, and to upload them to our virtual map, along with their opinions of them and why they chose to record it. ${ }^{75}$

Participants can either download a free application onto their smartphone, record the sound directly into the application, and then answer questions as the file uploads to the website; or they can use a digital recorder to collect sound, upload, and complete the rating system later. ${ }^{76}$ By relying on "everyday" technology, the hope is that anyone can contribute; and by requiring participants to submit their opinions and thoughts about

\footnotetext{
74 "Welcome to Sound Around You," Sounds Around You, http://www, soundaroundyou.com (accessed 17 January 2011).

$75 \mathrm{Ibid}$.

76 "How to Get Involved," Sounds Around You, http://www. Soundaroundyou.com (accessed 17 January 2011).
} 
sound, in addition to providing a sound file, the hope is to encourage a more critical and thoughtful engagement with sound more broadly.

This project correlates well with characteristics of "Web 2.0," described for the first time by web pioneer Tim O'Reilly in $2005 .{ }^{77}$ Developed after the tech bubble burst in 2001 , Web 2.0 was thought to have initiated a complete re-imagining of the internet and its structural limitations. Where the pre-crash version favored top-down content generation, Web 2.0 relied on the idea that user generated content was the "key to market domination," a way to harness collective, emergent wisdom, and function democratically: the more contributions, the more likely people would be engaged and loyal (e.g. to a brand), the more likely the web would remain a level playing field. But this enthusiasm has yielded unforeseen complications. The sheer volume of information that has accumulated on the web has lead some critics to wonder not just who owns whatwhether a user-submitted book review at Amazon.com is owned by Amazon or the userbut whether the web environment is really quite so level. ${ }^{78}$ While the "democratic" aspirations of Web 2.0 are admirable in many ways, the future of personal information and privacy remain uncertain.

Related concerns emerge about dynamic sound maps. Particularly troubling is the way the rhetoric of "democratization" has been accompanied by a lax sense of selfconsciousness, an almost regressive grasp of sound, technology, and the process of mapping itself. In an immediate sense, a map like "Sounds Around You" does seem to

\footnotetext{
77 Tim O'Reilly, "What is Web 2.0?" http://oreilly.com/pub/a/web2/archive/what-is-web-20.html? page $=1$ (accessed 30 January 2011).

${ }^{78}$ See for instance: Paul Hyman, "Gender Bias at Wikipedia?" Communications of the ACM 54, no. $10(2011): 18$.
} 
create what Pickles described: an ontology of "depth." But the details and discourse surrounding it suggest something else, too: an ontology of unevenness and confusion. Very often, dynamic maps are meant to "flatten" distinctions-between sound and representations of sound; between space and representations of space; between map designer and map contributor. But in doing so, they consequently mask the limited frame of the map itself, confusing the accumulation of data with factual reality. "Sounds Around You" suggests, for instance, that the more information submitted by users, the more accurate the map will be:

[a] soundscape map gives an insight into how soundscapes are perceived by different people in a given location. The map will be constantly evolving as it automatically retrieves new soundscapes from the database.

The addition of more soundscapes to the map brings about a more representative impression of the way in which people react to the sound around them. ${ }^{79}$

The idea that "more" equals "more representative" is flawed in both a technical and statistical sense. Where earlier sound maps, like those of the LNS, were both critically and consciously aware of their limitations, "Sounds Around You" seems by comparison to embrace the idea presented earlier by Lewis Carroll in Sylvie and Bruno: the larger the map, the more information it contains, the more representative it will be. ${ }^{80}$ Indeed, as the WSP showed, the creation of a "convincing image" of the soundscape depends on a multifaceted analysis, one that takes into consideration both subjective and empirical dimensions of the sonic environment. It is certainly possible to raise public awareness by encouraging ordinary people to record sound and participate in a mapping project; but the

\footnotetext{
79 "World Soundscape Map," Sounds Around You, http://www. Soundaroundyou.com (accessed 17 January 2011).

80 See Chapter 1, pp. 45-46.
} 
results cannot be universalized and do not stand outside this already narrow context. It is also important to emphasize that a recording is not equivalent to perception, plain and simple. The former is a material object, a sonic representation; the latter, is an extremely complicated construct - one that bridges, among other things, individual memory, physical variations in one's ability to hear, a sense of community, and shared (in this case, aural) history. In any sound survey, there exist many different layers to pull back, many different ways to experience sound and methods through which to study it. Certainly what is audible (in the words of the BRS) "objectively" is not the same as what is perceived; and certainly, what a recording captures is not equivalent to what a person hears.

Another dynamic map, however, seems more aware of these concerns even to the point of raising them explicitly. The website for the "Montréal Sound Map," argues that, what I have called dynamic maps,

are in many ways the most effective auditory archive of an environment, touching on aspects political, artistic, cultural, historical, and technological .... The Montreal Sound Map is an ongoing and continually evolving project with the goal of a constant addition of new recordings being placed into a browsable tagging system. ${ }^{81}$

Though compelling, this idea of the map as an "archive" rather than "representation," as the accumulation of fact rather than discourse-raises its own set of concerns: about sound as an artifact, about the potential for a map to function as a database. Something resembling a "map-archive" would suggest a radical ontological departure, one where the map gains a sense of formal "closure" (the boundaries and purpose of the map are

81 "About," Montreal Sound Map, http://cessa.music.concordia.ca/soundmap/en/ (accessed 17 January 2011). 
determined) and content "openness" (the specific sounds the map will represent are unknown). The consequent elevation of the sound map-from a cultural and social construction, to an all-consuming representation—seems troubling, because it raises questions about the kinds and types of sounds allowed into the archive. The Montreal map further compounds these problems by requiring users to "tag" meta-data for each clip according to a few predefined categories: human, mechanical, natural, societal, music, noise. (Figure 2-19) Further categories follow: "noise," for instance, can be subtagged as human, mechanical, or natural. Of course, these categorizations risk backsliding into uncritical terrain: Is a sound "noise" because it is "unwanted," or "harmful?" Or is it (in a more neutral way) "chaotic" or "unorganized?" Could the "noise" be meaningful to a specific community, as the WSP suggests? Or is "noise" rather a metaphysical category, its relative "importance" or clarity irrelevant?

A similarly ambitious project, and one with similar problems, is operated by "radio aporee." (Figure 2-20) Begun in 2006, the goal of this map is to connect

sound and space in order to create a cartography which focusses solely on sound, open to the public as a collaborative project. It contains recordings from numerous urban, rural and natural environments, showing its audible complexity, as well as the different perceptions, practices and artistic perspectives related to sound, space and sense of place. 82

Apart from the uncomfortable fact that sound maps cannot ever "focus solely on sound"- simply by virtue of being already embedded within cartographic discoursethere is in this map a concerted effort to disqualify contributions in which sound has been manipulated, even "musicalized." Sound, for this map, is somewhat paradoxically

82 "about the project," radio aporee, hitp:/laporee.org/maps/info (accessed 12 January 2011). 
defined as the "different perceptions, practices and artistic perspectives" ordinarily excluded from "music" in a more generic sense. "Do not send music, songs, your greatest hits collection, recordings of concerts," they write. "[W]orkings, mixing, composing or sound manipulations are also undesirable. ${ }^{83}$

Of course, the very notion of an "unmanipulated" sound is an oxymoron, since recording a sound, even for the sake of archiving it, intrinsically entails manipulation. While they may be used to foster close listening, recordings can never have "true fidelity" to the original sound no matter how skillfully they are made-since the entire notion of fidelity, as Jonathan Sterne has written, is a discursive construct rooted in corporate marketing schemes of the late $19^{\text {th }}$ and early $20^{\text {th }}$ century ${ }^{84}$ Nonetheless, "radio aporee's" project, as its operators understand it, concerns nothing more than "sounds and sites;" and the only way to participate is to "get yourself a recorder, and go out and listen." 85 Yet again, a somewhat confused ontology emerges, since sound recorders do not listen to sound: they record it.

Dynamic sound maps, however, do not always concern strictly "environmental" or "urban" sounds to the overt exclusion of music. One contrary example can be seen in the "Musical World Map," whose creators explain

users will be able to navigate on the map while listening to the music of the country or city associated with that particular location ... The main goal is to provide a teaching tool for students by providing listening examples from countries and cities while they

\footnotetext{
83 Ibid.

84 Jonathan Sterne, The Audible Past: The Cultural Origins of Sound Reproduction (Durham, NC: Duke University Press, 2003), 215-225, 261-66.

85 "about content," radio aporee, http://aporee.org/maps/info (accessed 12 January 2011).
} 
are exploring the world .... [1]t would be interesting to explore the concept of audio boundaries of countries, as opposed to actual national borders. ${ }^{86}$

Of course, simply by titling their project the "Musical World Map," they make an implicit value judgment about what music is, how an "audio boundary" might be defined (stylistically, tonally, rhythmically) and what kind of "listening examples" and "musical practices" are representative of a particular place. Simultaneously, they exclude a whole host of alternate possibilities, interpretations, and divergent practices. Indeed, music, in this case, is elevated to an almost universal status—an ideal without borders. Here again the idea of the base map as a representation of pure space reemerges. What makes a map "political," it is supposed, is the drawing of boundaries and borders. Without them, the map would, if not disappear, then recede quietly into the background. But in fact, as cartographic discourse has suggested, the exact opposite is true. It is when a map claims to show nothing but "pure space" that we must be especially cautious; it is when a map claims to depict only "what it shows" that the material processes operating beneath the surface become especially relevant.

Indeed, the "Musical World Map," like other dynamic maps, relies on Googlebased mapping software. And this, in and of itself, might reasonably cause concern. Though a tremendously powerful and versatile tool, and certainly a cheap one, Google Maps belongs to Google Inc.-an international corporation worth well over $\$ 100$ billion. Google, of course, has its own reasons for making software that is easy to use and easy to

86 "Long Info," Musical World Map (beta), http://www.musicalworldmap.org/long-info (accessed 17 January 2011). 
access: from data mining to geo-marketing ${ }^{87}$ More worrisome is that the software, especially GPS data and satellite imagery, depends more or less directly on military capabilities and the accumulation of corporate wealth. Certainly there is ample reason to be cautious of the emancipatory rhetoric that surrounds Google-based maps; so, while dynamic maps offer a potentially liberating way for us to rethink human relations and cultural boundaries-as the "Musical World Map" does, by drawing borders without regard for political territory - their existence nonetheless depends on the same forms of power they might seem otherwise to critique.

This raises perhaps the most important question of all: For whom are maps like these representative? If the "Musical World Map" is any indication, it is worth noting how the majority of contributions come from western Europe and the United States, though South America and Africa have a few. Most contributions furthermore seem to come from large, highly populated urban areas—suggesting the "silences" on this map are quite literal: rural, poor, isolated. These silences furthermore highlight even more serious concerns: those of global wealth and power inequality. Participation, that is to say, necessarily requires baseline technical competencies, not to mention easy and affordable access to the internet. So, in spite of the exuberant spirit of "democracy" and "participation" that surrounds dynamic maps, they also reinforce the unfortunate truth that being heard often requires material wealth. Visible, then, is a kind of sonic

\footnotetext{
87 Siva Vaidhyanathan, The Googlization of Everything (And Why We Should Worry) (Berkeley:
} University of California Press, 2011), 17. 
subalternity: ${ }^{88}$ entire communities of people whose sounds are not, and likely will not, be heard-either because of adverse political and economic circumstances, or because the idea of an "interactive sound mapping project" is itself so far removed from the concerns of everyday life that there is little reason to participate.

That dynamic maps depend on public participation seems a positive development. But de-professionalization risks legitimizing a confused-and deeply valued, not just evaluated -ontology, one plagued by the uncritical adoption of concepts like "sound," "music," "noise," "machine," "human," and "nature." Far from challenging existing boundaries and establishing new ones, dynamic maps tread a difficult path that risks confusing all of them. Yet, because their defining characteristic is participation, the maps themselves become important primarily as sociological and historiographic artifacts. Much like other Web 2.0 resources, including Wikipedia, dynamic maps are important primarily because they offer a limited glimpse into how untrained people hear the world and find meaning in it—problems, misconceptions, mappings, re-mappings, and confused ontologies included:

\section{Conclusion}

In this chapter, I outlined a broad typology that can be used to study environmental sound maps. In all, I proposed five general types, each distinguished by significant visual and methodological characteristics. Grid maps, based often on empirical measurements,

$88 \mathrm{My}$ obvious reference here is the postcolonial concept of "subalternity" proposed by Gayatri Spivak. While on the surface the connection between unheard sounds and the plight of marginalized peoples seems strained, I do believe the two are connected. Further analysis, however, will have to be left for a future project. See: Gayatri Chakravorty Spivak, "Can the Subaltern Speak?" in Marxism and the Interpretation of Culture, ed. C. Nelson and L. Grossberg (Champaign, IL: University of Illinois Press, 1990). 
weave a regular fabric of represented sound across a conventional base map. Field maps, though driven by professional observation, help show how sound establishes a community's sense of identity. Walk maps, or "soundwalk" maps, turn this identity into an experience, a creative act, by suggesting or prescribing movement between or among places with specifically sonic significance. Territory maps, like grid maps, return to more objective forms of analysis; except territory maps, unlike grids, are often backed by specifically political and regulatory forms of authority: they project an image of "estimated" sound for the purpose of controlling noise (and listening bodies). Dynamic maps return to subjective experience and claim to become radically participatory by foregrounding the active, though not always self-critical, contributions of ordinary people.

In the following chapter, I wish to model the kind of analysis this typology makes possible. I will therefore turn my attention to a specific "territory" mapping practicePart 150 "Noise Exposure Maps," which are created as part of a voluntary aviation noise exposure program managed by the Federal Aviation Administration in the United States. As I will show, these maps raise a host of questions and concerns that come into focus only once they are situated in a larger context of political power and property rights. Indeed, as I will argue, NEMs prefigure the closing of the "acoustic commons," performing through force of law the accumulation of the aural environment by powerful economic and state interests. 


\title{
Chapter 3: Analyzing a "Territory" Sound Map
}

\begin{abstract}
Through a long process of enclosures, the earth's surface has been almost completely divided up between public and private property so that common land regimes ... have been destroyed.

-Michael Hardt and Antonio Negri, Commonwealth
\end{abstract}

\section{Introduction}

Sound maps mediate power. As I explained in Chapter 2, recent work in the history of cartography has shown that maps are not merely self-evident presentations, but rather persuasive re-presentations with the potential to influence how we perceive the world surrounding us. Sound maps are certainly no exception, and the typology I proposed is designed to foreground some of their machinations. Conceivably, case studies of each type would involve following the (sometimes literal) contours of power, tracing how choices were made and why. And in defining each type in the previous chapter, I provided something of a model for how these case studies would proceed. A study of grid maps, for instance, would focus not only on the final image, the grid itself, but on how the size and scope of the underlying survey was determined, and how that study in turn shaped which aspects of sound were selected for representation. Similarly, studying a "dynamic" map would involve examining how contributors are enrolled, where they come from, and how sounds are qualified and classified in the (often concealed) metadata. Certainly, in this instance, a case study would also involve challenging the lofty rhetoric of "liberation" that too often surrounds dynamic maps.

In this comparatively brief chapter, however, I wish to focus my analytical gaze on one sound map type: a "territory" mapping practice, known as aviation "Noise Exposure Maps" (NEMs). The reason to focus extra attention on this type, and indeed, this 
particular kind of map, is quite simple: a defining feature of the territory map is its backing by political authority. Territory maps always have a bureaucratic, institutional, or regulatory purpose, even if that purpose is not clearly defined. For instance, DEFRA maps, mandated by 2002/49/EC, are used to estimate noise exposure in cities with populations greater than 250,000 people. While it is implied that these maps have (or at least, should have) some influence on our efforts to study and regulate noise, as a form of air pollution, the maps themselves are more generally used to focus public discourse. The maps I will discuss in this chapter, however, go even one step further. As interesting and compelling as NEMs may seem, they in fact wield an overt form of acoustic power. As I will suggest below, in functioning as an arm of the neoliberal economy and embedded within regulatory policy, these maps change not only how we relate to sound, but reconfigure the nature of that relationship altogether. Rather than establishing a right to quiet, they demonstrate affirmatively which sounds we must be willing to endure, and at what price-a process I call "positive" enclosure.

\section{On Noise}

Noise is a topic which regularly inspires vocal and, at times, militaristic activism. And with good reason. Beyond simply disturbing the peace, recent environmental and medical research suggests that noise - defined usually as "unwanted sound"- - has any number of detrimental health effects, not the least of which is the damage to our hearing. ${ }^{1}$

\footnotetext{
1 Some research suggests, however, that a sound's status as "unwanted" is an extremely significant factor when evaluating negative health impacts. One study found that "awareness and annoyance reactions to airplane noise were much more important in determining health problems than the level of exposure to airplane noise." (342) See: David B. Graeven, "The Effects of Airplane Noise on Health: An Examination of Three Hypotheses," Journal of Health and Social Behavior 15, no. 4 (December 1974): 336-343.
} 
It has been linked to a litany of health problems, from sleep deprivation to psychological damage. ${ }^{2}$ But as a threat to general health and welfare, noise is also a frustrating object, because, like the long-term health effects of cigarette smoke, it is, at least in theory, preventable. $^{3}$

Efforts to combat noise are themselves not recent, however. As Karin Bijsterveld writes in Mechanical Sound, a wide range of interest groups began to warn of the looming threat of environmental noise as early as the turn of the $20^{\text {th }}$ century. ${ }^{4}$ Many used the same list of enemies: industrial equipment and household machines--including gramophones, radios, automobiles, and vacuums - being used for the first time by a newly-emerging middle class. ${ }^{5}$ Of equal or greater concern, though, were "passive" noise offenders, like old houses and apartment buildings, which lacked sufficient insulation to protect their occupants from noisy neighbors. ${ }^{6}$ Often, activists used traditional political tactics to combat unwanted sound-from lobbying for the manufacture of quiet vacuum

2 Lisa Goines and Louis Hagler, "Noise Pollution: A Modern Plague," Southern Medical Journal 100, no. 3 (March 2007): 287-294. In addition to sleep loss, Goines and Hagler identify cardiovascular and mental health disturbances as particularly ominous health effects of prolonged exposure to noise.

3 Ibid., 293. "As a society, our history is filled with failures to recognize the agents that cause disease; once the causes have been recognized, we have responded reluctantly, slowly, and often inadequately. The case with tobacco is an instructive one. It took many years of lobbying by dedicated individuals before legislators and the general public recognized the links between the hazards of tobacco smoke and disease; as a result, laws were finally enacted and behaviors changed accordingly... Noise makers and the businesses that support them are as reluctant as smokers to give up their bad habits. Legislators at all levels should protect us from noise pollution the same way they protected us from tobacco smoke and other forms of pollution."

${ }^{4}$ Karin Bijsterveld, Mechanical Sound: Technology, Culture, and Public Problems of Noise in the Twentieth Century (Cambridge, MA: MIT Press, 2008), 6.

5 Ibid., 165-66.

6 Ibid., 163-64. 
cleaners, to mounting educational antinoise campaigns, complete with propaganda posters. ${ }^{7}$ As Bijsterveld explains, though, some of these efforts were condemned by leftleaning political parties, who believed working- and middle-class people were disproportionately effected by them. ${ }^{8}$ The leisure classes, they argued, did not have to worry about unwanted sound from cars or radios, since they had the dual luxuries of time during the day to enjoy their machinery, and physical distance from their neighbors, which would mitigates sonic seepage. Additionally, traditional forms of acoustic entertainment often favored by privileged classes-including live musical performancewere often exempted by noise legislation, despite being potentially as bothersome.

As complaints about noise became themselves too loud to ignore, a number of techniques were devised to help manage noise control. On the scientific front, the development of the logarithmic decibel scale meant loudness could be measured quantitatively and with some semblance of empirical consistency; ${ }^{9}$ on the enforcement front, towns and cities began to implement laws restricting noisy behavior, ${ }^{10}$ on the technological front, inventors began to manufacture handheld decibel meters, which,

7 Ibid., 174; 119-120; 122-123.

8 Ibid., 165-68. Some socialists also stressed that "it was in the interest of working-class children to get enough sleep and that working-class adults should have the opportunity to unfold their talents during the evening, which meant they should not be annoyed by radio noise." (167-68) But as Bijsterveld points out, these arguments were the exception, and that most on the left found it unreasonable to place limits on the gramophone and radio while allowing more traditional musical instrument to be played without restraint.

9 Ibid., 105.

$10 \mathrm{lbid} ., 179-81$. Bijsterveld points out, however, the belief that "the masses had a right to use their gramophones and radios and that sound perception was highly subjective." This made unlikely the regulation of private behavior based based on quantitative measurement alone. 
despite their initial unreliability, were widely adopted by police to catch noise violators in the act. ${ }^{11}$

But if the relative success of these efforts can be measured by the volume of noise complaints that persist today, they must surely be said to have failed. Not much, it would seem, has changed over the past hundred years to either ease the continuing production of "unwanted" sound or to reduce in a meaningful way its negative effects on daily life and human health. ${ }^{12}$ The latest and perhaps most aggressive volley of antinoise legislation was launched recently by the European Union. ${ }^{13}$ Partly inspired by World Health Organization research, ${ }^{14}$ directive $2002 / 49 / \mathrm{EC}$ requires cities with populations greater than 250,000 residents to create "strategic noise maps." Though limited in scope, the underlying hope is that maps like these can be used to help identify locations threatened by consistent and excessive noise exposure, isolate and identify the most egregious noise producers, and facilitate an ongoing public discussion about how to prevent future disruptions. ${ }^{15}$

\footnotetext{
11 Ibid., 174-78. The development of the handheld decibel meter itself can, indeed, be linked directly to attempts to regulate the production urban noise.

12 Goines and Hagler, "Noise Pollution," 288. "That noise pollution continues to grow in scope, variety, and magnitude is unquestioned; it is only the extent of the growth that remains unknown."

${ }^{13}$ Commission Directive No. 2002/49, O.J. L 182/12, The European Parliament and the Council of the European Union, Directive 2002/49/EC, relating to the assessment and management of environmental noise, L. 189/12.

14 World Health Organization, Guidelines for Community Noise, eds. Birgitta Berglund, Thomas Lindvall, Dietrich H Schwela, www.who.intdocstore/peh/noise/guidelines2.html (accessed 16 January 2010).

15 Department for Environment, Food, and Rural Affairs, "Noise Mapping England," http:/l services.defra.gov.uk/wps/portal/noise (accessed 18 January 2013).
} 
Maps, then, have become only the latest weapon in the ongoing "war on noise." However, I am hesitant to embrace the word "noise" too eagerly and without qualification. As highlighted above, while noise is generally accepted to be a legitimate threat to public health, its conceptual boundaries are permeable, fluid. Where, in one context, a particular sound might be "unwanted," in another, it could offer helpful and meaningful information - providing advanced warning of looming danger (tornado sirens) or of life-threatening situations (ambulance sirens). While it may, at times, seem random and bothersome, noise can also express order in surprising ways. ${ }^{16}$ As Henri Lefebvre explained in Rhythmanalysis, from the apparent chaos of automobile traffic, to the seemingly disorganized mass of people on the street, sound can express both circadian rhythms and the rhythms of economic activity with surprising clarity-if we care to listen. ${ }^{17}$ Still, despite my general preference for a more neutral terminology — that of "sound" and "sound map," rather than "noise" and "noise map"- I will throughout this chapter use the term adopted by each primary source.

\footnotetext{
${ }^{16}$ Henri Lefebvre, Rhythmanalysis: Space, Time and Everyday Life (New York: Continuum International, 2004), 27. "[T] he attentive ear begins to separate out, to distinguish the sources, to bring them back together by perceiving interactions. If we cease to listen to sounds and noises and instead listen to our bodies (the importance of which cannot be stressed too greatly), we normally grasp (hear, understand) neither the rhythms nor their associations, which nonetheless constitute us."

17 Ibid., 32. Although Lefebvre admits he provides more questions than answers, he suggests "there is somewhere in this present an order, which comes from elsewhere. Which reveals itself. Where? In the monuments, the palaces, from the Archives to the Bank of France, meteorites fallen from another planet into the popular centre, for so long abandoned, the Cour des Miracles, a place of rogues. Therefore, besides the present, a sort of presence-absence, badly localised and strong: the State, which is not seen from the window, but which looms over this present, the omnipresent State." (32) This thread of thought will be more directly developed in Chapter 5.
} 


\section{Dropping Lines}

By the late 1980s, Edmund Lindsey had reached a breaking point. The noise from the Memphis International Airport had become so unbearable that he decided to file suit, claiming "inverse condemnation" of his home located at the southwest end of runway 36L. His complaint was later grouped into a larger class action; but after a preliminary settlement was announced, Lindsey decided to file an appeal. He argued the proposed terms were inadequate, and that the suit should have continued until more favorable terms were reached. ${ }^{18}$ Lindsey's case ultimately found its way to the 6th Circuit Court of Appeals in Cincinnati. ${ }^{19}$ Court documents suggest, however, that his complaint concerned much more than a particular settlement or dollar amount. Many of his neighbors had been moving away since the initial claim was filed in the early 1990s. But because Lindsey found himself unable to sell his home, he believed he was being pressured and harassed by the airport authority to accept a new and inevitably noisy future-and that they were using unconventional means to do it.

This became clear during a particularly bizarre moment of a fairness hearing in 1998. Lindsey was asked: "Do you honestly believe that someone ... flew over ... in an airplane and dropped two raccoons on your house?"

Lindsey: Yes, sir. There's no other way it could have happened. Airplanes went over our house at the time this happened. So there's no other way it could have happened.

The Court: Memphis has got a lot [of] raccoons in it. Lindsey: But to get on top of my house you've got to have an airplane to get up there or helicopter one.

\footnotetext{
18 Alvarado v. Memphis-Shelby County Airport Authority, 2000 U.S. App LEXIS 21259 (August 15, 2000, Filed), "Overview."

19 Ibid.
} 
This exchange seems odd, but Lindsey was right in at least one respect. While the airport authority almost certainly did not conspire to intimidate him, something had been dropped on his house. Only, instead of raccoons, it was isobel lines. A map of the Memphis airport, produced in 1985 , locates Lindsey's home squarely within the $75 \mathrm{~dB}$ contour. (Figure 3-1.) In no small measure, it was this line that was responsible for the dismissal of his appeal. Its very existence meant Lindsey's house had become part of a sonic territory; and as a result, he had no right or legal grounds to expect special legal consideration beyond the limits of the class action.

The Noise Exposure Map, or NEM, is a powerful and under-scrutinized regulatory tool. Its contours function to establish boundaries in both a literal and figurative sense: not only do they define where sound is and what intensities should be expected, they establish sound as within the government's power to monitor and regulate. Though seldom discussed outside of a narrow regulatory and legal context, they raise important questions about the nature of property, about how "community" is defined, and more significantly, about how sound functions as an instrument of the state. In addition to exploring how NEMs are constructed, I will draw on the recent work of Michael Hardt and Antonio Negri to argue that, more than merely representing the acoustic environment, they work to change how and on what terms we relate to it.

\section{Technics and Technicalities}

As a component of the "Airport Noise Compatibility Planning Program," Part 150 was first issued on an interim basis under the the Aviation Safety and Noise Abatement Act of 1979. Although final rules were not issued until 1985, its purpose from the very 
beginning was to establish uniform guidelines for conducting Noise Compatibility Programs (NCPs). Part 150 has a few key functions. The first is to establish noise standards and units. It stipulates, for example, that all sound-level readings should be calibrated to the dBA-weighting-which is itself a peculiarity, since A-weighting tends to discriminate against low-frequency sounds, like airport noise. The second function is to define land-use compatibility by establishing what activities are suited to different levels and durations of sound exposure. Outdoor music shells, for instance, are not considered compatible with $65-70 \mathrm{~dB}$ or higher; neither are mobile home parks or schools. Third, it formalizes a review and approval process for NCPs and routinizes access to compensatory funds for those people adversely impacted by noise. ${ }^{20}$

Noise Exposure Maps (NEMs) are specifically authorized by Title 49 of the US Code and directly shaped by these standards. Creating a NEM means first establishing the DNL for a given area — that is, the average loudness, day or night, for any particular location near the airport. In theory, this information is then superimposed onto detailed geophysical maps, scaled not less than 1":2000', and connected using isolines; "in theory," because what might otherwise require localized and labor-intensive listening has been streamlined significantly following the introduction of automated analytical tools. Part 150 allows for the use of computer software called the Integrated Noise Model (INM), which can generate both noise readings and sound contours automatically. All that is needed is statistical, geophysical, and aviation data, including information about the "specific operation mode, thrust setting, and source-receiver geometry, acoustic

20 Federal Aviation Administration, "The FAR Part 150 Airport Noise Compatibility Planning Program: An Overview," http://www.faa.gov/about/office org/headquarters offices/apl/ noise emissions/planning toolkit/media/ll.B.pdf (accessed 20 June 2012). 
directivity and other environmental factors," as well as the topography of the airport and existing airspace restrictions. ${ }^{21}$ The Federal Aviation Administration (FAA) consequently describes the INM as the "preferred model" to create NEMs-and it is in fact among the most widely-used noise software in the world today. It can generate sound readings for almost any occasion, place, or moment in time, and contains officially-sanctioned sound profiles for well over 100 different aircraft types. It is also incredibly versatile. In addition to contour maps, the INM can also generate supplementary maps to show other kinds of acoustical information, like the statistical likelihood that sound above $65 \mathrm{~dB}$ will be heard at any particular moment. (Figure 3-2.)

While the FAA approves the final outcome, they neither create NEMs nor conduct NCPs. Local airport operators do all of this, though practically speaking, work is usually contracted to outside consulting firms. ${ }^{22} \mathrm{~A}$ further peculiarity about NEMs is that they are inadmissible as evidence in a lawsuit. Legally, their only function is to disqualify complaints. ${ }^{23}$ After announcing that a NCP will be conducted, preliminary NEMs must be presented during a public approval process. Afterward, however, nothing except a drastic change in airport operations can cause either the maps or the conclusions and recommendations of the NCP to be contested or reevaluated. NEMs are in that sense performative: rather than contributing to an analytical or evaluative process, they are

\footnotetext{
21 Federal Aviation Administration, "Integrated Noise Model (INM)," http://www.faa.gov/about/ office org/headquarters offices/apl/research/models/inm modell

22 One such consulting firm, which claims to have been "delivering solutions to our airport clients for more than 40 years," is Environmental Science Associated (ESA), http://esassoc.com/ (accessed 18 July 2012).
}

${ }^{23}$ Transportation. U.S. Code. Vol. 49, ch. 475, subchapter 1, "Noise Abatement." 
what stamps the process complete..$^{24}$ Once certified by the FAA, there is no mechanism for property owners—living, as Lindsey was, within the $75 \mathrm{~dB}$ isoline - - to challenge either the location of a contour or, more importantly, the underlying activities responsible for generating it.

\section{Context}

The concept of "mapping" sound is certainly not unique to Title 49 or Part 150. It can be traced to the work of musicians, anthropologists, and acoustic ecologists during the $20^{\text {th }}$ century who hoped to understand how sound shapes and is shaped by a community's physical form and everyday activities. One of the earliest examples of such sound mapping can be found in the work of Michael Southworth, whose research at MIT during the early 1960 s led him to study the aural composition of Boston. In his study, a group of volunteers was subject to sensory deprivation - eyes or ears—and taken on a wheelchair tour of the city. All were subsequently asked to explain the relative importance of sound in defining each neighborhood they visited. Among their observations was that some spaces seemed more meaningful and could be perceived more clearly when subjects could hear echoes of their own sounds. Spaces with ambiguous form confused subjects and they judged them differently. Opaque foreground sounds caused similar effects and camouflaged important information. ${ }^{25}$

These "textural" observations were later transferred onto a map-what I defined in Chapter 2 as a field map - which coded different areas of the city based on their

\footnotetext{
${ }^{24}$ Furthermore, as Section 47506 explains, "no person who acquires property or an interest therein ... shall be entitled to recover damages with respect to the noise attributable to such airport if such person had actual or constructive knowledge of the existence of such noise exposure map..."

25 Michael Southworth, "The Sonic Environment of Cities," Environment and Behavior 1, no. 1 (1969), 55.
} 
perceptual identity. (Figure 3-3) Though an impermanent presence, often passing unnoticed by people living within and moving through it, sound is shown to be a structural force, one that shapes and influences everyday life in ways we do not often appreciate.

This point was further elaborated during the 1970s by the World Soundscape Project (WSP), a consortium of musicians and scholars at Simon Fraser University in Canada. Their analyses, conducted throughout the 1970 s, showed how ordinary sounds, like the pitch of telephone dial tones, could be used to identify sonic relationships, sometimes literally consonant or dissonant, among neighborhoods within large urban areas. (Figure 2-7) They also used maps to show how memory and age can influence the perception of a community's acoustic boundaries, (Figure 2-9) and how environmental conditions like time, season, and weather can cause drastic fluctuations in ambient sound levels. (Figure 2-12) Maps like these were among the first of their kind to render sound cartographically, and the often visually compelling results functioned in subsequent WSP publications to raise our collective aural consciousness.

But no survey of sound maps would be complete without considering also how they have evolved in recent years. As digital maps began to emerge during the 1990s and early 2000 s, they promised an exciting array of advancements: not only would they allow us to see Earth in new ways and with incredible precision and detail, but they would become 
"immersive." ${ }^{26}$ As cartographic historian John Pickles wrote rather optimistically, "gone are ontologies of non-penetrable surfaces and objects. Now all objects are bundles of information that can be imaged in as many ways as they can be imagined."27

Many digital maps today allow other kinds of information—including sound filesto be embedded beneath the virtual surface. Space, then, becomes not just manipulable, but audible as well. One notable example is "Sounds Around You," a website operated by the Acoustic Research Centre at the University of Salford in Manchester. (Figure 2-18.) Although not explicitly stated, this project seems to adopt something of the earlier "ear cleaning" activism of the WSP. As they explain, their project asks

... people across the world to use their mobile phones ... to record 10-15 second clips from different sound environments, or 'soundscapes' from a family car journey to a busy shopping centre, and to upload them to our virtual map, along with their opinions of them and why they chose to record it. ${ }^{28}$

The presence of a digitally-embedded clip is indicated with a small flag pinpointing the GPS location in real space where the sound was recorded. When clicked, an embedded sound file begins to play; and to enhance the experience, a small box in the lower left hand corner defaults to street view. ${ }^{29}$ The result, as Pickles suggests, is not just

${ }^{26}$ See: Alan M. Maceachren and D. R. Fraser Taylor, eds. Visualization in Modern Cartography (New York: Elsevier Science, 1994). This collection of essays does an excellent job surveying the developments in cartographic visualization but has become somewhat dated given the rapid pace of technological change over the past 15 years. It nevertheless contains some early glimpses at how the arrival of digital mapping changed how we think about and practice cartography-and in that sense, is an important source.

27 John Pickles, A History of Spaces: Cartographic reason, mapping and the geo-coded world (London and New York: Routledge, 2004), 170.

28 "Welcome to Sound Around You," Sounds Around You, hittp://www.soundaroundyou.com (accessed 17 January 2011).

29 "World Soundscape Map," Sounds Around You, http://www.soundaroundyou.com (accessed 17 January 2011). 
interactive, but immersive. The ears, eyes, and hands all have something to do: listening, viewing, and clicking. Even though what is seen does not exactly line up with what is heard-for instance, the image captured by Google's street view car is almost certainly of a different moment than the sound clip-the hope is to encourage a more personal, critical, and thoughtful engagement with the acoustic environment.

In concept, these maps would seem to share much in common with NEMs. And indeed, Barry Truax, a founding member of the World Soundscape Project, served on a noise task force in Vancouver, which offered concrete recommendations for how to reduce the impact of aviation sound. ${ }^{30}$ It $t$ is important to emphasize, however, that NEMs are not the result of engaging with or listening to sound at all, nor can they be characterized as anything other than indifferent to what people actually experience. ${ }^{31}$ Especially when INM software is used—which, today, is the vast majority of the timethe acoustic environment, as they show it, is one that has been mapped into being. NEMs consequently exist in a literal "no-man's land:" at the peculiar intersection of "estimated" measurements, cybernetic feedback loops, and geophysical representation.

\section{Rationalizing Sound}

The fact NEMs hold the performative power to simultaneously create and define sound should not come as a terrible surprise. As cartographic historians including J.B.

${ }^{30}$ City of Vancouver, "City Noise: Report of the Urban Noise Task Force," http://vancouver.cal ctyclerk/cclerk/970513/citynoisereport/, April 1997 (accessed 18 July 2012).

31 Some acoustical specialists have begun to question the accuracy and relevance of NEMs. See: Ian Jopson, "Aircraft Noise Model Validation: How Accurate Do We Need to Be?" http:// www.caa.co.uk/docs/68/dap ercd 1102 modelaccuracy.pdf (accessed 10 July 2012). 
Harley and Pickles have argued, maps are a form of "power-knowledge." 32 They should never be seen as disinterested or purely "objective" documents, even when presented that way. Maps are rather discursive: more than merely representing space, they participate in shaping how we understand and interact with it. As Harley explains, maps exhibit "an external power often centralized and exercised bureaucratically, imposed from above, and manifest in particular acts or phases of deliberate policy." Their power is commonly used to maintain control over boundaries, commerce, internal administration, population, and military strength. ${ }^{33}$

There is no reason to believe that NEMs are any different, and an important concern is the kind of "external power" they exercise. The answer becomes clear when NEMs are situated proximate to a much broader discourse: real estate. Beyond compatible land uses, which are established by Part 150, the specifically monetary impact of unwanted aviation sound is broadly contested, as demonstrated by conflicting conclusions on the subject. In a study of Reno, Nevada, for instance, Molly Espey and Hilary Lopez identify a strong negative impact on real estate, such that the "average home in areas where noise levels are 65 decibels or higher" sells for "about $\$ 2,400$ less than equivalent homes in quieter areas." J. Tomkins, on the other hand, notes the opposite, explaining that "circumstances may exist where positive attributes, such as improved access and employment

\footnotetext{
32 J. B. Harley," Deconstructing the Map, Cartographica 26, no. 2 (Summer 1989): 1-19. 33 lbid., 12.
} 
opportunities, may be more highly valued by local residents than the negative ... effects of airport proximity."34

In either case, at issue is not whether aviation sound effects the price of propertythat much, it is supposed, goes without saying-but rather, by how much and in what direction. The larger discourse of power in which NEMs participate, the context they help literally to define, concerns hedonics: a form of property analysis aimed at determining how normative assessments of "goodness" and "badness" influence value. As critical theorists Michael Hardt and Antonio Negri have explained, and as Lindsey's legal case at least partly exemplifies, this kind of assessment has become increasingly common as the cultural and political climate affirms the belief that:

the value of an apartment or a building or land in a city is not represented exclusively by the intrinsic characteristics of the property, such as the quality and size of its construction, but is also and even primarily determined by externalities-both negative externalities, such as air pollution ... and positive externalities, such as proximity to playgrounds. 35

This is a belief very much woven-through with neoliberal economic philosophy, which David Harvey has written presumes "the existence of property rights over processes, things, and social relations, that a price can be put on them, and that they can be traded subject to legal contract." 36 What matters is not what we hear or experience as such, but whether or not the proper financial impact has been assessed. If it has not, Hardt and Negri explain, "[w]hen there are 'market distortions,' when externalities come into play

\footnotetext{
34 Molly Espey and Hillary Lopez, "The Impact of Airport Noise and Proximity on Residential Property Values," Growth and Change 31 (Summer 2000), 408; J. Tomkins et al., "Noise versus Access: The Impact of an Airport in an Urban Property Market," Urban Studies 35, no. 2 (1998), 243.

35 Michael Hardt and Antonio Negri, Commonwealth (Cambridge, MA: Belknap Press of Harvard University Press, 2009), 154-55.

36 David Harvey, A Brief History of Neoliberalism (New York: Oxford University Press, 2005), 165.
} 
and social costs do not equal private costs, market rationality is lost and 'market failure' results ... neoliberal economists thus spend their time ... seeking ways to monetize pollution or traffic ... in order to ... restore logic to market exchanges." 37

Indeed, this perhaps clarifies why NEMs have been so eagerly adopted by the political and sonic status quo. Because they are so commonly thought to represent "pure fact" rather than discourse, maps emerge as an almost ideal mechanism for rationalizing sound. Indeed, beyond their strictly technical function - the establishment or, more accurately, generation of noise contours and compatible uses-the broader purpose of NEMs is to prevent noise-induced market failure by reterritorializing space sonically. ${ }^{38}$ They assert the existence of a specifically aural form of property, whose presence and influence can not only be anticipated objectively, but monetized and paid-for in advance. This also explains why the surrounding legal structure prevents new claims against the airport once a NEM has been constructed: the hedonic effect, as it were, has already been priced in.

\footnotetext{
37 Hardt and Negri, Commonwealth, 155.

38 The concept of reterritorialization, as it is used by Deleuze and Guattari, refers to the emergence of new forms of being and new forms of power. Often used dialectically with the concept of "deterritorialization," reterritorialization is neither inherently "good" not "bad." As Deleuze and Guattari explain, minority groups must assert a sense of identity in order to achieve a coherent political voice. In this context, the context of the territorial map, "reterritorialization" refers to a process of consolidating power, extracting authority from ordinary people. And in that sense, reterritorialization is worthy of concern. See also: Chapter 4, page 181, note 90; Gilles Deleuze and Félix Guattari, $A$ Thousand Plateaus: Capitalism and Schizophrenia, trans. Brian Massumi (Minneapolis and London: University of Minnesota Press, 1987), 291.
} 


\section{Closing the Commons}

And yet, by operating on the assumption that sound is an externality to begin with, NEMs allow us also to glimpse their opposite: "a specter of the common." 39 This is because there is a secondary layer of power, a kind Harley explains is "internal" to the map and that "intersects and is embedded in knowledge." Studying it requires us to shift our gaze from "the place of cartography in a juridical system of power" to the "political effects of what cartographers do when they make maps." ${ }^{, 40}$ For NEMs, this means analyzing how the map functions as a technocratic instrument used to reconfigure existing relationships-not only those linking sound to space and property in a legal or economic sense, but those guiding the emergence of bio-political subjectivity more generally.

What NEMs do, in that sense, is continue the process of bracketing, or removing, sound from collective, community control. Rather than being something we create or create with, NEMs re-situate sound as something used to create $u s$. This may seem like an odd thing to suggest since the acoustic environment, even under the worst circumstances, would seem to be a common: a space we rely upon and are responsible for, one that sustains and invigorates our lives and that requires our care and respect in return. An "acoustic common" would furthermore seem inherently difficult to partition, since sound is nothing more than vibrations passing through the air. As anthropologist Tim Ingold has written, "sound flows, as wind blows, along irregular, winding paths, and the places it

\footnotetext{
39 Hardt and Negri, Commonwealth, 55.

40 Harley, "Deconstructing the Map," 13.
} 
describes are like eddies, formed by a circular movement around rather than a fixed location within. ${ }^{.41}$

And yet, like other environmental and resource commons-water and air especially, which have increasingly been divided into pieces for the benefit of multinational water and energy companies--sound would seem to be the next common to be placed beyond reach. And it can come as little surprise. In Commonwealth, Hardt and Negri explain that, "through a long process of enclosures, the earth's surface has been almost completely divided up between public and private property so that common land regimes ... have been destroyed." ${ }^{\prime 42}$ Enclosure is no less worrisome when the common is not otherwise tangible, since intellectual or sensory commons serve increasingly as an important site of experimentation and innovation. These commons allow, and even encourage, a kind of creative play that might not otherwise occur if they were segmented into parts that were owned and controlled by individuals or groups empowered to pursue their own selfinterest at the expense of others. The example Hardt and Negri use is language, which, they say, "is for the most part common."

[l]f language were made either private or public - that is, if large portions of our words, phrases, or parts of speech were subject to private ownership or public authority - then language would lose its powers of expression, creativity, and communication. 44

\footnotetext{
41 Tim Ingold, "Against Soundscape," in Autumn Leaves: Sound and the Environment in Artistic Practice, ed. Angus Carlyle (Paris: Double Entendre, 2007), 12.

42 Hardt and Negri, Commonwealth, ix.

$43 \mathrm{lbid}$.

$44 \mathrm{lbid}$.
} 
NEMs change how we relate to what we hear. They first erect an institutional framework -an act of reterritorialization, one that requires estimating sound levels and reassessing sound as a form of property. Then, they perform an act of "positive" enclosure. While the maps do not prohibit us from making new sounds of our own, they do specify the kind of sounds we must endure, willingly or not. NEMs take what was a shared environment, one we all contributed to and took from, and grant priority access to powerful economic and state interests. This means, in effect, that anything can be heard: in an abstract sense, our behavior —our ability to play music outside, have picnics, or make "noise"-is not changed. The defining feature of positive enclosure is that certain sounds, in this case, those of airplanes landing and taking-off, must be endured if they can be heard. All other activities come second; all other desires to hear sound must follow the necessary priority of a certain class of protected sounds and activities.

\section{Conclusion}

In addition to being technically and conceptually problematic, the simultaneous powers of NEMs-reterritorialization and enclosure-are troubling because of the way they shift the terms of our discussion about sound: from the nature and texture of everyday life, to juridical concerns about price and property. Noise, nonetheless, is a legitimate health concern-increasingly so as the world's population continues to expand and urbanize. While NEMs specifically, and Noise Compatibility Programs generally, seem to have good intentions, it is how they make noise "compatible" that is troubling. Maps could conceivably be used to help develop political mechanisms encouraging full access to the common, or to empower people to challenge harmful or abusive activities, 
or to help establish a human right to territorial quietude. Instead, they have been used to superimpose a price penalty, to ignore the human (and even aesthetic) problem of excessive noise exposure, while leaving specific details to the marketplace.

Hardt and Negri further warn that when the common is accumulated, "its productivity is blocked or lessened." ${ }^{.45}$ Enclosure is worrisome, then, in more than a few ways. For one, it provides for the continued development of sound as a weapon. Today, military and police forces are granted special access to the common, allowed to produce intense, highly focused sound at ordinarily prohibited levels-both as a form of crowd control and as an "enhanced interrogation" technique ${ }^{46}$ This not only impedes our literal ability to speak and think freely, but endangers our physical ability to congregate, to share ideas in a public forum without the looming threat of sonic violence.

In an even broader sense, enclosure is a concern because it impedes "expression, creativity, and communication," especially as shared social and intellectual resources are emerging as a primary means of economic transformation, social development, and artistic production. In recent years, musicians and artists have made very meaningful use of otherwise common sounds - in sound walks, ${ }^{47}$ installation sound art, and other kinds of musical compositions inspired by the environment. Each of these hinges on access to commonly-audible sounds—-"natural" or human, mechanical and otherwise-made

\footnotetext{
45 Ibid., 288.

46 Suzanne Cusick, "Music as torture / Music as weapon," Trans: Revista Transcultural de Música 10 (2006) http://www.sibetrans.com/trans/a152/music-as-torture-music-as-weapon (accessed 18 July 2012); "You are in a place out of the world": Music in the Detention Camps of the 'Global War on Terror'," Journal of the Society for American Music 2 (2008): 1-27.

47 Hildegard Westerkamp, "Soundwalking," Sound Heritage 3, no. 4 (1974), revised 2001, http:/l www.sfu.ca/\%7Ewesterka/writings\%20page/articles\%20pages/soundwalking.html (accessed 12 May 2010).
} 
available through clear access to an acoustic environment that is inclusive, participatory, and freely available.

The precedent set by "positive" enclosure stands to undermine these activities and countless others-not to mention the extremely serious threat it poses to the life and wellbeing of non-human animals. ${ }^{48}$ But I want to conclude this case study on a positive, if only speculative, note: it does not have to be this way. Indeed, the very reason Lindsey lost his appeal could conceivably become a vehicle for producing change: community. Maps were used to define Lindsey as part of a group of people living in Memphis, people who shared a common interest and a common concern. Where, as Hardt and Negri explain, "hierarchies segment the common and exclude populations from it," maps could help us resist enclosure by restoring "necessary forms of cooperation and communication." 49

More in the spirit of "dynamic" maps discussed in Chapter 2, NEMs could be used to raise our awareness of sound and its role in our lives. They could be used to facilitate "constructive interaction" by becoming a locus for cooperative advocacy, by reasserting the primacy of mutuality of what we share in (the acoustic) common. ${ }^{50}$ The ultimate

\footnotetext{
48 J.L. Dowling et al explain that "[b]ackground noise presents a challenge for animal communication because it increases the masked hearing threshold ... of receivers and thereby limits the signal's active space." This is especially worrisome, since animals like birds "use acoustic signals for functions like species recognition, mate attraction, and territory defense, making them central to their reproductive success and survival." See: J.L. Dowling, D.A. Luther, and P.P. Marra, "Comparative effects of urban development and anthropogenic noise on bird songs," Behavioral Ecology 23, no. 1 (Jan. 2012): 201-09.

49 Hardt and Negri, Commonwealth, 303.

50 In addition to demanding "open access to the common against the barriers of private property," reform requires of us to demand "equality against hierarchy, allowing everyone to become capable of participating in the constitution of society, collective self-rule, and constructive interaction with others." (Hardt and Negri, Commonwealth, 381.)
} 
problem with NEMs, then, is that they actively exclude the ears of ordinary people, favoring instead the mechanized "observations" of computer models. By defaulting to already-institutionalized observations, they are, if not contrary to the interests of what people actually hear, then completely indifferent towards it. What is needed, then, is to open these maps to a sense of place. They must reflect what acculturated residents observe (or are annoyed by) and experience (or wish to avoid). To serve the general good, people should be given the right to contest the maps as a regulatory medium-to challenge their history, process, methods, and application. And furthermore, instead of using maps to identify locations in need of acoustic retrofits, an application which treats the symptoms of noise rather than addressing its causes, they should be used to encourage and empower people to challenge the activities that motivate and justify their construction in the first place. ${ }^{51}$ Until then-until "everyday" ears and actual, human experiences are found at the center of regulatory noise mapping - the acoustic commons will remain positively enclosed.

51 In one notable lawsuit, the Supreme Court of Georgia ruled that the City of Atlanta was justified in compensating only owners of single-family homes for exposure to aviation noise. They ruled that "the city's actions did not violate the state constitution's equal protection provisions because the classifications that were drawn by the city [between single- and multi-family homes] bore a rational relationship to the legitimate governmental purpose of reducing land use that was incompatible with airport noise in a sound and responsible fiscal matter, and the city's decision to purchase single-family residences first was reasonable and not arbitrary." This case raises further serious questions about noise maps, including whether they tend to favor people of certain socio-economic backgrounds. Much more research needs to be done on this subject. See: City of Atlanta v. Watson, 1996 Ga. LEXIS 709 (September 23, 1996, Decided). 


\title{
Chapter 4: Sound Maps in Music Notation
}

\begin{abstract}
Every abstract machine is linked to other abstract machines, not only because they are inseparably political, economic, scientific, artistic, ecological, cosmic-perceptive, affective, active, thinking, physical, and semiotic - but because their various types are as intertwined as their operations are convergent.

-Gilles Deleuze and Félix Guattari, $A$ Thousand Plateaus
\end{abstract}

\section{Introduction}

Sound maps not only represent audible space, they change the terms on which we relate to it. As I argued in Chapter 1, the historical and conceptual roots of this change can be traced to early research into architectural acoustics. While experiments conducted at the turn of the $20^{\text {th }}$ century demonstrated that sound can be predicted, and indeed, controlled with precision, its relationship to space can also be seen as univocal. ${ }^{1}$ As depicted in the experimental diagrams of Wallace Sabine, a single room can have within it pockets of varying intensity - suggesting space not only serves as a container for sound, but exerts a creative influence that changes it. It is, in the words of Gilles Deleuze, univocal: singular, but internally differentiated.

One conceptual beneficiary of this research was thematic cartography: maps designed to show the acoustic and psychoacoustic contours of the everyday environment. As I explored in Chapters 2 and 3, sound maps have found a range of applications: from helping to manage the analysis of airport noise to showing how sound contributes to the formation of a community's identity; from becoming an environmental art object to emerging as the object of "sonic" crowd sourcing. None of these maps are self-evident presentations, though. As cartographic historians including Brian Harley and John Pickles

\footnotetext{
1 Emily Thompson, The Soundscape of Modernity: Architectural Acoustics and the Culture of Listening in America, 1900-1933 (Cambridge, MA: MIT Press, 2002).
} 
have argued, sound maps are rather persuasive re-presentations with the potential to shape how and what we hear. As a result, we should adopt a cautious and critical view of sound maps, one that focuses not on the surface of the map, but on the relationships they configure among sound, experience, the environment, and everyday life.

The underlying idea-to combine both sound and space within a single representational frame-correlates also with developments in music. Sound maps, whether composed using textual or visual media, can be found with surprising regularity throughout $20^{\text {th }}$-century music notation. As a kind of "musical graphic," these images "strive to stimulate without constricting the imagination."2 Yet, beyond this point, further analysis of what spatial diagrams do and the creative possibilities they engender is almost entirely lacking in scholarly literature today. This chapter will begin to remedy this oversight by taking these images seriously: both as instructions for the performance of music and sound, and as representations of the physical environment.

Sound maps in musical notation take two common forms. In the first section of this chapter, I will explore several cases where maps and diagrams are included alongside more conventional music notation. While there is nothing particularly revolutionary about a seating diagram per se, these images do much more than simply instruct performers where to sit; by being closely connected with the broader conception of the "work," they function to outline spatial and sonic relationships that should be actualized (or avoided) in performance. In a few cases, the diagram even becomes a vehicle for actualizing an inconsistent and irregular sonic environment, a space where placement and situation can

\footnotetext{
2 Erhard Karkoschka, Notation in New Music: A Critical Guide to Interpretation and Realisation (New York and Washington: Praeger Publishers, 1972), 77.
} 
profoundly influence what is heard, by whom, and how. In the second section, I will examine more extreme examples of sound maps in musical notation: instances where traditional notation is abandoned entirely, and where maps, photographs, or spatial diagrams become themselves the foundation of the score. While carefully indicating where sound should be made, these scores often ignore more conventional musical concerns-such as which sounds to make, and when to make them. Additionally, these works are unusual for the way they "enframe" mapped space, setting it aside as already sonically rich while asking us to perform cooperatively in and with the surrounding environment.

While sound maps in music notation are used to fill any number of specific purposes, beneath the surface lies a common, if unarticulated, grasp of the way in which space gives both literal and metaphorical shape to music and its performance. In treating these works as primary source documents, I will highlight key examples that ask us to reevaluate in broad terms what we mean by "writing music." As I will suggest throughout, these works should challenge not only our preconceptions of how notation looks, but the way it should be analyzed, and the human, material, technical, and temporal relationships it is thought to figure.

\section{Section I: Analysis on/of the Periphery?}

All of the works discussed in this chapter share a few common features. The first is representation: in all cases, the score "maps" the site of performance. Sometimes this is done quite simply, perhaps using a few stick figures or a textual explanation, that describes how performers and instruments should be situated. In others, the map becomes 
a sophisticated tool-a photograph, an explanation, or a carefully drawn technical diagram — with implications far beyond the placement of chairs. The second common feature is insufficiency: each map depends on a larger musical context. Where, in some cases, the sonic aspects of performance are left entirely open-in the more wellestablished sense of musical indeterminacy -in others, they are acquired by association with a more traditional musical score.

Perhaps one surprising place both features can be seen is among the work of American composer Steve Reich. Perhaps Reich's most important composition, Music for 18 Musicians is often thought to mark a key moment in the emergence of musical minimalism and is significant for the way it "comprehensively explored the possibilities afforded by ... simple musical process." In being "structured like the extended dance remixes of pop album tracks," it succeeded, in part, by bringing the domains of "high" and "low" musical practice closer together. ${ }^{4}$ As Robert Fink explains, Music for 18

\section{Musicians was}

able to channel and then release musical energy across several variations by using two musical devices not usually thought to exist in minimal music: a bass line that outlines semifunctional root progressions over large expanses of musical time; and a series of coherent, carefully controlled linear progressions in the soprano register. 5

Fink's comments in many respects typify what we expect from musical and theoretical analysis as it is practiced today. It involves first observing the way a small fragment of sonic material - a melody, a rhythm, or an idea - is manipulated and developed within the

\footnotetext{
${ }^{3}$ Robert Fink, Repeating Ourselves: American Minimal Music as Cultural Practice (Berkeley: University of California Press, 2005), 49.

4 Ibid., 47-48.

5 Ibid., 50.
} 
abstract realm of musical "space-time," within the theoretical domain of the text. ${ }^{6}$ These observations might later be reconnected with others about culture, society, or the life of the composer.

While this mode of analysis continues to be important, it tends to leave some aspects of the score unscrutinized; parts that seem structurally unnecessary are considered outside the domain of "space-time," and thus are beyond the analytical gaze. This is especially true in the case of Music for 18 Musicians, whose introductory material includes a seemingly self-explanatory staging diagram. Drawn with surprising detail, ${ }^{7}$ it consists of figures and shapes of varying sizes, representing people and musical instruments - vibraphones, pianos, and clarinets, among others. The arms of each humanlike image are shown outstretched—and in the case of percussionists, with mallets in hand, as though in the act of performing. Nearby, a brief text explains that the image shows a "suggested arrangement" for performance, a qualification that leaves open the possibility that some other orientation might work, too, depending on how (and how well) the performers communicate with each other. (Figure 4-1) Initially at least, it is not clear why this image is included with the score at all, or indeed, whether it has some special role to play beyond mere "suggestion." After all, the arrangement shown is neither so unusual nor so obscure that performers could not discover it independently. It

${ }^{6}$ Evan Jones provides a fascinating overview of different forms of what he calls spatial-temporal notation. While some are linear, others "posit new kinds of adjacencies or modes of succession." It is important to note, however, that "cartography" in his article becomes entirely metaphorical. See: Evan Jones, "Mapping Musical Space," in Mapping in the Age of Digital Media: The Yale Symposium, ed. Mike Silver and Diana Balmori (West Sussex, UK: WileyAcademy, 2003), 66.

7 Steve Reich, Music for 18 Musicians (New York: Boosey and Hawkes, 2000). 
is, by any conventional assessment, a familiar and practical setup: pianos and percussion located near the back, and singers with winds near the front.

Within the frame of musical analysis at least, the silence surrounding this map is indicative of what Lydia Goehr has called the "separability principle"- "the custom to speak of the arts as separated completely from the world of the ordinary, mundane, and everyday." ${ }^{\prime \prime}$ She explains:

The separability principle was abundantly used by theorists around 1800 . It was used to redefine various major distinctions: those between art and nature, art and craft, and the civilized and the popular; various aesthetic notions: artistic form, content, and medium; and various activities: the creation and reception of fine art. Each use of the principle ... ended up pre-supposing, demanding, or referring indirectly to one thing: the existence of an artwork at the centre upon which one's aesthetic concerns could focus. 9

As Goehr suggests, analysis has historically required insulating the "artwork at the centre" from the noise that surrounds it: nature, craft, "the popular." And while the definition of analytical noise has changed over time, the problem remains establishing what "is" and what "is not" important for analysis-and by extension, determining where "the work" ends and the rest of the world begins. In this particular instance, it is assumed the map appears so "ordinary" that it neither needs nor deserves further consideration. Its impact is therefore marginalized, contained by the introductory pages of the score, going absolutely no further than the resident stage technician at the performance venue.

But, if this is true, then other maps included among Reich's published works should also be ignored. Another similar map can be found in the score for his

\footnotetext{
8 Lydia Goehr, The Imaginary Museum of Musical Works (Oxford: Oxford University Press, 1994), 157.

9 lbid., 159.
} 
controversial piece 4 Organs. ${ }^{10}$ Like the map used in Music for 18 Musicians, this one includes textual instructions: the image, they explain, shows where the "electric organs, maracas, amplifiers and loudspeakers should be set up..." (Figure 4-2) But the map itself goes even one step further, providing rudimentary technical instructions addressing not only where each piece of equipment "should" be put, but how to connect them all together. For example, the two organists at the front should be connected to the amplifier at stage left; the organists near the rear should be connected to the amplifier at stage right. From there, the sound is further split: the front-right organist is connected to the speaker on the inside, stage right; the front-left organist is connected to the speaker on the inside, stage left; and so on. This diagram consequently emerges as more than a simple "seating diagram." It concerns not only where people should sit, but how to produce an effective result; it provides technical information designed to ensure that the performance sounds a certain way. These details might, then, explain why the accompanying instructions adopt the imperative "should," rather than the more lenient "suggested."

Visual representation, of course, is not the only way to communicate this type of information. For one, Alvin Lucier commonly relies on textual maps to achieve similar

10 In her interview with Steve Reich, Terry Gross quotes Michael Tilson Thomas' recollection from an early performance of the work:

In all my years as a performer, I have never seen such a reaction from an audience. There were at least three attempts to stop the performance by shouting it down. One woman walked down the aisle and repeatedly banged her head on the front of the stage wailing: "Stop! Stop! I confess!"' The audience made so much noise that, in spite of the fact the music was amplified, we were unable to hear one another's playing. ("Steve Reich at 70," by Tern Gross, Fresh Air, WHYY Philadelphia, 6 October 2006 (accessed 22 May 2012), http://www.npr.org/templates/story/story.php?storyld=6209213).

If this recollection is indeed correct, it suggests the woman beating her head was doing so behind the performers-no doubt a troubling and disruptive occurrence.

11 Steve Reich, Four Organs (London: Universal Edition, 1980); italics mine. 
ends. His score for Kettles, for example, provides a mixture of technical, practical, and acoustical directions, gathered (perhaps inaccurately) under the umbrella of "Set-up." Lucier writes:

5 timpani may be placed up to 10 feet apart in a shallow curve across the front of the stage. A pair of loudspeakers are positioned at shoulder height behind them. In non-proscenium spaces, however, they may be positioned in other configurations which favor the creation of audible beats. ${ }^{12}$

The implications of what Lucier writes here are nominalist: beneath the articulated surface, there is at least one particular configuration known to produce the sonic effect he has in mind. In spite of being apparently optional, then, the instructions function more strictly: everything written after the first "may" casts long shadows of words like "should" or "needs to be." And indeed, the end result, "the creation of audible beats," is so specific - and one can imagine, so liminal-that proper implementation takes on a sense of urgency. At the same time, the word "may" also suggests other arrangements, yet undetermined, might produce similar results; and these arrangements would be acceptable, too, so long as they "create beats." Lucier therefore grants permission to the performer to play with space (and in it) to find alternatives when necessary.

But maps, either visual or textual, are not used simply to provide technical and effective instructions. Even comparatively simple works-those using "low-tech" instruments and equipment, for instance-also make use of them. The score for Reich's Music for Pieces of Wood not only "urges" performers "to find and tune" specific claves, but features a map showing where each performer, using each clave, might be placed during performance. Meanwhile, as before, an accompanying text explains that " $[p]$

\footnotetext{
${ }^{12}$ Alvin Lucier, Kettles: for five timpani and two slow-sweep pure wave oscillators (Material Press: 1988); italics mine.
} 
erformers may stand while playing as illustrated in the drawing and photo below."13 While the explicit goal of this directive is to "allow [performers] to hear and see each other clearly," the arrangement is one nearly any classically-trained musician would choose almost instinctively: performers are shown in a slight arc facing the audience-a set up meant to enhance ensemble clarity and ease communication among players. (Figure 4-3)

In addition to complicating the notion that music can be understood analytically simply by studying "space-time," maps like these have implications far beyond ordinary concerns: the physical situation of performers, or the technical configuration of instruments and equipment. Despite seeming banal or obvious, they are important because they bring the assumptions of notation - its tangibles, including the very existence of human bodies and physical space-into the foreground. When filled with rich information about the materiality of performance, maps subsequently complicate the very notion that music can be removed from lived experience-or as Goehr wrote: "the ordinary, mundane, and everyday."14 Despite being physically and conceptually bracketed, located among "introductory" materials, maps in musical notation should challenge us to reconsider the boundaries of the musical "score." 15 No longer a uniform block consisting solely of staves, measures, dynamics, and rhythms, it emerges as a much

\footnotetext{
${ }^{13}$ Steve Reich, Music for Pieces of Wood (London: Universal Edition, 1980); italics mine.

14 Goehr, The Imaginary Museum, 157.

15 "Score," in the Grove Dictionary, is defined as a "copy which shows in ordered form the parts allotted to the various performers, as distinct from 'parts' which show only that of one performer." This is no longer an adequate definition, since a spatial graphic is neither a single "part," nor a highly condensed reduction of several. See: "Score," in The Oxford Dictionary of Music, 2nd ed. rev., edited by Michael Kennedy, Oxford Music Online, http:// www.oxfordmusiconline.com/subscriber/article/opr/t237/e9188 (accessed May 23, 2012).
} 
larger assemblage-a notational complex-composed of various types and modalities of instruction: graphical and textual, spatial and temporal, able to reference not just sound, but instruments, machines, and bodies. For musical analysis, conventionally understood, the effect of this expansion is important and profound. While older forms of theoretical praxis, focused, as they are, on pitch content and rhythm, may have a somewhat changed role, I want to suggest that the persistent appearance of maps throughout published musical notation in the $20^{\text {th }}$ century can no longer be ignored.

Maps can be used to guide the purposeful creation of a new environment, one that ensures not sonic regularity or consistency, but that sound will be heard differently and unevenly from place-to-place. The score and maps I will survey in the remainder of this section, all of which implicate space, continue to utilize the traditional five line clef. Nonetheless, much as I discussed in Chapter 2, it is the way in which the image of the map intersects with the materiality of performance and notation that should be the object of analysis. My focus, as a result, will be trained on the threads and sinews that connect each map to the more conventional aspects of the score. Throughout this chapter, I will show how sound maps, as a form of musical notation, both figure and pre-figure a complex series of relationships linking performers to the physical environment and the audience. In some cases, the maps are flexible—one or two possible configurations might be possible, both of which create an effective environmental "texture." In other cases, the image must be carefully avoided: the configuration shown is too conventional, too predictable, and otherwise not capable of producing a particular outcome. 


\section{Positives and Alternatives}

In a literal sense, the maps of Reich and Lucier are minimally restrictive since they are accompanied by equivocating terms like "may" or "should." This grants performers tacit permission to experiment with new spatial contexts and to accommodate unforeseen performance constraints-just so long as their eyes and ears remain fixed on the final effect. At the same time, there is nothing inherent to the idea of a map to prevent it from being used more strictly. Indeed, to the extent the maps I have discussed so far are somewhat more than optional, and at the same time, somewhat less than fixed, others are far more clear about which spatial considerations are necessary and required in performance, and alternatively, which can be (or must be) ignored or rejected.

Iannis Xenakis exemplifies the former. His maps are clearly defined and rigidly organized, although his decision to notate space so explicitly is perhaps not terribly surprising given his personal history and creative ambitions. Xenakis first developed his reputation as a composer of "spatial music" thanks to his work on the Philips Pavilion during the late $1950 \mathrm{~s} .{ }^{16} \mathrm{He}$ then spent much of his later career working with site-based and installation art, often with the expressed aim of developing novel ways to reconnect and reintegrate sound with space, light, and architecture. It was in this context that Xenakis devised an important concept, one that framed theoretically how space and sound could be utilized co-productively: the polytope. Made by combining together the Greek words for "many" and "space," the goal of a polytope—one shared with electronic spectral music as it developed during the 1960 s and 70 s—-was to project sound into

\footnotetext{
${ }^{16}$ For a broad but thorough overview, see: Marc Treib, Space Calculated in Seconds (Princeton: Princeton University Press, 1996).
} 
different areas of the performance environment. ${ }^{17}$ As musicologist Philipp Oswalt has written, the dynamic and immersive result was meant to create "an overlapping of many sound spaces" such that

[e]ach listener perceives the music in a different way according to his or her location at the time. The acoustical space is no longer homogeneous, but divides itself into different spatial areas. ${ }^{18}$

Xenakis first deployed the polytope in his work Terretektorh. Crucially, however, the means of projection was not speakers or electronics, but rather human performers. ${ }^{19}$ In the score, provisions are made to install them carefully within and throughout a tightlycircumscribed performance environment. The included map-a visually striking one, more resembling a scatterplot than a seating chart—shows a large circle divided into eight slices, labeled $\mathrm{A}$ through $\mathrm{H}$, each referring to a discrete group of performers and a portion of physical space. (Figure 4-4) The conductor, positioned in the center of the circle, is surrounded by large dots, each numbered and labeled, showing a careful dispersion of performers throughout the surrounding space. Only the percussion section is situated on the periphery, just beyond slices A, D, and G. The remainder of the diagram is filled with small, regularly-distributed and seemingly insignificant flecks representing the "Public," which consequently surround and envelop the performers.

This map is more than merely orientational, though, and actualizing it is anything but voluntary. On the contrary, the configuration of the physical environment might well

\footnotetext{
17 Gascia Ouzounian, Sound Art and Spatial Practices: Situating Sound Installation Art Since 1958 (Ph.D. diss., University of California San Diego, 2008), 53.

18 Philipp Oswalt, "lannis Xenakis' Polytopes," translated by Tas Skorupa, Contemporary Music Review 21, nos. 2/3 (2002), 39.

19 lannis Xenakis, Terretektorh: Pour Orchestre (Paris: Editions Salabert, 1969).
} 
be considered an integral feature of Terretektorh, since spatial position could have a profound (and not always positive) influence on the performed outcome-even as experienced by the audience. The result in one instance was recalled by musicologist and critic Brian Dennis:

[t]he first single note played by a solo viola revolved clockwise round the hall; moving regularly in a quasi-canon, it was to make two full circuits before further development ensued. This kind of linear circular movement with the instruments of a given kind not grouped together but situated at regular spacings around the instrumental arena could not nearly so easily be assimilated from the gallery, so that the second performance was for me, having moved from my former position on the floor, definitely less effective. 20

Placed alongside Dennis' description, the map functions not to help create a smooth or consistent "whole"- a performance setting, for instance, often idealized by the modern symphony hall. ${ }^{21}$ On the contrary, instead of ensuring an identical seat and sound for everyone, the diagram facilitates the creation of a dynamic and, more importantly, inconsistent sonic space. The planned outcome was for a performance environment where the location and interaction among performers and listeners creates a certain amount of variability. Moving from fleck to fleck, or from slice to slice, would, by design, result in a different experience for listeners and performers alike. Consequently, though perhaps inadvertently, the map prefigures what Oswalt explained earlier: the emergence of space as a non-homogeneous "whole."

At the same time, Dennis' description also foregrounds a significant challenge inherent to the spatialization of sound. To be effectively manipulated, to create a textured and heterogeneous performance environment, everything has to be physically, and in the

\footnotetext{
${ }^{20}$ Brian Dennis, "Xenakis's 'Terretektorh' and 'Eonta'," Tempo 82 (Autumn 1967), 27.

${ }^{21}$ For instance, see Edward Rothstein's comments in Chapter 1, pp. 20-21 and 28.
} 
case of people, corporeally managed. This is a crucial point, since, as Dennis recalled, being outside the designated envelope could have disappointing or at least unanticipated results. A performance could conceivably "go wrong" not because of more usual problems like wrong notes or poor conducting, but because otherwise "non-performing" participants drifted outside their designated area. Consequently, a map like the one in Terretektorh can be said not only to make provisions for the placement of performers and instruments, but to expand the field of notational control, blurring conventionallyunderstood and long-established boundaries between performer and auditor. In this particular example, every body has some place to be.

Xenakis' notation, in this respect, resembles other kinds of so-called "spatial" music, including polyphonic choral music, whose relevant similarities surface with particular clarity in the study of St. Gertrude's Chapel in Hamburg. Built in the late $14^{\text {th }}$ century, damaged by fire and refurbished in 1607 , then completely destroyed in 1842 , St. Gertrude's was home to some of the most well-known artists and performers of its time. Matthias Weckmann, Thomas Selle, and Georg Telemann all composed music for performance in St. Gertrude's, and at times, performed there themselves. ${ }^{22}$ While the building's distinct octagonal shape is shared by other pilgrimage chapels of the era, ${ }^{23}$ the special significance of St. Gertrude's lies with its identity as a historical locus for musical performance. As musicologist Frederick Gable writes, "[d]uring the first half of the $17^{\text {th }}$

22 Frederick Gable, "St. Gertrude's Chapel, Hamburg, and the Performance of Polychoral Music," Early Music 15, no. 2, Plucked String Issue (May 1987), 230.

23 Ibid., 230. 
century," St. Gertrude's became "the favourite setting in Hamburg" for the performance of polyphonic Passions. ${ }^{24}$

Expanding a line of argument common to the "authentic" performance practice movement, Gable argues that "the physical characteristics of the building for which a particular piece of music was written must be considered an essential element in any attempt to recreate the aesthetic impact of that piece." 25 It follows that studying St.

Gertrude's architecture can help us answer important questions about the spatial dynamics of musical performance in the past, and by extension, about "the appropriate environment for the performance of polychoral music" today. ${ }^{26}$ Gable subsequently models a number of practical and logistical questions. For instance:

Where should [each polyphonic ensemble] be located in order to enhance the musical effect and to avoid causing problems of coordination, balance and clarity? In large churches a rear organ gallery is usually too distant from the Choir, while transept or side balconies may be out of sight of the performers in the Choir and thus impractical. As some accounts suggest, special platforms built in the nave may be one solution, or it is possible that these three- and four-choir works were designed for performance in smaller buildings than is commonly assumed. ${ }^{27}$

The underlying puzzle of St. Gertrude's, however, is rooted not merely in its physical, historical, or architectural dimensions. An important assumption buttressing Gable's notion of "aesthetic impact," and indeed, the reason that impact needs to be actualized today, is that some kind of impression-spatial or musical, acoustical and otherwisehas been left on the text, coded subconsciously or unconsciously, within or beneath it. These traces must furthermore be excavated if we ever hope to understand either the

\footnotetext{
24 Ibid., 231-32.

25 Ibid., 229; italics mine.

26 Ibid., 238.

27 lbid.
} 
music (considered in the abstract sense of the separability principle) or the time period during which it was written. And indeed, these become especially problematic considerations where someplace like St. Gertrude's is concerned, since so few physical remnants of the space remain. ${ }^{28}$

Xenakis' map for Terretektorh, meanwhile, seems to implicitly embrace many of Gable's most fundamental assumptions about "aesthetic impact" while taking them in a decidedly more tangible direction. Which is to say, the fact Xenakis included a map at all suggests physical, spatial, and sonic interdependencies do not have to be excavated: they exist, on the surface, for everyone to see. But the clarity with which space is implicated in turn raises a practical question, one that is only ever implied by Gable's study of St. Gertrude's Chapel: Can a performance of Terretektorh continue in circumstances when the spatial directive cannot be actualized? Xenakis' score, like those of Telemann or Selle, is otherwise silent about the answer. Implied is a certain amount of personal risk and responsibility: for each person to do what, and be where, the notation specifies. Indeed, as Dennis' recollection makes clear, a "bad" performance could be defined as much by the misplacement and misperception of the audience as poor execution by the performers.

Other compositions by Xenakis, however, are far more clear on the answer to this question, including the aptly-named Polytope. This orchestral work by Xenakis was written for a specific place and occasion: the French Pavilion at Expo '67 in Montreal, 
Canada. ${ }^{29}$ While the building's primary function was not to exhibit cutting edge consumer electronics, it did nonetheless share some superficial resemblances to the Philips Pavilion from nearly a decade earlier. The exterior featured a striking glissando of steel and glass, which wrapped around the building while ascending toward the roof. But where Xenakis, in this case, had no say in the physical design of the building, he was granted complete control of the spectacle meant to be performed inside it. Polytope-not unlike Varèse's earlier Poème électronique —was meant to be performed in the central atrium of the building, which featured a large sculpture, crisscrossing staircases, and a central fountain. Polytope was conceived, then, as a fully-integrated spectacle, one where the senses benefit from a synergistic confluence among light, sound, and the physical environment, all of which work together to create an experience that none on its own could achieve.

The score for Polytope includes a map showing a large square divided into four quadrants. The orchestra is placed along the central "t," and the audience-here represented using a single, uninterrupted scribble-fills in the remaining space. (Figure 4-5A) What makes this image significant, and indeed quite different from the earlier example in Terretektorh, is the second arrangement that accompanies it. (Figure 4-5B) Rather than saying, more simply, that the first arrangement "may" be used-the solution favored by Reich and Lucier-the second diagram shows exactly how the performers and audience should be situated in the event the first map cannot be actualized. And this

\footnotetext{
29 lannis Xenakis, Polytope (London: Boosey and Hawkes, 1969); EXPO '67: The Memorial Album of the first category universal and international Exhibition held in Montreal from the twenty-seventh of April to the twenty-ninth of October nineteen hundred and sixty-seven (Thomas Nelson \& Sons, 1968).
} 
version depicts a far more conventional arrangement, with performers staged in columns opposite an audience-winds and strings near the front, percussion and brass to the back. Presumably not meant for use in the French Pavilion, this version is generic enough for circumstances when a more familiar "oppositional" seating arrangement is preconfigured: a concert hall, an auditorium, a church, etc.

Of course, at some level, this map might illustrate nothing more than Xenakis' hope that Polytope-unlike the earlier Poème-would acquire an active and vibrant performance life outside the French Pavilion. And indeed, following the end of Expo '67, the Pavilion was transformed into a casino, making any future performance of Polytope there unlikely ${ }^{30}$ But whatever his motivation, leaving the physical environment undetermined, unscripted, or at the very minimum, un-notated seems to have been inadequate. Space, for Xenakis, had to be planned for; and by providing two discrete possibilities-rather than one or none-the resulting sonic and spatial relationships are written-in to the score through a bifurcated exclusion. There is no "may" or "should" to be found, and there is little or no room for performative experimentation: it is either this arrangement, or that one.

\section{Negatives and Prohibitions}

Whether implied or explicit—whether written during the $17^{\text {th }}$ or $20^{\text {th }}$ century-one point on which all of the scores I have discussed so far agree is that notation functions in the affirmative: it says, to some degree, what should be done. But this is not always the case. Some composers are both explicit in their spatial notation and, at the same time, clear about the inadequacy of alternatives. One perhaps surprising example can be found

30 Québec's casinos, http://www.casinosduquebec.com/en/home (accessed 23 May 2013). 
in the work of Pauline Oliveros, whose music is often celebrated for its embrace of a feminist and environmentalist ethos. Her score for Aeolian Partitions, however, also makes prominent use of a map—and in this case, its actualization is anything but optional. (Figure 4-6) Nearby textual instructions detail three of the most essential considerations for performance: there should be a stage, preferably one with a proscenium arch; an overhead projector will be needed, as will a screen mounted to the rearmost vertical surface behind the performers; and the theater itself should be capable of producing a "total house and stage blackout"- necessary to ensure that the "volt flasher lamps" will produce the proper effect. Crucially, if these conditions cannot be met, the performance is to be abandoned entirely. ${ }^{31}$

These instructions, and the image that accompanies them, are peculiar. Most musical notation is not buttressed by a requirement, implicit or otherwise, to abandon a performance if a particular ideal cannot be guaranteed in advance - that is, to the extent anything resembling an "ideal performance" can be imagined. Furthermore, where someone like Reich or Xenakis provides instructions by suggestion and demonstrationoffering alternatives when not more simply labeling as voluntary the ones providedOliveros here raises the stakes: the only acceptable conditions are detailed in the score, and no others are satisfactory. Whether the reasons for this strictness are political or

\footnotetext{
31 Pauline Oliveros, Aeolian Partitions (Brunswick, ME: Bowdoin College Music Press, 1970). While recognizing the importance of alternative, non-scored ways of composing music, she nonetheless acknowledges that "the score ... is a symbol of control, a metaphor of control. If you write a score, then you've got control, so to speak..." (Pauline Oliveros and Fred Maus, "A Conversation about Feminism and Music," Perspectives of New Music 32, no. 2 [Summer 1994], 184) Aeolian Partitions demonstrates this, and to powerful effect.
} 
acoustical, the effect is the same: the notation presents an all-or-nothing dilemma, one that is striking for its absolute finality.

Explicit conditionality, what amounts to a spatial ultimatum, is certainly an unusual feature of this work, especially given Oliveros' broader reputation. But she is by no means the only composer to utilize sound maps as a "negative" instruction. Composer Henry Brant is comparatively more well known for his interest in the creative synergies of music and space; that he provided detailed spatial instructions among his scores is not likely to be a surprise. As musicologist Virginia Anderson has written:

Karlheinz Stockhausen claimed that he had invented spatial music with Gruppen (1958), but Brant's spatial music was both earlier and more complex. Brant experimented with the properties of space, including aspects of direction, projection, spill (the interaction between two group sounds), density, and the perception of movement. He had written 112 spatial pieces by 2003.32

Throughout his career, Brant argued passionately that composers have yet to fully explore the musical potential of sound-space interactivity. ${ }^{33}$ And indeed, his own works usually include some sort of "spatial plans" - textual or graphical maps that specify how musicians and the audience should be situated, in relation both to one another and to the physical performance environment. ${ }^{34}$

\footnotetext{
32 Virginia Anderson, "Henry Brant: experimental composer who scored for instruments ranging from massed trombones to kitchenware," The Independent (London), 2 May, 2008.

33 Henry Brant, "Spatial Music Progress Report," (1979) http://www.jaffe.com/ BrantSpatial 1979.pdf (accessed 22 February 2012), 2; Brant believed that spatial music "is still isolated from the main currents of musical thought and practice and cannot yet be said to represent a movement or tendency among composers. The more prominent composers now before the public have not adopted spatial techniques as an established element in their music, which may explain why writers on musical subjects have little to say about spatial musical concepts."

34 Ibid., 4.
} 
Far from exotic Pavilions or multimedia light sculptures, however, Brant usually assumes the setting for his works will be a modern concert hall, whose familiar structure and predictable limitations, he believed, could provide a useful constraint for experimenting with ostensibly "new" sonic-spatial possibilities. ${ }^{35}$ For example, his score for Ice Field, which is considered among Brant's finest compositions, features textual instructions that explain how strings, harps, pianos, timpani, and organ are to be "on stage," while piccolos, horns, and other assorted wind instruments and percussion are to be situated "in the hall"- "in the opposite corner, in the first balcony," or in "a series of boxes," or, at the very minimum, "behind the audience at the downstairs level."36 The striking outcome in performance was described by Robert Everett-Green, a music critic for The Globe and Mail:

Clusters of musicians surrounded the audience, with strings, harps and piano at the front, brass and percussion in the side aisles, and woodwinds in the rear gallery. From these positions, they launched what seemed at various times like a debate, a shouting match, or a tentative meeting of spirits across the intervening space. ${ }^{37}$

In an otherwise unfavorable review, Joshua Kosman writing for the San Francisco

Chronicle likewise notes how the work used "every nook and cranny" of Davies Hall:

At first, there is surprise and a certain amount of delight as the piece bounces exuberantly around the place in a winningly low-tech version of Sensurround. And it does inspire one to wonder why more composers don't take advantage of music's physical dimensions.... After the musical thread has been passed around a few times, a listener begins to long for some substance, only to

35 Ibid., 2; Brant also believed that the concert hall could become the site of aggressive architectural experimentation. He wrote: "a hall specifically designed to accommodate the spatial music of the past, present, and future, a space with moveable walls, floors and ceiling, is still a project for the future."

${ }^{36}$ Henry Brant, Ice Field: Spatial Narratives for Large and Small Orchestral Groups (New York: Carl Fischer, 2002), 4; Brant was awarded the Pulitzer Prize for Ice Field in 2002.

37 Robert Everett-Green, "Giving music some space," The Globe and Mail (Canada), 3 December 2005, sec. R, p. 21. 
encounter a soupy string chorale and a jazzy brass outburst lifted from "West Side Story." 38

But other works by Brant aim likewise to create novel spatial effects; except, instead of a textual map, they include graphics. A brief orchestral piece, the score for Verticals Ascending - After the Rodia Towers depicts the position of two "widely separated" ensembles - a clear homage to the titular Los Angeles landmarks. Beyond this general requirement, however, Brant details a few specific ensemble configurations that would qualify as acceptable. In one, the first group of performers would be situated on stage, with the second placed at the back of the hall: in an open balcony if possible, but explicitly not beneath an overhang. In another, both groups could be situated on opposite lateral sides of the hall-a sufficient separation, if only a narrow one, requiring no use of a stage or balconies at all. ${ }^{39}$

The score itself features a pair of maps; and what makes them significant is how they function: where the first shows an "acceptable distribution" of performers (Figure 4-7A), the second depicts an arrangement that is "contrary to the composer's intention and is specifically not authorized." 40 (Figure 4-7B) The latter is particularly striking, since it features what would otherwise be a conventional performance configuration: much like the alternate map in Polytope, or indeed, the primary map for Music for Pieces of Wood, this one shows two orchestras seated next to each other, forming a slight arch, facing an audience. Despite how comfortable the performers might feel in this

\footnotetext{
38 Joshua Kosman, "Brant's 'Ice Field' spreads across Davies," The San Francisco Chronicle, 14 December 2001, sec. D, p.5.

39 Henry Brant, Verticals Ascending after the Rodia Towers (New York: MCA Music, 1969), 2. 40 Ibid., 3.
} 
arrangement-and despite how smooth and consistent the ensemble might sound - the unequivocal message is that habit and tradition are not always to be trusted. In some cases, the goal of a performance is neither smoothness nor convenience. Indeed, the goal in this case seems rooted in univocality: the creation of a textured space, one that can be heard and experienced differently from place to place; the emplacement of an unconventional performance arrangement, one that promotes a productive interaction among the performers, the auditors, and the surrounding environment.

Even more generally, though, Brant's unusual negative instructions should cause us here to reconsider, in the broadest possible terms, the modality of notation. Usually, it is thought to tread a careful, sometimes fuzzy, line between "prescription" and "description"- between showing what ought be done and documenting, however crudely and imprecisely, what was done. ${ }^{41}$ Beyond this binary, it usually goes without saying that notation functions positively: a note appearing on the " $F$ " line does not mean to play an "E"- except, perhaps, in the case of a transcription error or an indecipherable note. In Verticals Ascending, however, something entirely different happens. As the notation forecloses-visibly and indisputably—a familiar and comfortable spatial situation, it simultaneously introduces a third term: not only can notation balance prescription with description, but also with prohibition.

\footnotetext{
41 John Spitzer and Neal Zaslaw argue that a similar distinction, though muddied and complex, applies also to representations of seating and placement. (John Spitzer and Neal Zaslaw, Birth of the Orchestra: History of an institution, 1650-1815 [Oxford: Oxford University Press, 2004], 345.) In addition, a fascinating investigation into the gap between "prescription" and "description" at the intersection of notation, music theory, and modern recording technology can be found in: Alexander Rehding, "Wax Cylinder Revolutions," The Musical Quarterly 88, no. 1 (Spring 2005): 123-60.
} 


\section{Relation to Earlier Forms}

An important question to consider is whether these images really are "sound maps" in the same sense as environmental maps or acoustical diagrams. The answer, I believe, is yes; and the reason can be traced to the definition I proposed in Chapter 1 . "Sound maps," I suggested, are defined not only by their surface appearance (i.e. their relative map-ness) or by their prospective uses (e.g. navigation, way-finding, etc.). They are defined also by the extent to which they reflect an awareness of the dynamic world in which they operate. Which is to say, sound maps do not merely show the world, they ask us to appreciate and value it in a certain way, by viewing the relationship between sound and space as internally differentiated—what Deleuze and Guattari call "univocal." In doing so, they resist absolute universalization while simultaneously reflecting a distinct way of thinking about the environment and making use of it. Sound maps in musical notation, particularly well-exemplified by Xenakis' score for Polytope, expect aural difference without, as Oswalt suggests, imposing homogeneity.

In that sense, these musical scores are sound maps, not only in a superficial sense - because they utilize rudimentary forms of spatial representation—but because they embrace the creative influence of the physical environment. Space, they suggest, is not only someplace to be played in but a medium to be played with. It consequently has to be configured differently from performance to performance, from site to site, not just for logistical reasons, but for acoustical and even political ones. This means, in some instances, that only one or two physical situations are acceptable; in others, different arrangements are possible, and performers are allowed to experiment until they find one that works. But the end result in either case is by no means Platonic. It is rather a 
contextually and circumstantially limited configuration-ideal, perhaps, but only contingently. So, while Brant stipulates clearly a "forbidden" arrangement, and Oliveros requires abandonment if the prescribed conditions cannot be met, the approved alternatives are not universally desirable. They "work," but only for one piece, one context, perhaps only one physical site.

By comparison, some seating diagrams function in precisely the opposite way: they foreclose both space and experimentation in pursuit of a singular ideal. One notable and important example is the diagram of the Dresden opera made by Jean-Jacque Rousseau. (Figure 4-8) This image, first published in Rousseau's Dictionary of Music from 1775 , and subsequently widely reproduced, shows the "first orchestra in Europe" to be "best distributed, and which form together in the most perfect manner."42 It is presented not just as a visual aid or a descriptive representation of a particular performance, but as an almost scientific demonstration, one that can be used to assess the "whole distribution" of the orchestra ${ }^{43}$ Rousseau explains what this means:

[The true distribution of an orchestra is a care not to be neglected. We owe in great part to this care, the astonishing effect of the symphony in the operas of Italy. The first, attention is paid towards the fabric of the orchestra, that is, of the materials which it contains. They give it propositions proper for the symphonists to be most assembled and distributed in the proper manner. They take care to make the case of it of a light thin wood, to establish it on a vide, with arches for supporters, to remove the spectators from it by a partition placed in the pit, at a

42 Jean-Jacques Rousseau, "Orchestra," A Dictionary of Music, translated from the French by William Waring (London, 1775), 302.

43 Spitzer and Zaslaw point out, however, that other theorists and performers during this time period seemed to be more flexible in their expectations for placement and seating. They point out that "[Francesco] Galeazzi, comparing [two different seating plans for an orchestra placed in a pit], remarks that the Dresden layout is better for maintaining ensemble but that the Turin plan is better for projecting a uniform orchestral sound to every corner of the theater." (Spitzer and Zaslaw, Birth of the Orchestra, 352.) Needless to say, sound "phasing" was not viewed as something positive: in the first case, it had to be dealt with and accepted; in the second, it could be avoided. But the ideal, in either case, seems to be the same: uniformity, whether at close or distant range. 
foot or two distance, so that the body of the orchestra, being in a manner borne in the air, and touching hardly any thing, vibrates and resounds without any obstacle, and acts as a large instrument, which answers to all the rest, and increases their effects. ${ }^{44}$

As explored here, the most important reason to exert spatial control is to enhance the orchestra's sound-that is, a reified orchestra: any or even all of them. Much like a violin or cello individually, the orchestra is described collectively as sounding like a single instrument - a vibrating body that needs not only time and physical space to resonate, but a certain material context. It is for this reason the orchestra must be carefully separated from the audience by "thin wood," which functions not only protectively-since touching the orchestra would, no doubt, dampen its sound-but to harness its collective vibrations. As a barrier, the wood serves a dual purpose: not only is it a functional division, but a political one that inscribes the distinction between "us" and "them" into the physical space of performance. ${ }^{45}$

Rousseau's comments may seem entirely unremarkable, since they present a view that was generally accepted as true for the time. ${ }^{46}$ Significant, nonetheless, is the way

44 Rousseau, "Orchestra," 302.

45 Some critics have found such divisions problematic. For instance, see: Christopher Small, Musicking: The Meanings of Performing and Listening (Hanover, $\mathrm{NH}$ : University Press of New England, 1998).

46 Spitzer and Zaslow go one step further than Rousseau, arguing that the development of orchestral placement can be understood in terms of acoustics. They write:

[I]n a large room like a theater with a high ceiling, the sounds of the orchestra tends to dissipate upward; in addition much of the sound will be absorbed by the spectators and by the upholstered interiors of the boxes. Placing the orchestra in the pit helps to address these acoustical problems. (361)

This assessment-though certainly technically accurate-is nonetheless ahistorical. The relationship between upholstery and absorption, for instance, though commonly understood today, was not established until the late 19th century. See: Wallace Clement Sabine, Collected Papers on Acoustics (Cambridge, MA: Harvard University Press, 1922). 
they identify (what Rousseau thinks is) an idealized orchestral sound and (what he understands as) universally-applicable principles-which can themselves be translated or transferred onto any particular space. And in that sense, Rousseau's remarks have a further implication: they can be used to determine the "best" seat for each member of the orchestra individually. 47 "In regard to the interior distribution," Rousseau writes:
we must be careful, first, that the number of each kind of instruments be proportioned to the effect which they should all produce together; that, for instance, the bass should not be stifled by the treble or stifle it; that the hautboys should not predominate over the violins; neither the seconds or the firsts. Secondly, that the instruments of each kind, except the basses, should be collected together, for them to agree and move together with more exactness. Thirdly, that the basses be dispersed around the two harpsichords, and throughout the orchestra, because it is the bass which should direct and sustain all the other parts, and all the musicians should equally hear it. ${ }^{48}$

These directions might be read in one sense as broadly symptomatic: yet another imprint of continuo practice, though left this time on the spatial environment. Indeed, what Rousseau describes here as the ideal orchestral arrangement- - one that remains ideal regardless of any local or specific constraints - is where both bass and harpsichord are a pervasive presence, acting as a physical, literal, and sonic scaffold around which the rest of the orchestra is built.

Put in a limited context, this diagram, and the explanation that accompanies it, might be read as foregrounding how space and sound are, in fact, mutually implicated. But given the broad, universalizing justification Rousseau provides, I want to suggest the opposite: unlike Xenakis or Brant, the physical environment for Rousseau is not something to be played with, but rather contained: made subordinate to a particular sonic

\footnotetext{
47 Rousseau, "Orchestra," 344.

48 Ibid., 302.
} 
ideology. Space is not valued for its internal or creative differences; it is rather thought to present practical, material, and even political hurdles that must be overcome, workedthrough, and forced into alignment with a coherent musical logic. ${ }^{49}$ In that sense, Rousseau's diagram behaves more like aspiration than notation, diagramming an idealized musical-spatial utopia.

At the same time, it is important to acknowledge how the maps of Brant, Xenakis, and others, do exert control—over space, over bodies, over sound. What separates them from Rousseau's map, however, is the kind of control they exert. Though different in countless other respects, each of these later maps shares at least one feature in common: an underlying belief that it is okay, even desirable, for music to sound differently from place to place during performance- - sometimes radically different, at other times, just differently enough to encourage open dialogue among performers, the audience, and the context of performance. The function of these maps, in any case, is seldom to ensure consistency; neither do they address anything resembling a (universally) "best distribution." Space appears, instead, as a resource that can be used to create interest and variation, rather than hold it in check.

In the second section of this chapter, I will push the study of sound maps even further by exploring what happens when all remnants of traditional notation are abandoned. Where each score discussed so far has found sound maps side-by-side with other, more familiar musical signs and symbols, it is not unusual to find those elements squeezed out, forced "open." What remains-the image of the map and perhaps a few

49 Daniel Chua, Absolute Music and the Construction of Meaning (Cambridge: Cambridge University Press, 1999). 
textual instructions-becomes the defining feature of the score, and in consequence, the principal and sometimes literal object of performance. As I will suggest, these scores represent a tectonic shift in the materiality of music, one whose results specify clearly where sound should be made (or encountered) without implicating any particular quality or characteristic of sound itself.

\section{Section II: Maps and Places}

The scores I will discuss in this section make prominent use of spatial representation—usually cartography, but also photography and other ad hoc diagrams. In that respect at least, these maps very much resemble the analytical varieties discussed in Chapter 2. Different, however, is the process by which sound comes to be implicated on the surface. On these scores-what I will call "map scores"- specific sounds are not always known or anticipated in advance. Rather, sound is encountered simultaneously with its placement in space-in fact, in some cases, the encounter is the means of placement. This further suggests the primary function of these maps is different: rather than documenting sound (acoustic or psychoacoustic; empirical or remembered), map scores are designed to enframe the physical environment as sonically rich. They identify a location, circumscribe or contextualize it as already sonically charged, then situate a performance there. ${ }^{50}$ Often, this is done without predicting which sounds will, must, or should be heard, by whom, how, or when.

In unusual circumstances, a map score can be made through (re)interpretation. Experimental and graphical scores are particularly amenable to this treatment since they

50 Certainly this owes some philosophical debt to John Cage's so-called silent work, 4'33". 
provide ample room for performers to re-imagine what various lines, squiggles, dots, and dashes mean. ${ }^{51}$ In one such instance, performers exploited the structural vagueness of Cornelius Cardew's Treatise to redefine both what and how notation functions. As Virginia Anderson reports, a group of improvising students at De Montfort University placed a copy of one page on the floor. This page was then used to indicate areas in the performance space in which musical events would happen. As a map, the symbols stood for movement and location, and may not have had anything to do with the resulting sound. 52

While the notation was certainly utilized and read in an unusual way, it is by no means clear, as Anderson suggests, that it no longer has "anything to do with the resulting sound." What this particular interpretation did was to change the referential object of notation itself: rather than indicating some aspect of pitch, timbre, or time in the abstract, it was performed as though it identified a physical spot in real space where sound was to be produced-whatever the sound, however it is made. Although unorthodox, the notational marks even during this performance did retain a connection with the resulting sound.

While indeed unusual, there is precedent for this kind of performative reinterpretation even in Cardew's published work. Written for a solo performer, the score for Memories of You consists of a single page filled with small vignettes-a series of small circular diagrams arranged into columns and rows. (Figure 4-9) Each vignette

\footnotetext{
51 Karkoschka, Notation in New Music, 77. Karkoschka finds this among music without a pitch/ duration lattice. The performed result "depend[s] on the interpreter's judgement far more than it does with a work based wholly on an untraditional drawing but having precise instructions at important points."

52 Virginia Anderson, “'Well, It's a Vertebrate...': Performer Choice in Cardew's Treatise 1," Journal of Musicological Research 25, no. 3/4 (December 2006): 291-317. http:/l www.tandfonline.com/doi/abs/10.1080/01411890600840578 (accessed 12 October 2011).
} 
contains a small icon, representing a piano, and a dot, representing sound. While it appears quite similar to John Cage's notational fragment "BT," from the Concert for Piano and Orchestra, ${ }^{53}$ (Figure 4-10) Cardew's notation is not strictly referential. Cage's notation shows more or less clearly which keys, key areas, or strings on the piano should be utilized during performance-to the point that an ambitious performer could write-out their realization on a traditional clef. By contrast, Cardew's vignettes indicate only the general location around, behind, or near the piano where sound should be produced: in the crook, or at the far end of the sound board.

Aside from lateral position, each dot indicates the general height at which sound is to be produced. Solid dots indicate a "sound made at floor level;" open dots indicate "sounds made above floor level;" and half-solid dots indicate "sounds made both on the floor and above the floor." ${ }^{54}$ Instrumentation, meanwhile, is determined by the location of each diagram within one of several rows and columns-labeled A, B, or C. Each letter refers to a particular object, such that "all sounds in a chain headed B are to be made with the object B." 55 Beyond this point, further sonic considerations, like dynamics and duration, are left unspecified. Even time is only loosely notated. Cardew explains that each diagram, in each row or column, is to be performed sequentially, although the specific direction-e.g. from the top down, or left to right—remains for the performer to choose. Any single diagram, however, may be played "once only," meaning shared

\footnotetext{
53 John Cage, Concert for Piano and Orchestra (New York: Henmar Press, 1960), 54.

54 Cornelius Cardew, Memories of You (London: Universal Edition, 1967), 2. 55 Ibid., 2.
} 
diagrams, those at the intersection of columns and rows, are to be skipped after their first use.

The piano, for its part, is left un-played throughout-at least in any conventional sense of "piano playing." While Cardew imagines "[t]he pedal may be engaged throughout the piece," suggesting it might serve as a giant resonator, it would be more accurate to say the piano functions as a fixed object: an idea around which the performer and performance both literally and conceptually circulate. Different from Cage's "BT," then, which seems comparatively focused on keys and strings, depressed or struck in a predictable fashion, ${ }^{56}$ Memories of You adopts a much broader view of what it means to "play" the piano: it can be played by playing in the space around, above, or below it; it can be played without being touched, using another instrument entirely. In a much more direct way than performative reinterpretation, then, Memories of You asserts an unconventional purpose for notation more broadly. While addressing, in a limited capacity, the qualities or types of sound that should be produced in performance-for instance, by identifying an instrument (by letter) or a general sequence of events (by column or line)-its defining characteristic is the way it specifies location and proximity, first and foremost.

Other scores from around this time period utilize notation similarly, although the final effect is sometimes more overtly theatrical. The score for Titus number 1 for amplified automobile, composed by American experimentalist Brian Moran, for instance,

\footnotetext{
56 The instructions included at the start of Concert... explain: "notes give place of performance with respect to piano." This suggests each dot might indicate a pitch: played on the string or on the keyboard. This is quite a significant difference from Memories..., since, except for its resonance, the piano itself remains un-touched.
} 
features a single page filled with ambiguous marks and squiggles, some of which bear a vague resemblance to traditional musical signs. (Figure 4-11) This page is to be copied onto a transparency then projected onto the side of a car. The result indicates "areas of activity"-presumably the marked/squiggled spots, not the blank ones-much in the same way Cardew's Memories of You does: by showing the performer which parts of the car to strike, rather than detailing the final sonic outcome. ${ }^{57}$ Moran further explains:

The automobile is amplified in a variety of manners; the performers, using contact mikes, hammers, files, metal scrapers, toilet plungers, etc., move slowly under, through, on top of and around the automobile. $\cdots$ After the score has been projected upon the automobile, and the performers have decided upon their individual working areas, the stage should be darkened. The performers use flashlights as they play the automobile. 58

The resulting spectacle gains further ironic overtones through playing a recording of "Brangane's Warning" from Tristan and Isolde, "softly and repeated numerous times," in the background.

Beyond these instructions, numerous practical and logistical concerns remain: how large the projection should be, where it should be aimed on the car, or even more generally, what kind of car to use. Depending on the brand or model chosen, one might imagine quite different sonic results. If hoods and doors rattle and resonate, roofs and windshields are likely to produce a dull thud; an old Chevy made of sheet metal would certainly make different sounds from a modern Mercedes. These same variations apply to the tools of assault: plungers and pipes will both produce distinct sonic effects, while amplification adds another layer of uncertainty—one with so many possible outcomes as

57 Brian Moran, "Titus number 1 for amplified automobile," in Source: Music of the Avant Garde 2 no. 1 (1968), 80.

$58 \mathrm{lbid} ., 80$. 
to render each performance nearly impossible to anticipate. Like many indeterminate compositions, none of these details are of any concern - or at least, the notation is indifferent towards them. The only aspects of performance addressed with any sort of specificity is where sound should be produced, which, in the case of Moran's score, means the literal site of each curve, scratch, or squiggle.

The scores for Titus... and Memories... might plausibly be considered a form of tablature; but in that case, it would be tablature of a very strange kind. Despite adopting an otherwise "spatial" mode of instruction, most tablature is otherwise quite specific about what sounds should be produced—for instance, by indicating which exact key should be pressed, which frets should be used, and in what order. ${ }^{59}$ But in these two works, the notation has no specific regard for the instruments, the performers, or the configuration of an instrumental interface (e.g. keyboard, fretboard, pedal). In that sense, it might be tempting to label these "event scores" or "action score" since, in a fundamental way, they provide directions for doing something - something whose very doing happens to result in the production of sound. But unlike most event scores, these do not say with any particular care what actions should be done. Instead, they behave as maps normally do: they circumscribe a territory, one that can be navigated any number of different ways, allowing for the actualization of a specific goal only the reader knows. Map scores, that is to say, do not mandate that a particular path should be followed, in a specific order, when, or how. While they often depict space with great care--though not without bias - they often leave details of use outside the frame. Likewise, map scores

59 Juraj Kojs, “Notating Action-Based Music," in Leonardo Music Journal 21 (2011), 66. 
present a field of possibilities where action and sound are deeply implicated, but where the exact outcome is indeterminate: shaped by the aesthetic sensibilities, the environment, and of course, the physical position of the performer.

\section{City Scale}

The idea to enframe space as the site of performance, sound, and audition becomes especially compelling in the work of composer Stuart Marshall. In the early 1970s, Marshall left Britain to attend Wesleyan University, where he studied composition with Alvin Lucier. Lucier is, of course, best known for his composition "I am sitting in a room," which has been variously explained as a demonstration of the contingent intelligibility of language (and its only incremental difference from music), ${ }^{60}$ or as a performance of raw space, as a slow unfolding of the fundamental pitch of the room where it is performed ${ }^{61}$ It may not be surprising that similar spatial and sonic indeterminacies feature prominently in Marshall's compositions. What is surprising, however, is the kind of notation he used to produce them. Where Lucier's notation very

60 This seems to be the reading favored by Lucier himself, who explained that " am sitting in a room," along with Steve Reich's Come Out, "employ repetition to turn everyday speech into music," and "are perhaps closer in spirit to alchemy, whose purpose was to transform base metals into pure gold." See: Alvin Lucier, "Origins of a Form: Acoustical Exploration, Science and Incessancy," Leonardo Music Journal 8 (1998): 11.

${ }^{61}$ Golo Fölmer has argued that, "in reality, what we are hearing is only different stages of one and the same phenomenon: the specific resonance of a space ... now the space expresses itself in the reverberation of a sounding object whose own sonic quality is only a coloring addition to the experience of space. The space changes from the surrounding context to the object." See: http://www.medienkunstnetz.de/themes/overview of media art/audio/1/ (accessed 24 August 2011). 
often relies on textual maps, ${ }^{62}$ Marshall made extensive use of visual representation in the form of maps and photographs which, at first, seem hardly related to the production of sound or the performance of music at all. At the same time, Marshall abandons whatever remnants of conventional notation remained for someone like Cardew or Moran, including highly stylized allusions.

Several of Marshall's pieces are worthy of mention here, all of which were part of his composition Zones, published in Source Music of the Avant Garde. ${ }^{63}$ One of them, titled "Golden Hill," (Figure 4-12) was named after the site in Monmouthshire, Wales where it was to be performed. In this piece, four auditors stand in place while four ice cream vans drive winding routes through town. As a van becomes audible, a performer is instructed to fire a flare gun into the air. And the result, as one can imagine, is not only sonic ("bang") but visual ("flash") —and at varying distances and points of view, it is likely to be perceived as visual before becoming sonic. Another piece, "Usk," inverts this procedure. (Figure 4-13) Here, seven sound producers (presumably radios or speakers) are scattered throughout the landscape surrounding the town. Auditors, this time mobile, wander the landscape with the intention of avoiding each stationary sound. Should they be encountered, however, the performer is instructed to produce some kind of "pulsed

62 "I am sitting in a room," for example, is more of an explanatory text than anything else. It explains the process by which the composition is performed, the various steps that have to be taken to perform it, and even what the results demonstrate. Textual instructions seem suitable for this work--while its object is the creative sonic potential of space, the larger message is that space can be reduced, simplified, generalized into a single pitch. This is quite different from Marshall's work, which, though less localized, does not reduce space or the complexity of sound to "fundamentals," but instead utilizes it's complexity as experienced, unmediated, in lived time.

63 Stuart Marshall, "Zones (1969-1970)," Source: Music of the Avant Garde 10 (1972): 5-29. 
sound," then move away. ${ }^{64} \mathrm{~A}$ third piece, "Synchronized Door Slam," is in some ways the most structured, although the notation is the least specific. (Figure 4-14) The score depicts an unrecognizable village, possibly in Wales, and calls for any number of performers, in any number of places, to slam doors in a synchronized fashion: maybe all at once, or maybe in sequence-again, the score is not specific about either sonic or temporal details.

In each of these pieces, we are challenged to think about the relationship among notation, sound, performance, and space in an unorthodox way. In "Golden Hill," for instance, the performers produce sound by creating light; in "Usk" sound is not supposed to be heard or enjoyed, but ideally avoided. Just as unorthodox, however, is the appearance of the notation itself. Marshall does not use traditional signs or anything remotely resembling them; an environment or situation, more broadly speaking, is the focus instead. Marshall uses notation to place a sonic experience, to enframe where it is to occur. Meanwhile, the physical position of objects and things is notated quite specifically—although the implications, the performed actuality of the notation, remains highly variable. As heard, a synchronized door slam, performed at the urban scale, might well become a slow "whoosh" rather than a quick "smack," simply by virtue of the speed at which sound travels. The fluidity and unpredictability of weather could also become important. If conditions are windy enough, the performers in "Golden Hill" waiting to

\footnotetext{
64 There is some confusion about the titles and instructions for these two pieces. In the original publication, the text-instructions for "Usk" better fit the map for "Golden Hill," and vice versa. Lucier's description seems only to reaffirm this combination in his article, "On Stuart Marshall." Nonetheless, this looks to me like a publishing error in the original edition; and my description of these works rectifies this puzzling series of misprints by re-matching the each set of instructions with the score that fits most logically.
} 
launch flares may never get to pull the trigger. Unusual, then, is the way that space, and to a lesser extent, behavior, is shown quite carefully, while the specific sonic outcome is left for the environment, for the indeterminacies of weather, time, distance, and human movement to complete. ${ }^{65}$

In some respects, Marshall's music might be said to resemble the installations of Max Neuhaus. Neuhaus was a classically-trained percussionist who, after encountering the writings of John Cage, eventually turned his attention to sound sculpture and placebased sound art. Among his most notable projects are Sound Figure (2007), where speakers projected ambient sounds on a walkway outside the Menil Collection in Houston, TX, and Drive In Music (1967), which positioned loud speakers on a roadway, so that auditors passing through in a car would encounter a series of sonic fields. ${ }^{66}$ These installations, and others like them, include a visual component, what Neuhaus calls a "circumscription drawing." ${ }^{967}$ As Yehuda Safran colorfully explains, Neuhaus' unique skill here is his ability to "extract from the incessant flight of sound forms, by means of memory and intelligence alone, the tentative trembling icons of the sound of human

\footnotetext{
65 Umberto Eco, The Open Work, translated by Anna Concogni (Cambridge, MA: Harvard University Press, 1989).

${ }^{66}$ Marshall composed a work much like this. Titled "Doppler," and also part of Zones, Marshall's work designates the position of 12 fixed sine wave generators and associated amplification equipment, which were to be mounted ("six feet above the central shoulder of the motorway") on the M5 south of Birmingham, UK.

67 Neuhaus has himself explained the conditions under which these drawings are made: "After finishing a sound work, if time allows, I wait several months before listening to it again. This is the first time I can stand outside the work and see what it is that I have made. It is only at this point after experiencing the work with distance that I make its circumscription drawing." See: "Drawings," http://www.max-neuhaus.info/drawings/ (accessed 24 August 2011).
} 
sensibility."68 In more straightforward musical language, these images are what might be called descriptive notation: a translation of something heard or experienced into a relatively stable, fixed, and reflective text. It just so happens that, in this case, the text adopts spatial representation as its medium.

Marshall's notation functions quite differently by comparison. For one, its goal is to help us create new sonic environments and new aural experiences, not to visualize reflexively ones that already exist. More like the notation of Moran or Cardew, Marshall's scores function like maps: they present an environment where a possible experience could be had, but without stipulating too strictly which paths to follow, and without any certainty of which sounds will be made or encountered along the way. In that respect, Marshall certainly owes some conceptual debt to Lucier, but his work also resembles Flux art for its apparent embrace of the ordinariness of the everyday. ${ }^{69}$ It challenges the notion that music is (or ought to be) a specialist or professional matter, and instead reframes it as something even untrained people can do. Marshall's notation does not require any special training to read or think about. It can be understood and performed without much technical difficulty, more like an event score by LaMonte Young, George Maciunas, or Alison Knowles. ${ }^{70}$ Also striking is the way Marshall's notation leaves in-tact whatever preexisting conceptions about spatial representation we

68 Yehuda Safran, "Drawings," in Max Neuhaus: Sound Works, vol. II, (Ostfildern-Stuttgart: Cantz, 1994), 7-8.

${ }^{69}$ As far as I can tell, Marshall had no affiliation with Fluxus-although the group's popularity throughout Europe and the northeastern United States throughout the 1960s and 70s suggests some circumstantial associations were possible.

70 For an excellent analysis of the importance of language to art event scores and the ontology of music, see: Liz Kotz, Words To Be Looked At: Language in 1960 s Art (Cambridge, MA: The MIT Press, 2007). 
bring with us. That is to say, even if all of the performance instructions were erased from the surface, each map and photograph would remain readable.

Indeed, what Marshall composes, and what his scores seem to represent, is the transformation of music from a sonically determined experience to one that is primarily determined by space. And this should underscore a final, unusual feature about his notation: its temporal flatness. To the extent Marshall's scores show when anything should occur-for instance, when an ice cream van will turn a corner, or when a door will be slammed - time itself is only ever implied. The path of each truck appears all at once, simultaneously, while doors remain either invisible or indistinguishable. Without any explicit prescriptions for speed, duration, or the simultaneity of events, this notation can be said to differ even from a score like Memories of You, which, at the very least, provides a film-like translation of snapshots. Instead, time in Marshall's work is blurred, condensed into a single frame, more like a time lapse photograph.

\section{(Hyper) Sound Maps}

Marshall's notation is unusual for relying so heavily on spatial representation, but it is certainly not the most "extreme" or unusual kind of map score. In other cases, notation moves away from actual cartography and instead resembles (what might be called) a "hyper-map." As Baudrillard explains of hyperreality in general, these maps are defined by preceding what it is they represent - when the map emerges as essentially 
fictional, backed by no actual corollary in real space, but is treated as though it mediates a place already and fully real. ${ }^{71}$

A fascinating example of a hyper-map score can be found in the work of Brazilian pianist and composer Jocy de Oliveira. Though best-known as a performer of Olivier Messiaen's piano works, de Oliveira turned her attention during the 1960 s and 70 s to composing experimental music with strong political overtones. Along the way, she proposed a number of spectacular and fantastical visions for how the environment could be played with, and to maximum creative effect. ${ }^{72}$ The score for Probabilistic Theater I is a collage made from different maps, only parts of which are identifiable: the border of Alabama and Mississippi, the western Mediterranean Sea, the Baltic Sea, parts of Italy outside of Milan, and a slice of Ankara, Turkey. (Figure 4-15) Despite obvious differences in scale and geophysical location, each fragment is sutured along thick black lines, what are explained in the score as "roads." 73 The combined image shows a

71 Very early in his essay "The Precession of Simulacra," Baudrillard explains:

Today abstraction is no longer that of the map, the double, the mirror, or the concept. Simulation is no longer that of a territory, a referential being, or a substance. It is the generation by models of a real without origin or reality: a hyperreal. The territory no longer precedes the map, nor does it survive it. It is nevertheless the map that precedes the territory-precession of simulacra ..." (Jean Baudrillard, "The Precession of Simulacra" in Simulacra and Simulation, translated by Sheila Faria Glaser [Ann Arbor: The University of Michigan Press, 2004], 1.)

72 In Polinterações - which calls not for a performance, but a series of "experiments in perception of sound, situations, sensations, visuality, ethics, time and movements"-de Oliveira proposes the creation of a series of physical environments, a "Main-Space" and a series of "Sub-Spaces." Sub-Space 1 is a human-sized kaleidescope designed to "stimulate the action of other kinesthetic sense organs as well as the visual;" Sub-Space 2 is a blow-up plastic enclosure, which the public inflates to the point of smashing the occupants. (Jocy de Oliveira, "Polinteraçōes," in Source: Music of the Avant Garde 4, no. 2 [July 1970]: 66-70.)

73 Jocy de Oliveira, "Probabilistic Theater I," in Source: Music of the Avant Garde 2, no. 2 (1968), 36. 
"symbolic town,",74 one that is to be traveled and traversed during performance. While a "traffic conductor," dressed to represent "any high rank," coordinates physical movement from a tall platform, a group of performers-including musicians, actors, and dancersmove among different areas of the hyper-town, performing, as instructed, along the way. ${ }^{75}$

Each enclosed section of the map, called a "frame," features a grid with four squares-some colored white, others orange—each labeled using a number to indicate the type and kind of performance that should take place there. The instructions are quite complex and would certainly require time and study to prepare. De Oliveira explains:

[a] white square represents an empty event, and a yellow one is to be considered a full event. They are both directed by the conductor who acts at this moment (during frames) as an orchestra conductor. He should use as many frames as possible and avoid long durations in each.

The numbers in the square are to be interpreted as event-time, 1 representing a short event and 2 a long one. How full and how empty, how long or how short the events are, is determined by the conductor. $\mathrm{He}$ is to consider a performer only as a part of his media in order to build an event in length or action.

The performance, as de Oliveira imagined it, is to take place in "an arena-like theater or a three-quarter amphitheater," ${ }^{96}$ although the performance record suggests a more modest setting. (Figure 4-16) Photographic evidence further suggests, unlike the performance of Cardew's Treatise discussed earlier, the map was not itself transposed onto the floor.

Rather than having performers move literally on top of it, the map was projected from a $35 \mathrm{~mm}$ slide onto a vertical surface, allowing the performers to see and move

\footnotetext{
74 Ibid., 36.

75 Ibid.

76 lbid., 35.
} 
sympathetically with each road. De Oliveira further describes the conditions of performance:

The conductor should be located in the center of the stage, high above, but visible to, the performers. His platform should not, however, obstruct the audience's view of the space behind him. It could either be suspended from the ceiling, or it could be supported on an open framework.

Meanwhile, the specific gestures and directions given by the conductor can be developed on an ad hoc basis, although the participants must all understand what each means: make up your own signals to interpret the score-map and be sure the performers clearly understand them. Do not speak during the performance. Act as a god! 77

While De Oliveira herself describes the piece as "an experiment toward an improvisatory action," it is also much more than that. The resulting hyper-environment, controlled, as it is, by a hyper-god, is temporary (lasting only for the duration of the piece itself), localized (constrained by the context and physical limits of the performance), and immediate (it has to be interpreted and performed simultaneously with its actualization). A crucial part of the performance is the way in which the "score-map," as de Oliveira called it, is transferred onto the space of performance. Since it possesses no useful resemblance to the physical world, the map functions as a kind of spatial Rorschach text: as an image which asks us to produce an immediate interpretation, one that will loosely guide the creation of a new space.

Of course, not all of de Oliveira's maps are quite so eccentric. Some, in fact, return from the realm of the imaginary to rely heavily on otherwise functionallyreferential cartography. Somewhat like the soundwalk maps discussed in Chapter 2, de Oliveira's work Treasure Hunt (urban event) instructs performers to use "their perceptive senses to explore their environment." After marking a central point on a map, a series of

77 lbid. 
concentric circles are drawn, then divided into narrow wedges using " 36 converging rays, each of which is separated by 10 degrees." (Figure 4-17) Each corresponding area in real space is then explored systematically: performers are told to travel using various forms of transportation, to document their experience on film or tape, and to bring "anything imaginary" along. ${ }^{78}$ The final product of this "urban event" includes not just objects found or sounds recorded, but the intangibles of experience - the memories and observations of the collectors. As de Oliveira explained, the purpose of Treasure Hunt is to demonstrate the way in which 'the work of art isn't found only inside the theatre, or the museum, but in the streets, on the corners, on the unknown faces of a city, in the life of each one... ${ }^{.79}$ The map, then, serves not just as a technical or geospatial guide, but as a kind of constraint, one that funnels and directs the movement and activities of the performers. More like Marshall's maps, it enframes an area, designates it as already rich with sound and experience. It outlines less a "happening" than a "not-yet-happened" in advance.

\section{Connections}

De Oliveira's compositions, and to a lesser degree Marshall's and Cardew's, might be said to resemble the work of Guy Debord, a leading member of the Situationist International during the $1950 \mathrm{~s}$ and $60 \mathrm{~s}$. Almost twenty years before Treasure Hunt, Debord imagined what he called a dérive_-"a technique of transient passage through varied ambiances"—entailing "playful-constructive behavior and awareness of

\footnotetext{
78 Jocy de Oliveira, Days and Routes Through Maps and Scores (Ramona, CA: Lingua, 1983), 94.

79 Ibid., 96.
} 
psychogeographical effects, which completely distinguishes it from the classical notions of the journey and the stroll." ${ }^{80}$ The dérive was developed in response to the much larger need to explain urban space in new ways, to dig "beneath the paving stones" in order to uncover how a city's identity is knit together ${ }^{81}$ Arguably for an entire generation of artists, architects, and musicians, the Situationists demonstrated how "the qualitatively or quantitatively different influences of diverse urban decors cannot be determined solely on the basis of the era or architectural style, much less on the basis of housing conditions." ${ }^{\prime 82}$

One tool closely associated with the dérive, both conceptually and functionally, is the psychogeographic map. Unlike more traditional forms of cartography, these maps are not in any sense linear or rational and share very little in common with space as it is traditionally understood - as a set of planar coordinates. The goal of psychogeography was not to aid navigation, but almost the opposite, to reflect a variegated encounter: "wanderings," Debord wrote, "that express not subordination to randomness but complete insubordination to habitual influences (influences generally categorized as tourism, that popular drug as repugnant as sports or buying on credit)." 83 The maps themselves were collages, made by "more or less arbitrarily transposing maps of two different regions." Perhaps the most famous example is The Naked City, created by Debord in 1957. It is, in

\footnotetext{
${ }^{80}$ Guy Debord, "Theory of the dérive," in Theory of the Dérive and other situationist writings on the city, Libero Andreotti and Xavier Costa, eds. (Barcelona: Museu d'Art Contemporani de Barcelona, 1996), 18.

81 Guy Debord, et al, Beneath the Paving Stones: Situationists and the Street, May, 1968, texts collected by Dark Star (Edinburgh: NK, 2001).

82 Debord, "Theory of the dérive," 20.

83 Ibid.

84 Ibid.
} 
many respects, a reconstituted dismemberment: an incomplete and almost disorienting image, made from a more traditional map of Paris, whose major sites have been disassembled then reconnected using a series of unlabeled red arrows. ${ }^{85}$ The myriad flows suggest, but do not explicitly identify, some kind of experiential affinity between each connected area. It is precisely by rearranging the map-sometimes literally marginalizing parts of Paris that might normally be considered central—-that a psychogeographic map proposes "a fragmented, subjective, and temporal experience of the city as opposed to the seemingly omnipotent perspective of the planimetric map."86

The musical scores I have discussed here might, in some ways, be thought of as instructions for a specifically sonic dérive. They enframe a specific environment, call us to wander through it, to perform in it, and listen to it. Sometimes they anticipate what we will hear (like the sound of ice cream vans and radios); at other times, they leave room for us to notice sounds that were unforeseen—or rather, "unforeheard." Simultaneously, there are at least two crucial differences between map scores and psychogeographic maps. The first is how they relate to the event. Psychogeographic maps reference an experience that has already happened: the drift. And while map scores might at times reflect an event that has already occurred, they are more commonly meant to guide those that haven't. The second difference is sound. Where psychogeographic maps reflect unspecified encounters, some of which may or may not be related to sound, map scores

\footnotetext{
85 For more on Debord and The Naked City, see: Simon Sadler, The Situationist City (Cambridge, MA: The MIT Press, 1998).

${ }^{86}$ Alison Sant, "Redefining the Base Map," Intelligent Agent 6, no. 2 (2006), http:/l www.intelligentagent.com/archive/Nol6 No2 interactive city sant.htm, accessed 18 November 2011.
} 
like Treasure Hunt or Zones are accompanied by an explicit assumption that sound is, as it were, always-already audible.

But it would be wrong to say that map scores are meant to be "used" in the same way it would be wrong to say that the The Naked City was designed to be read or followed. Many of them are otherwise silent on the question of what should happen and when; and furthermore, in some cases, the maps are not suitable for navigational purposes whatsoever. And yet, the reactions they elicit are likely to be similar. Map scores and psychogeographic maps disorient the viewer critically: they ask us to lose ourselves among the ordinary; they connect us to the world, by linking together different (and arguably overlooked) aspects of everyday experience, without saying how; they define a space for exploration, one that can be returned to, re-performed, drifted-through again.

These similarities in turn suggest other strong connections to the world of visual and performance art—specifically, place-based and site-specific environmental art. Certainly Robert Smithson's "Earth Works" should come to mind; but perhaps even more closely connected is the work of Richard Long, a British artist who first came to prominence during the 1970s. Long is well-known for his interest in the non-built environment, and his works often tell the story of a journey or experience using maps and other forms of spatial representation. One well-known example, On this Hillside, consists of a photograph, showing an unnamed site in England, and a simple, poetic description of something done there:

On this hillside I have walked five circles.

Each circle has been walked around for the distance of a quarter mile. 
The outermost

and most invisible circle of all

is a quarter of a mile around. ${ }^{87}$

There was no audience here, and there is nothing to be clapped for. Neither is this piece a dance or a performance that could be transferred to a stage. The site and the performance are woven together otherwise unremarkably. What matters is action and movement for its own sake - the unadorned relationship between the performer, a performance, and a place. The "art," then, is to be found not only in the final product, the representation, but in the tracing of lived experience that lies beneath.

Other works by Long gesture towards similar ends while making more explicit use of cartography - sometimes with, and at other times instead of, poetic description. This allows space to be clearly defined, sometimes at the expense of clarity in action and movement. A Walk of Four Hours and Four Circles, for instance, consists of a map, showing an area near Dartmoor forest in the southwest of England, with four concentric circles layered on top. Yet, what was done (or should be done) and experienced (or should be experienced) remains unclear. Except for the title, important details are left unanswered, including the direction, order, and speed each circle was walked. Part of what makes this work significant is Long's view of maps as "public, standardized, objective documents, [providing] readily available neutral grounds onto which the artist could chart both his idea and his course in a practical concrete manner." 88 The sense of objectivity they provide is important, even if problematic, because "[ $[$ ]o Long, a work of

87 Richard Long, On This Hillside, gelatin-silver print and pencil on printed paper, 1972, Museum of Modern Art, New York.

88 Dana Friis-Hansen, Richard Long: Circles, Cycles, Mud, Stones (Houston: Contemporary Art Museum, 1996), 17. 
art is created first in response to [his own] experience of nature; its resulting relevance to the art world has always been secondary." ${ }^{289}$ Maps distill this experience while not asserting their own identity too strongly. They are useful to Long because he views them as a straightforward way to highlight "the structural aspects of the walks." 90

Long's work might be characterized by its poetics and by the way it situates "the walk" as a fundamental, even formative, medium of aesthetic experience. While his maps share some striking similarities - both visual and conceptual—with map scores, they also have crucial differences. For example, Marshall and de Oliveira by no means view the map as a "neutral" or "objective" medium; for them, maps imply anything but detachment. They function, rather, to implicate the environment as an unstable and specifically sonic field—someplace defined not only by what has already been seen or experienced, but by what can be and, in some cases, can only be experienced there. Where Long's maps locate traces of his own body, map scores typically concern ours; like Cardew's diagrams for Memories of You, they designate or define a site for us to act within and move through—and sometimes suggest we do.

89 Ibid., 9.

90 lbid., 17. 
In the end, what map scores do is reterritorialize sound. ${ }^{91}$ The incorporation of cartography into musical notation can, in the first place, be thought of as what Deleuze and Guattari have called a "line of flight"-a sudden, if unexpected change, one that should prompt us to reconsider both what musical notation is and the material and sonic relationships it prefigures. In doing so, the map specifically, and notation generally, emerges expanded and enriched, both functionally and conceptually. Space no longer appears in the abstract or in the shadow of sound, but clearly and visibly as a place where sound is already audible, or at least ready to be heard. The map consequently acquires new potential and a new context. It functions both cartographically and as emplaced cartography - as a map that, to be understood, cannot simply be looked at optically but has to be engaged with haptically.

The act of making music consequently becomes a kind of game; and notation, the map, becomes the sometimes literal board on which it is played. While it may or may not constrain the possibilities for physical movement-as Marshall's notation prescribes the

91 Deleuze scholar Adrian Parr explains that "[r]ather than understanding deterritorialisation as destabilising that which produces meaning, in $A$ Thousand Plateaus Deleuze and Guattari regard it it as a transversal process that defines the creativity of an assemblage: a nonlinear and nonfiliative system of relations." (Adrian Parr, "Deterritorialisation / Reterritorialisation," in The Deleuze Dictionary, ed. Adrian Parr [Edinburgh: Edinburgh University Press, 2005], 68) Where deterritorialization "shatters" subjectivity, reterritorialization allows new forms of being to emerge, a process Deleuze and Guattari elsewhere call becoming. In one particularly memorable passage, they explain how new forms of being require initially self-differentiation:

One reterritorializes, or allows oneself to be reterritorialized, on a minority as a state; but in a becoming, one is deterritorialized. Even blacks, as the Black Panthers said, must become-black. Even women must become-woman. Even Jews must become-Jewish (it certainly takes more than a state). But if this is the case, then becoming-Jewish necessarily affects the non-Jew as much as the Jew. Becoming-woman necessary [sic] affects men as much as women. In a way, the subject in a becoming is always 'man,' but only when he enters a becoming-minoritarian that rends him from his major identity. (Gilles Deleuze and Félix Guattari, $A$ Thousand Plateaus: Capitalism and Schizophrenia, trans. Brian Massumi [Minneapolis and London: University of Minnesota Press, 1987], 291.) 
movement of ice cream vans, and de Oliveira's locates the position of hyper-roads - the specific outcome, including the sounds that will be heard, remains entirely virtual. Map scores guide but do not compel us to make sound. Neither do they cajole us to hear it in a certain way. As musical practice, map scores instead define the parameters of an encounter, provide a way for us to experiment with(in) it, to move through a space and notice sound. Crucially, they do this without requiring us to rearrange either our experience or what we hear into something else-something, perhaps, more conventionally "musical." What matters most is not any particular "outcome," but fostering a relationship among the constituent elements of each map: sound, the performer, the surrounding environment, and so on.

These developments are important because they prompt us to ask an unusual question about sound in general and music in particular: "Where?" Even from within the relatively diverse practice of experimental music notation, sound maps help to initiate a cascading series of tectonic shifts that challenge what we have conventionally and historically viewed as "essential" characteristics for music, while simultaneously drawing into question the characteristics we consider "essential" to the study of space and cartography.

\section{Conclusion}

In this chapter, I explored two ways sound maps appear in musical notation. The first was as work-specific spatial graphics. While seating charts are by no means a modern invention, these diagrams often have far reaching functional implications. As can be seen in the compositions of Steve Reich, Iannis Xenakis, Pauline Oliveros, and Henry 
Brant, maps are used not only to position people, instruments, and the audience, but to create a performance environment that is dynamic and differentiated: actualizing the diagram without due caution, or drifting beyond the designated envelope, may result in a failed or "unauthorized" performance. Indeed, as well as showing which arrangements should, may, or must be used, maps also prohibit certain configurations, or even force the abandonment of the performance entirely.

Sound maps also appear as "map scores." As discussed in Section II, this notational practice can be defined by its unusual reliance on spatial representationmaps, photographs, and other diagrams-rather than more conventional forms of musical signification. In some cases, the map remains functionally representational, referencing an actual place where a specific activity is to be performed; in others, the image is a hyper-map, showing a location that is, in effect, performed into existence. In both cases, these maps are unusual because they enframe the environment as already audible. From the beginning, they assume space is filled with sound that can be performed in and performed with. At the same time, they often stop short of specifying the qualities, characteristics, or even the exact temporal sequence of performance. Indeed, while the aural aspects are, to a great degree, left "open" in these works—-left for environmental and human indeterminacies to complete-they make clear spatial provisions by indicating where sound is to be heard, produced, or encountered. 


\section{Chapter 5: Sound Mapping the Utopian City}

Acoustic design is not merely a matter for acoustic engineers. It is a task requiring the energies of many people ... Artists, who have too long remained aloof from society, must now return to give direction to human navigation.

- R. Murray Schafer, The Vancouver Soundscape

\section{Introduction}

Where do sound maps lead us? As I have explored in previous chapters, sound maps are not just analytical tools: they have opened new experimental avenues in creative and artistic practice. From the staging diagrams of Iannis Xenakis to the cartography of Jocy de Oliveira; from the prescriptions of Steve Reich to the prohibitions of Henry Brant, sound maps, used as a form of graphical notation, change how and on what terms we relate to the performance of music — both the bodily act of making sound and the physical site of its production. In some extreme cases, like Memories of You by Cornelius Cardew, space becomes the priority. A particular quality of sound, or the particular sequence and simultaneity of sounds, matters less than the location where sound is to be made or encountered: above the piano, or a village in Wales. By reshuffling both material and sonic priorities, sound maps challenge recursively the boundaries of musical notation as they are traditionally understood. And in consequence, they empower us to make music cooperatively with, rather than opportunistically in, the surrounding environment.

But none of the sound maps I have analyzed address the most forbidding theoretical and practical challenge of sound-space interactivity: the configuration of the open air, the audible design of the city itself. Indeed, over the last twenty to thirty years, as soundscape and sound studies scholars have called our attention to the formative role sound plays in everyday life, they have also started to theorize as to how sound can 
become an agent of change and be utilized to improve our quality of life. In his book Acoustic Communication, for instance, Barry Truax explains how acoustic design is imperative in order to "create a balance between variety and coherence at the level of information exchange, and to create a functional equilibrium at the level of relationships within the community." Implementing a better, more thoughtfully considered soundscape would thus require both restructuring sound "to make it more informative and patterned,"2 and further modifying "relationships within the system, particularly those that have degenerated."3 In The Vancouver Soundscape, R. Murray Schafer likewise equated the city with "[a] huge musical composition ... unfolding around us ceaselessly. We are simultaneously its audience, its performers and its composers. ${ }^{14} \mathrm{He}$ furthermore argued the city's aural design should not be left simply to engineers. "It is a task," he wrote, "requiring the energies of many people: professionals, amateurs, young peopleanyone with good ears. $" 5$

While early efforts to compose (or rather, re-compose) the acoustic environment would require both close listening and systematic documentation—issues addressed earlier in Chapter 2 of this dissertation-it stands to reason that later stages would require implementing an intentional, thoughtful design. Yet Schafer, like Truax, provides little in the way of concrete details. He highlights the necessity of supporting noise abatement

1 Barry Truax, Acoustic Communication, $2^{\text {nd }}$ ed. (Westport, CT and London: Ablex Publishing, 2001), 114.

$2 \mathrm{Ibid}$.

$3 \mathrm{lbid}$.

${ }^{4}$ R. Murray Schafer, ed., The Vancouver Soundscape (Vancouver: A.R.C. Publications, 1978), 64.

5 lbid. 
organizations, and furthermore admits "we do not yet have enough facts to undertake the comprehensive acoustic design of the communities of the future," but the closest he comes to offering specific advice is by proposing:

...the erection of temples of silence ... temples where one could read or meditate ... We can also begin speculatively to prepare plans for acoustic parks, which would afford both reservoirs of stillness and areas where the ear and mind could be delighted in new and imaginative ways. ${ }^{6}$

It is surprising, if not paradoxical, that a soundscape scholar would suggest we escape from sound rather than seek out and embrace its creative indeterminacy. Moreover, the design solutions he recommends are nothing if not disappointing. "Acoustic parks," though clearly demonstrations of design, are diametrically opposed to fostering a deeper understanding of the urban ambience; likewise, if they are not already inconsequential, "temples of silence" would seem to provide an easy escape from the sounds of everyday life, possibly even a way to avoid them altogether. But Schafer is not alone in his escapism. Indeed, while arguing passionately for more harmonious cities, most plans to "design" sound at the urban scale resort similarly to discussions of noise mitigation, including the erection of highway barriers, ${ }^{7}$ the imposition of noise fees, ${ }^{8}$ or more generally, the need "for timely research into what is positive about the soundscape and how such knowledge can be effectively incorporated into policy." Equivocation,

6 Ibid., 66.

7 Urban Systems Research and Engineering, The Audible Landscape: A Manual for Highway Noise and Land Use, report prepared for U.S. Department of Transportation, Federal Highway Administration, Office of Research and Development (November 1974, reprinted August 1976).

${ }^{8}$ Committee on Appraisal of Societal Consequences of Transportation Noise Abatement, Noise Abatement: Policy Alternatives for Transportation (Washington DC: National Academy of Sciences, 1977).

9 Mags Adams, et al, "Sustainable Soundscapes: Noise Policy and Urban Experience," Urban Studies 43, no. 13 (December 2006): 2396. 
meanwhile, leaves unanswered important questions about how such a city would function sonically, philosophically, and technically — what it would sound like, and how the unstable aural textures of everyday life might be turned back on themselves.

The final chapter of this dissertation seeks to remedy these gaps and answer these questions, however provisionally, by exploring one area of research sound maps point toward: plans for the urban environment that make a concerted effort to anticipate the function and ideal role of sound in everyday life. In particular, I will examine the 1969 book La Ville Cybernétique, a kind of literary-utopian sound map written by Hungarianborn French sculptor Nicolas Schöffer. Not only does this text theorize the contemporary biopolitical subject, it provides a detailed explanation of how urban sound might be deployed cooperatively and creatively: re-composed, in real time, to create a pleasing sense place. Though Schöffer's work is occasionally mentioned in scholarly literature, it most usually appears in surveys on sculpture or cybernetics. ${ }^{10}$ To date, there has been no serious analysis of Schöffer's work on sound, nothing to cast in a critical light his plans to use the city as a site and source of musical invention (and intervention).

Consequently, this chapter will have two discrete goals. The first is to perform a close, sound-focused reading of La Ville Cybernétique. In Section I below, I will discuss the root social problems Schöffer observed in society and analyze how and why he believed sound could, once creatively and thoughtfully utilized, help to solve them. The second goal is to build a critical context around Schöffer's work. After examining why the Cybernetic City was greeted with skepticism, I will discuss how Schöffer's embrace

10 For instance, see: Julia M. Busch, A Decade of Sculpture: the 1960s (Philadelphia: The Art Alliance Press, 1974), 125-131. 
of participatory sound- and music-making, though mediated by machines, resembles what Jacques Attali saw optimistically as the future of music: "composing." In the end, this chapter will speak to some ideal (and idealizing) practices that draw upon the sound map as a way of thinking about and engaging with the everyday environment.

\section{Section I: Sensing Trouble}

In 1961, a large tower was erected outside of the Palais de Congres, near Boverie park in Liège, Belgium. Measuring some 52 meters in height, the scaffold-like structure stood in stark contrast to the sleek surface of the nearby façade of the Palais. But the tower was not just a static object; it was part of an artistic and technological spectacle: the literal focal point for a dynamic multimedia show, one that shifted in response to environmental fluctuations. Suspended from the tower's skeleton was a series of small arms, suspending 66 mirrors and 120 multicolor light projectors. (Fig. 5-3.) At nightfall, a bank of high-powered lamps would be switched on and aimed at the tower, dousing it in light and reflecting a chromodynamic spectacle onto the Palais. But there was more to the tower than could be seen. It was also connected to a computer system, which processed the collected data using "microphones for sound, photoelectric cells for light, thermometers, hygrometers, [and] anemometers." This information was later used to initiate an "ever-varied combination and numbers of movements, according to instruction given to the brain." 11

Called Chronos 3, Schöffer would explain in great detail how towers like this one could be used to remake the city. Far from museum pieces or works of public art, they

11 lbid., 107-08. 
could become tools capable of creating a more pleasing city, observing and responding to shifts in the urban ambience. ${ }^{12}$ In doing this, he believed, they could also help rectify some of our most vexing cultural ills-problems related both to over-consumption and a slackening in aesthetic sensibilities.

\section{Médiocrisation}

To begin with, Schöffer was unhappy with what cities had become. Like many of his contemporaries, including Yona Friedman and Constant Nieuwenhuys, Schöffer disliked how, following the Second World War, "the urban" had become increasingly synonymous with generic, large, confusing, and filled with cars. ${ }^{13}$ But rather than giving up-writing-off cities as places to be avoided or feared - he viewed them as places of promise, even creative potential. Schöffer outlined his vision for what the city could be in La Ville Cybernétique. ${ }^{14}$ The timing of its publication is worth noting: Schöffer's optimistic, even exuberant, effort to re-imagine the very texture of everyday life appeared at a time of tremendous social and political discontent. Aside from international upheavals caused by decolonization and persistent Cold War tensions, the world found itself more broadly engrossed by social uprisings, clearly articulated in the riots of Chicago throughout 1968 and the student uprising in Paris during May of that year. Little

\footnotetext{
12 Marcel Joray, ed., Nicolas Schöffer, introduction by Jean Cassou, with articles by Guy Habasque and Jacques Ménétrier, translated by Hakkon Chevalier (Neuchâtel, Switzerland: Éditions du Griffon, 1963), 148.

${ }^{13}$ Larry Busbea, Topologies: The Urban Utopia in France, 1960-70 (London and Cambridge, MA: The MIT Press, 2007).

14 Nicolas Schöffer, La Ville Cybernétique (Paris: Tchou, 1969), 135.
} 
surprise, then, that Schöffer chose to begin his book by stepping back from "real world" problems to dwell on where and why modern life had gone so terribly wrong. ${ }^{15}$

Central to his diagnosis was médiocrisation, which, he writes, can be understood first as "ignorance, the lack of information." While it is incumbent upon all people to be observant - for instance, in order to "establish a sense of direction, to acquire information, to remember it, and actualize its possibilities"-médiocrisation is the inevitable result of having too little information, or an abundance of low-quality sensory information. ${ }^{16}$ As Schöffer explains, however, médiocrisation is not meant in a pejorative sense to condemn any particular person or group of people. Rather, he hoped it would challenge the current emphasis on consumption by framing it in historical terms. But he also went a step further, suggesting that cultural and political elites are the executors and beneficiaries of médiocrisation, rather than more simply its exemplars.

Far from signifying health or prosperity, Schöffer argues our desire for specifically quantitative expressions of wealth, and moreover, our material capacity to actually provide that wealth, indicates an ominous socio-structural trend. Echoing Marx, he explains médiocrisation conceals a play of power, one presaged centuries ago:

The cultural elite of the Medieval rather easily obtained the support of the ruling class. Their artistic policy, first practiced for religious reasons, made extremely intelligent use of art. The Mass was the first audiovisual show [in] the Western world,

15 It is worth noting here that Schöffer's critiques of modern life share much in common with what Max Horkheimer and Theodor Adorno observe in Dialectic of Enlightenment. A full analysis of the similarities and tensions between them, however, will have to be left for another time.

16 Schöffer, La Ville Cybernétique, 15.

Le terme de médiocrisation ne doit pas être pris dans un sens péjoratif, mais envisagé sous l'angle de l'évolution et de l'Histoire. La médiocrisation, c'est l'anomie, le manque d'information. Chaque individu étant pourvu de sens qui lui permettent de percevoir les phénomènes ambiants, d'enregistrer des informations, de les mémoriser, d'exercer son combinatoire. La médiocrité résulte d'un niveau d'information extrêmement bas. 
a beautifully structured program, the perfect synthesis of all the basic elements of a total work of art: sound, light, space, ballet, mime, symbolic play. This setting provided for the use of religious ideas - as spiritual and political phenomenon-to facilitate greater control over médiocrisés. ${ }^{17}$

While médiocrisation today still hides political and cultural maneuvering, the site of the spectacle has changed. Rather than church, it can be found on television-which, by Schöffer's reckoning, consists of worthwhile content no more than $0.3 \%$ of the time. ${ }^{18}$ But it is not just television that promotes médiocrisation. Contemporary architecture and design do likewise, as do technological and scientific research more broadly. ${ }^{19}$ The latter may be particularly surprising, though, since science of all areas of inquiry claims to dispel ignorance - for instance, by encouraging the establishment of basic, empirical

17 Ibid., 16.

L'élite culturelle médiévale a obtenu assez aisément le soutien de la classe régnante. Sa politique artistique, pratiquée d'abord pour des motifs religieux, utilisa les ressources de l'art avec une extrême intelligence. La messe fut le premier spectacle audio-visuel du monde occidental, admirablement structuré, programmé, synthèse parfaite de tous les éléments de base d'une oeuvre d'art totale: son, lumière, espace, ballet, mime, jeu symbolique. Cette mise en condition servait l'idée de religion-phénomène spirituel et politique-et facilitait la mainmise sur les médiocrisés.

It is not clear what Schöffer means by "ballet" and "mime" here, since I can find no evidence that either were used in church during the Medieval period. While it is possible that Schöffer is using the word "mime" in a very broad sense, for instance, to reference ritual gestures like blessings, it is not clear how Schöffer believed dance was used. It may be a similarly broad use of the word, perhaps to reference kneeling, the kissing of papal rings, etc-but this much is purely speculation.

18 Ibid., 18.

II ne trouvera pas plus de $0.3 \%$ d'informations ayant une valeur quelconque sur le plan culturel ou historique.

19 Ibid., 24.

La fabrication de ces faux produits est massive. On crée des besoins artificiels, stéréotypés. 90\% des Français rêvent d'avoir un intérieur "de style." C'est là le côte inquiétant du problème. Jamais le passé n'incitera les individus à penser l'avenir, c'est-àdire à bouleverser l'état actuel des choses. Installés confortablement dans un environnement qui leur rappelle tout ce qui a été fait auparavant, ils ne pourront pas avoir de préoccupations prospectives. Le passé est un frein providentiel pour les manipulateurs et pour le système répressif actuel. C'est également une des causes de la collusion entre cette production du passé et les intérêts commerciaux de certains. 
truths. But it is here that Schöffer's alternate definition becomes important.

Médiocrisation is defined not just as a lack of good information, but also as an abundance of poor quality information—what might be called social, cultural, or sensory "noise."

From the perspective of sound studies, the latter definition of médiocrisation very closely resembles what $\mathrm{R}$. Murray Schafer has called "lo-fi" listening environments.

These are not places that are especially sound-poor, but rather environments so overwhelmed by large quantities of sound that very little sense or meaning can be gleaned from them. Schafer explains:

In a lo-fi soundscape individual acoustic signals are obscured in an overdense population of sound ... In the ultimate lo-fi soundscape the signal to noise ratio is 1 to 1 and it is no longer possible to know what, if anything, is to be listened to. The lo-fi soundscape results when accidental, trivial or boring sounds are allowed to proliferate unchecked. 20

Where lo-fi environments can be understood as victims of specifically sonic forms of excess - too many cars, too many airplanes, too many things that make sound-Schöffer likewise explains that médiocrisation more generally demonstrates our cultural desire for "always more." Quantity, in this analysis, precedes médiocrisation and is in fact principally responsible for it.

The suggestion that science and technology contribute to médiocrisation, intellectual "noise," therefore has crucial implications. Principally important is the way they were seen to replace religion as the primary purveyors of mythic truths. According to Schöffer, people were beginning to view scientific and technological advancements with a level of apathy similar to that with which they regard opaque religious ritualsnamely as things "beyond" or "outside" human understanding. In being both complex

20 Schafer, The Vancouver Soundscape, 48. 
and intangible, the developments of science and technology were reinforcing public bewilderment; in becoming the focus of our wonder and amazement-rather than a vehicle for our enlightenment-they frustrate as much as motivate our curiosity. ${ }^{21}$ Indeed, much as the spectacle of the mass facilitated the condensation of power into the hands of a select few, Schöffer worried that something similar was happening in the $20^{\text {th }}$ century. While manufacturing and mass production have allowed ordinary people to use technologically advanced consumer goods on a daily basis, the broader effect, Schöffer believed, was to discourage general cultural and scientific literacy. That is to say, in becoming so comfortable with sophisticated machinery, and moreover, familiar with the general existence of ontologically-difficult theories, ${ }^{22}$ people today believe science is either too complicated to understand or unnecessary to understand: simultaneously simple and unapproachable. One unfortunate result is that promising new technologiesespecially those like Chronos 3, which Schöffer believed could effect real cultural change

21 Schöffer, La Ville Cybernétique, 19.

Mais I'homme de science n'a pas été seulement utilisé, il est devenu complice de cette féodalité nouvelle, la science jouant un peu le même rôle que la religion dans le passé.

22 Slavoj Žižek, The Reality of the Virtual, directed by Ben Wright, Olive Films, 2007. Žižek argues quantum mechanics exemplifies what Lacan called the symbolic-virtual:

it's simply for example scientific discourse, scientific formulas ... that which resists symbolization, inclusion into our universe of meaning. And isn't it that which precisely happens when, for example, in quantum physics? What is quantum physics? Formulas which work ... but we cannot translate them into our daily experience ... we literally cannot understand it. Not in the sense that we-common people, idiots-cannot understand it, only a couple of scientists can; even they cannot. In what sense? In the sense that 'it just works;' but if you try to build a consistent ontology out of it, again, you get meaningless results. You get time running backwards, you get parallel universes ... you get things which simply are meaningless with regard to our ordinary notion of reality. 
- go largely ignored, assumed by ordinary people to be "unnecessary and inappropriate for their level of understanding. ${ }^{.23}$

It is worth noting, however, that Schöffer did not find material consumption itself problematic-at least not in a strict Marxist-materialist sense. For instance, he seems generally unbothered by issues of labor exploitation or the depletion of natural resources. His concern, rather, was that our interest in, and emphasis on, specifically quantitative expressions of wealth—not money per se, but "things" more generally—has resulted in a gross reduction in our quality of life: a proliferating sense of indifference, and a corresponding inability to interact meaningfully with the world and each other. Quantitative abundance had produced, in other words, a peculiar and paradoxical form of poverty, one expressed simultaneously by overfamiliarity and under-education, overstimulation and underutilization, shallow pleasure and harmful perturbations. The result was a disturbed people, a privileged elite, and a society at risk of collapse.

\section{Sensing Change}

To effect change would require interrupting or, better still, reversing médiocrisation. This promised to be difficult, as Schöffer explained, because médiocrisation had been woven into the very fabric of daily life. Unraveling it would therefore take place in stages. In the first, the material conditions of the city would have

${ }^{23}$ Schöffer, La Ville Cybernétique, 19.

Scientifiques et technocrates, s'engageant dans une série de compromis, orientant leurs recherches dans le sens d'une production massive de produits, ont soigneusement évité de toucher aux véritables problèmes culturels ... tout en profitant d'une façon évidente mais superficielle des produits de ce secteur, elles ne souhaitent pas être approvisionnées en produits culturels dont la compréhension et la jouissance leur échappent, considérant tout naturellement ces produits comme superflus et inadaptés à leur niveau d'information. 
to be reinvented: all traces of médiocrisation would need to be erased from the map. In the second, the social preference for abundance would have to be challenged directly, replaced by an appreciation of quality and clarity.

Emphasizing quality, however, should not be taken to mean Schöffer somehow sought deprivation or asceticism—although his plan, as he explained, would require people to "surrender some comfort, especially intellectual comfort." 24 Specifically, it would ask people to think differently, if not for the very first time, about social, architectural, and environmental relationships, the vast majority of which go unnoticed. This new way of living would require people to question the nature of work and leisure, and moreover, to rethink the material structure of daily life by becoming more cognizant of its experiential texture. But it would also require people to devise new ways to fill the gaps of experience- to engage creatively with this texture. Schöffer's ideal was not a smooth, unchanging, or stable state, though. To some extent, he believed psychological "perturbations" were "inevitable for the diversification and development of life"-though for the most part, unplanned and un-contained perturbations tend to be harmful..$^{25}$ Technology, therefore, has an important role to play: it can both mediate and ameliorate disruptions and social tensions as they occur, transforming them into a productive, welcome, artful intrusion. Rather than being the cause of social and political unrest, the city's technological infrastructure, once buttressed by a carefully designed program,

24 Ibid., 11.

25 Ibid: "Si les perturbations sont inévitables pour la diversification et le développement de la vie, les effets traumatisants sont souvent nocifs." 
could target specific aspects of the urban environment for creative intervention. Art could thus participate:

...directly in this newly-evolved society by offering the extraordinary conceptual and imaginative freedom that has always allowed it to escape all constraints and exceed all the other achievements of human activity. ${ }^{26}$

While Schöffer clearly understood the dangers of technology —at least in terms of médiocrisation-he seems not to have believed those dangers were inherent. Like other technophilic theorists of the period, Schöffer believed technology had the potential to liberate people from the oppressive conditions of daily life, functioning as an extension of human consciousness. This sentiment mirrors what Félix Guattari would later write:

[T]he fact that machines are capable of articulating statements and registering states of fact in as little as a nanosecond ... does not make them diabolical powers that threaten to dominate human beings. [Machines] are nothing other than hyperdeveloped and hyperconcentrated forms of certain aspects of human subjectivity, and emphatically not those aspects that polarize people in relations of domination of power. ${ }^{27}$

Much like Guattari, Schöffer viewed technology as a vehicle, one granting us the power and ability to do things we might otherwise not be able to-including the power to manipulate intangible parts of fractional space that would otherwise be difficult or impossible to access. While technology undoubtedly has the potential to change how and on what terms we relate to the world, when carefully utilized, it can also "serve us and lead us forward." 28 Technology emerges here as a kind of conceptual map, capable of

${ }^{26}$ Ibid., 12; "...directement à cette nouvelle forme d'évolution en offrant I' extraordinaire liberté conceptuelle et imaginative qui lui a toujours permis d'échapper à toutes les contraintes et d'accéder à des dépassements qu'aucune autre activité humaine n'a pu atteindre."

27 Félix Guattari, "Regimes, Pathways, Subjects," translated by Brian Massumi, Incorporations, eds. Jonathan Crary and Sanford Kwinter (New York: Zone, 1992): 16-19.

${ }^{28}$ Schöffer, La Ville Cybernétique, 64. 
guiding us down a path toward a more meaningful and creative engagement with

everyday life. Cities, in becoming cyber-technic installations, would reemerge as the site

of collective artistic engagement: places where harmful disruptions are actively expelled, replaced in real-time by artfully planned, computer-facilitated sensory environments.

\section{The Role of Art and Design}

Re-imagining the city, and subsequently remaking the very fabric of everyday life, would require first the redemption of art itself. And because many contemporary artists had already established opportunistic alliances with the materials and methods of mass production, Schöffer believed they had been corrupted irreversibly. Worse still: artists had capitulated to the desire for cultural legibility. In Schöffer's view, there was simply too much art in the world, too much of which had been made specifically to appeal to the masses. Beneath this apparent corruption, he believed the wealthy elites, especially Americans, stood to benefit. He explained:

Gradually, thanks to so-called experts, manipulators of history and art history, and through a prose as abundant as hollow and dangerous ... [artists] began to produce ... "pop" art and false surrealism, whose illustrious representative (whose name is easy to guess) is Salvador Dali. His work is the archetype of pure unabashed artistic alienation; it favors the annihilation of creative ferment and disturbance in the human imagination. All of this is the work of an unusually powerful social group which has achieved the highest peak of the oppressive organization and manipulation of the masses: wealthy society in the U.S. ${ }^{29}$

29 Ibid., 14.

Peu à peu, grâce à certains prétendus spécialistes, manipulateurs de l'histoire et de I'histoire de l'art, et par l'intermédiaire d'une prose aussi abondante que creuse et dangereuse ... ils commencèrent à fabriquer du faux dada ou post-dada, c'est-a-dire du "pop" art et du faux surréalisme dont l'illustrissime représentant (c'est facile à deviner) est Salvador Dali, pur prototype du système d'aliénation éhontée de l'art au profit de l'annihilation des ferments créatifs et perturbateurs de l'imagination humaine. Tout cela est l'oeuvre d'un groupe social exceptionnellement puissant qui a réussi à atteindre le plus haut sommet de l'organisation oppressive et de la manipulation des masses: la société des possédants aux U.S.A. 
By encouraging cheap art—and indeed, art that was conceptually impoverished —-today's elites have initiated a transfer of power, one that has solidified the existing social hierarchy and further spread médiocrisation. The remedy was not simply to banish accumulation, or to force artists like Dalí to stop their work. This, by Schöffer's logic, would only amplify the effects of médiocrisation in the near term-further hastening the transfer of power. The solution, instead, was more radical: it was to undermine both médiocrisation and the subsumption of power simultaneously by challenging the very aesthetic and social paradigm that made quantitative accumulation desirable in the first place. In theory, this would require analyzing the structure and materiality of daily life; in practice, it would require us to access and make use of what Schöffer called "fractional space. ${ }^{\prime 30}$

Schöffer believed the ultimate challenge of design was not the question of where to put walls. Buildings, he thought, should be flexible, modifiable, even moveable—and to that end, he gives special praise to Eero Saarinen's design for the "mobile lounges" at Dulles airport in Washington. ${ }^{31}$ It is perhaps not surprising, then, that Schöffer believed space should be defined not exclusively by its fixed or material properties, but in a more complex fashion, by the sensory textures between the proverbial walls. Despite any apparent "emptiness," he viewed space as richly dense, filled with "phenomena of

30 lbid., 72.

...il s'agit de supprimer totalement le modelage des matériaux solides et de les utiliser exclusivement pour la captation de fractions d'espace définies pour rythmer ces programmes.

31 Schöffer, La Ville Cybernétique, 134. 
powerful energy." ${ }^{32}$ The ultimate conceptual and practical challenge, then, was to control these phenomena, thereby giving discrete sensory form to the city, and new shape and meaning to everyday life. ${ }^{33}$

Turning our attention to the design of fractional space, Schöffer says, would require a new design philosophy, a new conceptual approach, one where the design of physical materials is given "some importance," but where the intangibles, "the space included in the structures," become the principal focus ${ }^{34}$ Design would therefore mean learning to control and manipulate "fractional space" to achieve maximum effectivitycreating a pleasing environment that challenges and enlightens us, that would be conducive to constructive activity rooted in work or leisure. Like "fractional" phenomena themselves, which would change, flow, and dissipate over time, no singular configuration of the city would be "ideal:" by nature, it would have to be dynamic, able to change and adapt to feedback provided both purposefully (by the city's residents) and automatically (by environmental readings collected by sensors).

It is worth reemphasizing here that the goal of the Cybernetic City was not to stabilize all moment-to-moment fluctuations. It was rather to redeploy them creatively and productively—an idea Schöffer qualifies at some length:

32 Ibid., 118.

En effet, le plus petit fragment de l'espace contient des phénomènes énergétiques puissants.

33 Ibid., 72.

34 Ibid.

... être construite avec rigueur; elle doit être à la fois légère, monumentale et stable. Sa structure doit obéir à certaines règles. L'objet a de l'importance, mais c'est le côté immatériel, en l'occurrence l'espace inclus dans les structures, qui détermine l'importance de l'œuvre ... 
Indeed, every day we find that "it changes;" but it is important that these changes occur without shock, that they are to some extent amortized by the beneficial presence of art. Art is able to address both aesthetic concerns and the needs of society, and its interventions offer solutions posing no danger. On the contrary, they humanize all of the elements of developing progress; and it is this progress that leads us, every day with increasing haste, to distant and unknown worlds. ${ }^{35}$

In the end, if médiocrisation was responsible for producing and reproducing social, political, aesthetic, and wealth inequality, the challenge of the Cybernetic City was to do the opposite: to generate, in part through technological processes, an equitable society, one where emphasis is placed on the quality (rather than quantity) of life.

Schöffer thus maps his way out of contemporary problems through negation, but in doing so, finds himself chasing awkwardly incompatible goals: to actively prevent disruptions while utilizing indeterminate creative methods; to embrace change while avoiding cheapness; to design space by embracing what seems implausible to construct; to appreciate the artistic potential of fractional space while preempting the emergence of yet another false consciousness. His solution to each of these problems-technologywould require a complex network of sophisticated computers. The resulting cybernetic ecosystem, once connected to environmental sensors, input control consoles, and an array of (often unspecified) "active" intervention technologies, would be able to produce specific and context-appropriate sensory interventions in real time.

35 Ibid., 136.

Nous constatons en effet, chaque jour, que "cela change," mais il importe que ces changements surviennent sans secousse, qu'ils soient amortis en quelque sorte par la présence éminemment bénéfique de l'art. Celui-ci axé sur des préoccupations à la fois esthétiques et sociales impose, en intervenant, des solutions qui ne comportent aucun danger, mais au contraire humanisent tous les éléments du progrès en formation, ce progrès en formation, ce progrès qui nous entraîne chaque jour plus rapidement vers des mondes lointains et inconnus. 
Despite any techno-totalitarian overtones, however, the goal of Schöffer's plan was to create a responsive, indeed, participatory city, one where residents could themselves register any change in mood or sentiment by turning a dial or pressing a button. This information would then be sent to a central cybernetic brain, "where it would be quantified constantly and transformed into flexible orders, reacting immediately to the events in question." ${ }^{36}$ Indeed, as will be explained in further detail below, while Schöffer does not always specify what these reactions would be or how they would be implemented, the goal nonetheless was to use technology to open the black box of fractional space, to provide ordinary people some say in how the sensory experience of the city is composed, as Schafer explains in the epigraph to this chapter.

\section{Composition}

To organize this new cybernetic environment, Schöffer proposed dividing fractional space into five constituent parts, what he called topologies: time, light, weather, smell, and sound. "Time," the first topology, is closely related to what other theorists, including Henri Lefebvre, have called "rhythm." ${ }^{37}$ The Cybernetic City would have

36 Ibid., 109-10.

Chaque fois qu'un habitant désire un changement quelconque dans un domaine donné, dans le sens de la diminution ou de l'augmentation, il tourne jusqu'au degré souhaité et appuie sur le bouton correspondant aux phénomènes choisis. Les informations ainsi recueillies sont reçues par le cerveau central où elles sont constamment quantifiées et transformées en ordres souples réagissant immédiatement sur les événements en question.

${ }^{37}$ Henri Lefebvre, Rhythmanalysis: Space, Time and Everyday Life, trans. Stuart Elden and Gerald Moore (New York and London: Continuum, 2004). 
"zones with varying density," arranged so that "a set of rhythms ... will fit together, forming a structure or a sculpture of time, or more accurately, temporal variation." Planning a city, Schöffer believed, meant anticipating how and where different activities unfold, how frequently they recur, and mechanisms capable of encouraging a pleasing indeterminacy of sound. In that way, the city's design would prefigure a series of unplanned encounters, some of which are more likely to occur than others, and, like a work of chance-based art or music, none of which strictly prescribe the order, sequence, or necessary outcome.

Specifics beyond this are scarce; but it is at least clear from Schöffer's drawings that the city would be divided into different use-zones-zones for sleeping, zones for working, among others. These zones would, in turn, contain buildings designed specifically to suit the activities that would take place inside of them. For instance, Schöffer estimates that two-thirds of our lives are spent either in a state of recreation or in a state of sleep, and this would have a necessary effect on the city's physical design. Leisure activities, sleep especially, would necessarily take place in buildings oriented horizontally: "skyscrapers cannot be a place of sleep," he wrote, "because they do not promote peaceful and inactive dreams." 39 Living quarters consequently were to be in buildings both low and long, slightly elevated on pylons to allow for ample green space below. (Fig. 5-1) Each individual living module would be fully adaptable-able to be

38 Schöffer, La Ville Cybernétique, 111.

39 Peter Weibel, Beyond Art: A Third Culture (New York: Springer, 2005), 316-17; Wiebel here quotes and translates Schöffer: "the visual impression of verticality incites us to rise so that we find ourselves in a position parallel to our surroundings. The horizontal stimulates relaxation and de-concentration." 
changed to suit the physical, mental, and environmental needs of each resident. It would also be completely isolated by "impermeable walls," and therefore protected from noise, unwanted climatic change, or other social disturbances. ${ }^{40}$

And yet, for a plan that seems to idealize the purposeful manipulation of fractional space, there is a surprising embrace of indeterminate change evident in Schöffer's writing. This becomes especially clear in the way Schöffer theorizes another important topology. Light, he says, should not be taken for granted as inevitable, neither should it be understood as an immutable part of daily life. It is, he explains, a plastic medium like any other, one whose full potential has yet to be effectively implemented at the urban scale. The right kind of light, beamed at the right place and moment, can "activate or shut down life in the city, or a specific part of it, should the need arise."41 The central cybernetic regulation system would again have an important role to play. It would become possible:

...to capture natural light and to introduce it temporarily or permanently into shadowed areas - to create points of intense radiance, or conversely, daytime shadows, as they are needed and pleasing. The artificial coloration of bright areas during daytime. 42

40 Schöffer, La Ville Cybernétique, 107.

Sur le plan individuel, l'occupant se sentira à l'aise dans sa cellule, n'ayant pas de vis-àvis, ses voisins latéraux étant isolés par des parois étanches. Les cellules sont extensibles latéralement et en hauteur, aptes par conséquent à recevoir des familles en nombres variés.

41 Weibel, Beyond Art, 317.

42 Schöffer, La Ville Cybernétique, 113.

...la captation de la lumière naturelle et son introduction temporaire ou définitive dans les zones d'ombre. La création de points de rayonnement intense ou, au contraire, de zones d'ombres diurnes, selon les besoins fonctionnels ou esthétiques. La coloration artificielle des zones lumineuses diurnes. 
Even more incredible than his plan to focus the interventions of light, however, was Schöffer's proposal to manipulate the weather. "Climate," another topology, was qualified to mean "temperature, humidity, and wind" 43 —aspects of the environment that, even under the best of circumstances, are difficult or impossible to isolate and modify. ${ }^{44}$ Not surprisingly, Schöffer provides little in the way of technical details for how this system might work, saying only that the weather would be subject to cybernetic modification. And yet, it is clear he did have specific modifications in mind-changing the weather, he wrote, can "help stimulate, neutralize, or calm."45 Schöffer furthermore believed it would be possible to implement these modifications. Marginally plausible was his plan "to create artificially protected and air conditioned areas around homes to avoid the traumatic effects of climatic oscillations, ${ }^{, 46}$ but it remains unclear whether fully implementing this topology would require enclosing the city itself with a giant dome, or some other large-scale shelter.

43 Ibid., 117.

${ }^{44}$ Climate modification conspiracy theories aside, of course.

45 Schöffer, La Ville Cybernétique, 117.

L'organisation des climats doit s'adapter harmonieusement aux fonctions des lieux et contribuer à stimuler, à neutraliser ou à décontracter, c'est-à-dire à déterminer, les conditions optima de l'ambiance climatique des ensembles habites.

46 lbid.

Dans les zones saturées de froid, de chaleur ou d'humidité, il sera nécessaire de créer des zones artificiellement protégées et climatisées autour des habitations afin d'éviter les effets traumatisants des alternances climatiques. 


\section{A 'Sound' Topology}

Closely associated with the topologies of weather and time is that of "sound," which Schöffer neatly, if problematically, divides into two subcategories. The first includes sounds that are "natural" and which, he says, produce a pleasing indeterminacy. By his estimation, this category includes sound made by animals, wind (such as rustling trees), and other inorganic phenomena (like gurgling streams). ${ }^{47}$ The second category is "artificial" sounds-which is not to say "sounds that are not really sounds," but rather sounds that have a human or otherwise industrial origin. ${ }^{48}$ Though unwieldy, these subcategories sketch a baseline aural configuration for the Cybernetic City: while . "natural" sounds would require no modification or intervention whatsoever-they could, in essence, be enjoyed and appreciated as-is-the latter would need to be eliminated or suppressed all but completely, especially when perceived as unwelcome. ${ }^{49}$

In practice, the topology of sound is closely related to that of rhythm, since different sounds are unavoidably linked to the activities that generate them. For instance, in order to keep the city temporally ordered, its inhabitants unperturbed, Schöffer envisioned the need to divide the city into sonic zones-not unlike the use-zones of Corbusier's "Radiant City," or those found throughout today's suburbia-that would keep especially industrial activities isolated on the urban edge. Aside from sheer physical distance, though, artificial sounds would also be counteracted through various creative

\footnotetext{
47 Ibid., 116.

48 Ibid.

49 lbid.
} 
means: noise cancellation, suppression, insulation, or other such "technical processes." 50 But relative silence was by no means universally ideal. On the contrary, Schöffer believed noise would be common, even welcomed, in areas of leisure and recreation-though surely not those of sleep.

Sound would also have an important role to play within several specific buildings in the Cybernetic City. One of them is the Spatiodynamic Theater, imagined to be the most important entertainment and cultural venue in the city. The theater would consist of a slowly rotating hyperbolic shell 100 meters across. Its interior surface would be left bare so as to host a range of performances: from what he called "moving poems," to cybernetic ballets (performed by humans and machines), and other kinds of audio-visual shows. Spectators, meanwhile, would be free to move among different areas inside. The technical operations of the theater, however, were by no means simple, and Schöffer explained in great detail how they would work. Much more than a site for performance, the building itself could move and change along with the multimedia art works performed inside:

Sound is broadcast in stereo, generally in the direction opposite to the rotational movement of the public, who perceive the projections in all portions of visible space. The entire show is directed by an electronic control tower, located at the top of a central cylindrical frame. The programming of the spectacle is composed and recomposed constantly to avoid any sense of repetition ... To establish nonsaturation, the varied rotation of the public also plays an important role. Multiple perspectives, moving sounds, varied rhythms, smells, and climatic changes actively unfold during the show, without a beginning or an end. Spectators, upon entering their box, encounter a set of rhythmic sensations whose unfolding does not pass unnoticed. In front of each spectator is a control panel that allows them to

50 lbid.

Ces sons, par contre, devront être plus ou moins éliminés et il faut prévoir leur neutralisation ou leur localisation dans des lieux où ils ne sont pas gênants ou bien encore leur réduction par divers procédés techniques. 
communicate impressions or commands to the control tower, which are constantly quantified, and that influence how the program unfolds. ${ }^{51}$

The Spatiodynamic Theater was designed, then, as a mini-Cybernetic City: modeling not only the same kinds of participatory (inter)action that would define urban experience, but the same types of creative, specifically sonic, adaptation.

Schöffer's description here might also be said to share much in common with other multi-media and installation art venues, notably the Philips Pavilion constructed for the World's Fair in Brussels in 1958 - nearly ten years before the publication of the $L a$ Ville Cybernétique. While this comparison seems apt, Schöffer's Spatiodynamic Theater nonetheless differs in two important ways. For one, the Pavilion was a stand-alone space, constructed among other stand-alone spaces. It was, even according to Corbusier's drawings, an "organ without a body:" a metaphorical stomach where immersive artwork is digested by viewers, but otherwise unconnected to the surrounding environment. ${ }^{52}$ Schöffer's theater, by contrast, both inside and out, functioned seamlessly as part of an integrated urban-artistic program. Even though it could conceivably have been built without the larger context of the Cybernetic City, the conceptual line dividing the two is 51 Ibid., 131-33.

Le son est émis en stéréophonie, en général dans le sens opposé au mouvement de rotation du public qui perçoit les projections dans toutes les fractions de l'espace visible. L'ensemble du spectacle est dirigé d'une tour de contrôle électronique, située au sommet du bâti cylindrique central. Le programme du spectacle est composé et recomposé constamment pour éviter toute sensation de périodicité, grâce au répertoire disponible. Pour obtenir la non-saturation, la rotation variée du public joue elle aussi un rôle important. Visions multiples, sons en mouvement, rythmes toujours variés, odeurs et climats projetés participent activement au déroulement de ce spectacle sans commencement ni fin. Le spectateur, en entrant dans sa loge, perçoit un ensemble de sensations rythmées dont le déroulement ne lui échappe pas complètement. Devant chaque spectateur est placé un tableau de commande qui lui permet de communiquer à la tour de contrôle ses impressions ou ses ordres qui, sans cesse quantifiés, influent sur le déroulement du programme.

52 Marc Treib, Space Calculated in Seconds (Princeton: Princeton University Press, 1996), 26-27. 
very narrow. This observation mirrors the second important difference: if the Philips Pavilion can be understood as a discrete, if not disguised, advertisement for Philipsbranded consumer electronics, then the Spatiodynamic Theater puts its relationship to consumption in the open. In spite of his concern about quantity-driven médiocrisation, Schöffer nonetheless identifies the Spatiodynamic Theater as one of the few places within the Cybernetic City where residents would be able to shop. ${ }^{53}$

Despite how well-planned the integration of sound promised to be, Schöffer seems not to have anticipated the full extent to which "artificial" sounds would seep into everyday life. His diagrams, for instance, depict activities in "residential" areas that would surely be the source of acoustic annoyance. Helicopters, for one, appear in almost every sketch he produced: landing on rooftops and hovering near office and university buildings. (Fig. 5-1.) Elsewhere, cars can be seen speeding along wide boulevards, built to "allow for direct and rapid movement," but without any physical acoustical barriers. ${ }^{54}$ These apparent contradictions are nowhere addressed in Schöffer's writing; and this suggests either that sonic-cybernetic mitigation would be quite aggressive, or more likely, that the conflicting priorities he described-helicopters and relative quiet in areas of leisure and sleep—were not adequately considered.

It is also in the topology of sound that the Cybernetic City itself begins to emerge as a work of art. While it would be possible to develop ad hoc accommodations for other

${ }^{53}$ Schöffer, La Ville Cybernétique, 131. He writes:

Ce dernier contient un centre commercial évoqué précédemment. Le public peut circuler aisément entre le centre commercial et les loges des spectateurs, bien que le dispositif hyperbolique contenant les loges tourne lentement à des vitesses variées et dans les deux sens.

54 Ibid., 106. 
topologies, sound in particular would require significant advanced planning. The active sonic material of the city-as opposed to suppression or mitigation techniques-would become something akin to the music of ordinary life and would consequently require "great craft and skill" to be organized. ${ }^{55}$ Indeed, while Schöffer viewed music in general as something of a lagging indicator-and, moreover, believed the so-called "music of ideas" had failed to achieve its aims ${ }^{56}$ - he nonetheless believed composers were particularly well-suited to the task. Composers, he said, possess the skills, knowledge, and discipline to manipulate sound in order to achieve specific effects. ${ }^{57}$ But because urban design is not a task to which they are usually accustomed, it would become an interdisciplinary endeavor with composers at the lead-directing technical workers from other fields. ${ }^{58}$

While Schöffer never explains exactly what kind of music might be composed for the Cybernetic City, he nonetheless includes a small notational fragment that offers some hints. Included alongside the textual explanation for each topology is a small sketch that

55 Ibid., 116.

56 Ibid., 93.

Toutes les tentatives pour créer une musique d'idées ont échoué. Les plus grands créateurs, J.-S. Bach, Haydn, n'ont recherché que la sublimation de pures structures d'effets. Ceux qui ont essaye de faire une musique d'idées, comme Wagner, Verdi, Tchaikovsky par exemple, ont nettement échoué.

57 Ibid., 116. He explains: "Il est logique que le bâtisseur manie ce matériau de première importance avec art et compétence."

$58 \mathrm{lbid} ., 93$.

L'organisation des effets esthétiques sonores, dans les ensembles audio-visuels et dans l'urbanisme, sera d'une importance primordiale. Mais le créateur d'effets sonores esthétiques sera obligé de s'intégrer dans de larges équipes de créateurs artistiques et de techniciens spécialisés, qui, ensemble, élaboreront des œuvres audio-visuelles collectives. 
"performs" the imagined interaction among experiential and environmental elements.

Schöffer's notation for weather, for instance, shows swirls and dots, illustrating the the transformation of cold, dry air into a more temperate environment. (Fig. 5-4A) The diagram for sound, however, shows lines, squiggles, and zigzags at varying vertical and horizontal distances-marks which very much resemble avant-garde musical notation used by Luigi Russolo, Karlheinz Stockhausen, or Edgard Varèse. ${ }^{59}$ (Fig. 5-4B) The sharpness of these marks, their relative precision, implies the use of electronic sound-or at least, suggests electronic sound would not be unwelcome. And indeed, if the music Schöffer broadcast from Chronos 3 is any indication of what the Cybernetic City would sound like, this inference is justified.

\section{Cybernetic Towers}

Of the many technological components Schöffer planned for the Cybernetic City, none was as integral as the cybernetic towers. Towers, in one form or another, appear in virtually every sketch and visual example Schöffer produced: sometimes human-sized and self-propelled, capable of roaming the city freely on their own; at other times taller than skyscrapers, fixed in place, able to broadcast a spectacle of sound and light into the urban environment. His CYSP—short for "cybernetic sculptures"-were human-sized towers, standing between 2 and 6 meters high. And like larger, later examples, they were equipped with myriad sensory attachments, allowing them to move throughout a performance space while reacting and interacting to both human and environmental

\footnotetext{
59 For an example of notation used by Varèse, specifically his sketches for the Poème électronique, which has particular relevance to the Cybernetic City and the Spatiodynamic Theater, see: Treib, Space Calculated in Seconds, 198-201, figures 5-10 and 5-11.
} 
change. ${ }^{60} \mathrm{~A}$ cross between public art and public utility, these towers were the primary mechanism for observing and modifying fractional space: thoughtfully, creatively, but never to disturb. He explains how

...their increased agitation may, for example, announce bad weather. In such a case, at certain times of day, they will act as a true barometer. At other times they will give all sorts of information about the economy, sports, politics, etc. ${ }^{61}$

But the towers also had a symbolic function. They occupy the physical site, become the physical manifestation, of an otherwise invisible network of power and control.

It is important to recognize, however, the extent to which Schöffer's plans for cybernetic towers predates the publication of La Ville Cybernétique. Chronos 3 has already been discussed at some length; but other, similar towers can be found even earlier. During the 1950s, for example, Schöffer created the first self-directed, selfpropelled sculpture —one able to travel throughout the city entirely on its own. Others he made were capable of interacting dynamically with humans. Conceivably let loose to roam the city on their own, sculptures like these, Schöffer believed, would lend "a maximum of dynamism to the spectacle of the street.'\%2

60 Joray, 60; Schöffer, La Ville Cybernétique, image opposite page 105.

61 Schöffer, La Ville Cybernétique, 129.

...leur agitation accrue pourra, par example, annoncer le mauvais temps. En ce cas, à certaines heures de la journée elles joueront le rôle de véritables baromètres. A d'autres moments elles donneront des informations de toutes sortes, économiques, sportives, politiques, etc.

It is not clear what Schöffer means by "agitation" in this passage. While mobile towers would have the capacity to broadcast sound electronically, to announce economic and sports news, it is possible that agitation could be expressed mechanically.

62 Ibid., 60. 
One of his most fully-developed and fully-realized cybernetic towers was erected in the Park at St. Cloud, on the outskirts of Paris, for the International Building and Public Works Exhibition in 1955. Using equipment manufactured by the Philips corporation, the tower was designed to produce a multimedia spectacle integrating light with music and movement—all of which was guided by a dynamic computer program capable of responding to environmental fluctuations in real-time. ${ }^{63}$ Musical interventions, though, were among the tower's most novel features. As consulting engineer J. Bureau explained, the tower would

...produce anharmonic musical motifs, many of which will be of no great interest and will constitute a background of sound, while others will appeal to the ear. The sound material ... will always be interesting and rich. 64

The source for these "anharmonic musical motifs" would be Spatiodynamisme, a work of musique concrète specially composed by Pierre Henry. ${ }^{65}$ Microphones attached to the tower's superstructure would observe ambient sound as it occurred. These observations would later be processed through a central computer brain, which would analyze them to determine how to "balance and avoid discordant sounds." 66 Under the "correct" conditions-which changed over time, thanks to a built-in randomizer-music would be played to counteract or complement what was already audible.

But Bureau is wrong to say, as he does above, that any part of Spatiodynamisme is of "no great interest." While the first few minutes are relatively sparse-functioning, as

63 Ibid., 45.

${ }^{64}$ Quoted in Joray, 45.

65 The earliest available recording of Spatiodynamisme is from 1963 and is published in two parts on a 45rpm disc included with Joray's Nicolas Schöffer.

66 Ibid., 46. 
in many works of tape music, to introduce each new sound in sequence-the next few gain tremendously in complexity. Density and texture in particular are played with in interesting and compelling ways. For instance, a crescendo, beginning at the 1:35 mark eventually builds into a frenzy of activity lasting two minutes, continuing until a sudden scraping sound interrupts. (Fig. 5-2A) This is followed by a momentary return to calm, a new section of harsh bangs, rapid and abrupt tape cutting, and a noticeable increase in the diversity of timbre. Arguably the most striking moments, however, occur at the 17 -minute mark, when a brief clip—what sounds like wooden sticks being dragged along the arms of the tower itself-is looped almost hypnotically for nearly four minutes without interruption. (Fig. 5-2B)

The tower in St. Cloud was not simply a tool for city-wide broadcasting, the equivalent of an air-raid siren or tornado warning system. It was, rather, meant to improve how people live and what they hear on a daily basis, in part by broadcasting sonic references to itself. Many of the clips collaged in Spatiodynamisme sound as though they were produced by the tower: sounds of metal creaking and wobbling in the wind, the sound of scrapes (as if made by bird's claws), bangs, and rattles (as if made by hail or debris blowing in the wind). At the same time, there is nothing deceptive or deceitful about how Spatiodynamisme was produced. Even in the final recording, the medium is always apparent. Much of the 23-minute piece features quite roughly-executed tape processes common to the 1950s: layering, looping, and cutting. From another point of view, this very roughness seems appropriate, since the tower was never meant to hide its technological operations. 
Two decades after the tower in St. Cloud was built, Schöffer proposed his most ambitious project yet. Planned for construction in La Défense, and imagined to stand an impressive 300 meters high, it was called the "Tour-lumière cybernétique." In addition to being his most practical tower, if built, it would have left a profound mark on the landscape ${ }^{67}$ Its luminodynamic interventions, for instance, were designed to target the roadways: like giant highway lamps, the lights mounted on its superstructure would be activated automatically as weather conditions began to deteriorate. A similar process would hold true for sound. Not only would information about ambient urban noise be collected and processed by a central cybernetic brain, but some sort of (unspecified) sonic amelioration would be introduced to combat audible unpleasantness.

Far from being outliers, the towers Schöffer imagined for the Cybernetic City fit comfortably within his broader works. They were, first and foremost, vehicles for making connections - between individuals, people and computers; between technology and the environment. But they were also a key demonstration of the city as a dynamic and changing place, an exemplification of how fractional space can become the very site and source of creative engagement, rather than simply a means to suppress perturbation and annoyance. Though seeming stoic, they would serve as a visible and indeed audible reminder that the city can be made into a work of art, an ongoing and indeterminate composition. In that sense, the towers had both practical and ideological elements: whether large or small, fixed in place or self-directed, they were to become vehicles for social and aesthetic transformation.

67 Nicolas Schöffer, La tour lumière cybernétique (Paris: Denoël, 1973). 
As Schöffer wrote, "everything moves, or we can make it move." ${ }^{968}$ And indeed, coaxing both the moveable and seemingly immovable aspects of everyday life to action was among the most central functions of cybernetic towers. Not only did Schöffer believe fractional space could be articulated creatively, he believed that it was filled with creative potential that should be created-with for the benefit and enhancement of ordinary life. Alternating between stability and instability - between being pleasant, useful, and surprising - each topology would be anticipated, organized, allowed to unfold, then artistically responded to. The outcome would encourage people to develop a critical awareness of their surroundings rather than contribute to médiocrisation, all while playing an active role in their own wellbeing.

Though seldom discussed in scholarly literature on the subject, Schöffer's towers seem to have anticipated more recent developments in sound installation art. ${ }^{69}$ One example is "Airport Sound Experience," a 1996 installation at Cairns International Airport by Peter Mumme. This computer-controlled project was "synchronised with the airport flight schedule," and at opportune moments, would introduce sound collected from the natural environment, including birds and water, to complement or contrast with changes in the ambience or activity level of the surrounding space. ${ }^{70}$ Another clear beneficiary, Richard Serra's "Berlin Junction," was installed beginning in 2001 outside

\footnotetext{
68 Schöffer, La Ville Cybernétique, 112. “...tout objet, être, phénomène naturel ou artificiel qui peut se mouvoir, ou que l'on peut faire mouvoir."

69 Gascia Ouzounian, "Sound Art and Spatial Practices: Situating Sound Installation Art Since 1958," PhD diss, University of California, San Diego, 2008. Ouzounian is the only scholar in music I have found who mentions Schöffer's cybernetic towers.

70 Ros Bandt, "Designing Sound in Public Space in Australia: a comparative study based on the Australian Sound Design Project's online gallery and database," Organised Sound 10, no. 2 (2005): 133
} 
the Berlin Philharmonie. This work consists of two large metal slabs, each molded into a slight curve, balanced on one edge, roughly parallel to each other. The result is a narrow corridor; and as visitors venture inside, sensors hidden in the walkway beneath are tripped, causing an already-present background sound to change and respond to their movement. Much like Schöffer's tower at St. Cloud, these inputs are fed through a computer system located in the foyer of the nearby Philharmonie. "Over time," as critic George Klein has explained, "visitors cause the sound to change day and night. Listeners transform what they hear. The visitors become players in a musical process lasting months.".71

"Players," writes Klein, but arguably only after an initial gesture of intent. That is to say, unlike Schöffer's towers, Serra's installation only becomes active (and interactive) after a person goes out of their way to venture inside the metal corridor. By comparison, Schöffer's towers at Liège and St. Cloud—in addition to those planned for La Défense and the Cybernetic City--were programmed to engage automatically with the environment on a massive, city-wide scale. More importantly, they were designed to respond to both purposeful and un-purposeful action, both intentional and unintentional engagement. While the desire for change could be registered by listeners, it could also be initiated automatically by the computer program, without the need for any direct interaction at all, at the very instant a "perturbation" could be detected. Schöffer's sonic interventions, then, unlike "Berlin Junction," were preprogrammed to be responsive.

\footnotetext{
71 Georg Klein, "From the Sound Installation to the Sound Situation: on my work transition - berlin junction eine klangsituation," Organised Sound 8, no. 2 (2003): 187.
} 


\section{Section II: Criticism}

Schöffer's ambitious and far-reaching plan — which seemed to idealize an alreadyaestheticized hierarchical scripting of everyday life-has been greeted quite skeptically. Critiques of his work follow one of two paths. The first is more or less direct criticism, aimed at problematizing both the specifics of what Schöffer hoped to achieve and the larger social and political implications of the final result. The second path is a more general historical critique, framing the Cybernetic City as symptomatic of a naive technoutopianism.

The latter is best exemplified in the recent work of architectural historian Larry Busbea. In his book Topologies, he explains how Schöffer's vision for a technologicallycontrolled, aesthetically-planned city of the future can be situated among a small group of utopian theorists associated with the Groupe International d'Architecture Prospective (GIAP) after the Second World War. ${ }^{72}$ While any number of visionaries and utopians independently proposed novel configurations (and reconfigurations) of the cityincluding composer and architect Iannis Xenakis ${ }^{73}$ - the GIAP is especially notable for its interest in semiotics. To its members, the meaning, purpose, and most importantly, structure of the city had been obscured following the influx of American-style consumer capitalism after the Second World War. One goal of the GIAP, then, was to find ways to restore "semiotic consistency" to the city — which had been disrupted by cars, advertising, and thoughtless growth and development. Art would have a crucial role to play-not

72 Busbea, Topologies.

73 lannis Xenakis, Arts-Sciences, Alloys, trans. Sharon Kanach (New York: Pendragon Press, 1985); Musique, architecture (Paris: Casterman, 1976). 
merely a recursive one, operating "via the critique of its ideological superstructure," but rather more directly, by turning "its technical mechanisms" toward "aesthetic ends."

Schöffer, in that sense, achieved some significant and concrete successes-at least compared to many of his peers. The cybernetic towers were designed as large-scale demonstrations for how everyday life could, in some measure, be "improved" by technology. But he also succeeded in having a limited number of small-scale consumer goods manufactured. His goal, rather than creating yet another art object, was to introduce a sense of artful change into everyday life-change in and of itself, not alwaysalready commodified change, like television programming. The Lumino, for instance, was a tabletop, TV-like device designed to do nothing more than show a slowly-moving spectacle of colored light and abstract shapes. 1,500 were manufactured by the Philips corporation; and a further batch was produced by Clairol in the United States, marketed and sold as the "Dream Box." 75

Whether or not these devices actually can, in the end, do anything as ambitious as "restore semiotic consistency," the belief was that they could expose Schöffer to political and cultural critique. Among his most vocal critic was Jean Baudrillard, who, along with noted spatial theorist Henri Lefebvre, was a contributor to the periodical Utopie during the mid-1960s. Baudrillard's critique emerged as part of a much broader condemnation of "functionalism"-which Baudrillard believed could be traced to the Bauhaus school of architecture and design. Functionalism, he thought, was worrisome because it marks the

\footnotetext{
74 Busbea, Topologies, 171.
}

75 "The Lumino - 1968," http://www.olats.org/schoffer/lumin.htm (accessed 30 Nov 2012). 
extension of aesthetics "to the entire everyday world." If all that previously existed were "things"—objects not created to fill a specific function, not designed with a particular use in mind-then it was the Bauhaus that marked "the theoretical extension of this field of political economy and the practical extension of the system of exchange value to the whole domain of signs, forms and objects." $" 77$

To Baudrillard, functionalism marked the rising importance of signification as such. This had the effect of further cementing the connection between object and purpose -even to the point that an object itself came to signify that purpose. A chair, in this sense, is not just a thing, but also information: about where one can sit, about what kind of activities can be done while sitting in it. Objects, as a result, become a quick and easy way to communicate. And this, at least as far as the consumption of material goods is concerned, has a problematic and unintended effect: the emergence of a social age whose principal concern was clear communication. As Baudrillard explains, the spirit of the age is articulated by a belief that "the more signs there are, the more messages and information there are, the more one communicates-the better it is." 78

Of course, communication may not necessarily seem like a bad thing, since clarity and transparency would presumably enable a more thoughtful and critical engagement with the world. But here, "communication" has a double meaning. It inidcates the growing influence of material consumption, along with a corresponding "'irrational' or

\footnotetext{
76 Jean Baudrillard, "Design and Environment," in For a Critique of the Political Economy of the Sign, trans. Charles Levin (St. Louis, MO: Telos Press, 1981), 186.

77 Ibid.

78 Ibid., 199.
} 
'fantasy' counter-discourse, which circulates between the two poles of kitsch and surrealism." 79 The resulting impasse suggests two possible outcomes: the first, a reemergence of the very same social and political "contradictions" that drove functionalist design in the first place; the second, the one Baudrillard seems to think is more likely, an "intensification of the play of signifiers, a mathematization and cybernetization of the code. ${ }^{980}$ The latter, indeed, can be quite clearly seen today in neo-liberal economics, which has brought an "irrational exuberance" for ever more data.

Baudrillard believed adopting technological solutions to the management of everyday life was tantamount to "blind faith." ${ }^{.81}$ All that would remain of the natural environment, which is to say, the undifferentiated space not territorialized by capitalist production and aesthetic functionalism, would be little more than a parody, "a simulation model," an empty reference to a more meaningful relationship to the world and the past. ${ }^{82}$ He worried that, by embracing this kind of change, we would move from a complex society, one that is "contradictory, non-homogeneous, and not yet saturated with political economy," 83 to one where "abstract communication and an immanent manipulation no longer leave any point exterior to the system." 84

\footnotetext{
79 lbid., 192.

80 Ibid., 192.

81 lbid., 199.

82 Ibid., 202.

83 lbid.

84 Ibid.
} 
In attempting to recover the very notion of reality, a truly cybernetic city would in fact be a hyperreality. ${ }^{85}$ And indeed, on its surface, Schöffer's vision might be viewed as a kind of urban Disneyland. ${ }^{86}$ Each element, in each area, is carefully designed for a specific purpose, and in many cases is controlled by computer, with the goal of maintaining a certain atmosphere: not just literally, in terms of temperature, lighting, and sound, but affectively, in terms of what we feel and experience as we move through it. Space, indeed, as Baudrillard understood it, is produced by the "field of signifiers generated by the objects within it." 87 And to manipulate space at the level of effects is to guarantee subjective alienation-doing so forces adherence to an imposed script, lived in an "endless, meaningless permutation," that distances ordinary people from the underlying reality of their condition.

Baudrillard, it seems, found little or no redeeming qualities in Schöffer's city: it exemplified what he called, "operational metadesign."88 Despite their apparent differences, however, Schöffer and Baudrillard have a few concerns in common. While Baudrillard never uses the term médiocrisation, it seems clear that his concern for too

85 Jean Baudrillard, Simulacra and Simulation, trans. Sheila Faria Glaser (Ann Arbor: The University of Michigan Press, 2006). He explains: "[i]t is no longer a question of a false representation of reality (ideology) but of concealing the fact that the real is no longer real, and thus of saving the reality principle." (13) Meanwhile, the overall effect of hyperreality is to conceal "that reality no more exists outside than inside the limits of the artificial perimeter." (14)

86 Ibid., 12. Baudrillard explains:

Disneyland is presented as imaginary in order to make us believe that the rest is real, whereas all of Los Angeles and the America that surrounds it are no longer real, but belong to the hyperreal order and to the order of simulation.

87 Larry Busbea, "Toward Superland: ambient objects and environmental semiotics in France, c. 1965," Architecture + Art: new visions, new strategies, International Alvar Aalto Research Conference on Modern Architecture, Jyväskylä, Finland (2007): 162.

88 Baudrillard, "Design and Environment," 198. 
much communication, and too many signifiers, bears much in common with the problem of médiocrisation, as defined by Schöffer. Furthermore, Baudrillard, like Schöffer, was openly critical of capitalist alienation, in addition to the uses and abuses of modern art. Both dislike "pop" and surrealist art, which they viewed as responsible for dumbingdown and withholding knowledge from ordinary people. But Baudrillard, unlike Schöffer, believed surrealism in particular, once properly contextualized, should be understood as integral to functionalism. The two, he wrote, are "inseparable, like the monstrous, anomic critical discourse of objects." ${ }^{\prime 99}$

[Surrealism] plays upon the distance instituted by the functionalist calculus between the object and itself, or between man and his own body, upon the distance between any term and the abstract finality that is imposed upon it, upon the cleavage that makes men and things suddenly find themselves split apart as signs and confronted with a transcendental 'signified'.90

At the same time, though openly wary of meta-design, Baudrillard never directly objected to any particular part of Schöffer's plan. Indeed, from a certain point of view, the towers can be said to pose an interesting challenge to his critique, principally because they did not have a fixed program, a fixed purpose, or a fixed repertoire of "effects." The sound they produced, while already-aestheticized, was aimed only at creating a more pleasing ambience - whatever that meant at any given time, however it needed to occur, according to whoever happened to be listening.

This, in turn, suggests Baudrillard's two most pointed objections to Schöffer's work-that it represented the peak of functionalism; that its goal to manipulate the city on the level of effects facilitated only greater alienation-are off target. After all, the

\footnotetext{
89 Ibid., 193.

$90 \mathrm{lbid}$.
} 
towers had no stable or ideal function, other than change itself. Certainly, the city was designed with a purpose in mind - that is to say, regulating the urban ambiance-but the specific regulations themselves would be left open. Baudrillard's concern, that the Cybernetic City presented a vision of structured "effects," seems to lack teeth, since the very effects with which he was concerned more closely resemble feedback loops, whose moment-by-moment configurations were reflected back on the already-observable ambience of the urban fabric.

Perhaps a better, more focused critique of Schöffer is that his plans merely defer answering difficult questions about agency. For instance: What would happen if two people with different aesthetic tastes-who experience sound and are "perturbed" by different things - attempt to influence the sonic ambience in conflicting ways? According to Schöffer's vision, the computer input consoles, working in consort with the central cybernetic brain, would develop a solution automatically. But this only begs the question, since relying on a computerized compromise merely shifts the location of the problem: from the divergent tastes and perceptions of listeners, to the computer programming itself. So indeed, while Schöffer's vision does provide a plan for how sonic indeterminacies might be incorporated creatively, it ducks difficult questions about human variables.

\section{Indirect Criticism}

This final observation opens another line of critique, though an indirect one, that asks how Schöffer's theorization of sound might be said to prefigure social relationships. The central question here was addressed at great length by Jacques Attali in Noise: The 
Political Economy of Music. One of Attali's central contentions is that social structure cannot be understood simply by studying what can be seen. "More than colors and forms," Attali writes, it is "sound and their arrangements" that give shape to society. 91

From this point of view, Baudrillard's concerns about functionalism, intersecting as they do with the materials economy, are more like symptoms than causes. Limiting our critical gaze to consumer goods and their relationship to the political superstructure would consequently be too narrow. More telling, Attali says, is sound: the way it first "links a power center to its subjects, and thus, more generally ... is an attribute of power in all of its forms." ${ }^{.92}$ Where Baudrillard and Attali both agree, however, is that the underlying social fabric is structural. Life, that is to say, is filled with "codes" that "analyze, mark, restrain, train, repress, and channel" how we interact with the world..$^{93}$ The crucial difference is that, for Attali, these codes manifest first in what is audible, only to appear later in more tangible forms, like new modes of political authority, consumables, architecture, and entertainment. Sound therefore should be understood as a leading indicator of a developing political order-rather than merely its byproduct.

But to understand what this means for the Cybernetic City, it is necessary to understand a few key parts of Attali's analysis; namely, that it is fundamental that society, read through the filter of sound, suggests several discrete phases of development. The first is what he calls "sacrificing," and it begins with an act of symbolic violence. ${ }^{94}$

\footnotetext{
91 Jacques Attali, Noise: The Political Economy of Music, trans. Brian Massumi (Minneapolis and London: University of Minnesota Press, 1985), 6.

92 Ibid.

93 lbid.

94 Ibid., 25.
} 
Sounds that are welcome and wanted are labeled "music," while those that are unwelcome are marginalized, labeled "noise." The result, Attali says, is that the very notion of "music" plays a negative function: it is used, in part, to distinguish insiders from outsiders, to channel and define social acceptance, while allowing for the development of "social order and political integration." authorities later assume control of this process in much the same way as they assume control over violence—what Althusser elsewhere called "repressive" authority. ${ }^{96}$ They do it by "monopolizing control over the deployment and definition of music," in order "to keep noise from spreading. 997

The second phase, called "representing," is marked by the emergence of a sonic marketplace. This does not necessarily refer to technologies of sound reproduction, but rather the process by which the violence inherent to sacrificing acquires an economic cloak. Music, Attali explains,

did not emerge as commodity until merchants, acting in the name of musicians, gained the power to control its production and sell its usage, and until a sufficiently large pool of customers for music developed outside the courts, for which it had been formerly reserved. 98

As the political and economic interests of composers, patrons, and performing musicians among others came increasingly to conflict, the ability to define music was also balanced precariously. Ultimately, the democratization of printing resolved this tension by allowing

\footnotetext{
95 Ibid., 26.

96 Louis Althusser, "Ideology and Ideological State Apparatuses," translated by Ben Brewster, Lenin and Philosophy and Other Essays (New York: Monthly Review Press, 1972).

${ }^{97}$ Attali, Noise, 28.

98 Ibid., 52.
} 
powerful, authorial interests to merge with strong legal and political backing. ${ }^{99}$ Representing, in that respect, also facilitated the elevation of music, the belief in its "universal value, in its impossibility outside of exchange."100

The third phase, called "repeating," constitutes "a fundamental change in the relation between man and history." 101 It is marked by the transformation of time into money - a transformation that asks people to "believe in the stability of the links between things and in the indisputable harmony of relations." Repeating brings the introduction of music to everyone in every place: "in all of the world's hotels, all of the elevators, all of the factories and offices, all of the airplanes, all of the cars, everywhere..." 102 As in sacrificing, this "total" sonic environment, this always-already saturation, effects an ominous silencing, one whose principal effect can be heard in the diminished effectivity of aural signifiers. ${ }^{103}$ This loss of power, the inability to make sound mean something, has other political effects too, some of which can be seen, he writes, in "a cybernetician" who, "transcended by his own tools," allows an inversion: "instruments no longer serve to produce the desired sound forms ... but to monitor unexpected forms." 104 In the end, this (unnamed) cybernetician is as much the victim of "repeating" as anything else. S/he

\footnotetext{
99 Ibid., 54.

100 lbid., 57.

101 Ibid., 101.

102 Ibid., 111.

103 Ibid., 113.

104 Ibid., 115.
} 
is little more than a hostage to the existing social order, "a spectator of the music by his computer."105

This steady progression-from unqualified sound to its emergence as a mechanism of corporeal and environmental control-suggests an uncomfortable observation about the Cybernetic City: the latter two phases Attali describes, representing and repeating, would seem to occur nearly simultaneously. That is to say: Schöffer assumes from the very beginning that the urban ideal is sound saturation. This alone would seem to signal, as Baudrillard suggested, that the power "to mean" has already ended, and that the power "to signify" has been already appropriated up the cybernetic chain. Even more striking is the way Schöffer's vision would seem to ask us to relinquish control over the everyday sonic environment. As in "repeating," sound is not something the composer working within the Cybernetic City is directly responsible for. Rather, as Attali suggests, $s /$ he becomes its spectator: responsible only for setting the initial program into motion, and not for any particular outcome. So, if Attali is right-if the sociostructural function of sound is most worthy of our concern-then Schöffer's plan would seem to distill everything that is worrisome about the initial act of sacrificing. Not only do the towers condense power technically, they also mark the physical site where the ordinary people relinquish their ability to control sound to the machines.

Because Attali was involved with French politics and civil service throughout the 1960s and 70s, he was likely aware of Schöffer's work-especially his proposal to build 
the cybernetic tower at La Défense. ${ }^{106}$ And yet, despite their apparent differences, Schöffer and Attali share many concerns. Both, for instance, were clearly troubled by the uncertainty they observed: the rise of consumerism and a general decay in social consciousness. This overlap consequently warrants asking whether there is any space for reconciliation — and indeed, whether Schöffer's plan to map and manipulate the sonic indeterminacies of the city is as terrifying as it first seems.

\section{Reconciliation}

At first glance, Schöffer's vision appears frightening: it proposes a city where sensation itself has been subject to almost totalitarian control. Conceivably, every sound one might expect to hear-simple or complex, mechanical or natural; from people talking, to street musicians performing, to birds chirping-could be manipulated or suppressed automatically. And if, as Attali argues, new forms of sonic control anticipate new forms of political and social control, then Schöffer's plans for sound in particular would seem to be ominous: the first page of a dystopian blueprint, an almost inhuman future, where power is exercised anonymously and ubiquitously, and with such a sense of routine that it has been pre-coded both literally and figuratively into the very structure of everyday life.

${ }^{106}$ Schöffer, La tour lumière, 73; Historian Larry Busbea seems skeptical that the tower was as close to construction as Schöffer suggests:

Who knows how close this mammoth structure ever was to being constructed. Even if it carried de Gaulle's approval, surely it would not have been so heartily embraced by Pompidou, and certainly not by Mitterrand. Obviously, the Défense tower was meant to be the Eiffel Tower of the twentieth century-a new Parisian monument, located in the new business development that was ... also quickly becoming a cultural center as well. (Busbea, Topologies, 136.) 
But this is arguably a cynical view, one that makes sense only in so far as we overemphasize a few key aspects of the Cybernetic City. First, it is important to not exaggerate the role of machines, since Schöffer's plan left ample space for both autonomous and interactive elements. Control panels would be placed throughout the city, including inside housing pods and the Spatiodynamic Theater, for the purpose of encouraging qualitative, human insight that could later be combined with sensory information collected by the towers. Ordinary people would therefore be able to contribute directly to the sensory composition of the everyday: flipping switches, twisting knobs to reflect their state of mind. Far from trivial, these behaviors seem designed to encourage the development of good habits, like environmental observation and thoughtful self-reflection. The apparent dependence on machines is really co-dependence, underscoring how the primary aim of the city was not to impose a "new" reality (by covering up a previous one), or to implement a "metadesign" (that leaves nothing unplanned), but rather to respond and react creatively to the city as it already is and can be heard.

Schöffer's vision for the Cybernetic City therefore sits precariously on the boundaries: between technology and architecture; between art and politics; between sound and power. At the same time, the emphasis it places on collaboration, on cooperative creativity, might be said to exemplify the very sort of art-making Attali admired. This perhaps unexpected resonance becomes clear in the final section of Noise, where Attali describes with apparent optimism the fourth and future phase of social-sonic development, what he terms "composing." Although it has yet to fully take shape, 
it can be seen today, incoherent and fragile, subversive and threatened, in musicians' anxious questioning of repetition, in their works' foreshadowing of the death of the specialist, of the impossibility of the division of labor continuing as a mode of production. ${ }^{107}$

The music of "composing," Attali explains, might be called the music of difference. ${ }^{108}$ It appears as "a truly spontaneous music of immediate enjoyment that escaped all crystallizations," but one that, at the same time, "was also very carefully crafted and at times very intellectual." 109 While this description mirrors almost exactly Bureau's earlier comments about Chronos 3,110 it also marks an important shift in the power dynamics of sound-making: it describes the point at which the right to make sound, and to define it as music, is returned to ordinary people-marking the "essential fracture back at the entry of noise into music." "11 At the same time, it is worth mentioning how the "fracture" here is not democratic; it rather evolves over time, part of a developing consensus, established through self-discovery and self-observation: "a blossoming of the body," marked by the ability to define one's own aesthetic tastes and to implement them effectively. ${ }^{112}$

There are three central components to composing. The first is an embrace of process. As sound and music begin to reemerge not as tools of political control, but as expressions of pleasure and desire, ${ }^{113}$ the earlier phases of repetition and representation

\footnotetext{
107 Attali, Noise, 136.

108 Attali explains, the goal is "...first of all to take pleasure in the production of differences;" Attali, Noise, 142.

${ }^{109}$ Attali, Noise, 139.

110 See page 226 of this dissertation.

111 Attali, Noise, 139.

112 Ibid., 142.

113 Ibid., 143.
} 
become frustrated. Music consequently regains its focus "in the present, in production and in one's own enjoyment."'14 The second is novelty. In composing, Attali explains, "stability, in other words, differences, are perpetually called into question."115

Emphasizing the importance of difference-defined in a Deleuzian sense, as changes discerned through repetition ${ }^{116}$ — has the perhaps unintended result of empowering people to resist the fixed control and political appropriation of sound. As a result, sound, a slippery signifier, adapts and conforms to the surrounding milieu. The third component can only be described as "post-capitalism." Attali suggests composing only emerges under conditions of "permanent fragility," one where stable relations-use and exchange, among others-are no longer assumed. ${ }^{117}$

Schöffer's Cybernetic City very strongly resonates with what Attali sketches here. The embrace of process is particularly noticeable: the pleasing ambiance the towers help create is actualized in real-time as a response both to human and environmental changes. And the music they produce in response is never "finished," but rather always different, always unfolding, changing, and adapting. This leads to the second component, novelty. Indeed, if there is one persistent feature in the cybernetic city, it is change itself. As Schöffer recognized, change cannot be avoided or muted_-"everything moves"-it can only be played with and responded to. This is the special function of the towers: to monitor change, both human and natural, and to react creatively.

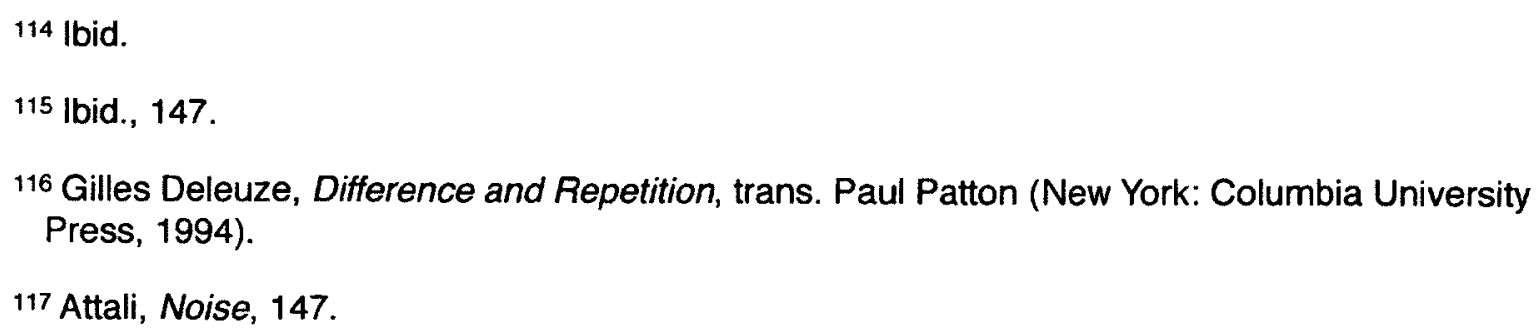


Attali also describes how sound and music, in the final phase of composing, can become a kind of sonic "cartography," performed through the incorporation of "local knowledge, the insertion of culture into production and a general availability of new tools and instruments." 18 While using the word "cartography" here metaphorically, Attali nonetheless provides a sketch that explains how and why Schöffer's vision for the Cybernetic City can be understood as a sound map. Indeed, as I argued in Chapter 1, sound maps should be understood not only as graphical representations-showing literally where or how sound can be observed-but also as a way of thinking about sound-space relationships. While leaving room for scientific principles to operate, sound maps encourage us to embrace complexity, to appreciate the pleasing and productive sonic indeterminacies as they can be found already around us.

Read through the lens of Attali's Noise, La Ville Cybernétique is not only a work of utopian literature, but a vision for what the city will sound like after the end of the music-noise dialectic. But in a much broader sense, it can also be read as a sound map. This is for several reasons. First, the philosophy underlying it resonates with the belief that space is not simply a "container" for sound. Sound, along with other sensory aspects of everyday experience, are produced together with the physical form of the city-which itself can no longer be analyzed strictly in terms of its spatial, functional, or optical characteristics. The senses, especially hearing, must be actively considered because of the way they are interwoven with form and rhythms of everyday life. The second reason is that Schöffer's plans make an attempt to represent these complex relationships: to map- 
out, technically and metaphorically, the way each element reacts and interacts with others. This can be seen not only in Schöffer's drawings and written descriptions, but in his computer schematics, which demonstrate how each element of daily life would be processed within the central cybernetic brain. Though often quite broad-leaving open, in a technical sense, how each element would be manipulated-these diagrams nonetheless demonstrate a keen understanding of the way in which designing the city means creating room for indeterminate sensory input and output.

Finally, the towers and their cybernetic programming define music broadly and inclusively - an approach that resonates with the work of composers like Stuart Marshall and Jocy de Oliveira, discussed in Chapter 4 of this dissertation. But here, in the Cybernetic City, technology comes to play a new and significant role. Not only does it demonstrate awareness of the constructive role of sonic ambience, it performs this ambience turned back on itself, showing how everyday art can be made using everyday sonic materials. Even as Schöffer leaves open the possibility that some sounds would have to be actively suppressed, for instance using "sonic mufflers," Chronos 3, among other towers, demonstrated how a particular installation site can become both the site and source of music.

\section{Learning from Schöffer's City}

Perhaps the greatest lesson of Schöffer's Cybernetic City becomes clear through studying sociological work on movement and behavior. In his book Pas à pas, for instance, Jean-François Augoyard discusses shortcuts: why people take them, how they 
rationalize taking them, and how that rationale shapes the kind of shortcut they choose. ${ }^{119}$ While this may seem banal, it is the underlying social, environmental, and political tensions-for instance, between the shortcut and the institutionally-approved pathwaythat bring to mind serious questions about Schöffer's plans for the Cybernetic City: Should we design for and with sound, accepting that people will inevitably forge their own (sonic) path, create or leave their own (sound) mark? Or do we do provide a "nonplan:" a very loose sonic framework that encourages and accommodates indeterminate action?

Indeed, with regard to the physical environment, architects over the last few decades have experimented with nearly every conceivable answer to these questionsfrom the playful work of Cedric Price to the anarcho-individualism of Archigram; from the walkable neighborhoods of New Urbanism to the philosophy of historical preservation. Meanwhile, sound artists, composers, and soundscape scholars have adopted a far more limited, indeed conservative, approach. Their work often exhibits a general resignation to the inevitability or unavoidability of "noise;" and in practice, the tendency is to react only when unplanned and unwanted sound has already become burdensome or intrusive —and to respond only by making noise less objectionable, less intolerable, or at the very least, less cheap. This, it seems, is a losing strategy, akin to resodding each new foot path through the grass in a popular urban park, or closing-up each and every unapproved passageway in a housing project.

\footnotetext{
119 Jean-François Augoyard, Step by Step: Everyday Walks in a French Urban Housing Project, trans. David Ames Curtis (Minneapolis and London: University of Minnesota Press, 2007): 29-40.
} 
The alternative becomes clear at the point where Schöffer's Cybernetic City intersects with the sound map: a city where sensory experience is considered first, rather than last or not at all; an urban environment where sonic indeterminacies become integral to the textural fabric of everyday experience, rather than potential "noise." Schöffer's plan is a radical demonstration of what $R$. Murray Schafer described at the beginning of this chapter-a leap of the imagination, a schematic that both describes "the ideal city" and provides general plans for "the types of sounds, the permitted intensities, frequencies and periodicities to be featured in different zones." ${ }^{120}$ And while some aspects present legitimate cause for concern, it bears asking what Schöffer's imaginative plans can teach us about future attempts to design the seemingly un-designable, to plan what seems unplannable. Three observations come to mind:

1. Design for change, not consistency. This is arguably the most direct lesson of the Cybernetic City. While it is easy to imagine how sound design at the urban scale might require nearly totalitarian control, Schöffer's solution suggests something else: that design is possible by engaging with what can already be heard, and by only occasionally resorting to outright prohibition or direct suppression. As Schöffer himself writes, "everything moves or we can make it move"-which suggests the most certain way to design for sound is to anticipate its very inconstancy. ${ }^{121}$ To do this, Schöffer's specific proposal relies on cybernetic intervention; but there are surely other strategies that are less reliant on technology.

\footnotetext{
120 Schafer, The Vancouver Soundscape, 66.

121 Schöffer, La Ville Cybernétique, 112.
} 
2. Technology has a role to play, but it should not dominate. If Schöffer is right, then cybernetics will enhance our ability to harness and manipulate fractional space in new and productive ways. While it is important not to be deterministic about the promise of new technology, it should not be feared either. Unlike Schafer and the World Soundscape Project, who seem to idealize pre-industrial sound environments, Schöffer recognizes the already pervasive presence of technology in society. In that sense, not only might "noisy" technologies like helicopters be welcomed for enhancing transportation flexibility, but for introducing a new sense of dynamism to the urban-sonic program.

3. Leave room for people. Despite the impressive, even phantasmagorical, nature of Schöffer's city, the focus never strays too far from human experience. While largescale questions of agency are ultimately left unanswered in his work-questions, for instance, about people who do not want to live in a cybernetically controlled urban environment-small scale agency lies at the very center of his vision. Despite seeming highly planned, scripted, and centrally organized, ordinary people continue to have an active say in how the city sounds. There is no feedback without new input; and for that reason, the city's cybernetic infrastructure leaves open the possibility that anyone can participate in the artful construction of everyday life: twisting knobs, making new ambient sounds, taking note of the world as it can be heard.

\section{Conclusion}

I began this chapter by exploring the work of mid- $20^{\text {th }}$ century utopian urbanist Nicolas Schöffer. His 1969 book La Ville Cybernétique observed a general decline in contemporary society—the result of what he called "médiocrisation"—readily apparent 
in manufactured goods, popular entertainment, and importantly, the sequestration of scientific knowledge. This decline had another important effect: a cultural preference for quantitative abundance, a desire for more things, whose accumulation has ultimately impeded our ability both to navigate the world and interact with it meaningfully. To remedy this problem, Schöffer proposed to remodel urban life completely.

Doing this would first require gaining control of fractional space-the experiential and sensory textures-which would itself require adopting a topological view of the environment—one that subdivides ordinary experience into five areas: light, climate, sound, weather, and air. In doing so, Schöffer believed it would be possible to restore balance to modern life, to elevate the human spirit, and to minimize disruptive "perturbations." Many interventions into fractional space would be executed by giant cybernetic towers. A number of prototypes, some of which predate the publication of $L a$ Ville Cybernétique, model what Schöffer had in mind. Chronos 3, built outside Liège during 1961, used environmental sensors to observe shifts in the urban ambience. It subsequently performed a visual and sonic spectacle, one that complemented the urban ambience as it could be seen and heard already. The program for Chronos 3 included broadcasting randomized fragments from a piece of musique concrète called Spatiodynamisme, composed by electronic music composer Pierre Henry.

In later sections of this chapter, I explored several critical approaches to Schöffer's work. The first and most recent critique is exemplified by architectural historian Larry Busbea, who historicizes Schöffer's vision by situating it relative to other utopian visionaries of the period. Another critical approach analyses how the Cybernetic 
City intersects with materialist critiques of capitalism. Jean Baudrillard, for instance, argues that Schöffer's vision legitimizes functionalism, and in doing so, becomes little more than an attempt to control "effects." A third line of critique can be developed from Jacques Attali's Noise. The Cybernetic City, I suggested, could be read as performing the third phase of sonic-social development, what Attali called "repeating."

Many of these critiques, however, seem to miss their mark. Schöffer, in fact, shared many of Baudrillard's and Attali's concerns-about consumerism, alienation, political power, and technology - which he lumped under the single term "médiocrisation." His plan for the Cybernetic City furthermore left ample space for human interactivity, cooperative social engagement, and collective art-making. And in that sense, it might be said to exemplify the "future" of music, what Attali rather optimistically termed "composing." As a form of social and political cartography, the Cybernetic City marks the return of "local knowledge, the insertion of culture into production and a general availability of new tools and instruments." 122

It is clearly more difficult to propose a vision than to critique one, or to suggest it is possible to have one. Where scholars including Barry Truax and R. Murray Schafer have identified the need for acoustic design at the urban scale, none have offered a coherent vision for how and why the city might be literally composed. In that respect, the Cybernetic City, its towers especially, deserve a prominent place among contemporary music and sound studies scholarship. As a literary sound map, it not only raises important 
questions about our relationship to sound, it theorizes in extraordinary detail how those relationships might be more effectively and dynamically sutured. 


\section{Conclusion}

The increasing mobility of music technologies, and the seemingly paradoxical emphasis on identity that surrounds analysis of musical consumption today, reveal how much the ongoing (re)shaping of listening habits is tied to our changing sense of location: where we are, where the music can take us, where we belong.

-Jody Berland, "Locating Listening"

\section{Concluding Thoughts}

Over the last five chapters, I have sketched a critical and cultural history of sound maps: from their conceptual origins in architectural acoustics, to their wide-spread use in urban noise studies and music notation, and their influence on utopian urban planning. Perhaps it goes without saying that the definition of a "sound map" is necessarily broad and, like sound itself, slippery and ephemeral. And yet, this very slipperiness is what makes sound maps both versatile and widely useful. In general, sound maps can be understood as both physical objects and as a modality of engagement; a form of writing and a way of thinking; a means of describing sound while summoning it from invisibility. Still, much work remains to be done from this point. While the identification, analysis, and critique of sound maps could proceed in a number of new directions, in the last few pages of this dissertation, I wish to highlight a few that offer special promise and appeal.

\section{Place-studies}

As Jody Berland explained in her essay, "Locating Listening," the rise of portable media technologies has, over the last few decades, radically transformed how we relate to sound. Electronically-broadcast music—what Berland, following the World Soundscape Project, calls "schizophonic"-has altered not only the way in which identities are created, but, even more extensively, it has changed the nature of our interactions with the everyday environment and the economy more broadly. When we move, whether by car or 
by foot, we bring our own, personalized and individualized sounds with us. And while music is commonly understood to articulate time, "which we then notice all the more," the space and spatiality of sound continues to pass virtually unnoticed. ${ }^{1}$ As a result, she writes,

[w] don't place ourselves and the sounds in a spatially conceived map of synchronic and diachronic movement, evaluate from whence we are addressed, or consider how we are positioned by the instruments that bring that touching address to our ears. Thus we fail to apprehend the places we inhabit, not as visible points in physical space, but as the product of diverse and complex forces. ${ }^{2}$

Maps, it would seem, could play a significant role in changing (or at the very least, challenging) how we experience and define a sense of place. As a tool, they can be used to highlight complexity, to expose the social, cultural, and economic forces that give shape to identity. As Berland further explains, "the presence of Canadian music-whether white, Native, African, or Afro-American, or many others- - on radio or television becomes the electronic equivalent of land claims on the ground."3 Disentangling such territorial claims might very well become a primary function of sound maps. Much like the dynamic type discussed in Chapter 2, they could be used to trace the outline of "reproducible space" — an especially important and relevant task today, as the geography of music continues to emerge as a serious area of research.

\footnotetext{
1 Jody Berland, "Locating Listening: Technological Space, Popular Music and Canadian Mediations," in The Place of Music, edited by Andrew Leyshon, David Matless, and George Revill (New York: The Guilford Press, 1998), 129.

2 Ibid., 130.

3 lbid., 145.

4 lbid., 146.
} 


\section{Regulatory Verification}

As discussed at length in Chapters 2 and 3, sound maps are commonly used as an instrument in government regulation-exemplified by the territory sound map type, and epitomized by Part 150 "Noise Exposure Maps." And yet, an important question remains unanswered: Do these maps bear any resemblance to what actual people experience, or do they represent nothing more than an already-institutionalized image of sound? Or, put in the words of Cornelius Cardew: ${ }^{5}$ Whom do these maps serve? Even as this dissertation nears completion, questions like these leave me feeling apprehensive. Conceivably, though, sound maps could be turned back onto this problem. Much as I suggested at the end of Chapter 3, we could create a counter-discourse: new maps, especially dynamic and field maps, intended to verify and/or challenge the image of sound proposed by regulatory authorities like the FAA or DEFRA.

This is unquestionably an activist approach, one that requires opening the performative authority of the map to critique, while simultaneously relying on specialists to enroll the public in the process of mapping. The resulting counter-discourse would engage crucial questions: Do the contours shown on any particular NEM reflect noise exposures that can actually be heard? Does the DNL resemble anything that approximates the psychoacoustic conditions of everyday life? This information would then need to be buttressed by the observations of acculturated residents, much in the spirit of the World Soundscape Project. It may be discovered, for instance, that sound emanating from an airport is perceived psychoacoustically as much louder than empirical measurements would otherwise suggest-especially in cases where the surrounding environment is rural

${ }^{5}$ Cornelius Cardew, Stockhausen Serves Imperialism (London: Latimer New Dimensions, 1974). 
(or "hi-fi"). Conversely, airplane noise might be perceived as much quieter than empirically measured if a nearby highway has already, in effect, desensitized the publicwho have already become accustomed to a higher level of ambient noise. In either case, these subtleties, these possible disjunctions between empirical fact and perceived reality, need focused attention.

The medium of the sound map I believe will play an increasingly important role in collating observations and directing further inquiry. Indeed, whatever specific methodology is used, the goal must be to find the coordinates of the "middle ground:" it must be to locate where lived reality intersects with sound estimates, decibel readings, the institutional power of the state, and the economic power of the global economy.

Furthermore, and when necessary, it must be to challenge the performativity of maps, especially those which put the interests of non-living entities above the needs and wishes of human and non-human animals, whose health and well-being otherwise depend on clear and consistent access to the environment as audible.

\section{Music notation}

Earle Brown once wrote that "[we] have a 'crisis of consciousness,' and it has changed the nature of the artist's relationship to his work, and the relationship of the work to a performer, reader, viewer, or listener." This "crisis," he said, was being driven as much by the evolution of philosophical and scientific thought as anything else. "What is being challenged" is the "concept of what is 'art' in music today, and this is rightfully a

\footnotetext{
6 Earle Brown, "The Notation and Performance of New Music," Musical Quarterly 72, no. 2
} (1986): 197. 
constantly recurring problem which indicates that the art is still vital and alive." 0 One way to tell whether music is "vital and alive," he suggests, is through examining its notational practices. Just as composers living centuries ago (though Brown mentions none by name) were concerned with how their music was written, Ives, Cowell, and other composers throughout the late 19th and early 20th centuries often sought innovative ways to notate their ideas. But today's composers, Brown writes, have become too heavily burdened by history. Worse still, they have increasingly erred in the direction of "discrete control," only to find themselves unable to achieve the precise results they are looking for.

Indeed, all too often, developments in musical notation are framed as though they reflect strictly musical problems. The appearance of sound maps as a notational form complicates this tendency, however, by linking new ways of writing sound with new ways of thinking about sound-space interactivity-with developments in science and philosophy that Brown mentions above. This, in turn, suggests two possible directions for composers and scholars of music. First, it suggests a return to notational experimentation. Many new and ambitious forms, including what Erhard Karkoschka has called "musical graphics," ${ }^{8}$ were in large part abandoned at the end of the $20^{\text {th }}$ century as composers and audiences returned to more conservative ways of writing music. By articulating un- and under-appreciated conceptual linkages, sound maps challenge us to try new things, to develop new forms of notation that to reflect the current state of scientific, cultural, and artistic discourse.

\footnotetext{
7 Ibid., 180.

${ }^{8}$ Erhard Karkoschka, Notation in New Music: A Critical Guide to Interpretation and Realisation, trans. Ruth Koenig (New York and Washington: Praeger Publishers, 1972), 77.
} 
Second, it suggests scholars should begin to theorize musical notation in terms that are much broader than those they have become accustomed to. As I outlined in Chapter 4, notational practices should not be considered apart from culture and society: as it is written and conceived, music unavoidably contributes to and participates in a dialog with politics, public discourse, and even attitudes about the environment. Sound maps, then, are just one of many "unusual" and "unorthodox" notational practices worthy of broader contextualization. Now, other varieties deserve similar treatment. In addition to developments in architectural acoustics, it is conceivable that cold war game theory, theories about the "selfish gene," and radical social experiments of the 1960s and 70s (including "hippie" communes) could and should be linked to mid-century notational practice.

Finally, whatever the future study of sound maps may bring, I hope this dissertation has provided a useful starting point, a few places to begin thinking about and engaging with the environment as already and richly sounded. 
Appendix: Figures 


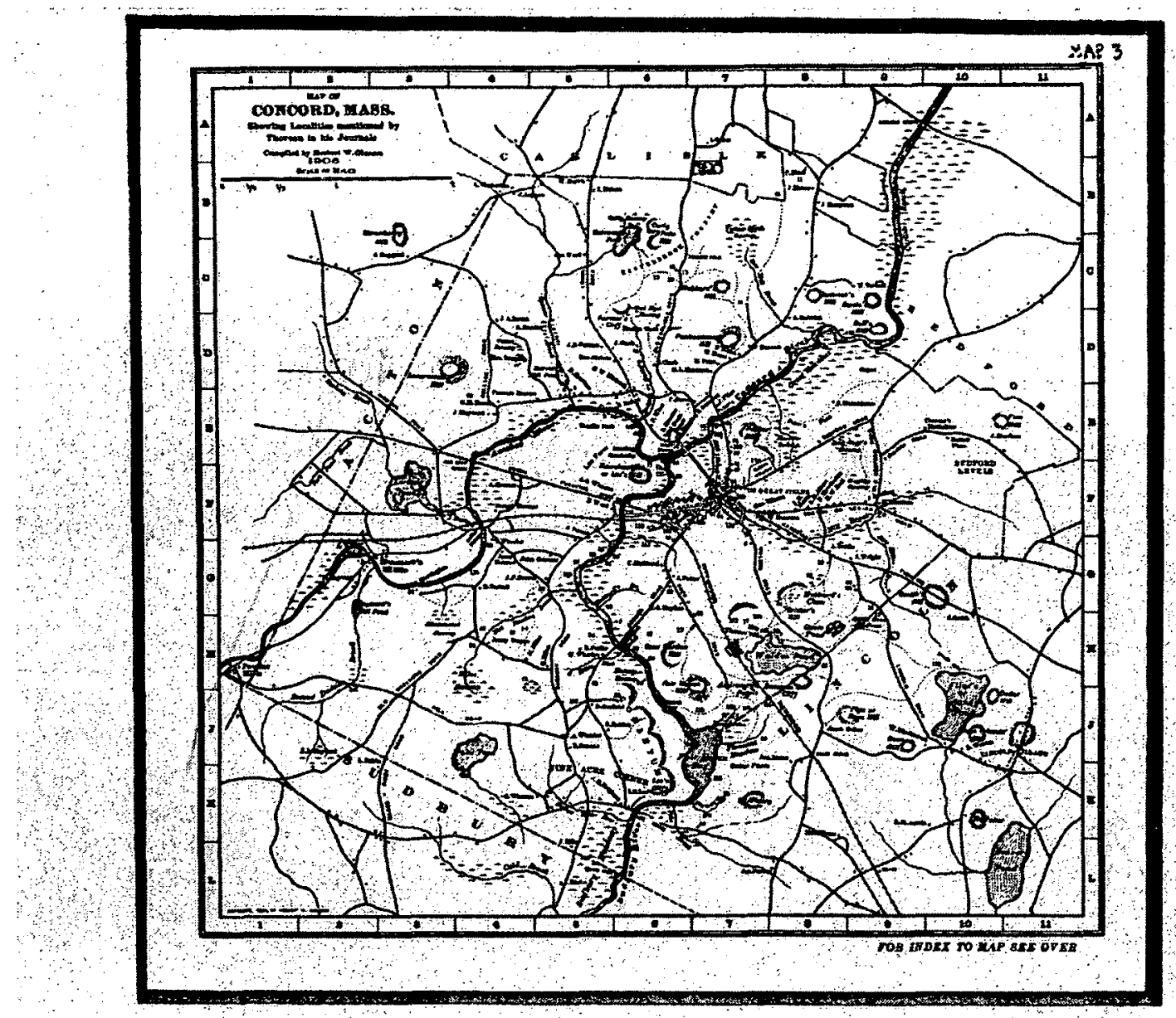

Figure 0-1. Map of Concord, MA included with the score for Song Books, Volume I by John Cage. The accompanying text instructs performers to draw a line between two places on the map and to interpret the resulting trace as a melody. The words to be sung with the melody come from a poem by Henry David Thoreau. (Image from: John Cage, Song Books Song Books, Volume I: Solos for Voice: 3-58 [New York and London: C.F. Peters, 1970].) 


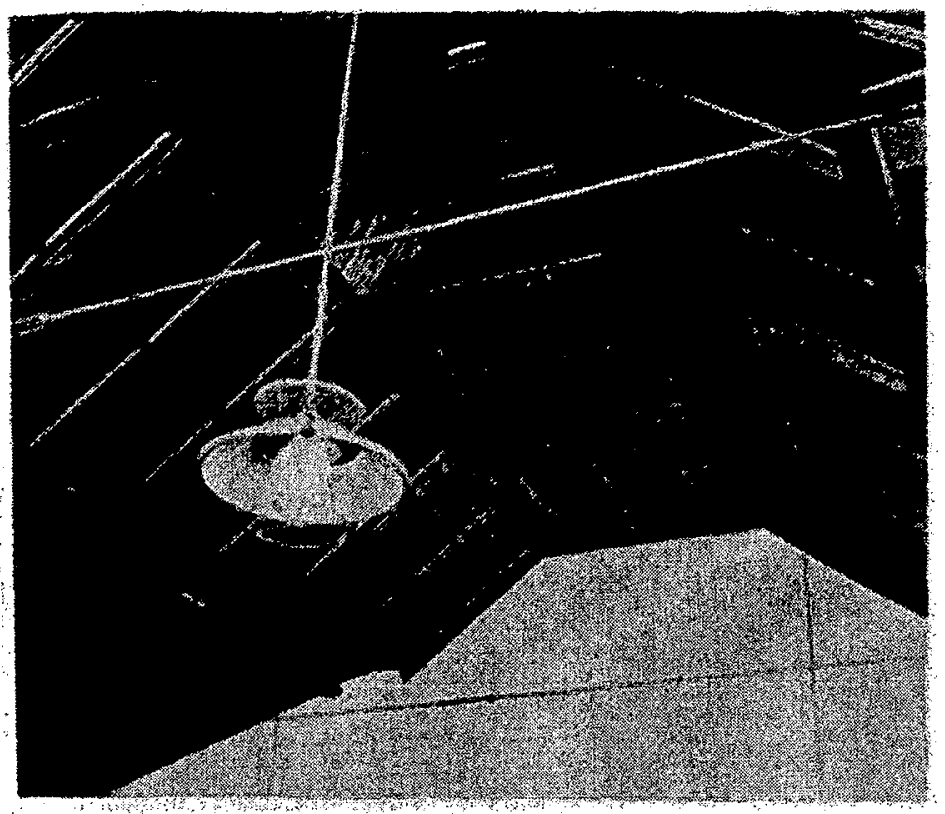

Figure 1-1. A superstitious solution to the problem of unwanted reverberation: suspending long lengths of metal wire from one end of a room to the other, just below the ceiling. The belief that strings would mitigate poor acoustics was dispelled by the research of Wallace Sabine. (Image from: Wallace Clement Sabine, Collected Papers on Acoustics [Cambridge, MA: Harvard University Press, 1922], 133.) 


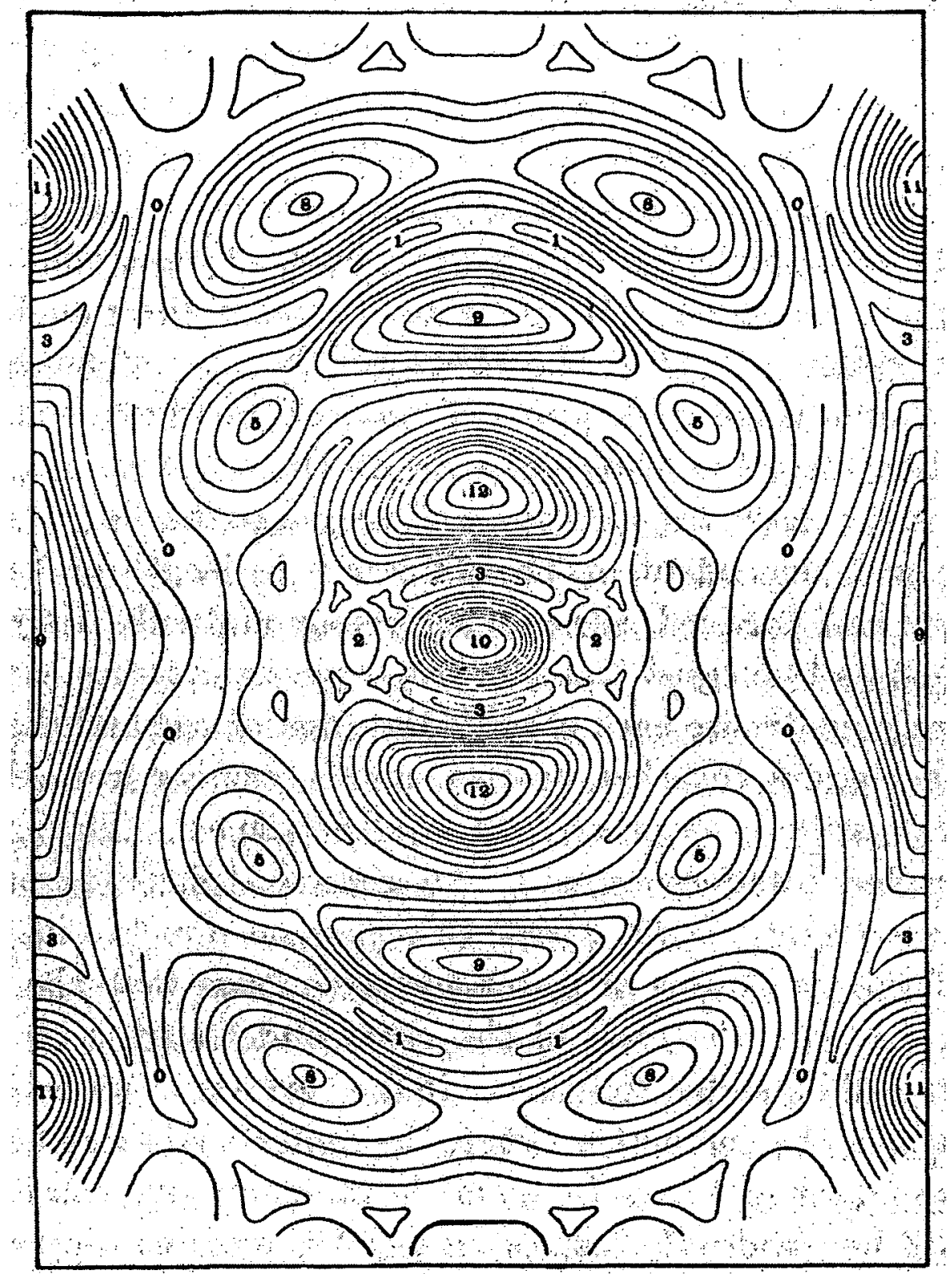

Figure 1-2. A sound map showing intensity contours. This image, created by Wallace Sabine, shows observed variations in a rectangular room with a barrel-shaped ceiling. The varying intensity levels shown on this map, for instance, 10 in the center and 11 in the corners, are relative and not determined by an "objective" scale. (Image from: Wallace Clement Sabine, Collected Papers on Acoustics [Cambridge, MA: Harvard University Press, 1922], 152.) 

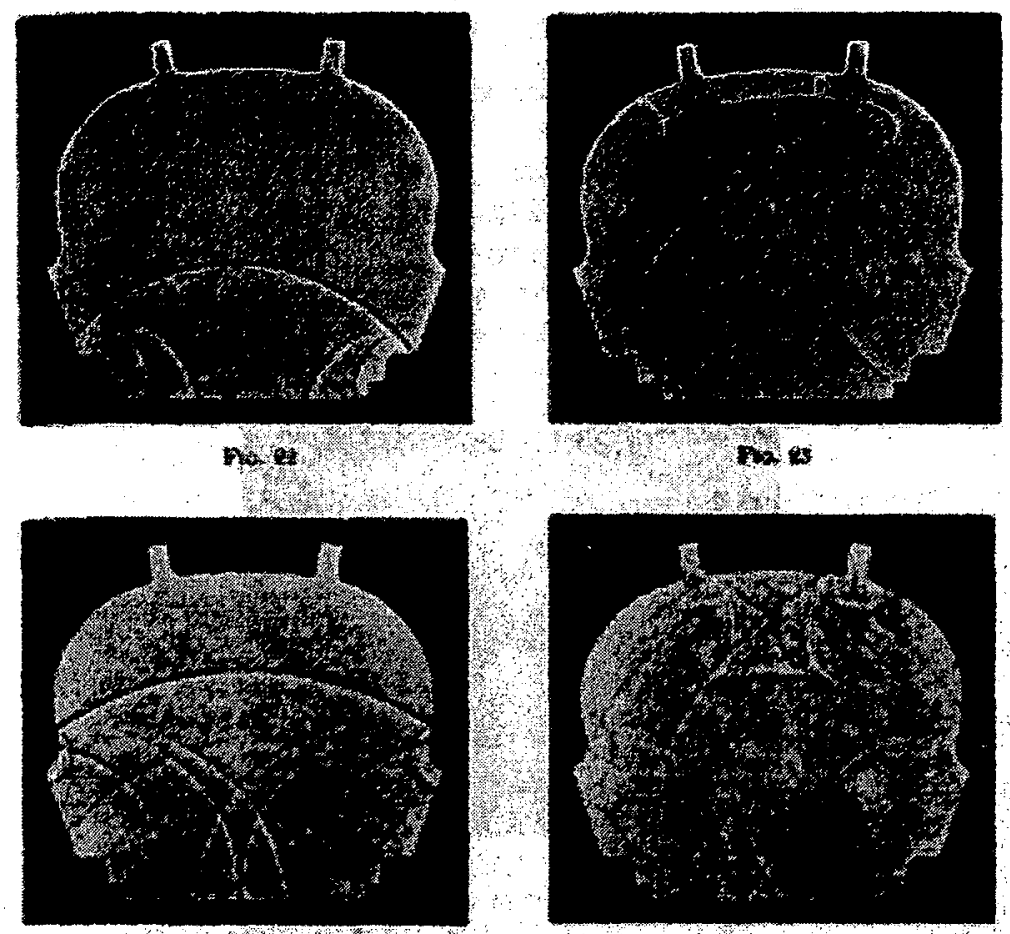

Ax.

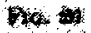
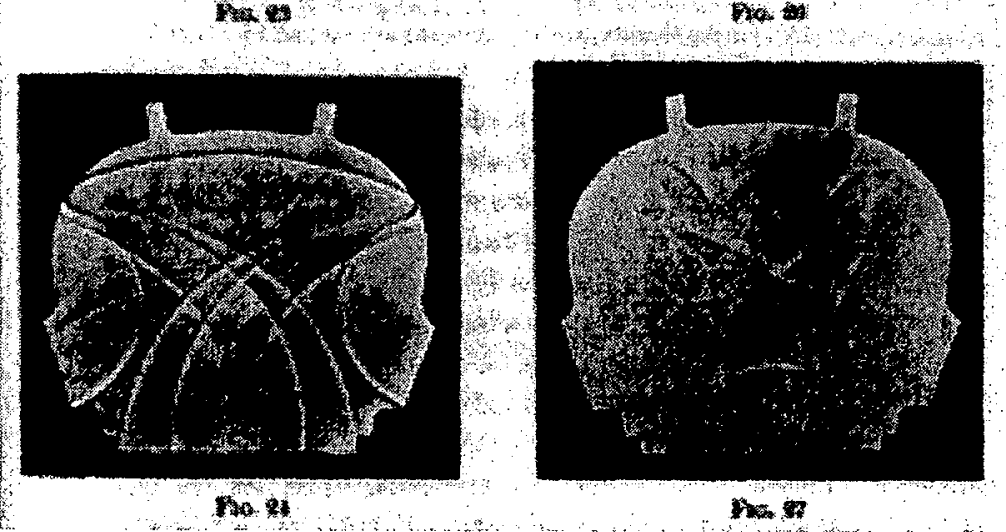

Figure 1-3. A succession of photographs made by Wallace Sabine using schlierenMethode photography. These image show the movement, reflection, and dispersion of a single pulsed wave. The image sequence proceeds from the top left to the bottom right. (Image from: Wallace Clement Sabine, Collected Papers on Acoustics [Cambridge, MA: Harvard University Press, 1922], 185.) 


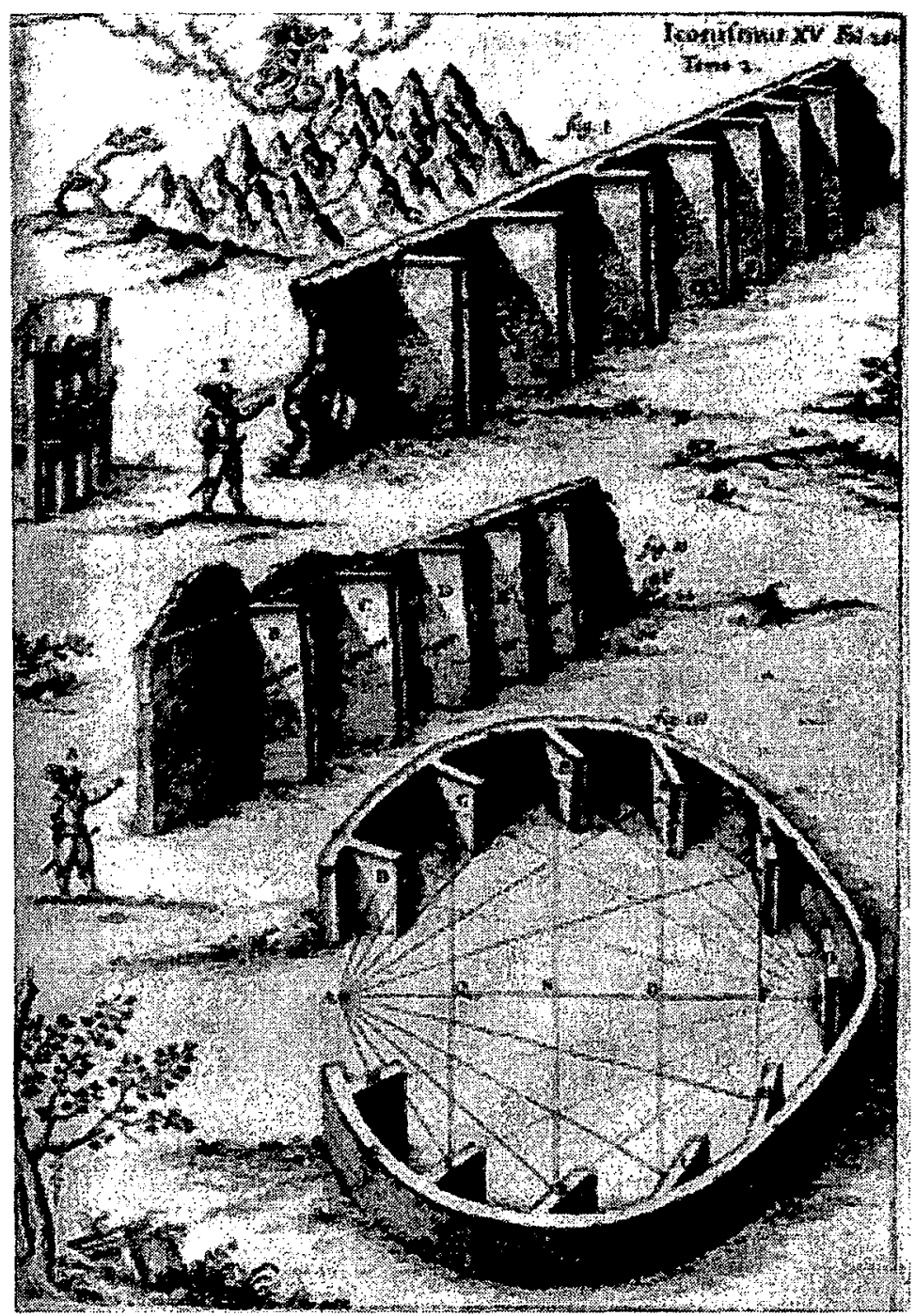

Figure 1-4. In this image, Kircher shows how "a series of equally spaced walls, or towers, will reflect the voice in a multiple echo." (Joscelyn Godwin, Athanasius Kircher's Theatre of the World: The Life and Work of the Last Man to Search for Universal Knowledge [Rochester, VT: Inner Traditions, 2009],164) The lines have a double function: not only do they demonstrate the specific acoustic effect in question, but are speculative stand-ins for sound as it encounters each new reflective surface. It is, in that respect, an inaccurate and misleading image, since sound does not move like a ray, but as shown by Sabine, like a wave. (Image from: Athananasius Kircher, Musurgia Universalis [Rome, 1650], 246.) 


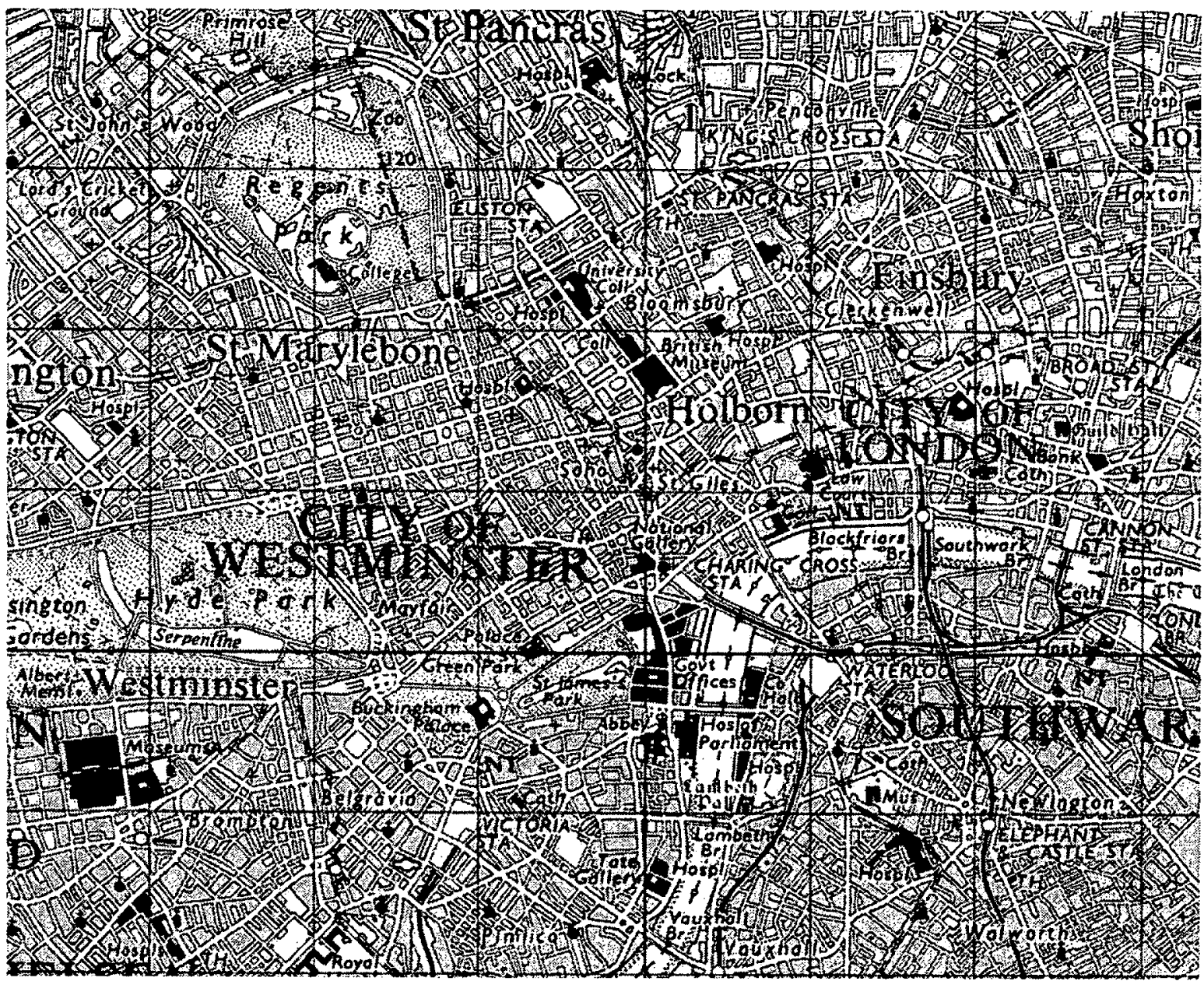

Figure 2-1. Detail view of a map published in the London Noise Survey showing the area covered during the objective survey. While this image depicts reference lines, this grid was not used to frame the scope and aims of the survey itself. (Image from: Building Research Station, Ministry of Public Building and Works, London Noise Survey, Her Majesty's Stationery Office: London, 1968.) 


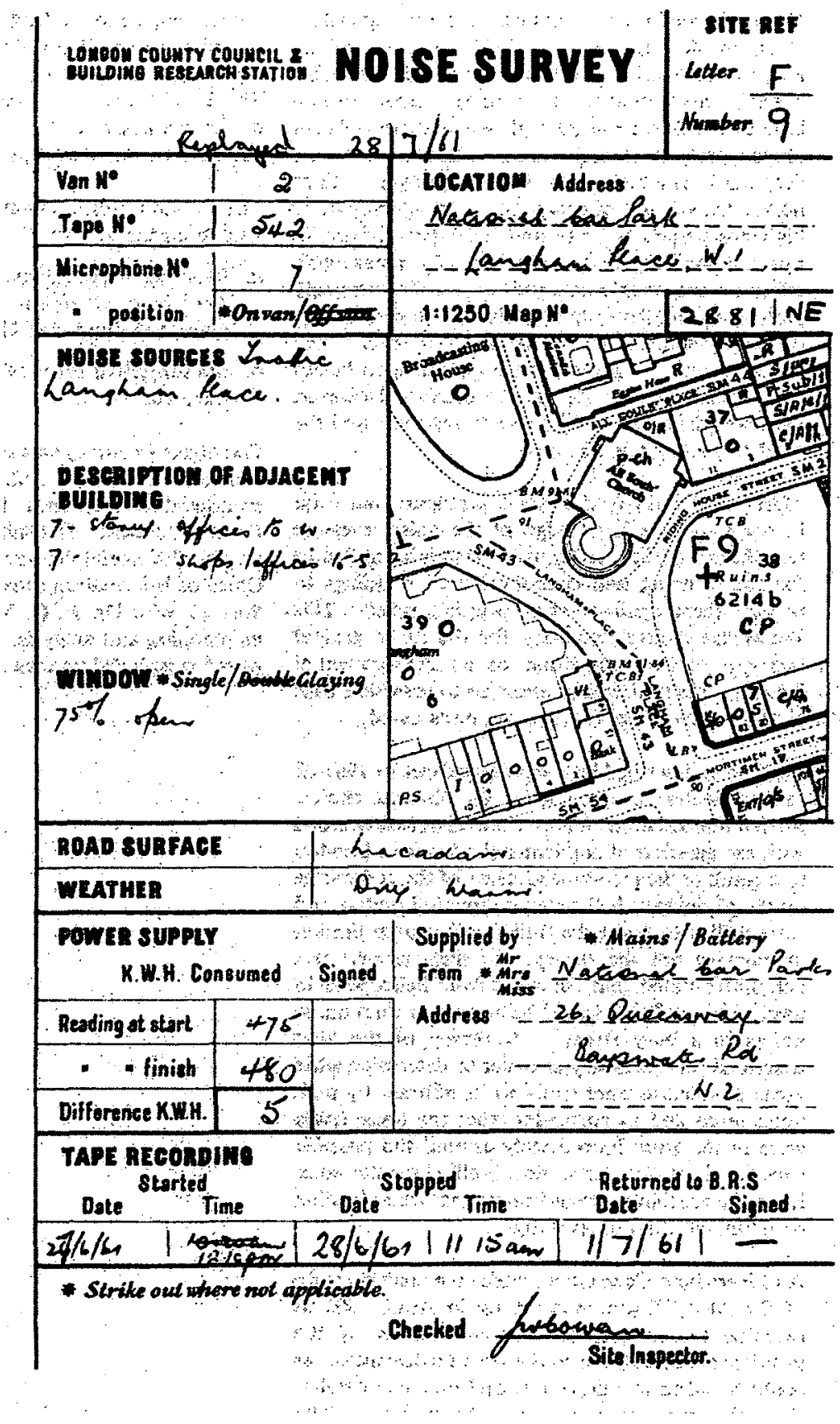

Figure 2-2. Initial report form published in the London Noise Survey, showing the location of the recording van, a description of the local environment, and other details, such as weather conditions. (Image from: Building Research Station, Ministry of Public Building and Works, London Noise Survey [Her Majesty's Stationery Office: London, 1968], 2.) 

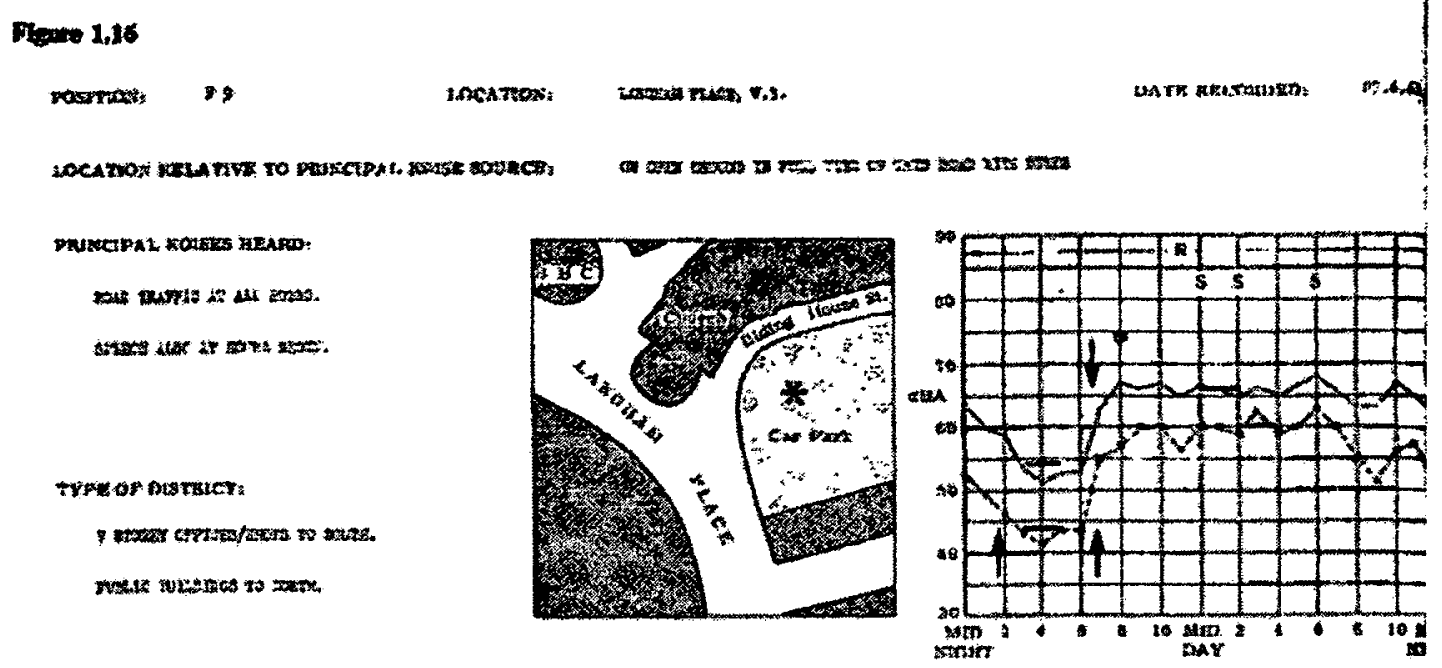

Figure 2-3. Published version of Figure 2-2 above. The asterisk marks the location of the recording van. Principal noises heard include "road traffic," and the graph to the right shows the average high and low decibel readings for an average day of the week. (Image from: Building Research Station, Ministry of Public Building and Works, London Noise Survey [Her Majesty's Stationery Office: London, 1968], 44.) 


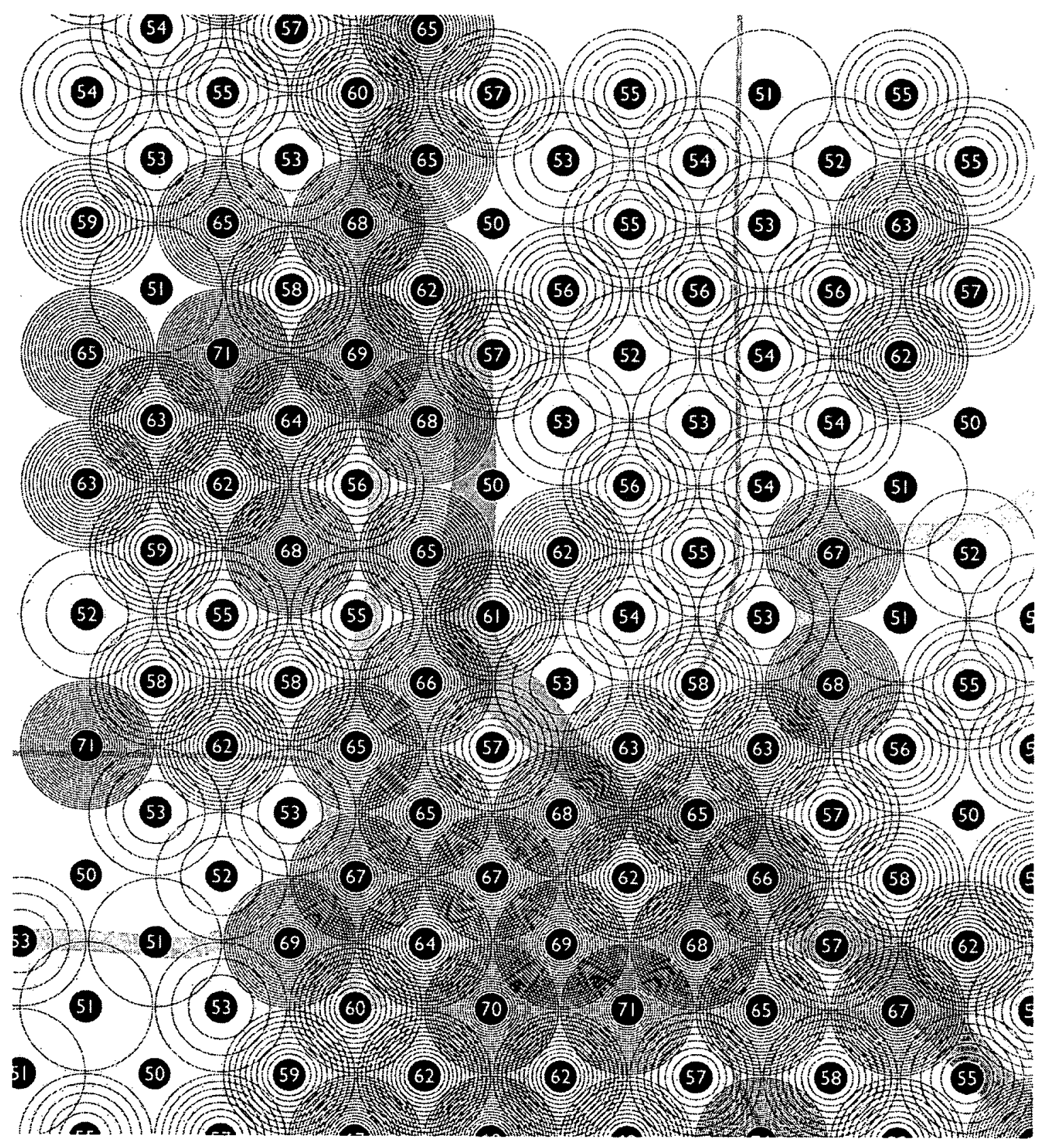

Figure 2-4. Detail of grid map, "466 Decibel Readings," designed by Rachel Thompson and Jonathan Zorn. (Image from: Jonathan Zorn, Rachel Thompson, et al, 466 Decibel Readings and 50 Sound Stories, map created for the Twin Cities Design Festival in 2003, organized by the Walker Art Museum; copy held in the author's possession.) 


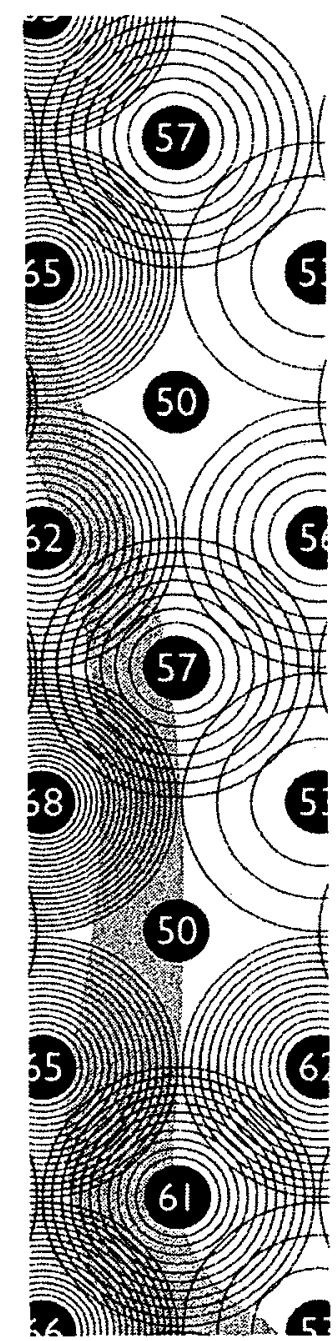

Figure 2-5. Detail of Figure 2-4 showing decibel readings with a corresponding number of concentric circles. (Image from: Jonathan Zorn, Rachel Thompson, et al, 466 Decibel Readings and 50 Sound Stories, map created for the Twin Cities Design Festival in 2003, organized by the Walker Art Museum. Copy held in the author's possession.) 


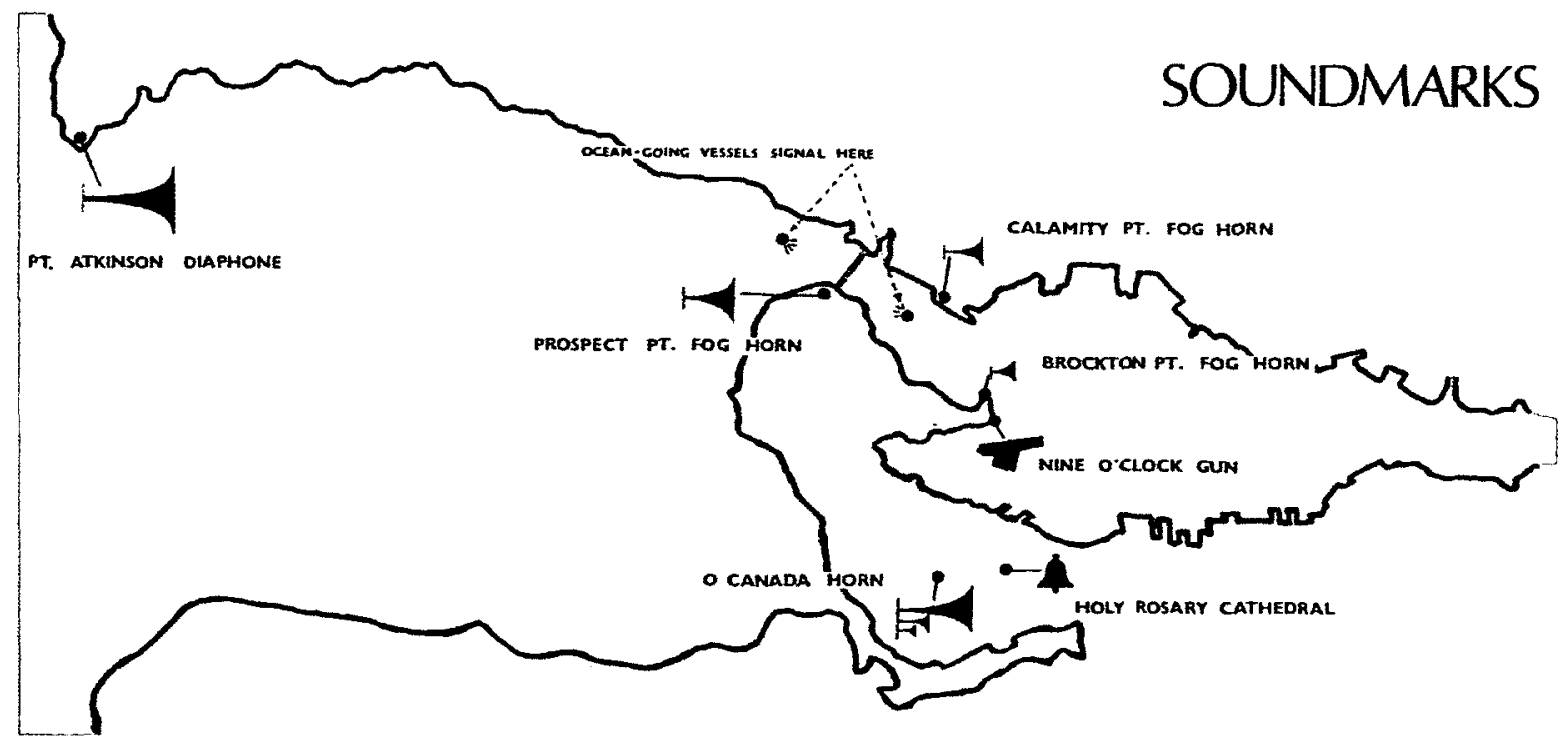

Figure 2-6. Field map of Vancouver showing "soundmarks" in the harbor. (Image from: R. Murray Schafer, ed., The Vancouver Soundscape [Vancouver: A.R.C. Publications, 1978], 36.) 


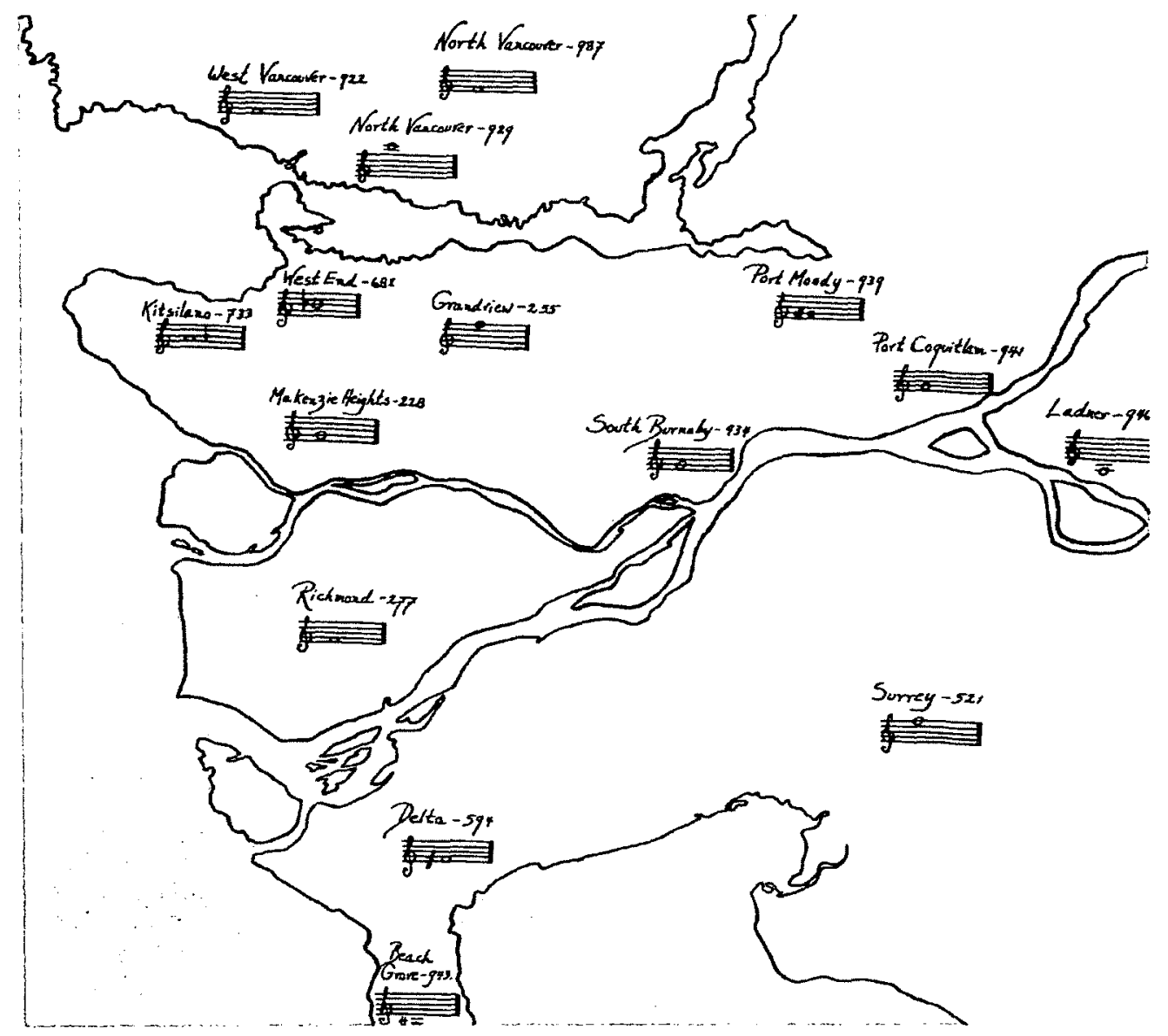

Figure 2-7. Map showing the pitch of various telephone dial tones in Vancouver. (Image from: R. Murray Schafer, ed., The Vancouver Soundscape [Vancouver: A.R.C. Publications, 1978], 43.) 


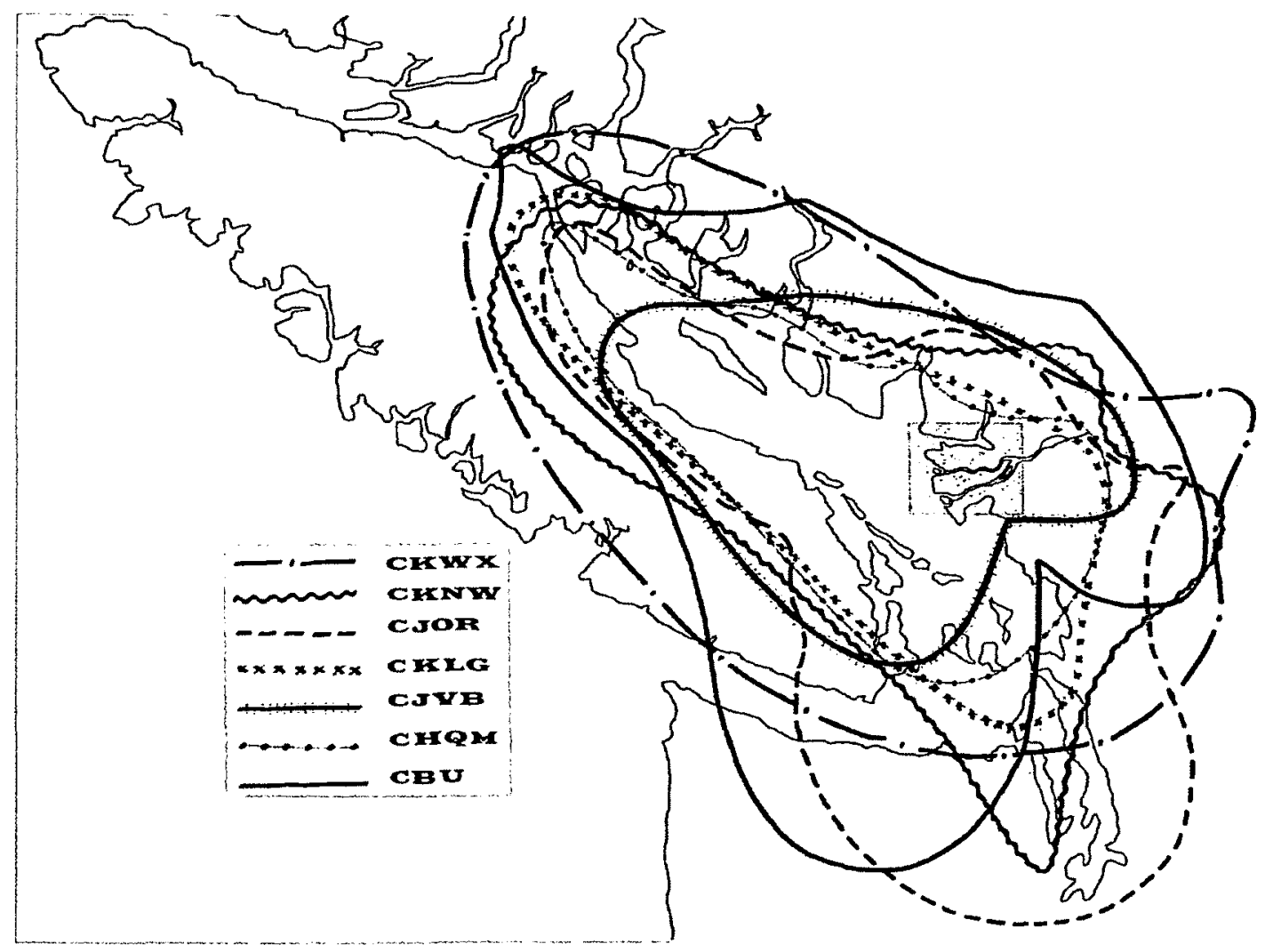

Figure 2-8. Map showing the broadcast range of different radio stations in the Vancouver area. (Image from: R. Murray Schafer, ed., The Vancouver Soundscape [Vancouver: A.R.C. Publications, 1978], 40.) 


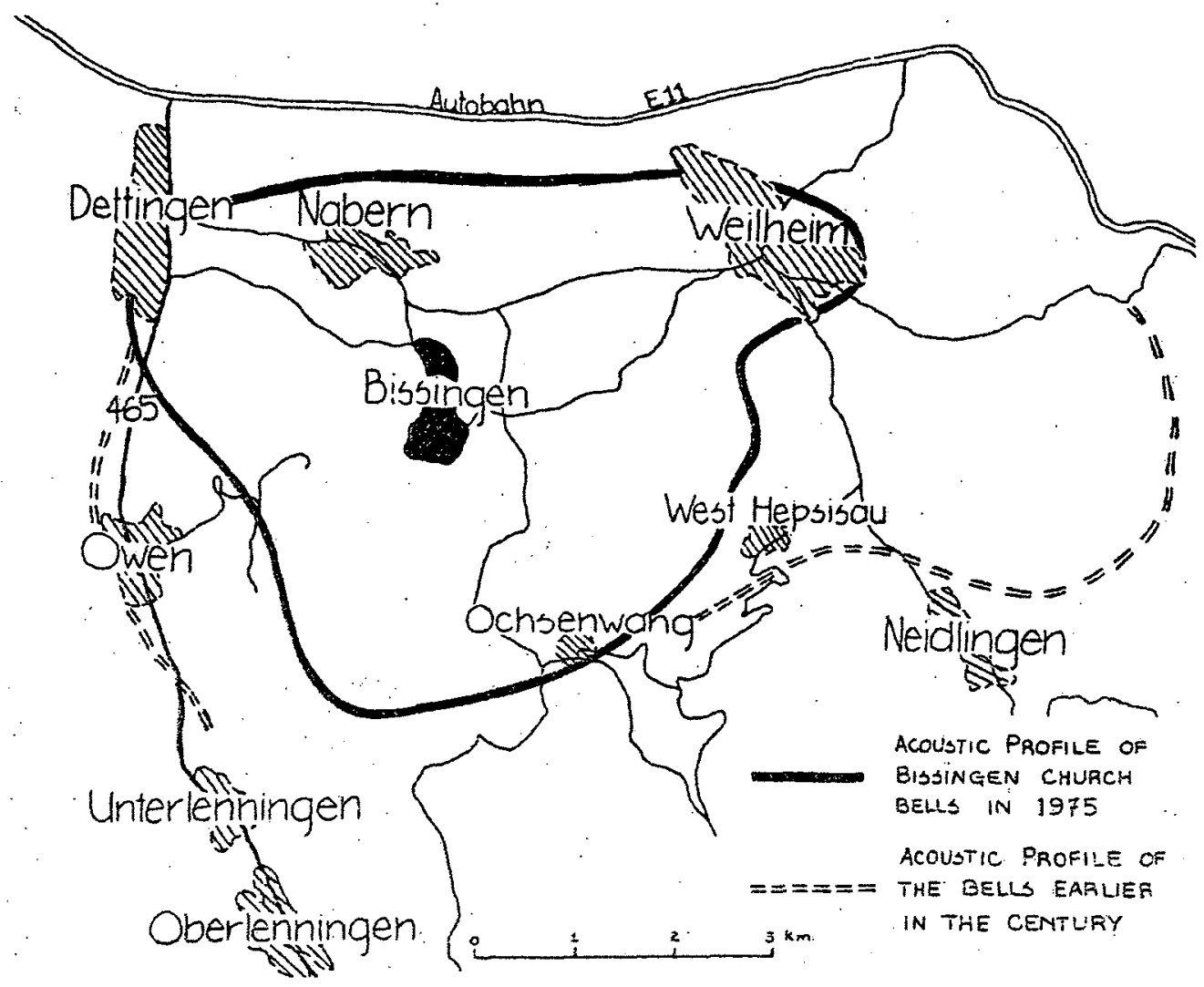

Figure 2-9. Map of Bissingen, Germany showing the psychoacoustic profile of the village church's bell. (Image from: R. Murray Schafer, ed., Five Village Soundscapes [Vancouver: A.R.C. Publications, 1977], 53.) 


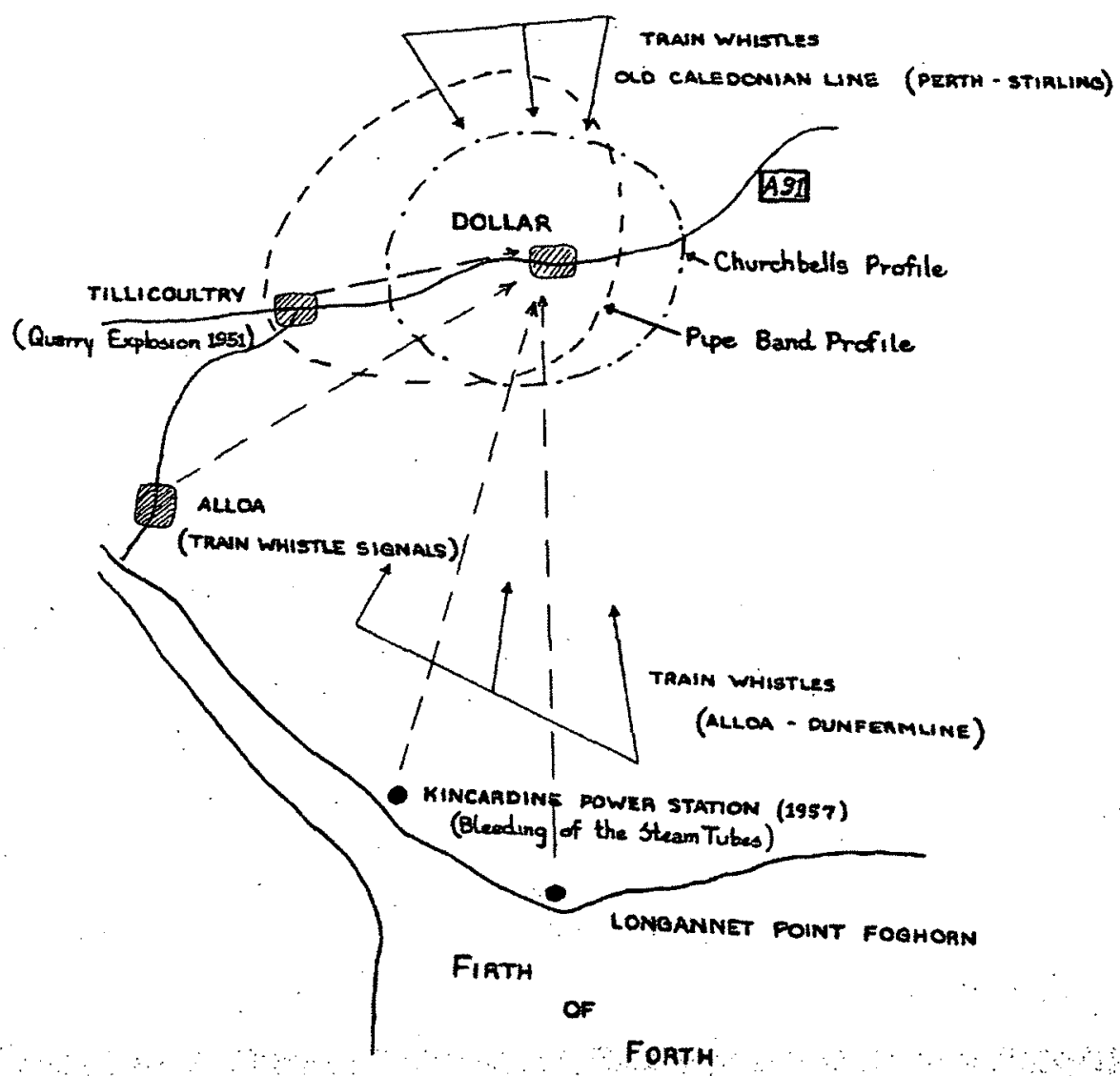

Figure 2-10. Map showing the aural composition of Dollar, Scotland. (Image from: R. Murray Schafer, ed., Five Village Soundscapes [Vancouver: A.R.C. Publications, 1977], 57.) 


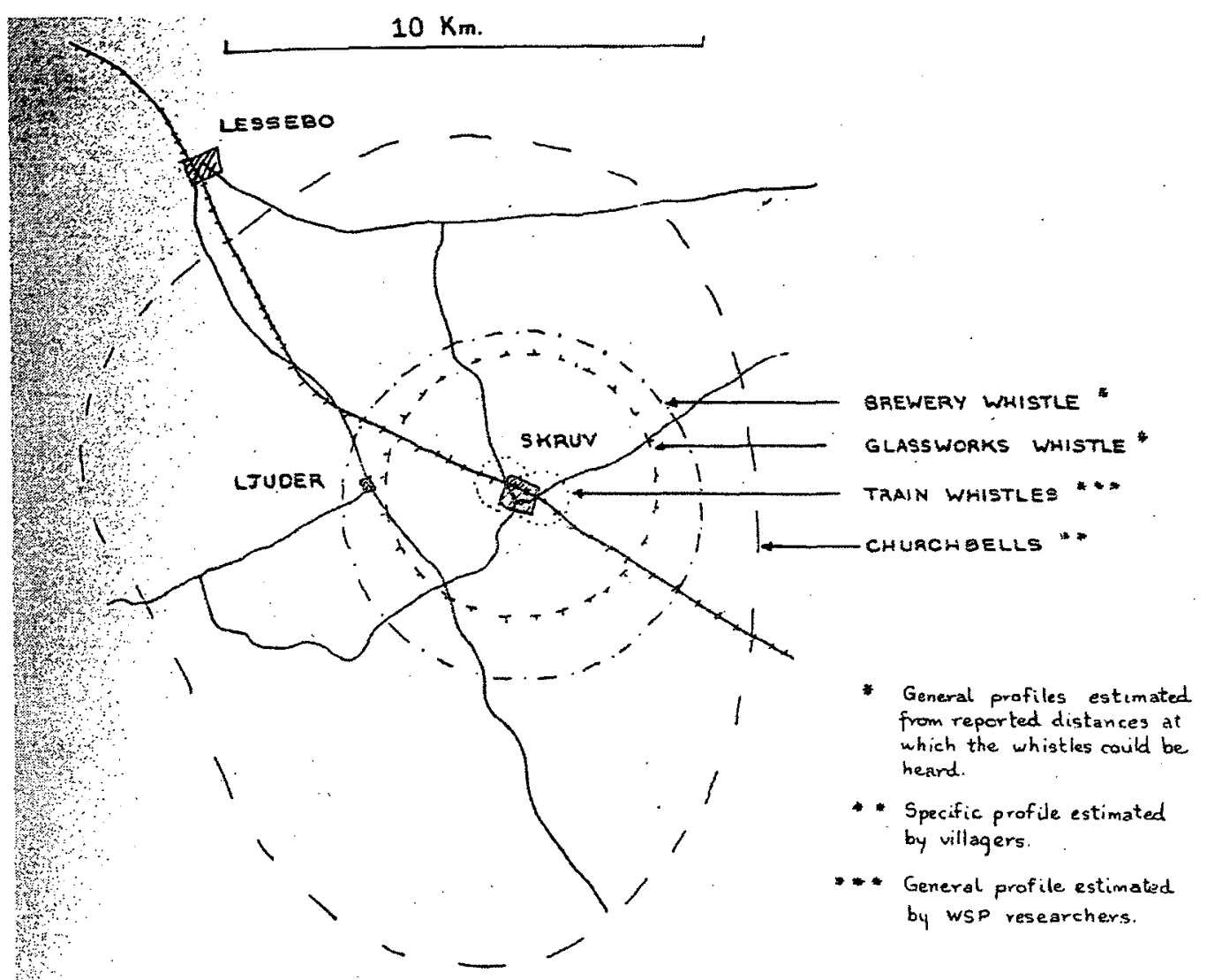

Figure 2-11. Map showing the "physical areas encompassed by the signal sounds of Skruv." (Image from: R. Murray Schafer, ed., Five Village Soundscapes [Vancouver: A.R.C. Publications, 1977], 51.) 


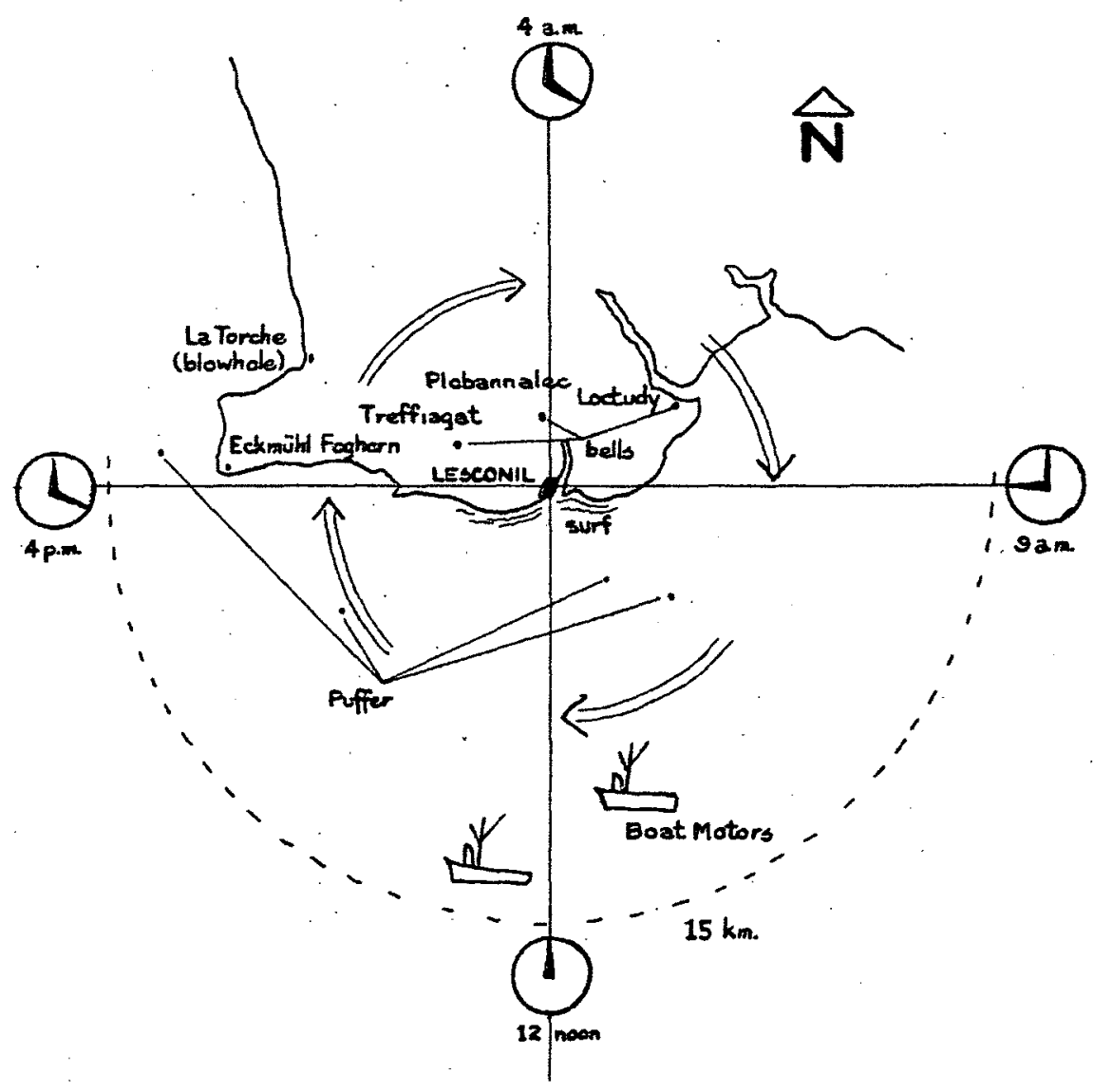

Figure 2-12. "Solar Wind Cycle and Sound" map of Lesconil, France. (R. Murray Schafer, ed., Five Village Soundscapes [Vancouver: A.R.C. Publications, 1977], 55.) 


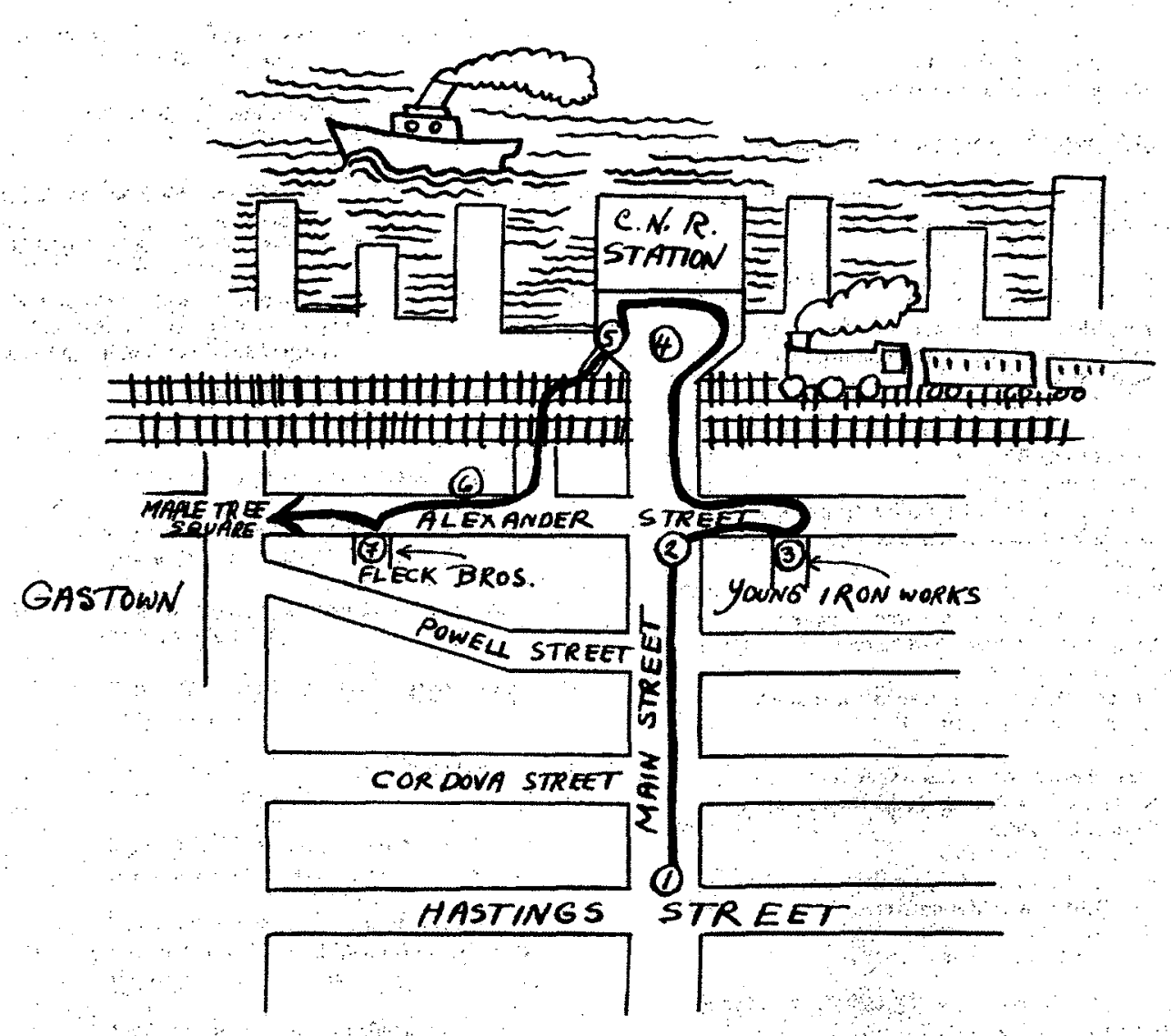

Figure 2-13. Soundwalk map showing a sequence of points and a path to be followed. (Image from: R. Murray Schafer, ed., The Vancouver Soundscape [Vancouver: A.R.C. Publications, 1978], 70.) 


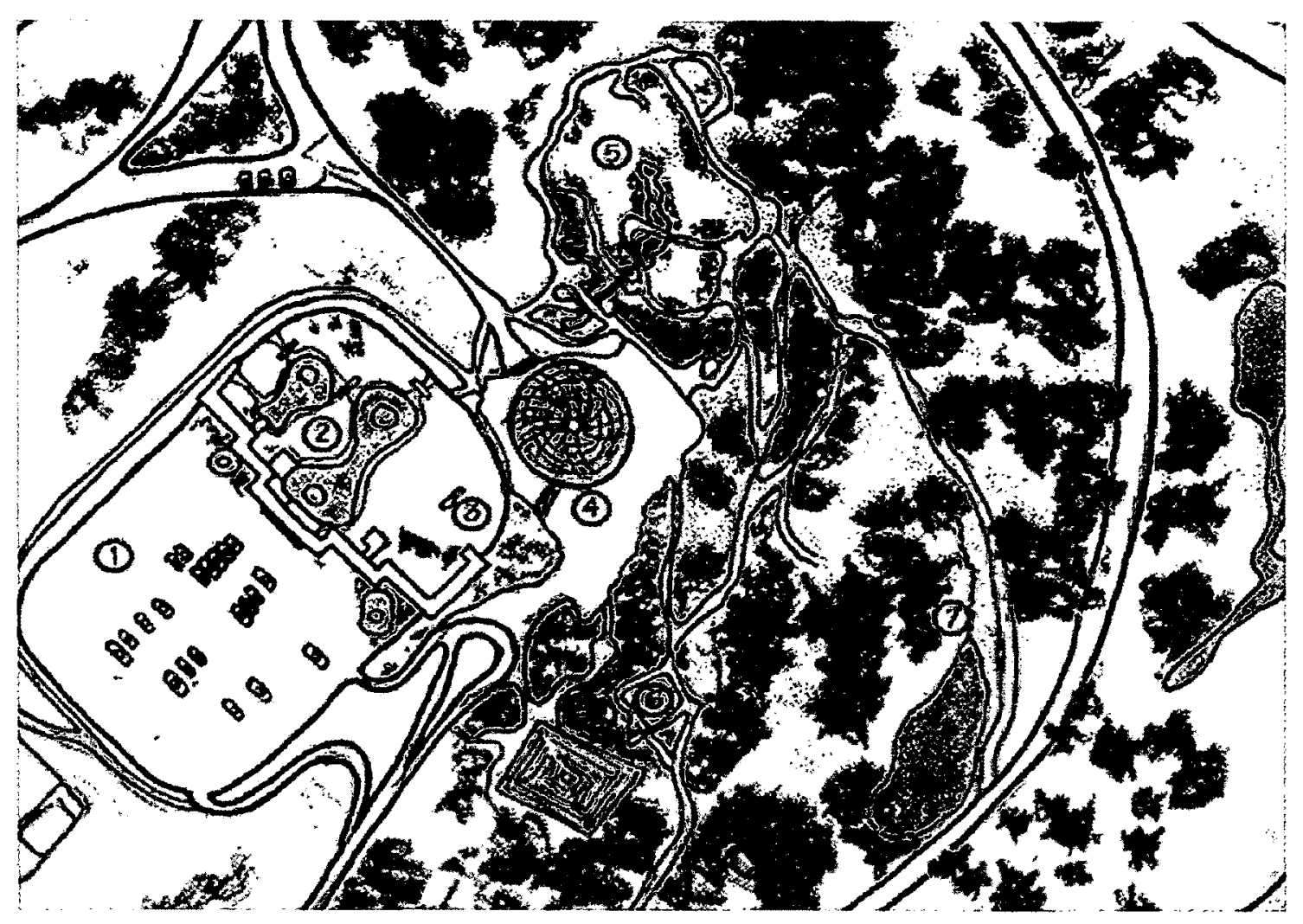

Figure 2-14. Detail of a soundwalk map by Hildegard Westerkamp, titled "A Soundwalk in Queen Elizabeth Park in Vancouver." (Image from: Hildegard Westerkamp, "Soundwalking," Sound Heritage 3, no. 4 [1974], http://www.sfu.ca/\%7Ewesterka/ writings\%20page/articles\%20pages/soundwalking.html [accessed 12 May 2010].) 


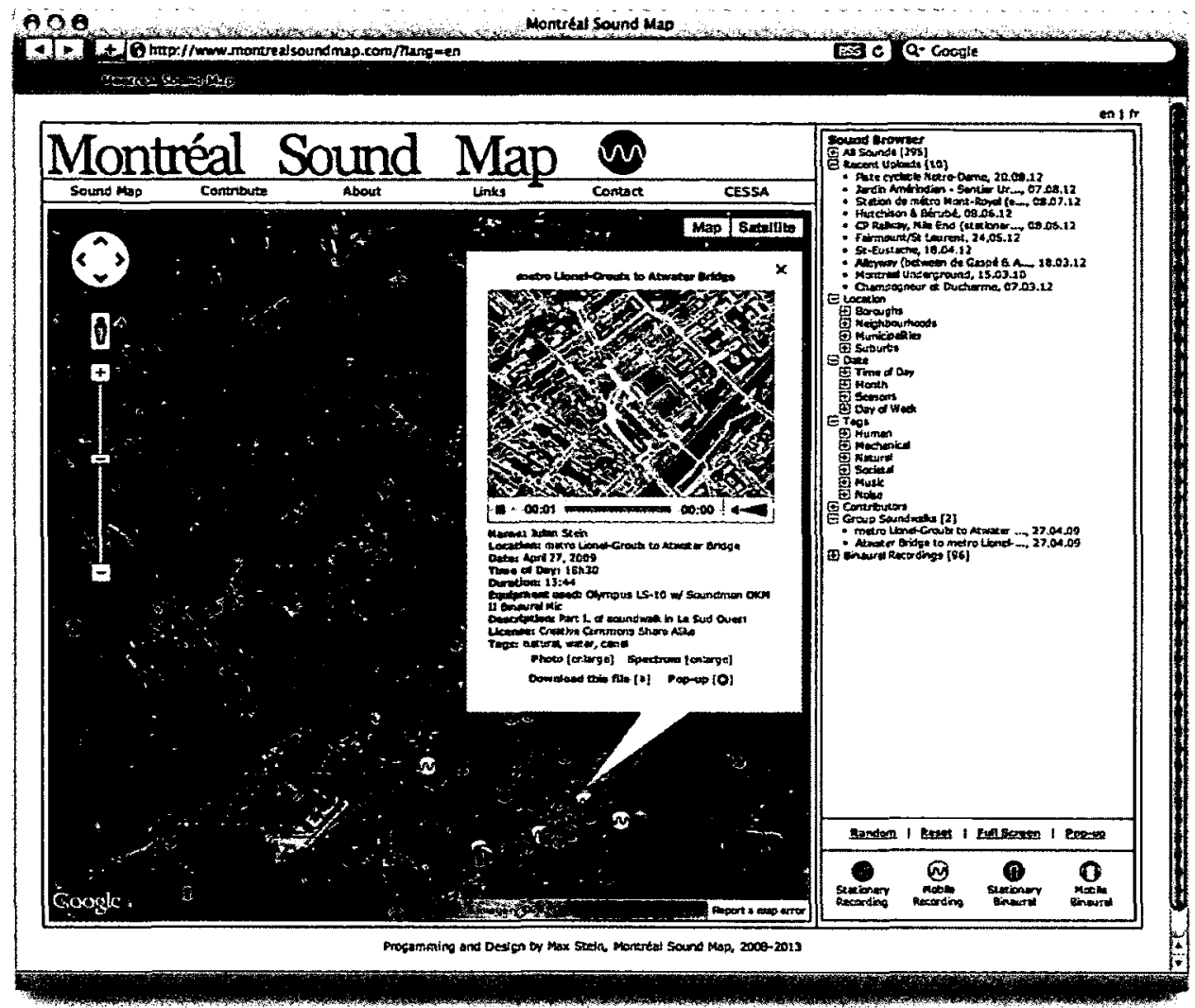

Figure 2-15. Screenshot of the "Montréal Sound Map" showing a pre-recorded soundwalk in the pop-up. (Image from: "Montréal Sound Map," http:// cessa.music.concordia.ca/soundmap/en/ [accessed 1 February 2010].) 


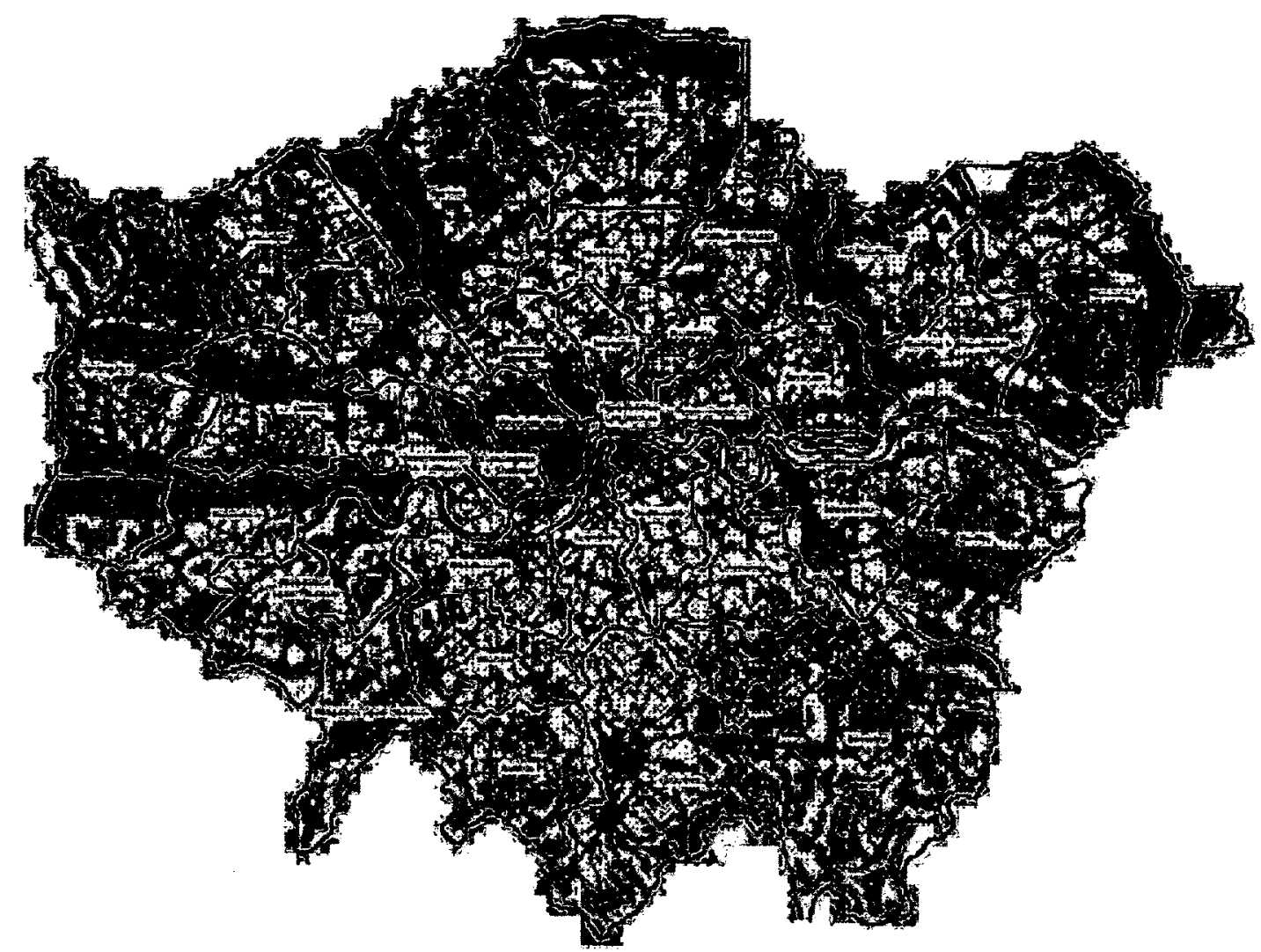

Figure 2-16. Composite image of DEFRA's London noise map. (Image from: "NoiseMap: Environmental Noise Mapping Software," http://londonnoisemap.com/ [accessed 6 February 2013].) 

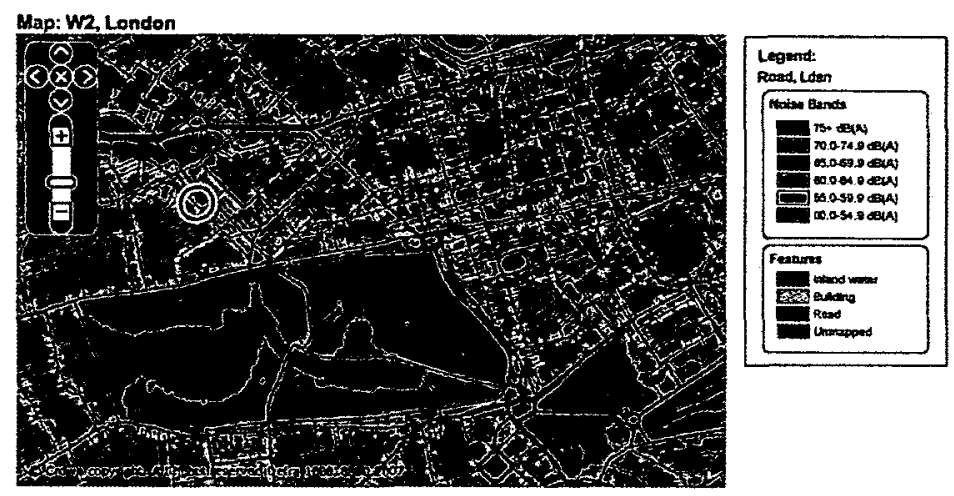

Figure 2-17A. Screenshot of DEFRA's online noise map showing the area around Hyde Park in London. Note that human pathways, including those through Hyde Park, are marked gray, indicating they are "unmapped." (Image from: "Noise Mapping England." Department for Environment Food and Rural Affairs. http://services.defra.gov.uk/wps/ portal/noise [accessed 6 Feburary 2013).)

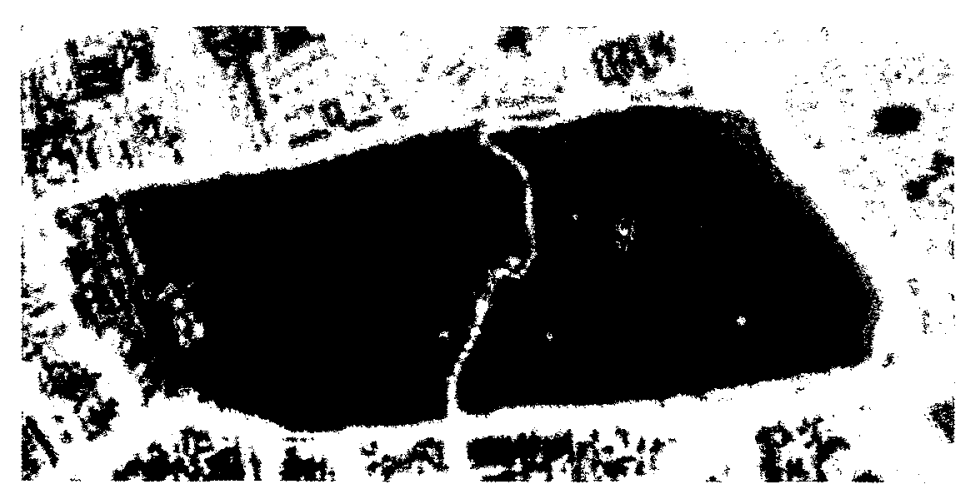

Figure 2-17B. Detail of Simon Elvin's "Silent London" showing the same area detailed in Figure 2-16A. Reliance on DEFRA's visualization yielded some unusual results: walkways, even through parks, were rendered the same color as the loudest of urban roads. (Image from: Simon Elvins, "Silent London," digital reproduction of a blind embossed etching, http://www.simonelvins.com/silent london.html [accessed 6 February 2013].) 


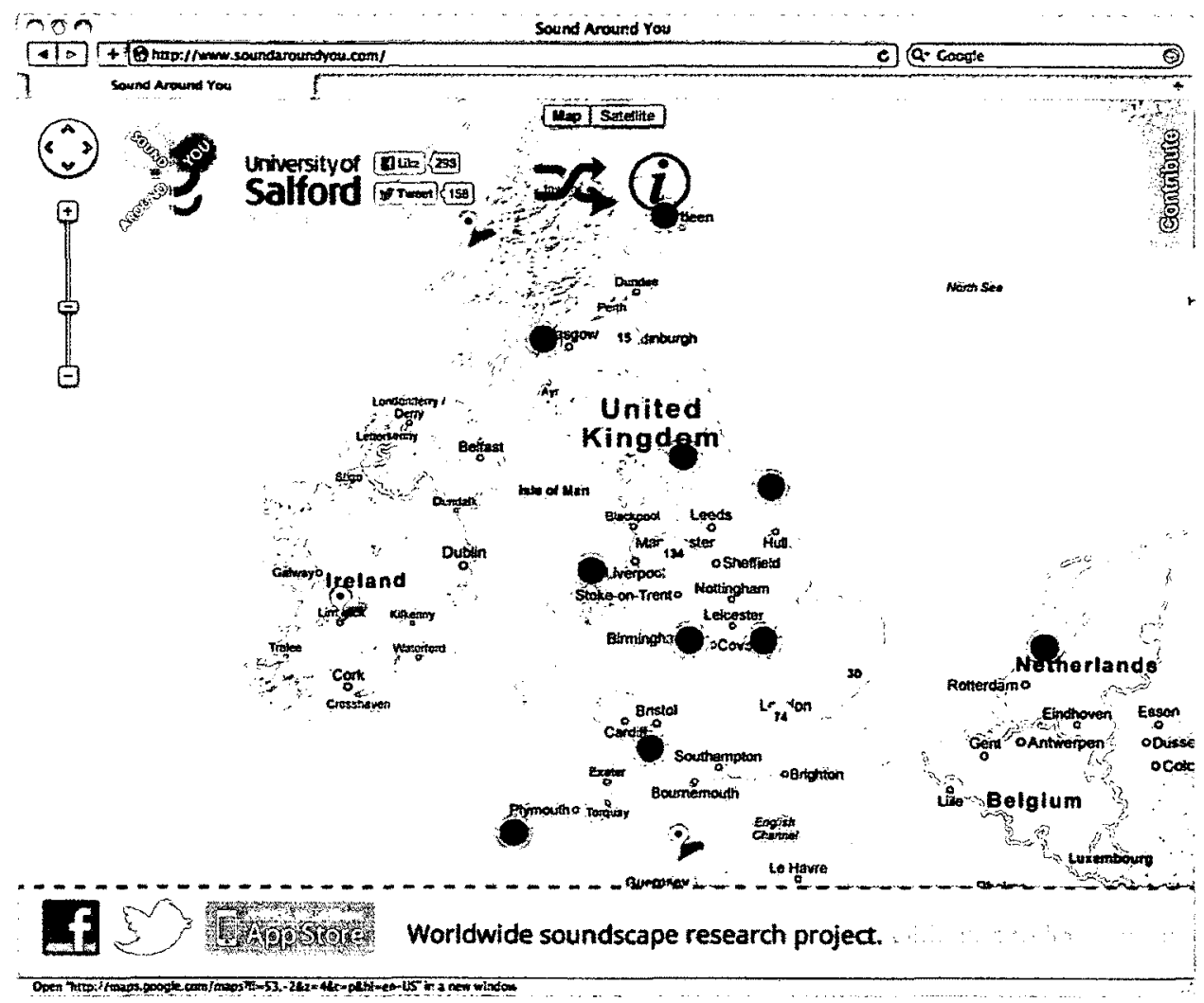

Figure 2-18. Screenshot of "Sounds Around You," a dynamic sound map website operated by the University of Salford. (Image from: "How to Get Involved," Sounds Around You, http://www.soundaroundyou.com [accessed 10 November 2013].) 


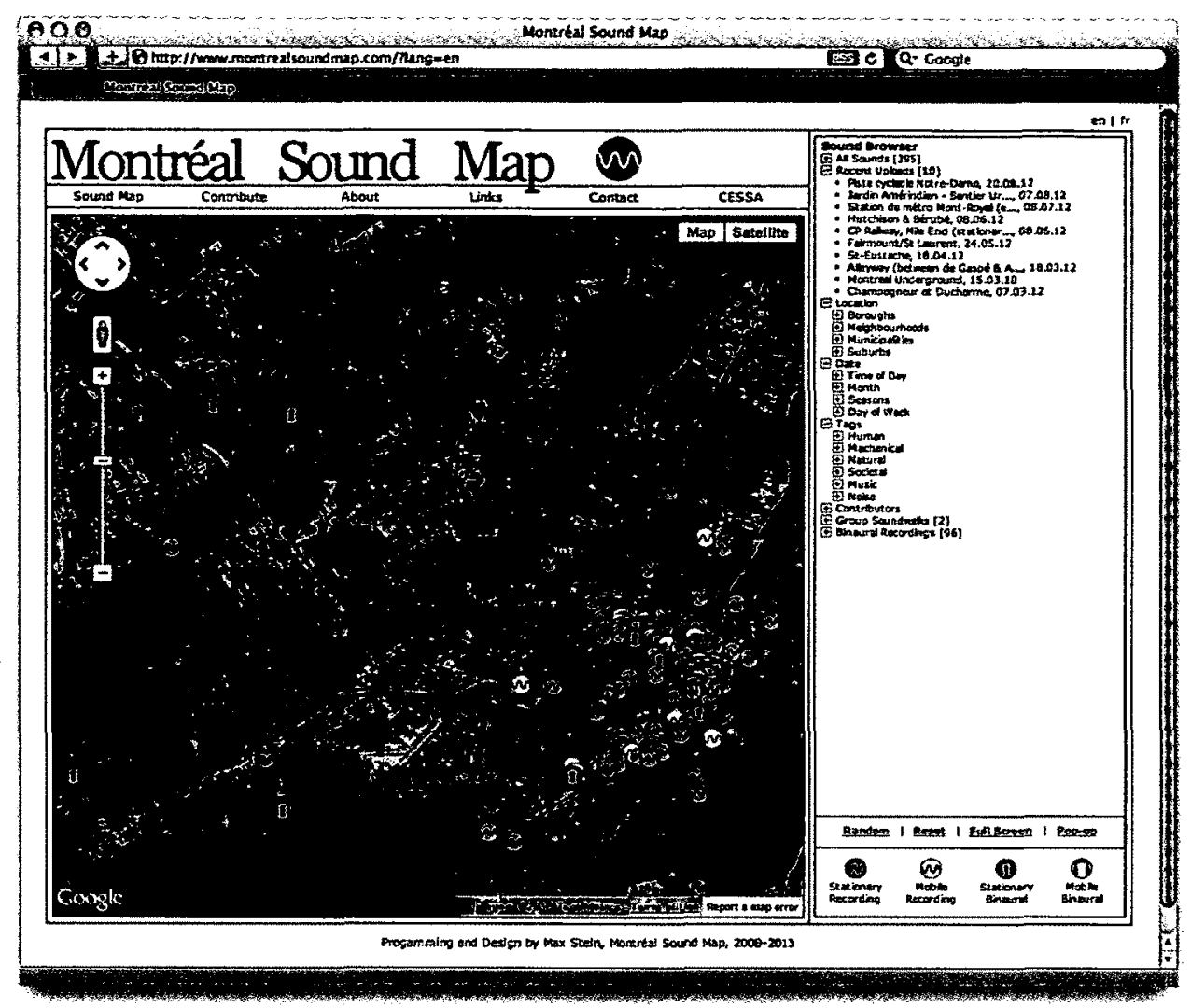

Figure 2-19. Screenshot of the "Montréal Sound Map," showing tagged and labeled sound categories in the right hand column. (Image from: "Montréal Sound Map," http:/l cessa.music.concordia.ca/soundmap/en/ [accessed 17 January 2011].) 


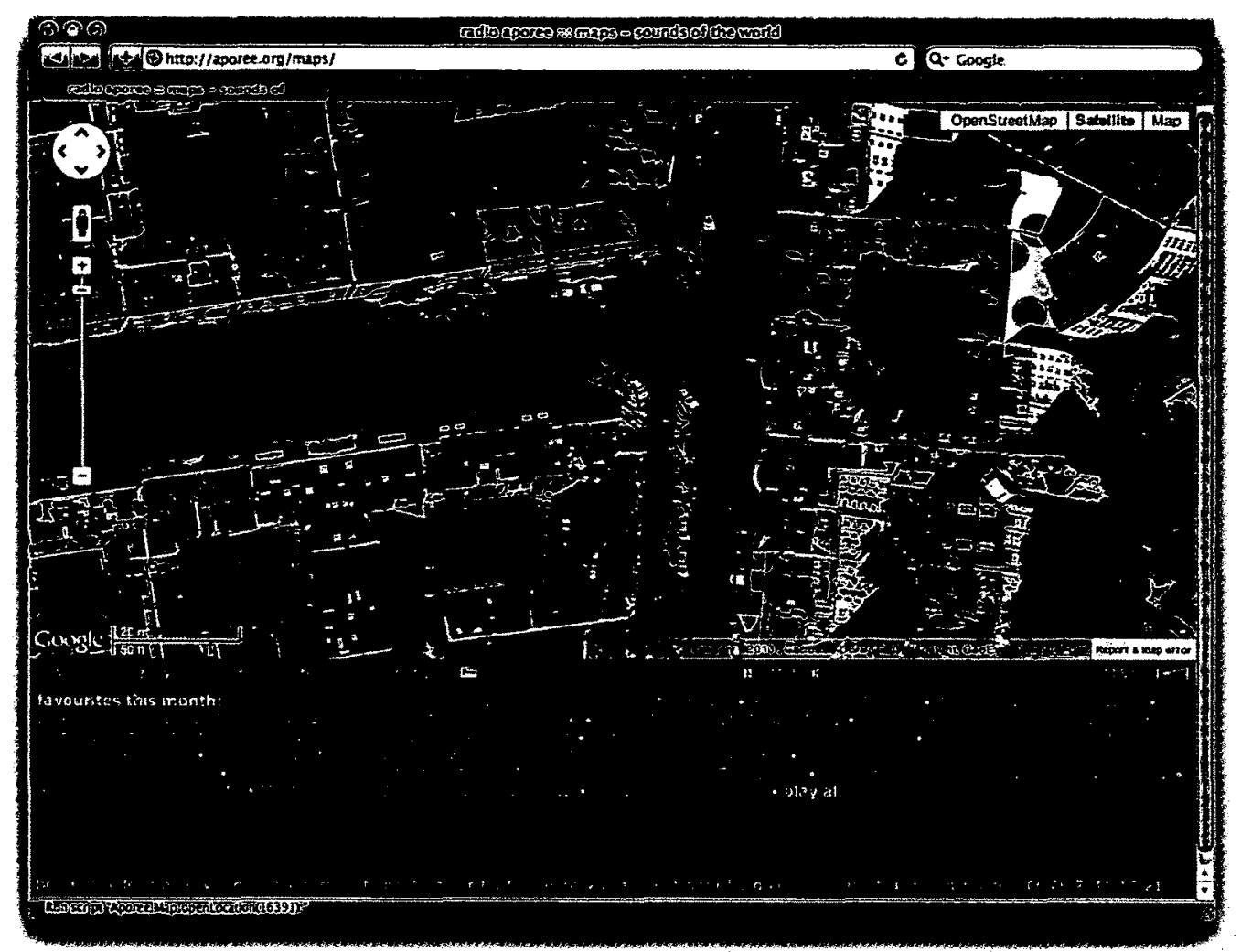

Figure 2-20. Screenshot of the sound map organized by "radio aporee." Red dots indicate embedded sound files. (Image from: Radio aporee, http://aporee.org/maps/info [accessed 10 January 2013].) 


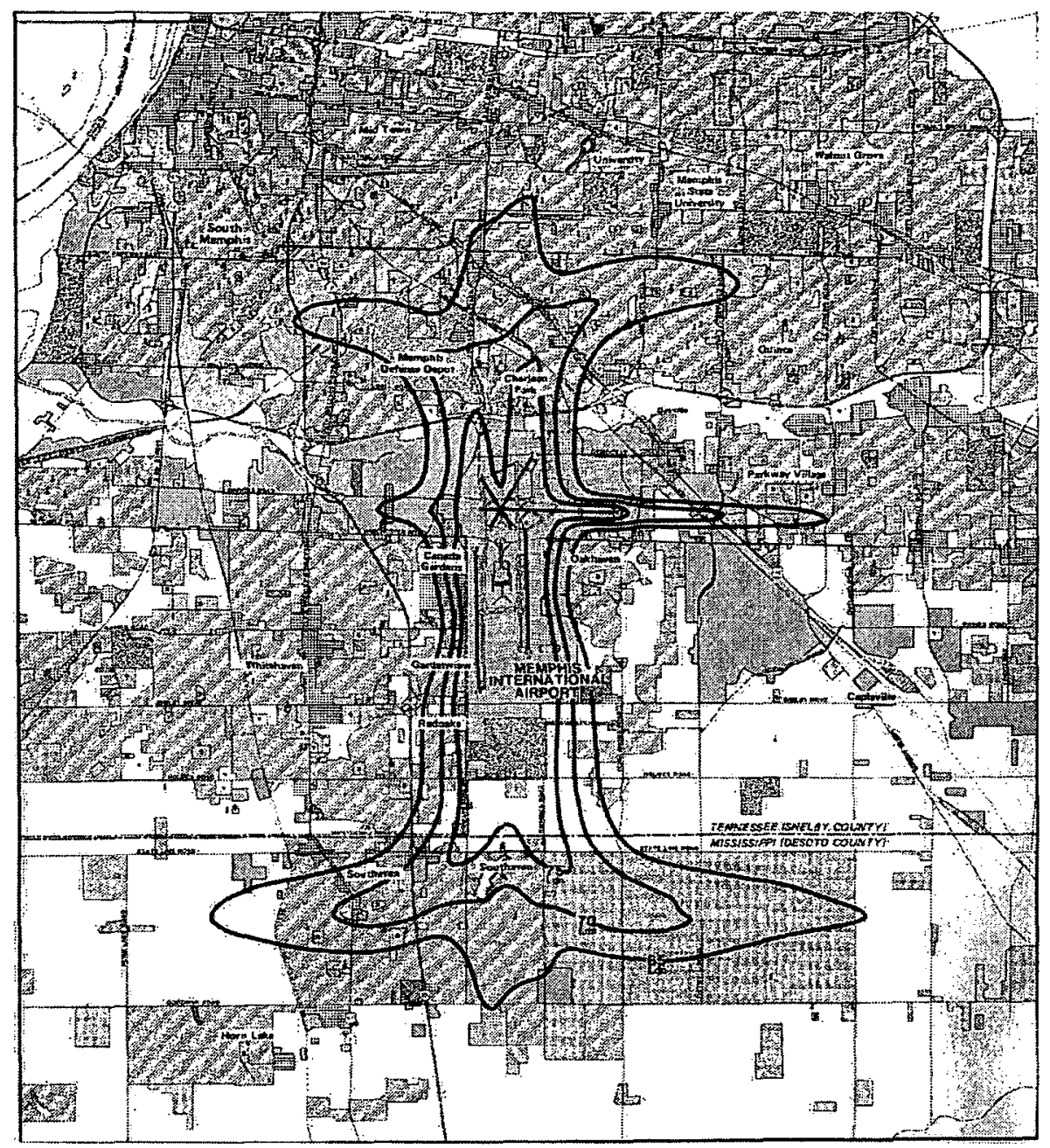

Figure 3-1. "Noise Exposure Map" of the Memphis International Airport showing noise contours as stipulated by CFR 49, Part 150. (Image from: PEAT Marwick, Master Plan and Noise Compatability Program, Memphis International Airport, "Noise Exposure Map: 1985 Operations," public document available through the Memphis International Airport Authority; report in possession of the author.) 


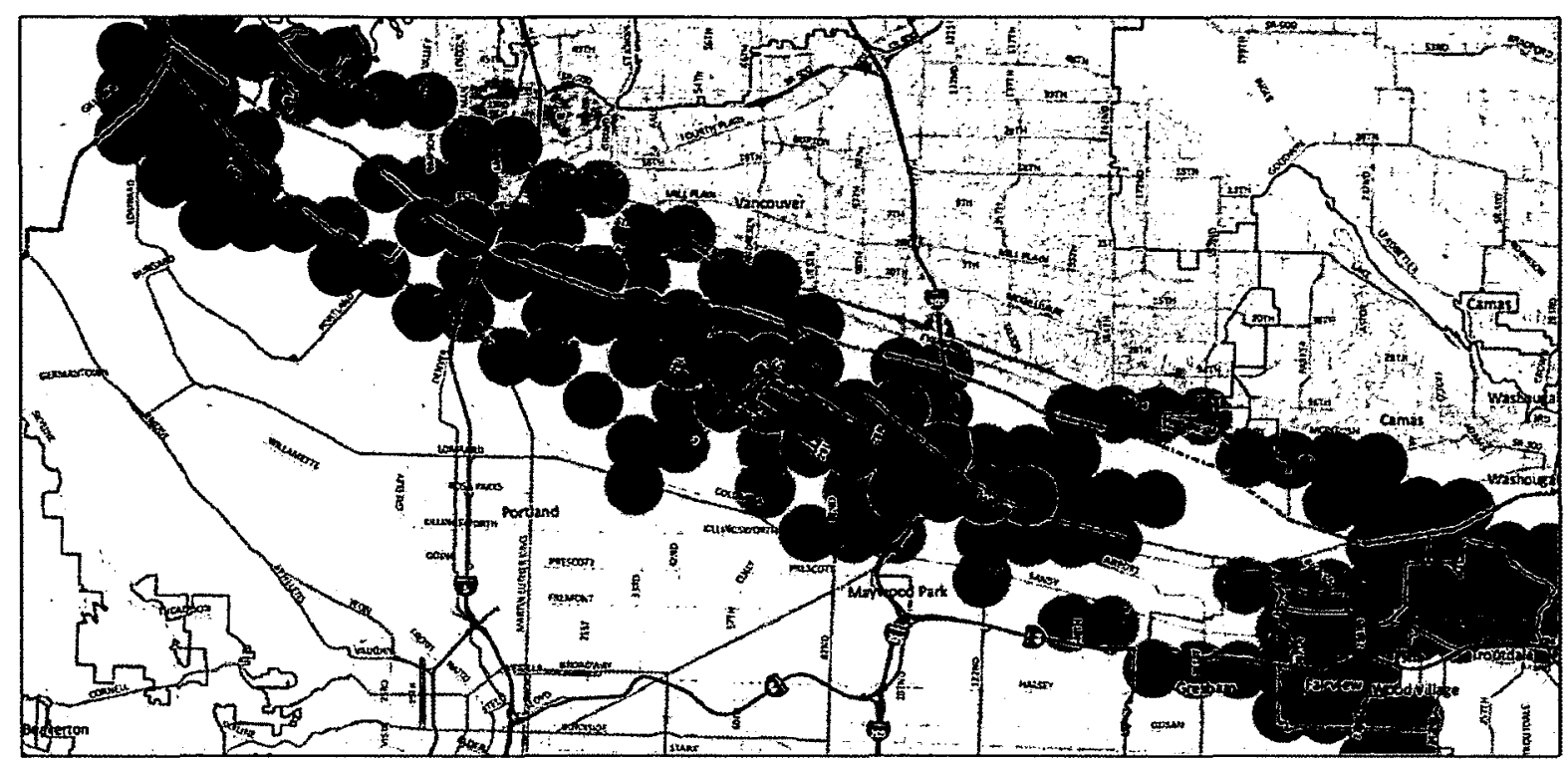

Figure 3-2. Supplementary NEM showing the statistical likelihood that sound above $65 \mathrm{~dB}$ will be heard at any moment in the area surrounding the Portland International Airport. Red indicates a high probability while green indicates low. (Image from: Jacobs Consultancy, FAR Part 150 Noise Exposure Map Update, Portland International Airport, Prepared for the Port of Portland, Portland, OR, Appendix D, Figure D-3, July 2010; report in possession of the author.) 


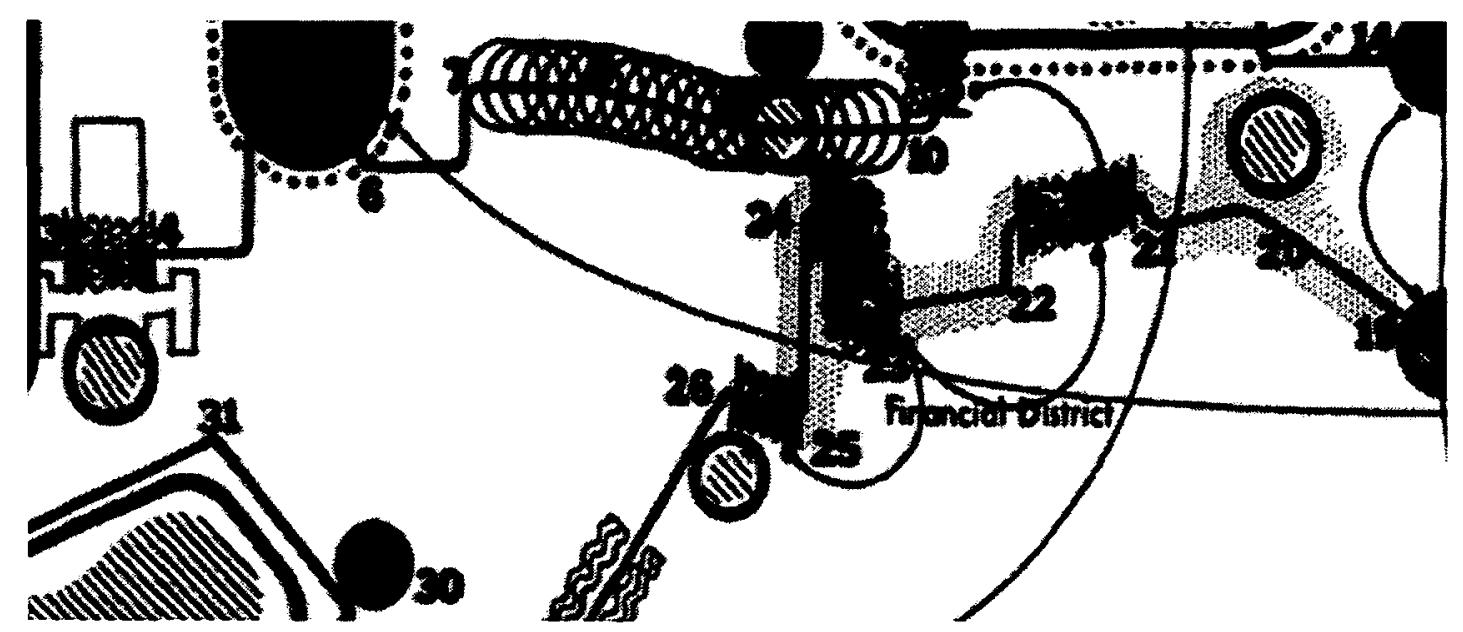

Figure 3-3. Detail of Michael Southworth's map of Boston showing different neighborhoods coded according to their aural identity. (Image from: Michael Southworth, "The Sonic Environment of Cities," Environment and Behavior 1, no. 1 [1969], 55.) 
Set up: It is suggested that the instruments be set up as shown below:
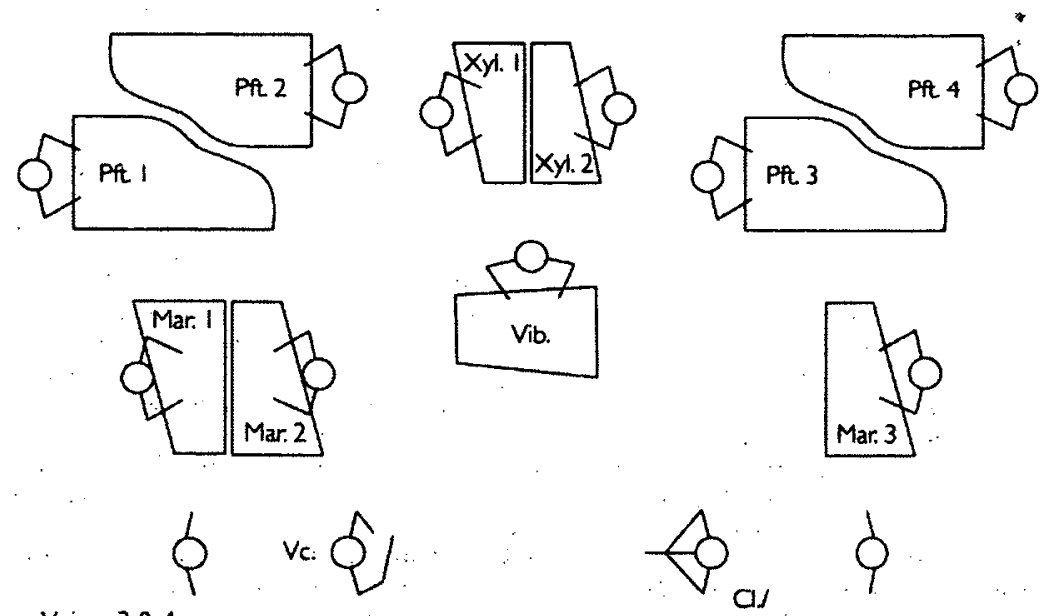

$\oint$

Voices $3 \& 4$
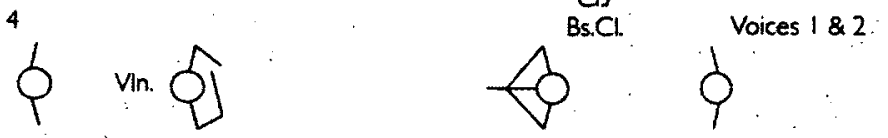

Figure 4-1. Diagram included with Music for 18 Musicians. (Image from: Steve Reich, Music for 18 Musicians [New York: Boosey and Hawkes, 2000].) 


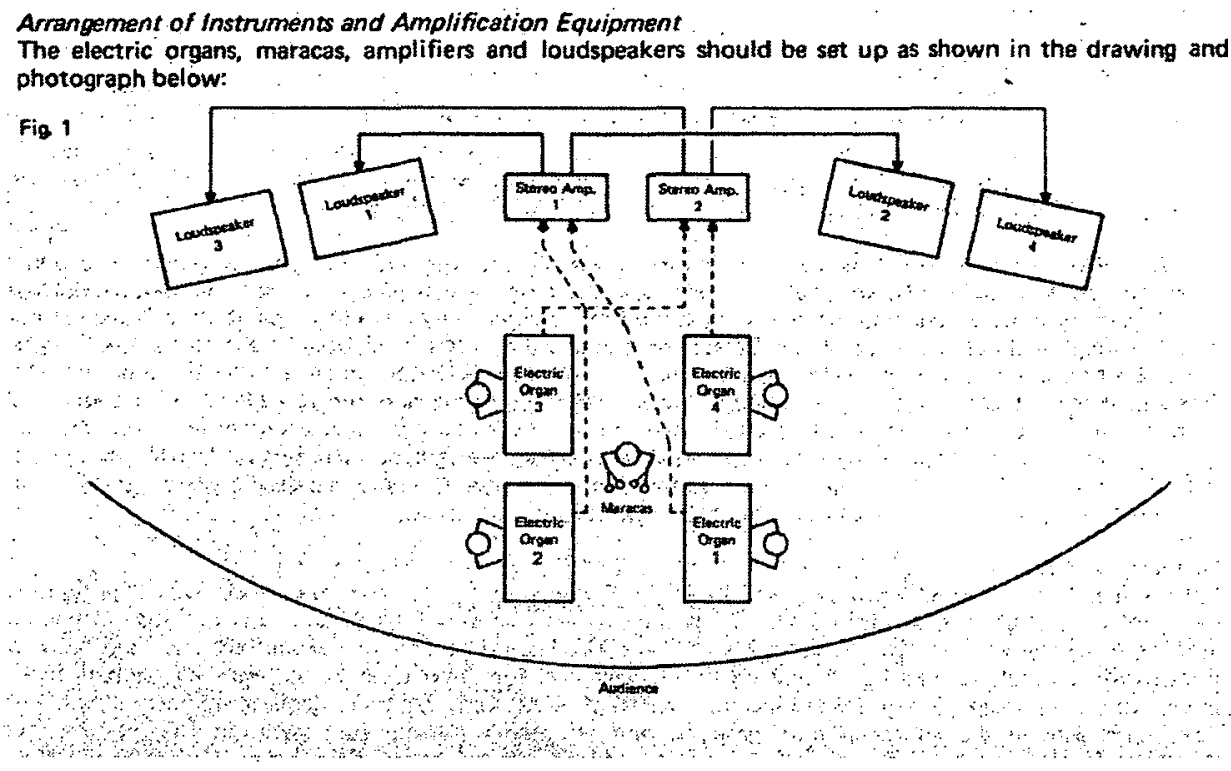

Figure 4-2. Diagram included with 4 Organs. (Image from: Steve Reich, Four Organs [London: Universal Edition, 1980].)

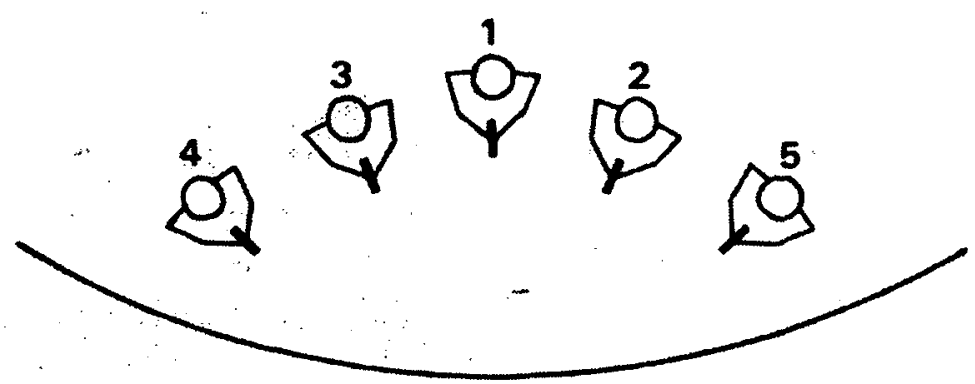

Audience

Figure 4-3. Diagram included with Music for Pieces of Wood. (Image from: Steve Reich, Music for Pieces of Wood [London: Universal Edition, 1980].) 


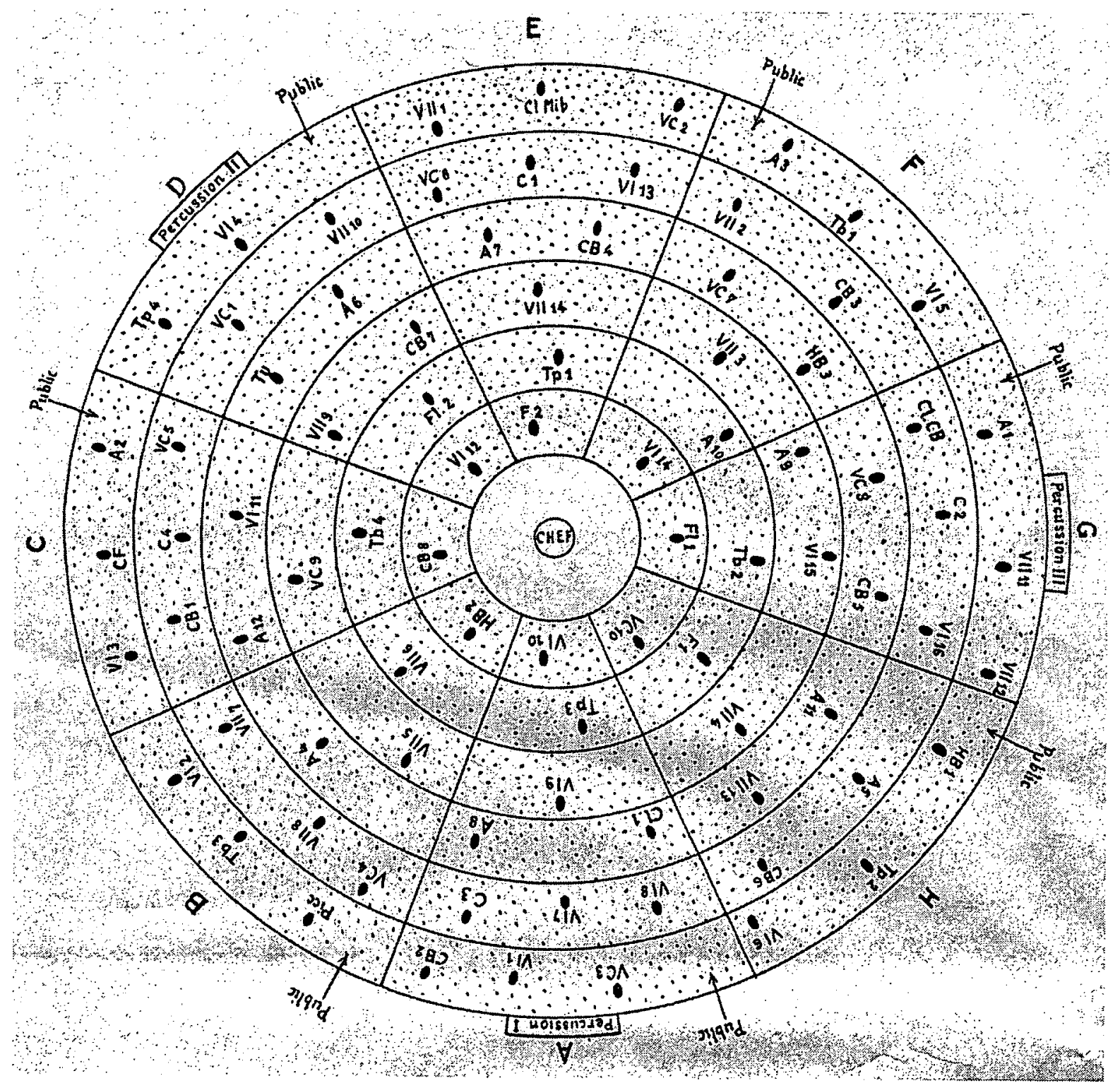

Figure 4-4. Spatial diagram included with Terretektorh. (Image from: Iannis Xenakis, Terretektorh: Pour Orchestre [Paris: Editions Salabert, 1969].) 


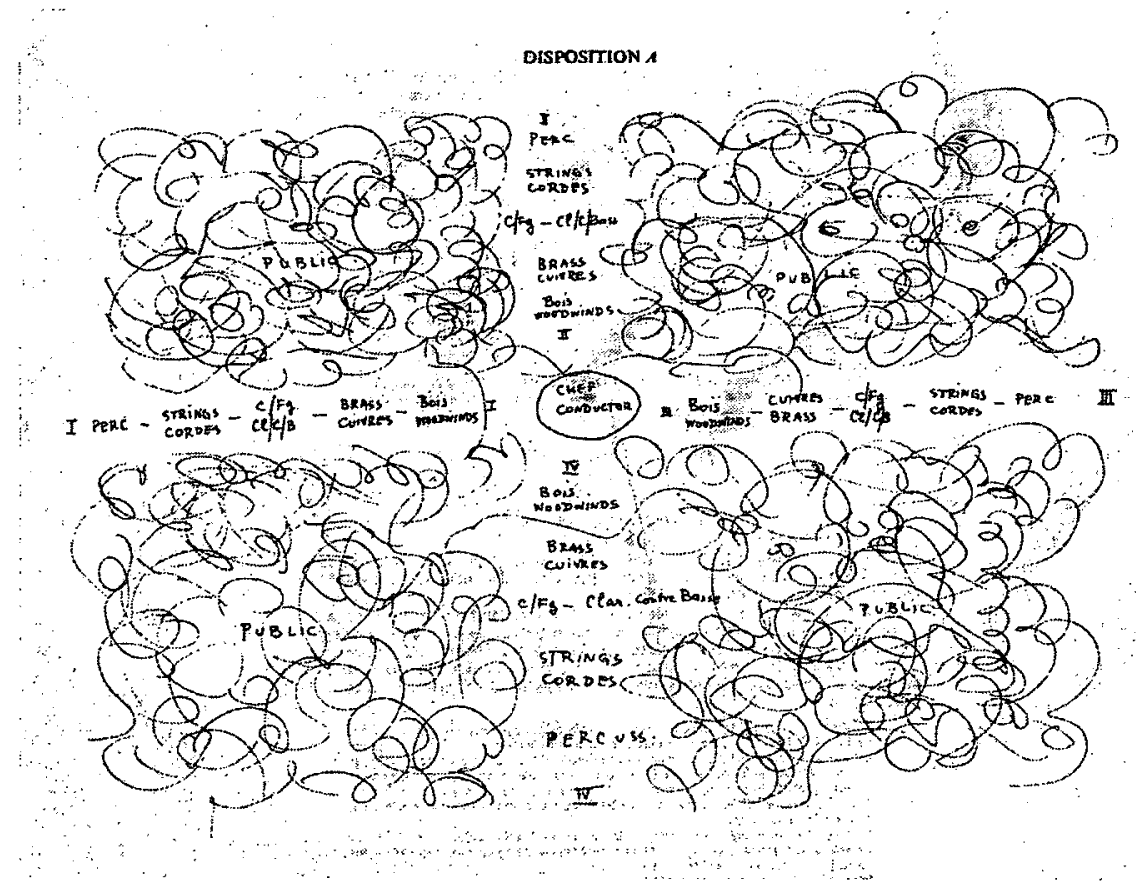

Figure 4-5A. Spatial diagram showing "Disposition A" for the performance of Polytope. (Image from: Iannis Xenakis, Polytope [London: Boosey and Hawkes, 1969].)

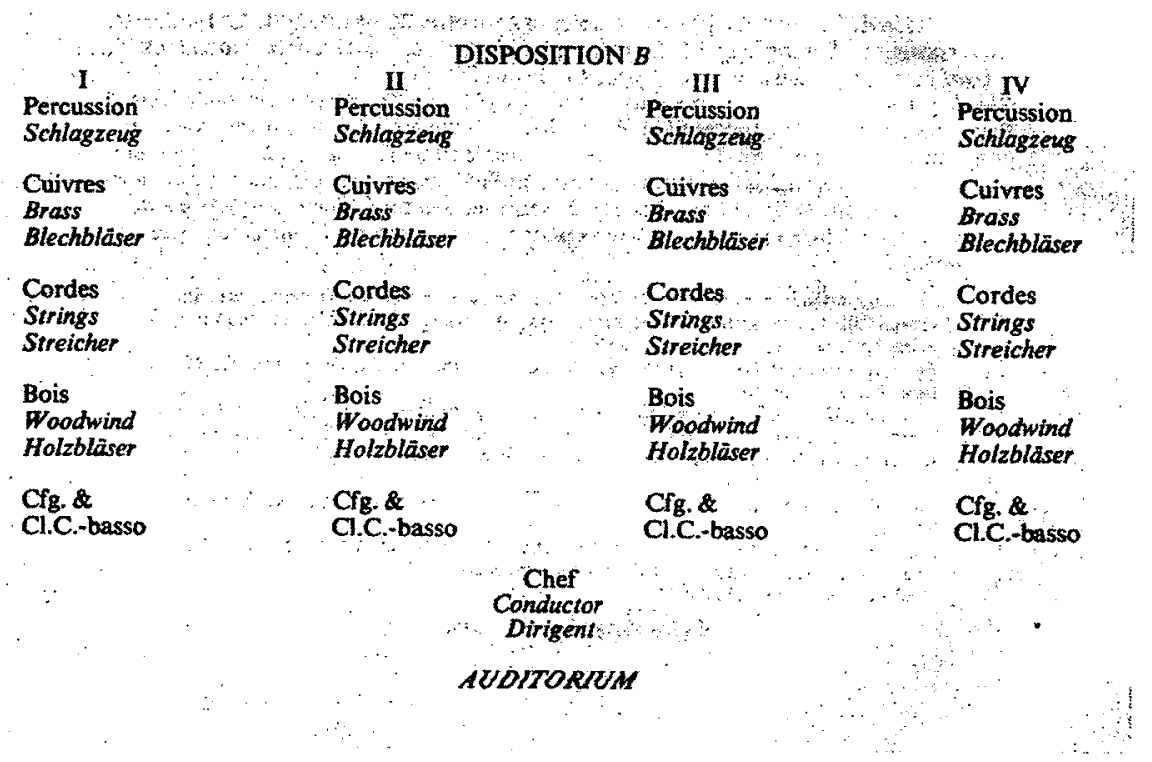

Figure 4-5B. Spatial diagram for "Disposition B" for the performance of Polytope. (Image from: Iannis Xenakis, Polytope [London: Boosey and Hawkes, 1969].) 

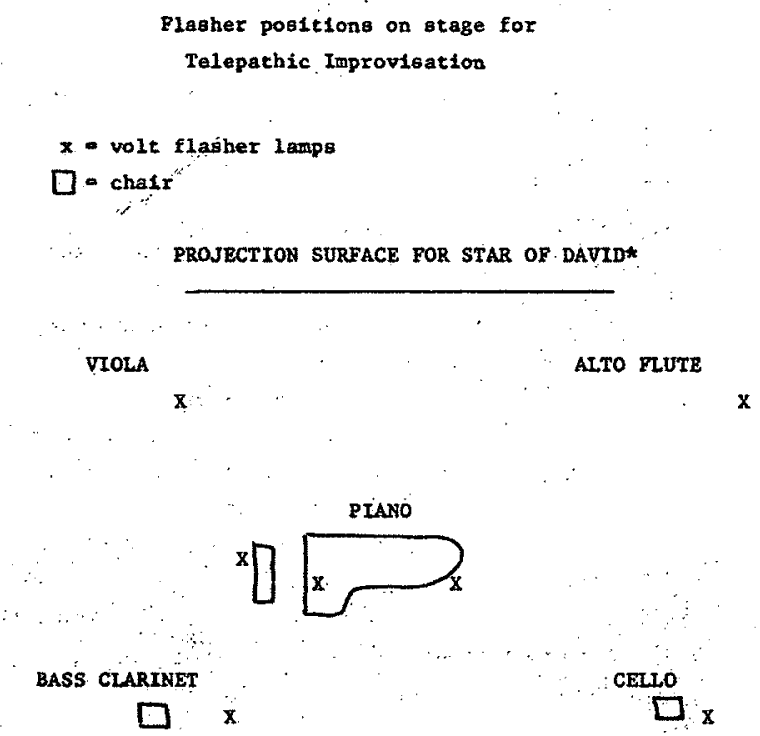

Figure 4-6. Spatial diagram showing required components for a performance of Aeolian Partitions. (Image from: Pauline Oliveros, Aeolian Partitions [Brunswick, ME: Bowdoin College Music Press, 1970].) 


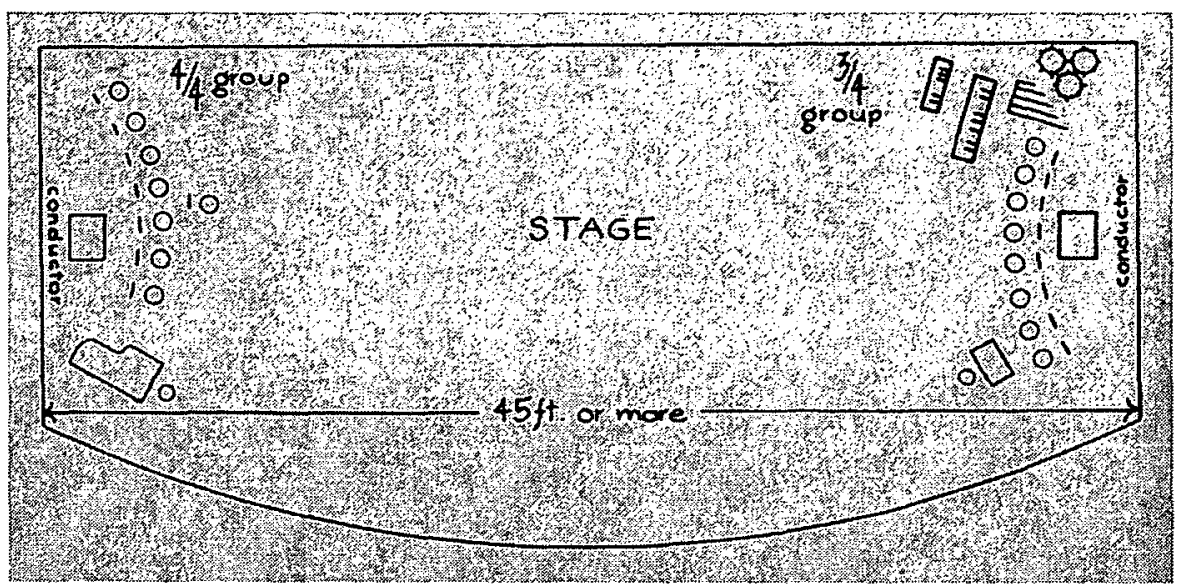

Figure 4-7A. Spatial diagram showing the approved distribution of performers in Henry Brant's Verticals Ascending. (Image from: Henry Brant, Verticals Ascending after the Rodia Towers [New York: MCA Music, 1969].)

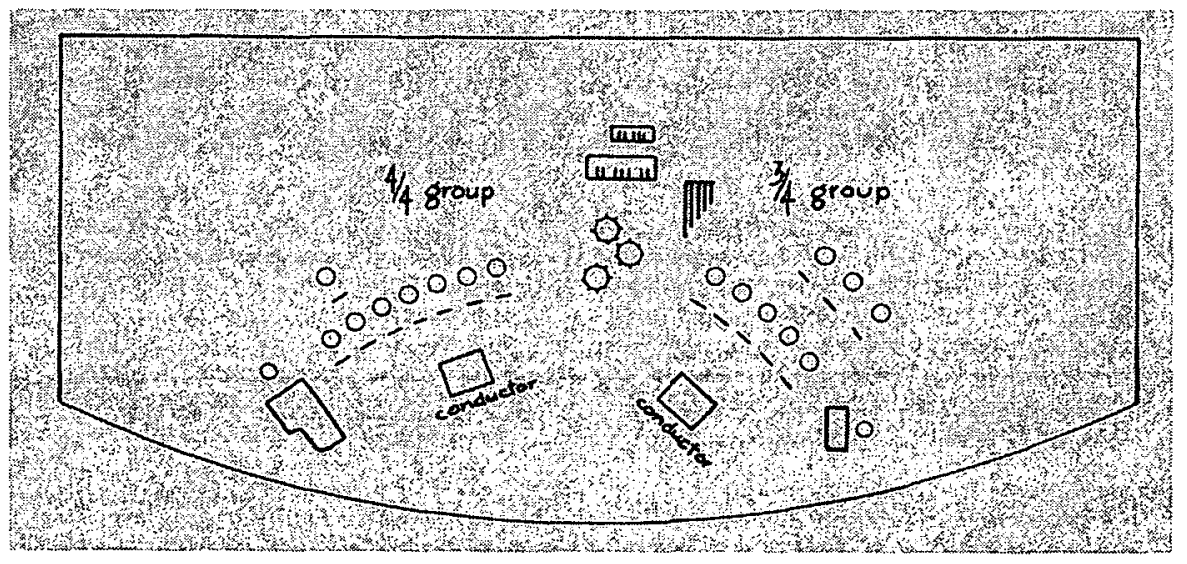

Figure 4-7B. Spatial diagram showing a prohibited distribution of performers. (Image from: Henry Brant, Verticals Ascending after the Rodia Towers [New York: MCA Music, 1969].) 


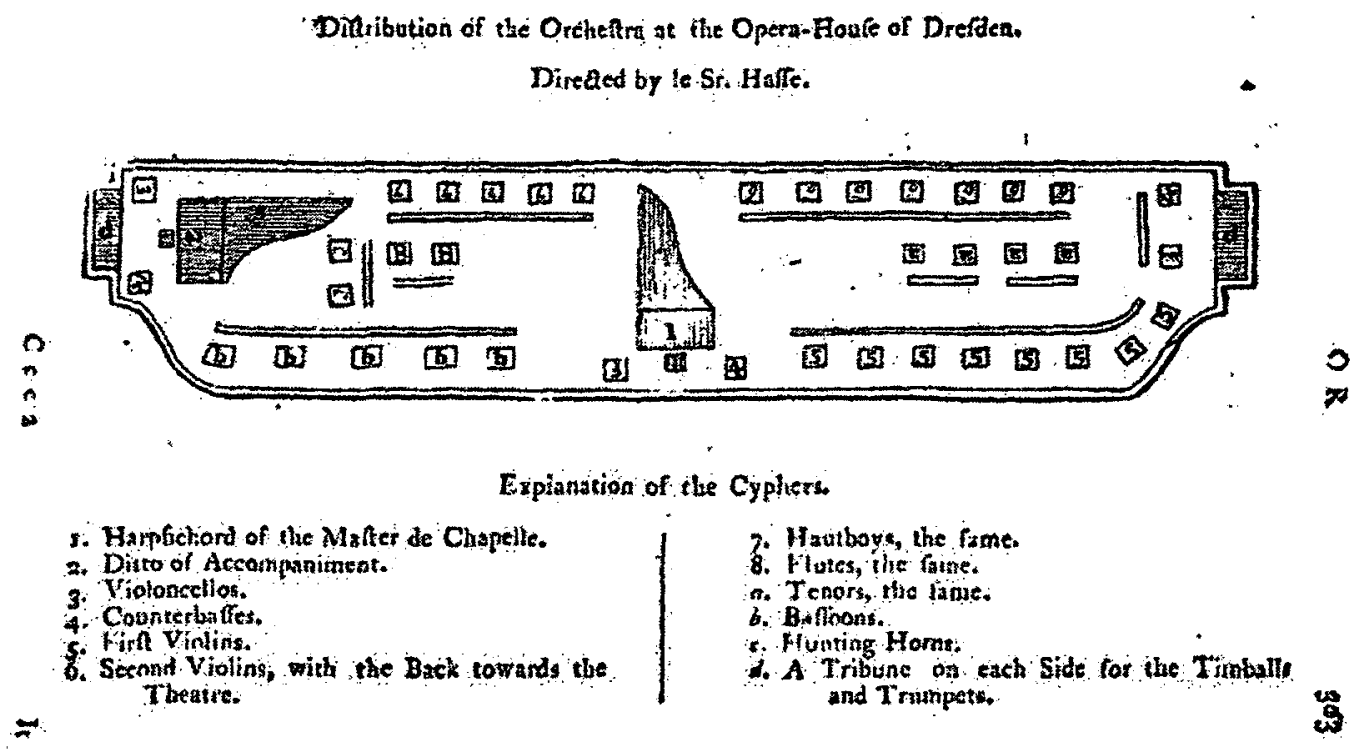

Figure 4-8. Jean-Jacques Rousseau's drawing of the orchestra at the Dresden Opera. (Image from: Jean-Jacques Rousseau, "Orchestra," A Dictionary of Music, translated from the French by William Waring [London, 1775], 302.) 


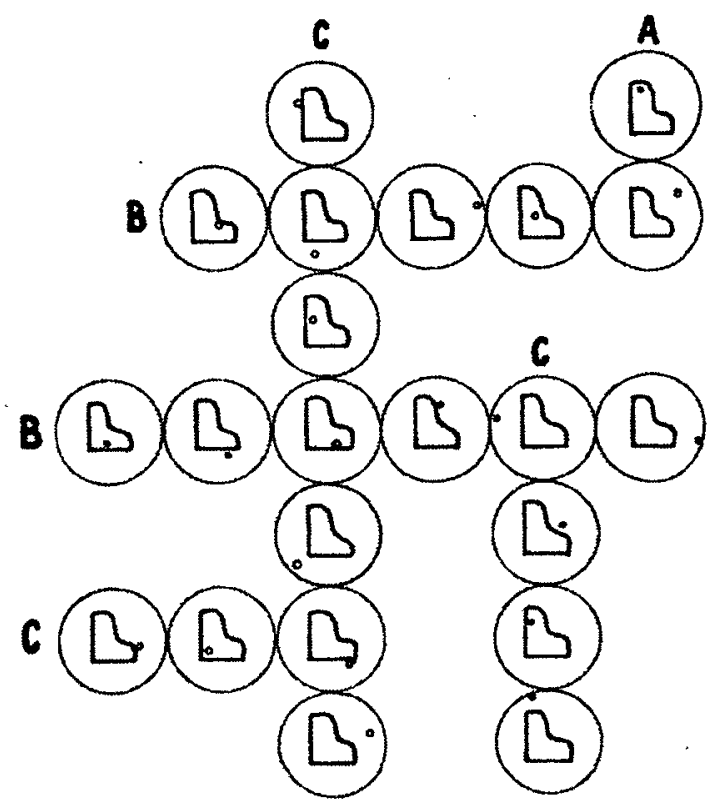

Figure 4-9. Score for Memories of You by Cornelius Cardew. (Image from: Cornelius Cardew, Memories of You [London: Universal Edition, 1967].)

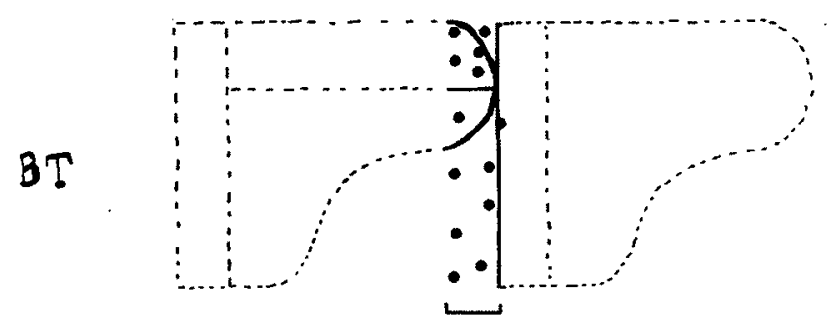

Figure 4-10. Notational fragment "BT" from John Cage's Concerto for Piano and Orchestra. (Image from: John Cage, Concert for Piano and Orchestra New York: Henmar Press, 1960].) 


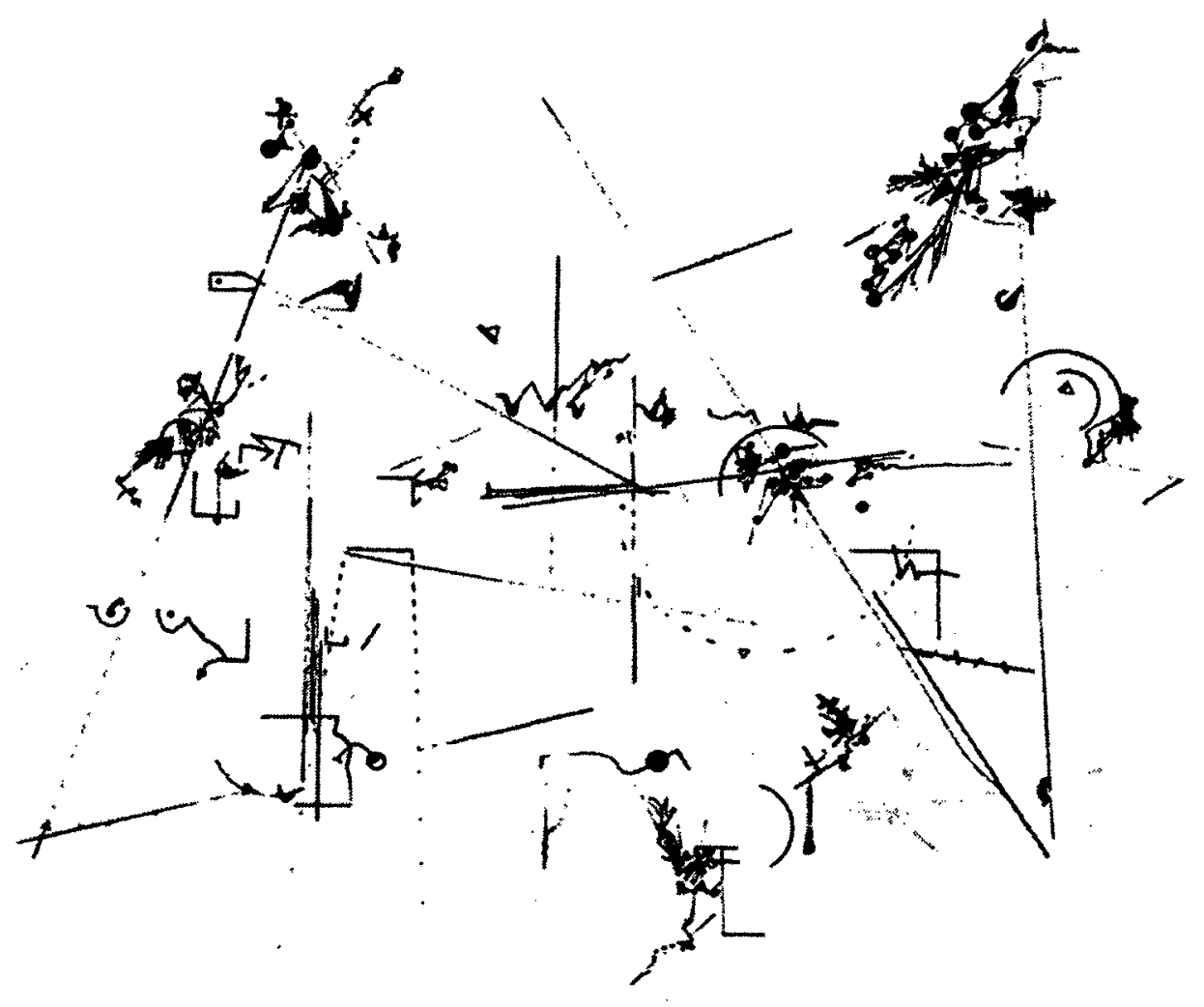

Figure 4-11. Projection for Titus number 1 for amplified automobile. (Image from: Brian Moran, "Titus number 1 for amplified automobile," in Source: Music of the Avant Garde 2, no. $1[1968]$.) 


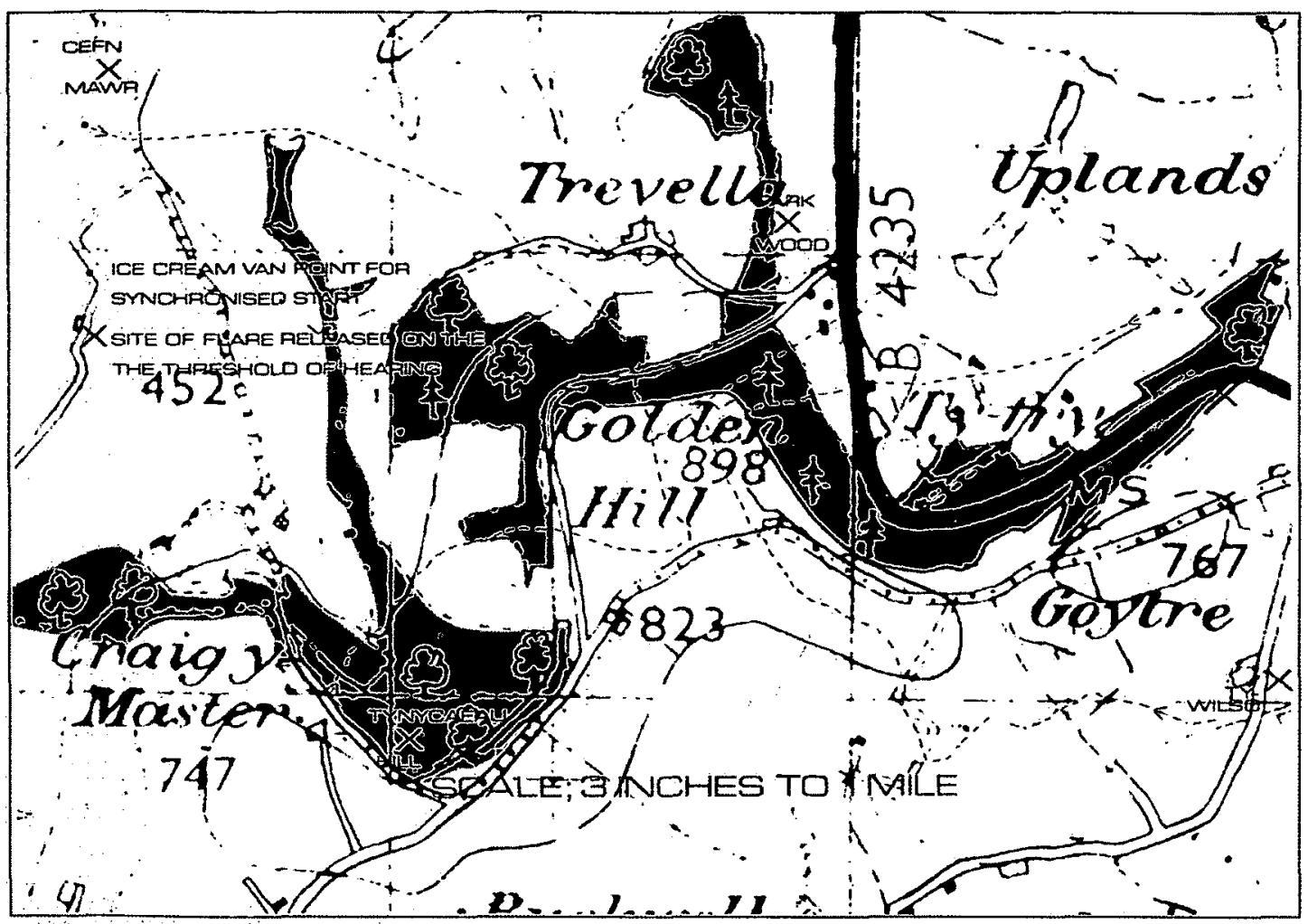

Figure 4-12. Map for "Golden Hill," from Zones by Stuart Marshall. (Image from: Stuart Marshall, "Zones (1969-1970)," Source: Music of the Avant Garde 10 [1972], 18.) 


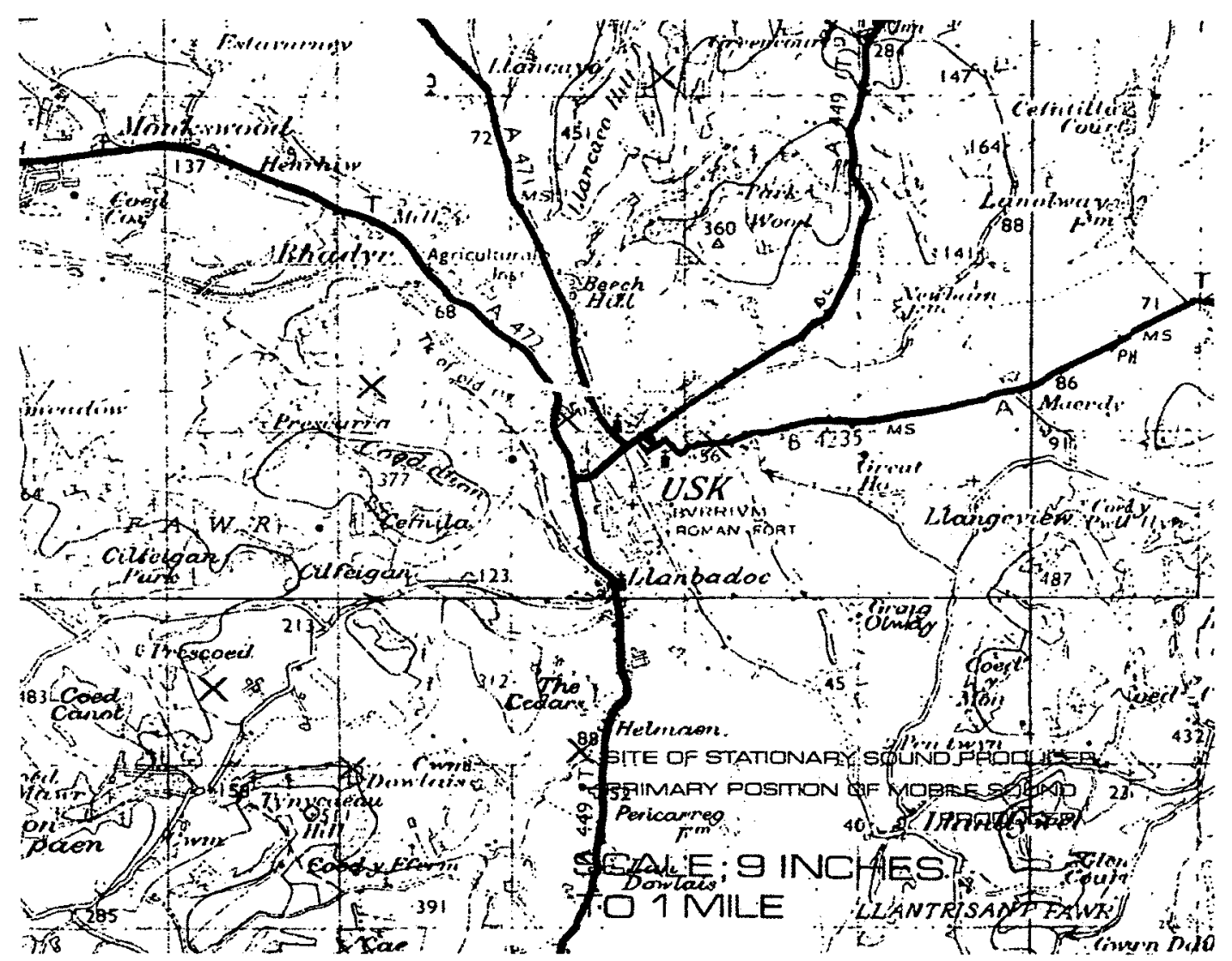

Figure 4-13. Map for "Usk," from Zones by Stuart Marshall. (Image from: Stuart Marshall, "Zones (1969-1970)," Source: Music of the Avant Garde 10 [1972], 21.) 


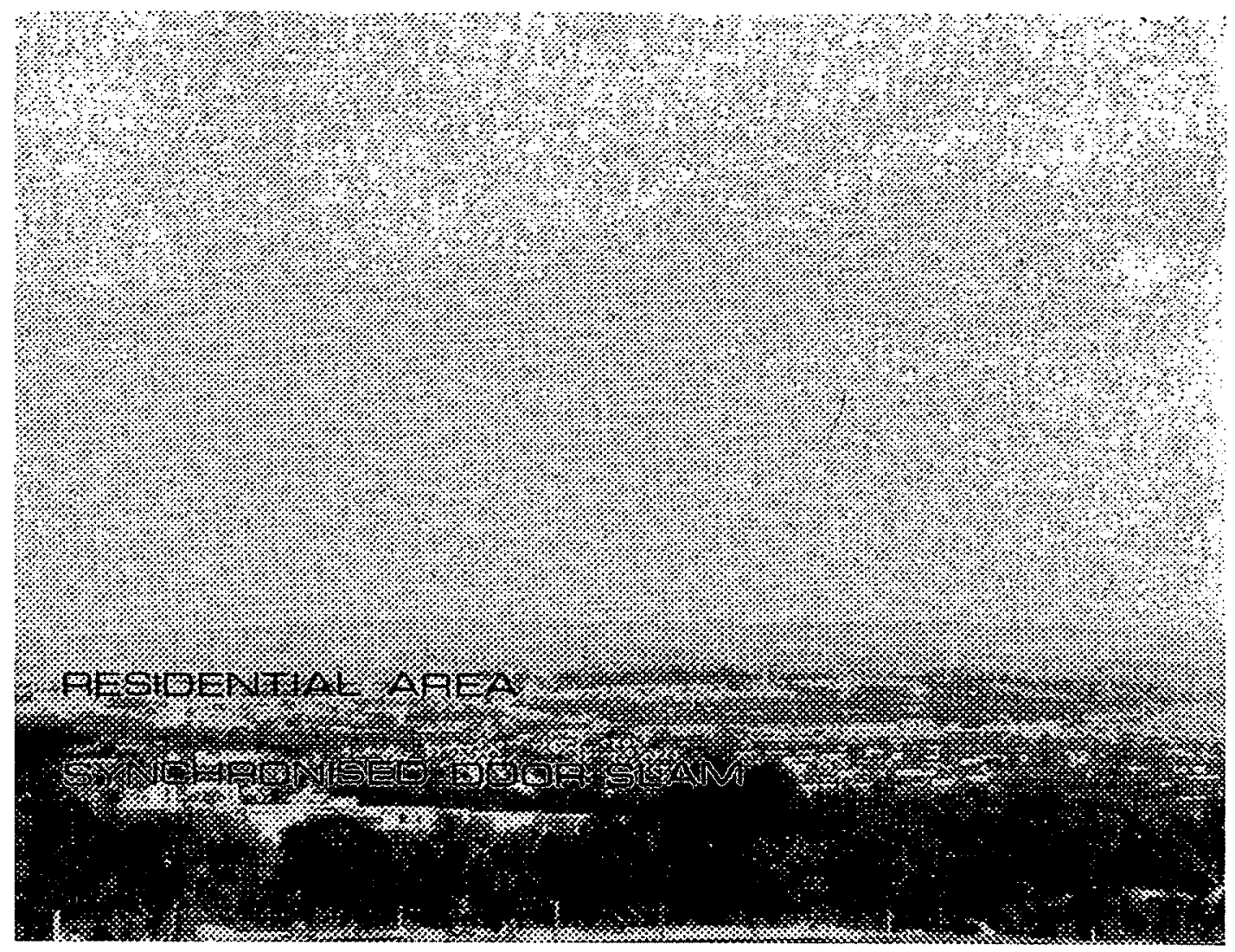

Figure 4-14. Image for "Synchronized Door Slam," from Zones by Stuart Marshall. (Image from: Stuart Marshall, "Zones (1969-1970)," Source: Music of the Avant Garde 10 [1972], 14.) 


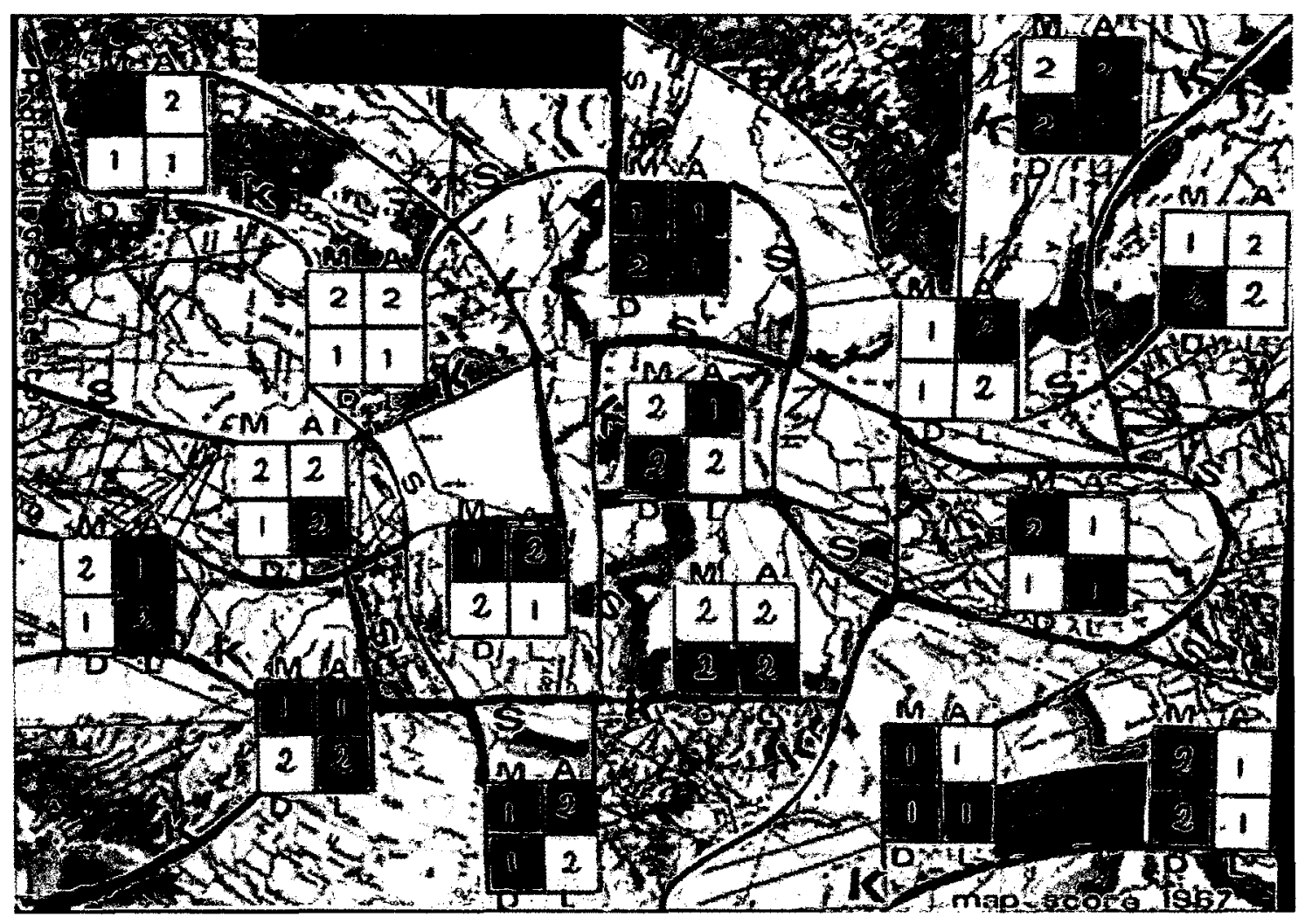

Figure 4-15. Hyper-map score for "Probabalistic Theater I" by Jocy de Oliveira. (Image from: Jocy de Oliveira, "Probabilistic Theater I," image produced from a single $35 \mathrm{~mm}$ slide, in Source: Music of the Avant Garde 2, no. 2 [1968].) 


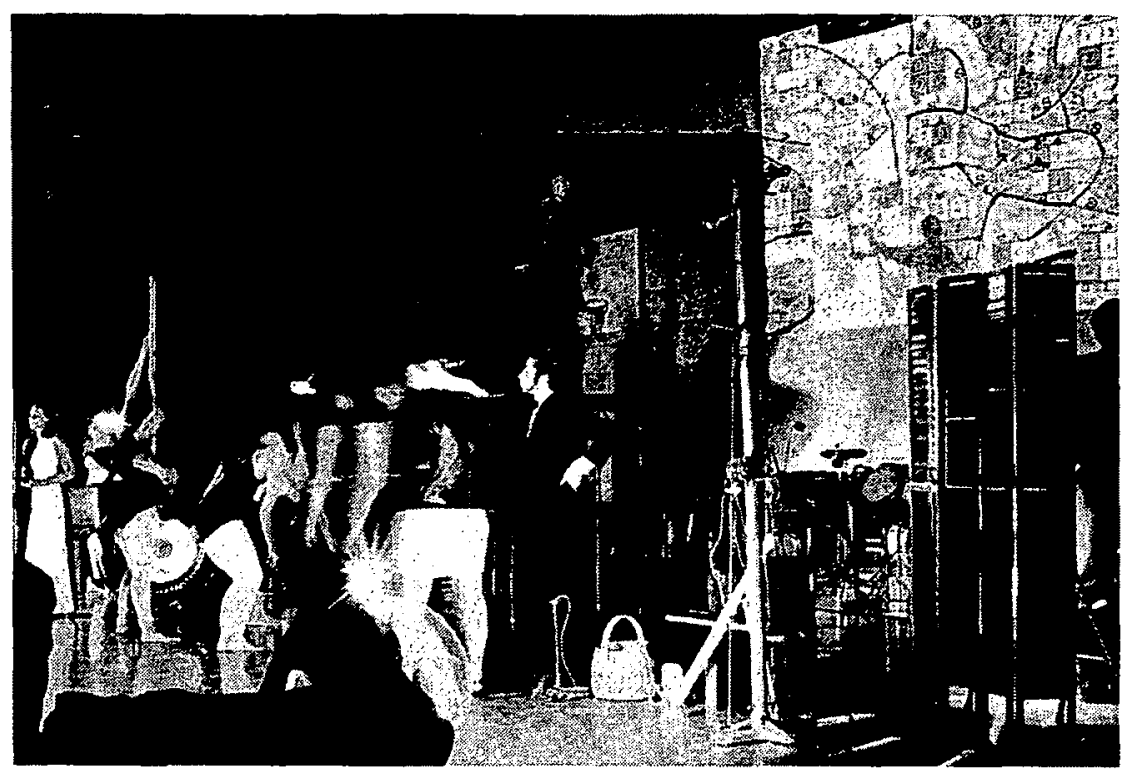

Figure 4-16. Image taken during a performance of Probabilistic Theater I, showing the hyper-map score projected behind the traffic conductor. (Image from: Jocy de Oliveira, "Probabilistic Theater I," in Source: Music of the Avant Garde 2, no. 2 [1968].) 


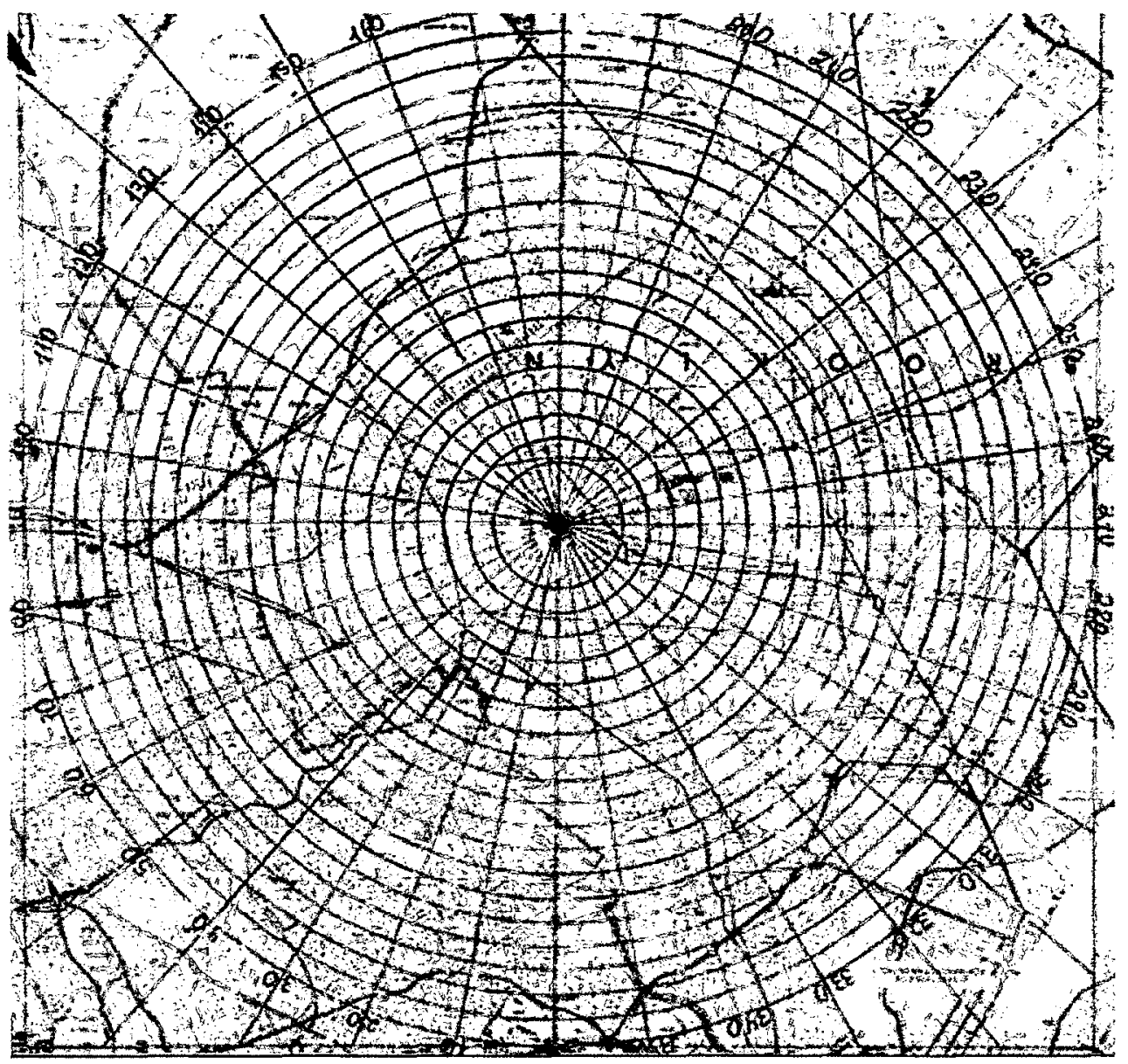

Figure 4-17. Score for Treasure Hunt (urban event). A standard geographic map is segmented into territories that are to be systematically explored, experienced, and "collected" during performance. (Image from: Jocy de Oliveira, Days and Routes Through Maps and Scores [Ramona, CA: Lingua, 1983]. 94.) 


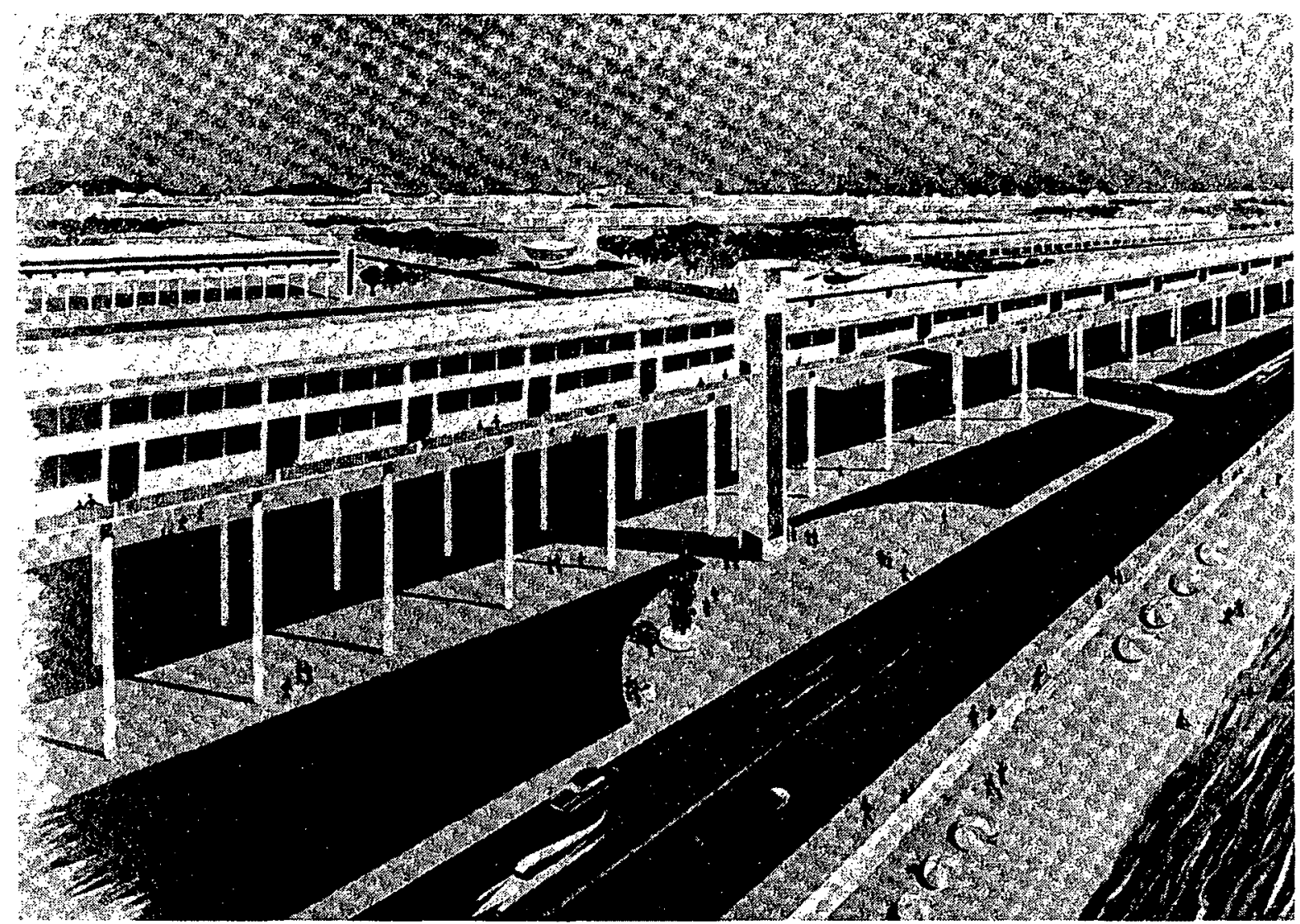

Figure 5-1. Drawing from La Ville Cybernétique showing a zone for sleeping. Buildings are oriented horizontally so as to promote sleep; however, Schöffer's plans do not seem to anticipate the effects of a rooftop helipad. (Image from: Nicolas Schöffer, La Ville Cybernétique [Paris: Tchou, 1969], insert near page 120.) 


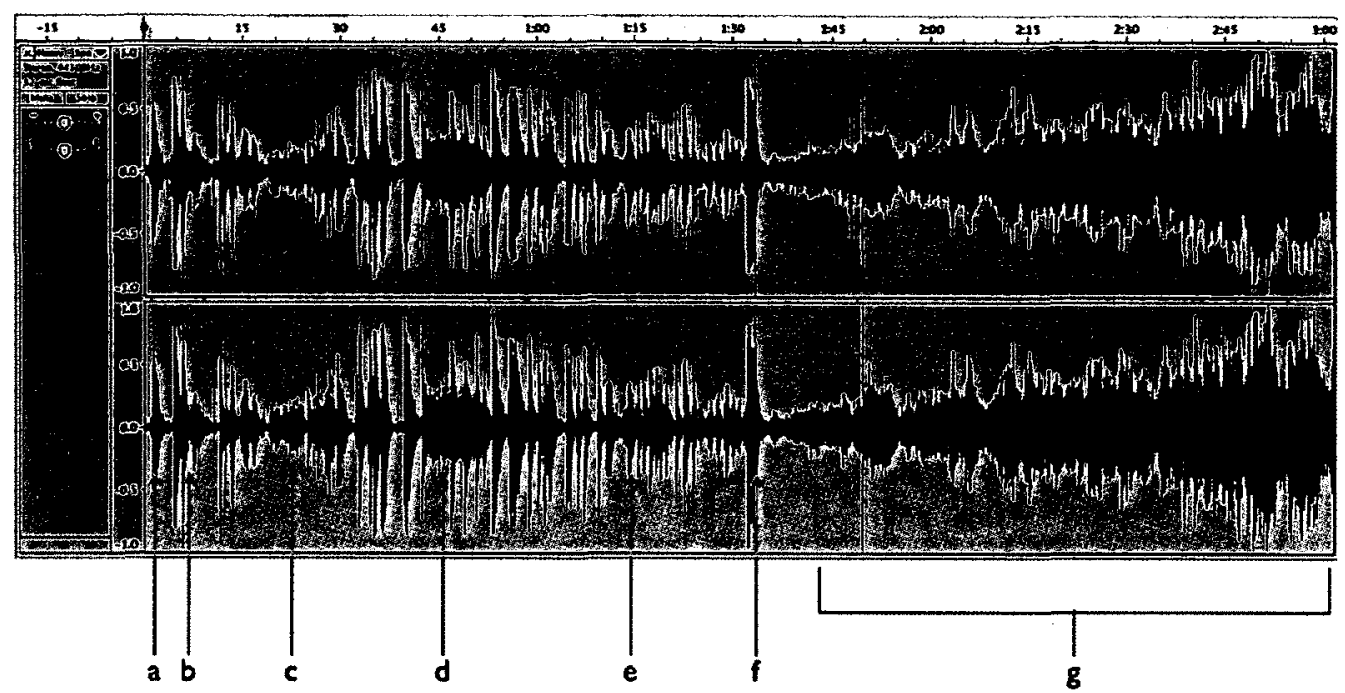

Key

a. punctuated sounds

b. punctuated sounds followed by scraping

c. rattling / rolling

d. period of counterpoint: sustained low tones layered by ratding / punctuated sounds

e. punctuated sounds followed by rattling / rolling

f. bang followed by deep thud

8. building intensity; layered counterpoint: high-pitched sound of bending metal (saw-like); lowpitched rumble; growing frequency of punctuated sounds, bangs, and thuds; ends with loud rattling.

Figure 5-2A. Annotated waveform of Spatiodynamisme, composed by Pierre Henry for broadcast from Schöffer's tower in St. Cloud. Image by the author. 


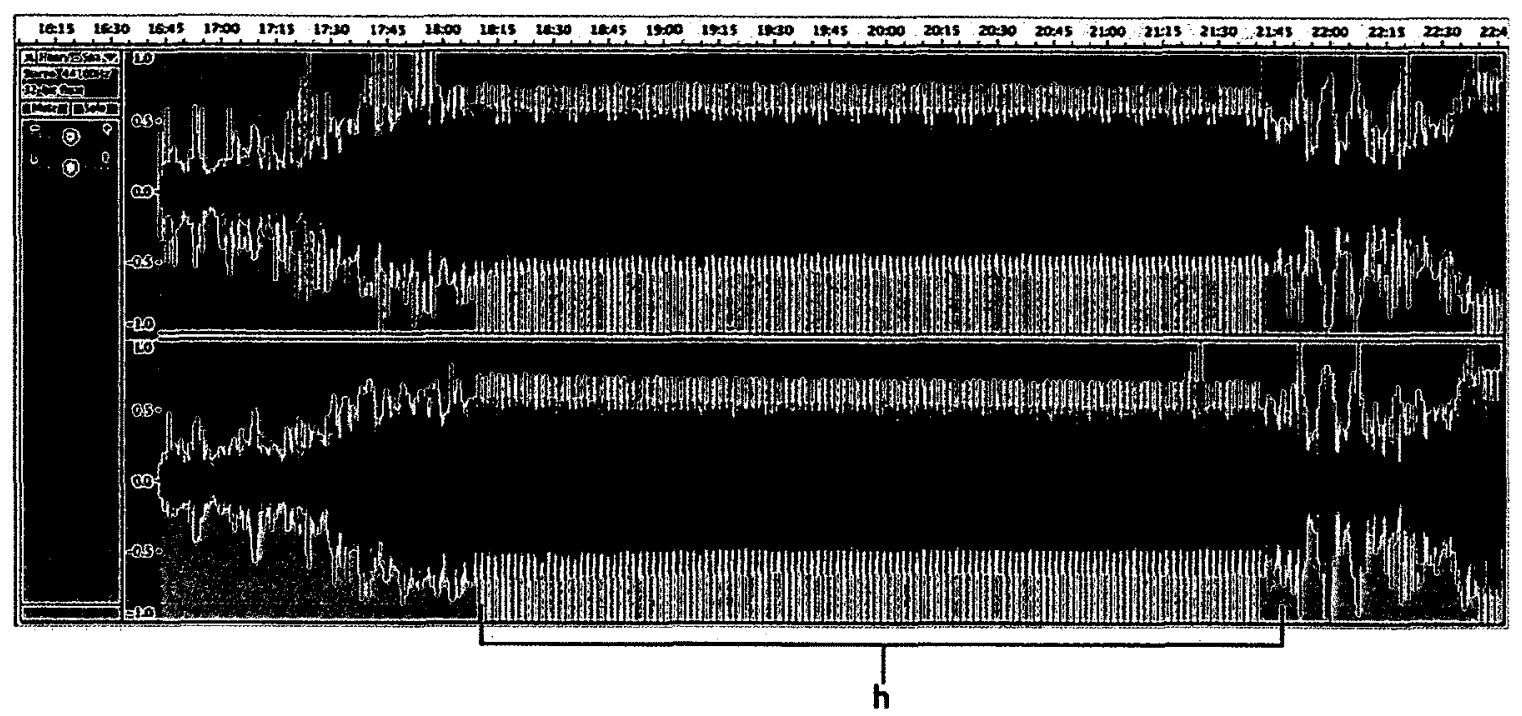

\section{Key}

h. sustained looping (about 3 loops per second); rattling, slight pitch bending

Figure 5-2B. Annotated waveform of Spatiodynamisme, composed by Pierre Henry for broadcast from Schöffer's tower in St. Cloud. Image by the author. 


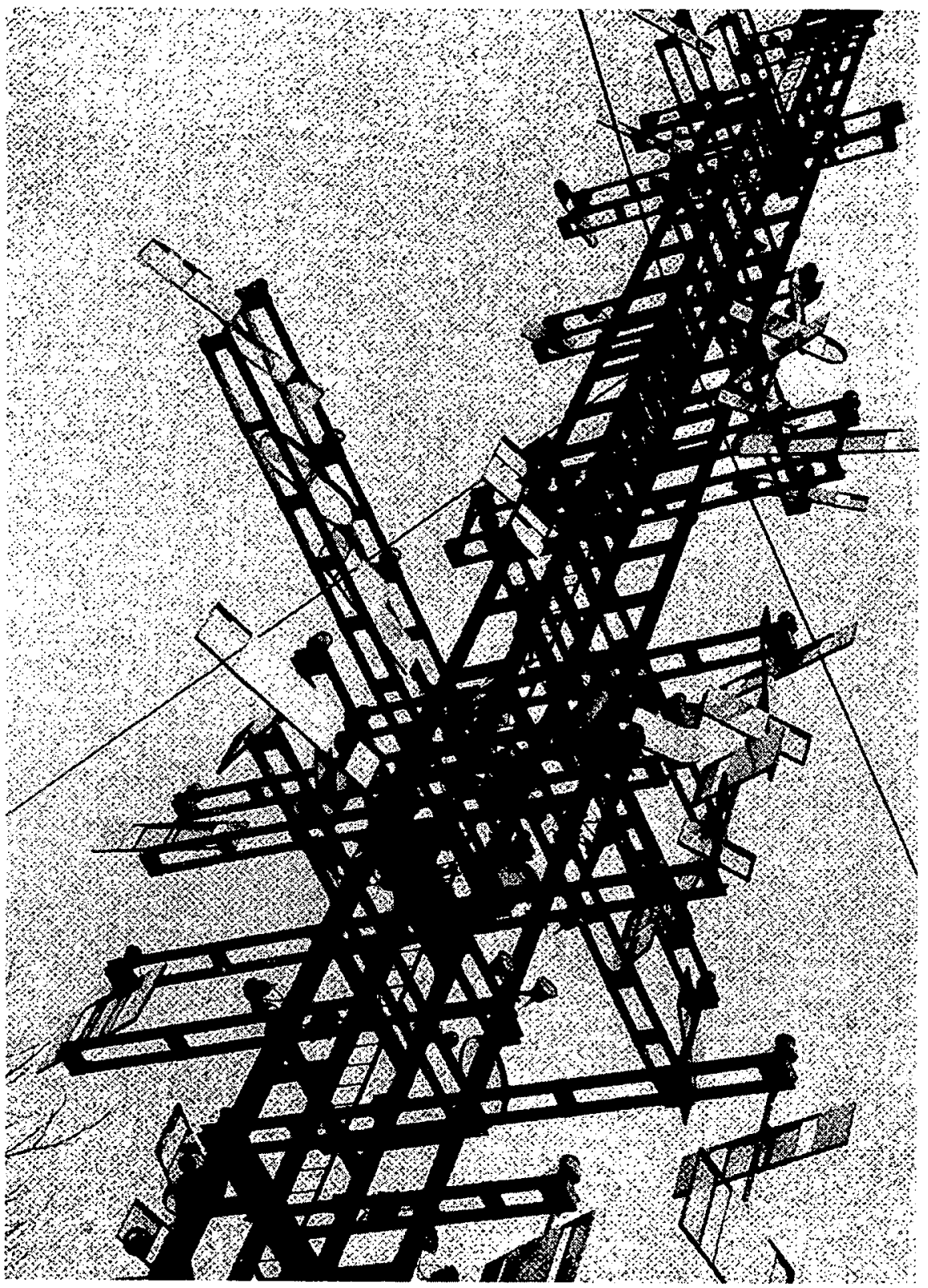

Figure 5-3. Photograph of Chronos 3, a cybernetic tower constructed in Liège, Belgium in 1961. (Image from: Nicolas Schöffer, La Ville Cybernétique [Paris: Tchou, 1969], insert near page 65.) 


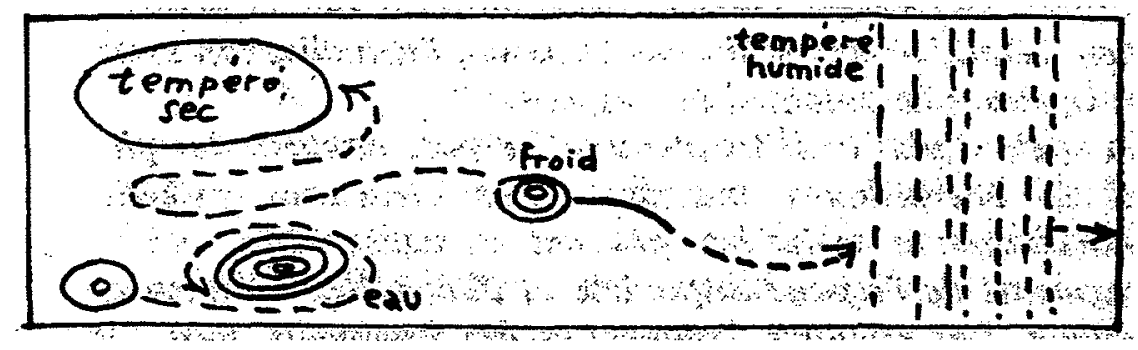

Figure 5-4A. Notational fragment for the topology of weather. (Image from: Nicolas Schöffer, La Ville Cybernétique [Paris: Tchou, 1969], 117.)

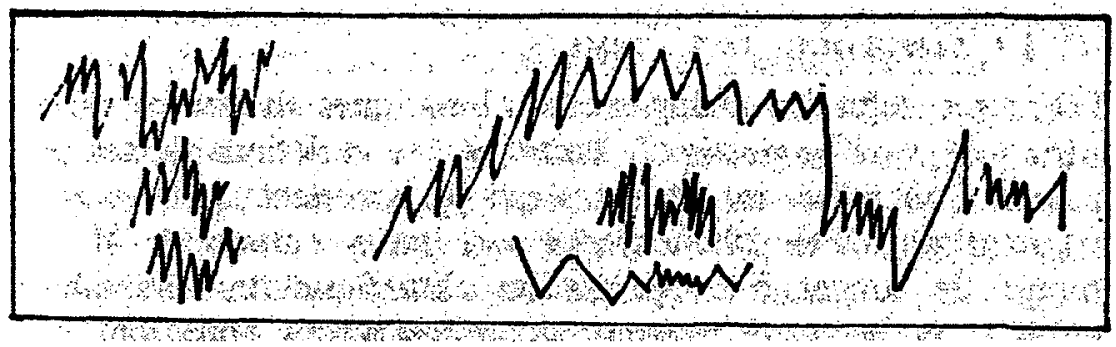

Figure 5-4B. Notational fragment for the topology of sound. (Image from: Nicolas Schöffer, La Ville Cybernétique [Paris: Tchou, 1969], 115.) 


\section{Bibliography}

Adams, Mags, Trevor Cox, Gemma Moore, Ben Croxford, Mohamed Refaee, and Steve Sharpless. "Sustainable Soundscapes: Noise Policy and Urban Experience." Urban Studies 43, no. 13 (December 2006): 2385-2398.

Aichele, K. Porter. "Paul Klee's 'Rhythmisches': A Recapitulation of the Bauhaus Years." Zeitschrift für Kunstgeschichte 57, no. 1 (1994): 75-89.

Airport Noise and Capacity Act of 1990. U.S. Code. Vol. 49, secs. 9302-09.

Alvarado v. Memphis-Shelby County Airport Authority. 2000 U.S. App LEXIS 21259. August 15, 2000, Filed.

Anderson, Virginia. "Aspects of British Experimental Music as a Separate Art-Music Culture." Ph.D. diss., Royal Holloway College, University of London, 2004.

_. "Well, It's a Vertebrate...': Performer Choice in Cardew's Treatise 1." Journal of Musicological Research 25, no. 3/4 (December 2006): 291-317.

Anderson, Sven. "Microsound in Public Space: Compositional Methods to Enhance SiteSpecific Sound." Organised Sound 13, no. 1 (2008): 51-60.

Andreotti, Libero and Xavier Costa, eds. Theory of the Dérive and other situationist writings on the city. Barcelona: Museu d'Art Contemporani de Barcelona, 1996.

Appleyard, Donald, Kevin Lynch and John R. Myer, The View from the Road. Cambridge, MA: The Massachusetts Institute of Technology, 1964.

Atkinson, Rowland. "Ecology of Sound: The Sonic Order of Urban Space." Urban Studies 44, no. 10 (September 2007): 1905-1917.

Augoyard, Jean-François and Henry Torgue, eds. Sonic Experience: A Guide to Everyday Sounds. Translated by Andra McCartney and David Paquette. Montreal and London: McGill-Queen's University Press, 2006.

Bain, Mark. "The Live Room: Transducing Resonant Architectures." Organised Sound 8, no. 2 (2003): 163-170.

Balaÿ, Olivier. "Discrete mapping of urban soundscapes." Translated by Harry Forster. Soundscape: The Journal of Acoustic Ecology 5, no. 1 (Spring/Summer 2004): 13-14. 
Bandt, Ros. "Designing Sound in Public Space in Australia: a Comparative Study Based on the Australian Sound Design Project's Online Gallery and Database."

Organised Sound 10, no. 2 (2005): 129-140.

- "Sound Installation: Blurring the Boundaries of the Eye, the Ear, Space and Time." Contemporary Music Review 25, no. 4 (August 2006): 353-365.

Baranzini, Andrea and José V. Ramirez. "Paying for Quietness: The Impact of Noise on Geneva Rents," Urban Studies 42, no. 4 (April 2005): 633-646.

Barrett, Natasha. "Spatio-musical Composition Strategies." Organised Sound 7, no. 3 (2002): 313-323.

Baudrillard, Jean. Simulacra and Simulation. Translated by Sheila Faria Glaser. Ann Arbor, MI: The University of Michigan Press, 1994.

Berland, Jody. "Locating Listening: Technological Space, Popular Music, and Canadian Mediations." In The Place of Music. Edited by Andrew Leyshon, David Matless, and George Revill. New York: The Guilford Press, 1998.

Bijsterveld, Karin. Mechanical Sound: Technology, Culture and Public Problems of Noise in the Twentieth Century. Cambridge, MA: The MIT Press, 2008.

Böhme-Mehner, Tatjana. "Sound and Musics in the Global Village: On Landscapes in Sound and Landscapes in Culture." Organised Sound 13, no. 2 (2008): 153-160.

Borges, Jorge Luis. "On Exactitude in Science." In Collected Fictions. Translated by Andrew Hurley. New York: Viking, 1998.

Braasch, Jonas, Nils Peters and Daniel L. Valente. "A Loudspeaker-Based Projection Technique for Spatial Music Applications Using Virtual Microphone Control." Computer Music Journal 32, no. 3 (Fall 2008): 55-71.

Brainard, Julii S., Andrew P. Jones, Ian J. Bateman, and Andrew A. Lovett. "Exposure to Environmental Urban Noise Pollution in Birmingham, UK." Urban Studies 41, no. 13 (December 2004): 2581-2600.

Brant, Henry. Ice Field: Spatial Narratives for Large and Small Orchestral Groups. New York: Carl Fischer, 2002.

- On the Nature of Things (after Lucretius): Spatial Tone Poem. New York: Carl Fischer, 1996.

- "Spatial Music Progress Report." http:/www.jaffe.com/BrantSpatial1979.pdf. Accessed 22 February 2012. 
— Verticals Ascending after the Rodia Towers. New York: MCA Music, 1969.

Braziller, George. Richard Long: Walking in Circles. London: The South Bank Centre, 1991.

Brown, Earle. "The Notation and Performance of New Music." Musical Quarterly 72, no. 2 (1987): 180-201.

Buchen, Bill and Mary Buchen. Urban Sound Park Design. New York: by the authors, 1994.

Buderer, Hans-Jurgen. "Kinetische Skulptur - Beispiele der Visualisierung von Bewegung." Marburger Jahrbuch für Kunstwissenschaft 23. Plastische Erkenntnis und Verantwortung: Studien zur Skulptur und Plastik nach 1945 (1993): 55-68.

Building Research Station. Ministry of Public Building and Works. London Noise Survey. Her Majesty's Stationery Office: London, 1968.

Burnett, Charles, Michael Fend, and Penelope Gouk, eds. The Second Sense: Studies in Hearing and Musical Judgement from Antiquity to the Seventeenth Century. London: The Warburg Institute, 1991.

Busbea, Larry. Topologies: The Urban Utopia in France, 1960-1970. Cambridge, MA: The MIT Press, 2007.

- "Toward Superland: ambient objects and environmental semiotics in France, c. 1965." Architecture + Art: New Visions, New Strategies. Helsinki, Finland: Alvar Aalto Academy, 2007.

Bush, Julia. A Decade of Sculpture: The 1960's. Philadelphia: The Art Alliance Press, 1974.

Butler, Toby. "A Walk of Art: The Potential of the Sound Walk as a Practice in Cultural Geography." Social \& Cultural Geography 7, no. 6 (December 2006): 889-908.

Cage, John. Concert for Piano and Orchestra. New York: Henmar Press, 1960.

—. Silence. Middletown, CT: Wesleyan University Press, 1939.

- Song Books, Volume I. Solos for Voice: 3-58. New York and London: C.F. Peters, 1970. 
Callon, Michel. "Some Elements of a Sociologigy of Translation: Domestication of the Scallops and the Fisherman of St. Brieuc Bay." In Power, Action, and Belief: A New Sociology of Knowledge? Ed. J. Law. London: Routledge, 1986.

Cardew, Cornelius. Memories of You. London: Universal Edition, 1967.

—. Treatise. Frankfurt and New York: Edition Peters, 1970.

Carlyle, Angus, ed. Autumn Leaves: Sound and the Environment in Artistic Practice. Paris: Double Entendre, 2007.

Carrol, Lewis. Sylvie and Bruno Concluded. New York: MacMillan and Co., 1893.

Chua, Daniel K. L. Absolute Music and the Construction of Meaning. Cambridge: Cambridge University Press, 1999.

City of Atlanta v. Watson. 1996 Ga. LEXIS 709. September 23, 1996, Decided.

City of Vancouver. "City Noise: Report of the Urban Noise Task Force." April 1997. http://vancouver.ca/ctyclerk/cclerk/970513/citynoisereport/. Accessed 18 July 2012.

Cohen, Sara. "Sounding Out the City: Music and the Sensuous Production of Place." In The Place of Music. Edited by Andrew Leyshon, David Matless, and George Revill. New York: The Guilford Press, 1998.

Collins, Nicolas. "Ubiquitous Electronics: Technology and Live Performance 1966-1996." Leonardo Music Journal 8, Ghosts and Monsters: Technology and Personality in Contemporary Music (1998): 27-32.

Commission Directive No. 2002/49, O.J. L 182/12. The European Parliament and the Council of the European Union. Directive 2002/49/EC. Relating to the assessment and management of environmental noise, L. 189/12.

Conley, Verena. "Minoritarian." The Deleuze Dictionary. Edited by Adrian Parr. Edinburgh: Edinburgh University Press, 2005.

Contemporary Arts Museum, Houston. Richard Long: Circles, Cycles, Mud Stone. Essays by Richard R. Brettell and Dana Friis-Hansen. Houston: Contemporary Arts Museum, 1996.

Couprie, Pierre. "Graphical Representation: An Analytical and Publication Tool for Electroacoustic Music." Organised Sound 9, no. 1 (2004): 109-113.

Cox, Christoph. "Sound Art and the Sonic Unconscious." Organised Sound 14, no. 1 (2009): 19-26. 
Cupers, Kenny. Walking as Do-It-Yourself Urbanism. London: Goldsmiths, University of London, 2004.

Cusick, Suzanne. "Music as Torture / Music as Weapon." Trans: Revista Transcultural de Música 10 (2006). http://www.sibetrans.com/trans/a152/music-as-torture-musicas-weapon. Accessed 18 July 2012.

- " "You are in a place out of the world": Music in the Detention Camps of the 'Global War on Terror."' Journal of the Society for American Music 2 (2008): $1-27$.

Debord, Guy, et al. Beneath the Paving Stones: Situationists and the Street, May 1968. Texts collected by Dark Star. Edinburgh and San Francisco: AK Press, 2001.

- "Theory of the dérive." In Theory of the Dérive and other situationist writings on the city. Libero Andreotti and Xavier Costa, eds. Barcelona: Museu d'Art Contemporani de Barcelona, 1996.

Deleuze, Gilles. Difference and Repetition. Translated by Paul Patton. New York: Columbia University Press, 1994.

- Kafka: Toward a Minor Literature. Translated by Dana Polan. Minneapolis: University of Minnesota Press, 1986.

Deleuze, Gilles and Félix Guattari. A Thousand Plateaus: Capitalism and Schizophrenia. Translated by Brian Massumi. Minneapolis and London: University of Minnesota Press, 1987.

Dennis, Brian. "Cardew's 'Treatise' (Mainly the Visual Aspects." Tempo 177 (1991): 10-16.

—_. "Xenakis's 'Terretktorh' and 'Eonta'." Tempo 82 (Autumn 1967): 27-29.

Department for Environment, Food, and Rural Affairs. "Noise Mapping England." http:// services.defra.gov.uk/wps/portal/noise. Accessed 18 January 2013.

Dowling; J.L., D.A. Luther, and P.P. Marra. "Comparative effects of urban development and anthropogenic noise on bird songs." Behavioral Ecology 23, no. 1 (Jan. 2012): 201-09.

Eco, Umberto. The Open Work. Translated by Anna Concogni. Cambridge, MA: Harvard University Press, 1989.

Ednie-Brown, Pia. "The Texture of Diagrams: Reasonings on Greg Lynn and Francis Bacon." Diadalos 74 (2000): 72-79. 
Elvins, Simon. "Silent London." In Mapping London: Making Sense of the City. Ed. Simon Foxell. London: Black Dog Publishing, 2007.

— . "Silent London." Digital reproduction of a blind embossed etching. http:// www.simonelvins.com/silent_london.html. Accessed 6 February 2013.

Espey, Molly and Hillary Lopez. "The Impact of Airport Noise and Proximity on Residential Property Values." Growth and Change 31 (Summer 2000): 408-419.

Evans, Brian. "Foundations of a Visual Music." Computer Music Journal 29, no. 4 (Winter 2005): 11-24.

EXPO '67: The Memorial Album of the first category universal and international Exhibition held in Montreal from the twenty-seventh of April to the twenty-ninth of October nineteen hundred and sixty-seven. Thomas Nelson \& Sons, 1968.

FAR Part 150 Noise Exposure Map Update Noise Exposure Maps Report. Prepared for the Port of Portland, Portland, Oregon. July 2010.

FAR Part 150 Study: Noise Exposure Maps Report. Prepared for the Hartsfield-Jackson Atlanta International Airport. 21 March 2007.

Federal Aviation Administration. "The FAR Part 150 Airport Noise Compatibility Planning Program: An Overview." http://www.faa.gov/about/office org/ headquarters_offices/apl/noise_emissions/planning_toolkit/media/II.B.pdf. Accessed 20 June 2012.

- "Integrated Noise Model (INM)," http://www.faa.gov/about/office org/ headquarters_offices/apl/research/models/inm model/. Accessed 20 June 2012.

Feingold, Mordechai and Penelope M. Gouk. "An Early Critique of Bacon's Sylva Sylvarum: Edmund Chilmead's Treatise on Sound." Annals of Science 40 (1983): 139-157.

Feld, Steven. Sound and Sentiment: Birds, Weeping, Poetics, and Song in Kaluli Expression. Philadelphia: University of Pennsylvania Press, 1990.

Feldstein, Richard, Bruce Fink and Maire Jaanus, eds. Reading Seminar XI: Lacan's Four Fundamental Concepts of Psychoanalysis. Albany, NY: State University of New York Press, 1995.

Fells, Nick. "On space, listening and interactions: Words on the streets are these and Still Life." Organised Sound 7, no. 3 (2002): 287-94. 
Fink, Bruce. "The Nature of Unconscious Thought or Why No One Ever Reads Lacan's Postface to the Seminar on 'The Purloined Letter'." In Reading Seminars I and II: Lacan's Return to Freud. Edited by Richard Feldstein, Bruce Fink, and Maire Jaanus. Albany: State University of New York Press, 1996.

—. "The Real Cause of Repetition." Reading Seminar XI: Lacan's Four Fundamental Concepts of Psychoanalysis. Edited by Richard Feldstein, Bruce Fink, and Maire Jaanus. Albany: State University of New York Press, 1995.

Fink, Robert. Repeating Ourselves: American Minimal Music as Cultural Practice. Berkeley: University of California Press, 2005.

Föllmer, Golo. "Klangorganisation im Öffentlichen Raum." Klangkunst 12 (1999): 191-227.

Fontana, Bill. "The Relocation of Ambient Sound: Urban Sound Sculpture." Special issue, Leonardo 20, no. 2 (1987): 143-147.

Forsyth, Michael. Buildings for Music: The Architect, the Musician, and the Listener from the Seventeenth Century to the Present Day. Cambridge, MA: The MIT Press, 1985.

Foucault, Michel. Discipline and Punish: The Birth of the Prison. Translated by Alan Sheridan. New York: Vintage Books, 1977.

Foxell, Simon. Mapping London: Making Sense of the City. London: Black Dog Publishing, 2007.

Frayne, Nigel. "Acoustic Design in the Built Environment." Soundscape: The Journal of Acoustic Ecology 5, no. 1 (Spring/Summer 2004): 15-19.

Gable, Frederick. "St. Gertrude's Chapel, Hamburg, and the Performance of Polychoral Music." Early Music 15, no. 2, Plucked String Issue (May 1987): 229-241.

Galerie Denise René. “Nicolas Schöffer.” Exhibition catalog. New York: Galerie Denise René, 1972.

Giere, Ronald. Scientific Perspectivism. Chicago: University of Chicago Press, 2006.

Gillies, John. "Maps, Knowledge, and Power." In The Iconography of Landscape. Edited by D. Cosgrove and S.J. Daniels. Cambridge, MA: Cambridge University Press, 1988.

- "Silences and Secrecy: The Hidden Agenda of Cartography in Early Modern Europe." Imago Mundi 40 (1988): 57-76. 
Giomi, Francesco, Damiano Meacci, and Kilian Schwoon. "Electroacoustic music in a multi-perspective architectural context: a sound installation for Renzo Piano's Auditorium in Rome." Organised Sound 8, no. 2 (2003): 157-162.

Godwin, Joscelyn. Athanasius Kircher's Theatre of the World: The Life and Work of the Last Man to Search for Universal Knowledge. Rochester, VT: Inner Traditions, 2009.

Goehr, Lydia. The Imaginary Museum of Musical Works. Oxford: Oxford University Press, 1994.

Goetz, Andrew R. and Christopher J. Sutton. "The Geography of Deregulation in the U.S. Airline Industry." Annals of the Association of American Geographers 87, no. 2 (June 1997): 238-263.

Goines, Lisa and Louis Hagler. "Noise Pollution: A Modern Plague." Southern Medical Journal 100, no. 3 (March 2007): 287-294.

Gouk, Penelope. Music, Science and Natural Magic in Seventeenth-Century England. New Haven and London: Yale University Press, 1999.

- "The Role of Acoustics and Music Theory in the Scientific Work of Robert Hooke." Annals of Science 37 (1980): 573-605.

_. "In Search of Sound: Authenticity, Healing and Redemption in the Early Modern State." Senses \& Society 2, no. 3 (2007): 303-328.

Graeven, David B. "The Effects of Airplane Noise on Health: An Examination of Three Hypotheses." Journal of Health and Social Behavior 15, no. 4 (December 1974): 336-343.

Grant, Morag Josephine. "Experimental Music Semiotics." International Review of the Aesthetics and Sociology of Music 34, no. 2 (December 2003): 173-191.

Greene, Lindsey A. "Noise Pollution: FAA Turns Down the Volume." Environmental Health Perspectives 108, no. 4 (April 2000): A166.

Guattari, Félix. "Regimes, Pathways, Subjects." Translated by Brian Massumi. Incorporations. Jonathan Crary and Sanford Kwinter, eds. New York: Zone, 1992.

Hanoch-Roe, Galia. "Musical Space and Architectural Time: Open Scoring versus Linear Processes." International Review of the Aesthetics and Sociology of Music 34, no. 2 (December 2003): 145-160. 
Hardt, Michael and Antonio Negri. Commonwealth. Cambridge, MA: Belknap Press of Harvard University Press.

Harley, J.B. "Deconstructing the Map." Cartographica 26, no. 2 (Summer 1989): 1-20.

- "Historical geography and the cartographic illusion." Journal of Historical Geography 15, no. 1 (1989): 80-91.

— . "Silences and Secrecy: The Hidden Agenda of Cartography in Early Modern Europe." Imago Mundi 40 (1988): 57-76.

Harley, Maria Anna. "Music of Sound and Light: Xenakis's Polytopes." Leonardo 31, no. 1 (1998): 55-65.

Harvey, David. A Brief History of Neoliberalism. New York: Oxford University Press, 2005.

Hawking, Stephen. The Grand Design. New York: Bantam Books, 2010.

Higgins, Dick. "Intermedia." Leonardo 34, no. 1 (2001): 49-54.

Higgins, Hannah. The Grid Book. Cambridge, MA and London: The MIT Press, 2009.

Hyman, Paul. "Gender Bias at Wikipedia?" Communications of the ACM 54, no. 10 (2011): 18.

Ingold, Tim. "Against Soundscape." In Autumn Leaves: Sound and the Environment in Artistic Practice. Ed. Angus Carlyle. Paris: Double Entendre, 2007.

- Lines: A Brief History. London and New York: Routledge, 2007.

Irvine, Katherine N., Patrick Devine-Wright, Sarah R. Payne, Richard A. Fuller, Birgit Painter, and Kevin J. Gaston. "Green space, soundscape and urban sustainability: an interdisciplinary, empirical study." Local Environment 14, no. 2 (February 2009): 155-172.

Jameson, Fredric. "Cognitive Mapping." In Marxism and the Interpretation of Culture. Ed. C. Nelson and L. Grossberg. Champaign, IL: University of Illinois Press, 1990.

Järviluoma, Helmi, Kytö Meri, Barry Truax, Heikki Uimonen, and Noora Vikman. Acoustic Environments in Change and Five Village Soundscapes. Tampere, Finland: Tampereen ammattikorkeakoulu, 2009. 
The Jewish Museum of New York. 2 Kinetic Sculptors: Nicolas Schöffer and Jean Tinguely. With essays by Jean Cassou, K.G. Hultèn, and Sam Hunter. New York: Jewish Museum, 1965.

Jones, Evan. "Mapping Musical Space." In Mapping in the Age of Digital Media: The Yale Symposium. Mike Silver and Diana Balmori, eds. West Sussex, UK: WileyAcademy, 2003.

Jones, Stuart. "space-dis-place: How Sound and Interactivity Can Reconfigure Our Apprehension of Space." Leonardo Music Journal 16 (2006): 20-27.

Jopson, Ian. "Aircraft Noise Model Validation: How Accurate Do We Need to Be?" http://www.caa.co.uk/docs/68/dap ercd 1102 modelaccuracy.pdf. Accessed 10 July 2012.

Joray, Marcel, ed. Nicolas Schöffer. Introduction by Jean Cassou. With articles by Guy Habasque and Jacques Ménétrier. Translated by Hakkon Chevalier. Neuchâtel, Switzerland: Éditions du Griffon, 1963.

Katz, Barry M. "Technology and Design - A New Agenda." Technology and Culture 38, no. 2 (April 1997): 452-466.

Karkoschka, Erhard. Notation in New Music: A Critical Guide to Interpretation and Realisation. New York and Washington: Praeger Publishers, 1972.

Kleilein, Doris and Anne Kockelkorn, eds. Tuned City: Zwischen Klang- und Raumspekulation. Berlin: Kookbooks, 2008.

Klein, Georg. "From the sound installation to the sound situation: on my work transition - berlin junction eine klangsituation." Organised Sound 8/2 (2003): 187-93.

Kline, Ronald and Trevor Pinch. "Users as Agents of Technological Change: The Social Construction of the Automobile in the Rural United States." Technology and Culture 37 (1996): 763-795.

Kostelanetz, Richard. "Text-Sound Art: A Survey." Performing Arts Journal 2, no. 3 (Winter 1978): 71-84.

Kotz, Liz. Words to Be Looked At: Language in 1960s Art. Cambridge, MA: The MIT Press, 2007.

$\mathrm{Ku}$, Ja Hyon. "Uses and Forms of Instruments: Resonator and Tuning Fork in Rayleigh's Acoustical Experiments." Annals of Science 66, no. 3 (2009): 371-395. 
Lacan, Jacques. Ecrits: The First Complete Edition in English. Translated by Bruch Fink in collaboration with Héloïse Fink and Russell Griggs. New York: W.W. Norton \& Co., 2006.

—_. "Radiophonie." In Scilicet 2/3 (Paris: Seuil, 1970): 55-99. Translated by Jack W. Stone. http://web.missouri.edu/ stonej/Radiophonie.pdf. Accessed 6 February 2013.

LaBelle, Brandon. Background Noise: Perspectives on Sound Art. New York and London: Continuum, 2006.

LaBelle, Brandon and Steve Roden, eds. Site of Sound: Of Architecture and the Ear. Los Angeles: Errant Bodies Press, 1999.

Landy, Burton A. and Carl E. B. McKenry. "Aviation Report." Lawyer of the Americas 12 , no. 3 (Fall 1980): 704-716.

Lange, Barbara Rose. "The Politics of Collaborative Performance in the Music of Pauline Oliveros." Perspectives of New Music 46/1 (Winter 2008): 39-60.

Latour, Bruno. Science in Action: How to Follow Scientists and Engineers through Society. Cambridge, MA: Harvard University Press, 1987.

Law, John. "Monsters, machines and sociotechnical relations." A Sociology of Monsters: Essays on Power, Technology and Domination. Ed. John Law. London: Routledge, 1991.

- "Notes on the Theory of the Actor Network: Ordering, Strategy and Heterogeneity." Centre for Science Studies - Lancaster University. http:// www.lancs.ac.uk/fass/sociology/papers/law-notes-on-ant.pdf. Accessed 10 January 2012.

- "On power and its tactics; a view from the sociology of science." Sociological Review 34 (1986): 1-38.

_- "Power, discretion and strategy." A Sociology of Monsters: Essays on Power, Technology and Domination. Edited by John Law. London: Routledge, 1991.

Lefebvre, Henri. Rhythmanalysis: Space, Time and Everyday Life. New York: Continuum International, 2004.

Leupin, Alexandre. Lacan Today: Psychoanalysis, Science, Religion. New York: Other Press, 2004. 
Lockwood, Annea. Sound Map of the Hudson River. Lovely Music. Audio compact disc. 1989.

Lucier, Alvin. "I Am Sitting In A Room." In Source: Music of the Avant Garde 4, no. 1 (1970): 60 .

- Kettles: for five timpani and two slow-sweep pure wave oscillators. Material Press, 1988.

- "On Stuart Marshall: Composer, Video Artist and Filmmaker, 1949-1993." Special issue, Leonardo Music Journal 11 (2001): 51-52.

—_. "Origins of Form: Acoustical Exploration, Science and Incessancy." Special issue, Leonardo Music Journal 8 (1998): 5-11.

Maceachren, Alan M. and D. R. Fraser Taylor, eds. Visualization in Modern Cartography. New York: Elsevier Science, 1994

Macnaughtan, Chelle. "Indeterminate notation and sound in the space of architecture." The Journal of Architecture 11, no. 3 (2006): 335-344.

Maffiolo, V., M. Castellengo, and D. Dubois. "Qualitative Judgements of Urban Soundscapes." Proceedings of the International Congress on Noise Control Engineering 2 (1999): 1251-1254.

Maffiolo, V., D. Dubois, S. David, M. Castellengo, and J-D Polack. "Loudness and Pleasantness in Strucutration of Urban Soundscapes." Proceedings of the International Congress on Noise Control Engineering 2 (1998): 1059-1062.

Maffiolo, Valérie, Sophie David, Danièle Dubois, Corsin Vogel, Michèle Castellengo, Jean-Dominique Polack. "Sound Characterization of Urban Environment." Internoise 3 (1997): 1239-1242.

Malone, Kareen Ror and Stephen R. Friedlander, eds. The Subject of Lacan: A Lacanian Reader for Psychologists. Albany, NY: State University of New York Press, 2000.

Manolopoulou, Yeoryia. "Unformed drawing: notes, sketches, and diagrams." The Journal of Architecture 10, no. 5 (2005): 517-525.

Marry, Solène. "Assessment of Urban Soundscapes." Organised Sound 16, no. 3 (2011): 245-255.

Marshall, Stuart. "Zones (1969-1970)." In Source: Music of the Avant Garde 5, no. 2 (1971): 5-29. 
Matless, David. "Effects of History." Transactions of the Institute of British Geographers, 20, no. 4 (1995): 405-409.

McCartney Andrea Shirley Jean, Sounding Places: Situated Conversations Through the Soundscape Compositions of Hildegard Westerkamp. Ph.D. Diss, York University (Toronto, Ontario), 1999.

Miller, Nicholas P. "US National Parks and Management of Park Soundscapes: A Review." Applied Acoustics 69 (2008): 77-92.

Möntmann, Nina, Yilmaz Dziewior, and Hatje Cantz. Mapping a City. Published for the exhibition Mapping a City: Hamburg-Kartierung at the Kunstverein in Hamburg, 22 November 2003 - 22 February 2004. Ostfildern-Ruit, Germany: Hatje Cantz Verlag, 2004.

Montréal Sound Map. http://cessa.music.concordia.ca/soundmap/en/. Accessed 17 January 2011.

Moran, Robert. "Titus: Number 1 for Amplified Automobile." In Source: Music of the Avant Garde 2 no. 1 (1968): 80-81.

Morgan, Robert. "Musical Time / Musical Space." Critical Inquiry, 6, no. 3 (Spring 1980): 527-538.

Morrison, Steven A., Clifford Winston, and Tara Watson. "Fundamental Flaws of Social Regulation: The Case of Airplane Noise." Journal of Law and Economics 42, no. 2 (October 1999): 723-743.

Musical World Map. http://www.musicalworldmap.org/long-info. Accessed 17 January 2011.

National Galleries of Scotland. Richard Long: Walking and Marking. Trustees of the National Galleries of Scotland, 2007.

Nelson, Jon P. "Meta-Analysis of Airport Noise and Hedonic Property Values: Problems and Prospects." Journal of Transport Economics and Policy 38, no. 1 (January 2004): 1-27.

Ohlson, Birger. "Sound fields and sonic landscapes in rural environments." Geographical Society of Finland 148 (1976): 33-45.

de Oliveira, Jocy. Days and Routes Through Maps and Scores. Rio de Janeiro: Imprinta; Ramona, CA: Lingua, 1983. 
—. "Polinterações." In Source: Music of the Avant Garde 4, no. 2 (July 1970): 66-70.

_. "Probabilistic Theater I." In Source: Music of the Avant Garde 2, no. 2 (1968): 34-36.

Oliveros, Pauline. Aeolian Partitions. Brunswick, ME: Bowdoin College Music Press, 1970.

- Single Stroke Roll: for a soloist or an ensemble of drummers. Baltimore: Smith Publications, 1990.

- Tashi Gomang for orchestra. Smith Publications, 1981.

Oliveros, Pauline and Fred Maus. "A Conversation about Feminism and Music." Perspectives of New Music 32, no. 2 (Summer 1994): 174-93.

O'Reilly, Tim. "What is Web 2.0?" http://oreilly.com/pub/a/web2/archive/what-isweb-20.html?page=1. Accessed 30 January 2011.

Oswalt, Philipp. "Iannis Xenakis' Polytopes." Translated by Tas Skorupa. Contemporary Music Review 21, nos. 2/3 (2002): 35-44.

Ouzounian, Gascia. "Sound Art and Spatial Practices: Situating Sound Installation Art Since 1958." Ph.D. diss., University of California, San Diego, 2008.

Packer, Randall and Ken Jordan, eds. Multimedia: from Wagner to virtual reality. New York: Norton, 2001.

Padrón, Ricardo. "Mapping Plus Ultra: Cartography, Space, and Hispanic Modernity." Representations 79 (Summer 2002): 28-60.

-The Spacious Word: Cartography, Literature, and Empire in Early Modern Spain. Chicago: University of Chicago Press, 2004.

Parr, Adrian. "Deterritorialisation / Reterritorialisation." In The Deleuze Dictionary. Edited by Adrian Parr. Edinburgh: Edinburgh University Press, 2005.

Parr, Joy. "Notes for a More Sensuous History of Twentieth-Century Canada: The Timely, the Tacit, and the Material Body." The Canadian Historical Review 82, no. 4 (December 2001): 720-745.

Pennington, G., N. Topham, R. Ward. "Aircraft Noise and Residential Property Values Adjacent to Manchester International Airport." Journal of Transport Economics and Policy 24, no. 1 (January 1990): 49-59. 
Pickles, John. A History of Spaces: Cartographic Reason, Mapping and the Geo-Coded World. London and New York: Routledge, 2004.

—_. "Texts, Hermeneutics and Propaganda Maps." In Writing Worlds: Discourse, Text and Metaphor in the Representation of Landscape. Edited by by T.J. Barnes and J.S. Duncan. London and New York: Routledge, 1992.

Pinch, Trevor and Wiebe E. Bijker. "The Social Construction of Facts and Artifacts: Or How the Sociology of Science and the Sociology of Technology Might Benefit Each Other." In The Social Construction of Technological Systems. Eds. W. Bijker, T.P. Hughes, and T. Pinch. Cambridge, MA: The MIT Press, 1987.

Pinch, Trevor and Karin Bijsterveld. “'Should One Applaud?': Breaches and Boundaries in the Reception of New Technology in Music." Technology and Culture 44, no. 3 (July 2003): 536-559.

Pinch, Trevor and Frank Trocco. Analog Days: The Invention and Impact of the Moog Synthesizer. Cambridge, MA: Harvard University Press, 2002.

Pink, Sarah. Doing Sensory Ethnography. Los Angeles and London: Sage, 2009.

Pisaro, Kathryn Gleasman. "Music from Scratch: Cornelius Cardew, experimental music and the Scratch Orchestra in Britain in the 1960's and 1970's." Ph.D. diss., Northwestern University, 2001.

Plessas, Demetrius J. "Airport Noise: Some Analytic and Policy Perspectives." Land Economics 49, no. 1 (February 1973): 14-221.

Pocock, Douglas. "Sound and the Geographer." The Geographical Association (1989): 193-200.

Pocock-Williams, Lynn. "Toward the Automatic Generation of Visual Music." Leonardo 25, no. 1 (1992): 29-36.

van Praag, Bernard M. S. and Barbara E. Baarsma. "Using Happiness Surveys to Value Intangibles: The Case of Airport Noise." The Economic Journal 115 (January 2005): 224-246.

Radio Aporee. http://aporee.org/maps/info. Accessed 12 January 2011.

Rebelo, Pedro. "Performing space." Organised Sound 8, no. 2 (2003): 181-186.

Rehding, Alexander. "Wax Cylinder Revolutions." The Musical Quarterly 88, no. 1 (Spring 2005): 123-60.

Reich, Steve. Four Organs. London: Universal Edition, 1980. 
- Music for 18 Musicians. New York: Boosey and Hawkes, 2000.

- Music for Pieces of Wood. London: Universal Edition, 1980.

Rodaway, Paul. Sensuous Geographies: Body, Sense, and Place. London and New York: Routledge, 1994.

Rosler, Martha. "In the Place of the Public: Observations of a Frequent Flyer." Assemblage 25 (Dec. 1994): 44-79.

Rousseau, Jean-Jacques. "Orchestra." A Dictionary of Music. Translated from French by William Waring, London: 1775.

Sabine, Paul E. Acoustics and Architecture. New York and London: McGraw-Hill Book Company, 1932.

Sabine, Wallace Clement. Collected Papers on Acoustics. Cambridge, MA: Harvard University Press, 1922.

Sadler, Simon. The Situationist City. Cambridge, MA: The MIT Press, 1998.

Safran, Yehuda. "Drawings." In Max Neuhaus: Sound Works. Vol. II. Ostfildern-Stuttgart: Cantz, 1994.

Samartzis, Philip. "Surround Sound in Installation Art." Ph.D. diss, Royal Melbourne Institute of Technology, 2004.

Sant, Alison. "Redefining the Basemap." Intelligent Agent 6, no. 2 (2006). http:// www.intelligentagent.com/archive/Vol6 No2 interactive_city_sant.htm. Accessed 18 November 2011.

Schafer, R. Murray. The Soundscape: Our Sonic Environment and the Tuning of the World. Rochester, VT: Destiny Books, 1994.

Schafer, R. Murray, ed. Five Village Soundscapes. Vancouver: A.R.C. Publications, 1977.

The Vancouver Soundscape. Vancouver: A.R.C. Publications, 1978.

Schell, Lawrence. "Effects of Noise Contribute to Physicians' Challenges." Southern Medical Journal 100, no. 3 (March 2007): 240-241.

Schöffer, Nicolas. La Nouvelle Charte de la Ville. Paris: Denoël/Gonthier, 1974.

—. La Tour Lumiere Cybernétique. Paris: Denoël, 1973.

—. La Ville Cybernétique. Paris: Tchou, 1969. 
- "Sonic and Visual Structures: Theory and Experiment." Translated by Elizabeth Wright. Leonardo 18, no. 2 (1985): 59-68.

Sheridan, Ted and Karen Van Lengen. "Hearing Architecture: Exploring and Designing the Aural Environment." Journal of Architectural Education (2003): 37-44.

Silver, Mike and Diana Balmori, eds. Mapping in the Age of Digital Media: The Yale Symposium. Chichester, UK: Wiley-Academy, 2003.

Small, Christopher. Musicking: The Meanings of Performing and Listening. Hanover, NH: University Press of New England, 1998.

Smalley, Denis. "Space-Form and the Acousmatic Image." Organised Sound 12, no. 1 (2007): 35-58.

- Spectromorphology: Explaining Sound-Shapes." Organised Sound 2, no. 2 (1997): 107-26.

Soja, Edward. "The Socio-Spatial Dialectic." Annals of the Association of American Geographers 70, no. 2 (June 1980): 207-225.

Sounds Around You. http://www.soundaroundyou.com. Accessed 17 January 2011.

Southworth, Michael. "The Sonic Environment of Cities." Environment and Behavior 1, no. 1 (June 1969): 49-70.

Spitzer, John and Neal Zaslaw. Birth of the Orchestra: History of an Institution, 1650-1815. Oxford: Oxford University Press, 2004.

Spivak, Gayatri Chakravorty. "Can the Subaltern Speak?" In Marxism and the Interpretation of Culture. Ed. C. Nelson and L. Grossberg. Champaign, IL: University of Illinois Press, 1990.

Sterne, Jonathan. The Audible Past: The Cultural Origins of Sound Reproduction. Durham, NC: Duke University Press, 2003.

Stone, Kurt. Music Notation in the Twentieth Century: A Practical Guidebook. New York: Norton, 1980.

Szlicheinski, K.P. "The Art of Describing Sounds." Applied Ergonomics 10, no. 3 (1979): 131-139.

Thompson, Emily. The Soundscape of Modernity: Architectural Acoustics and the Culture of Listening in America, 1900-1933. Cambridge, MA: MIT Press, 2002. 
Tilbury, John. Cornelius Cardew (1936-1981): A Life Unfinished. Harlow, Essex: Copula, 2008.

Tomkins, J., N. Topham, J. Twomey and R. Ward, "Noise versus Access: The Impact of an Airport in an Urban Property Market." Urban Studies 35, no. 2 (1998): 243-258.

Traub, Peter. "Spatial Exploration: Physical, Abstracted, and Hybrid Spaces as Compositional Parameters in Sound Art." Ph.D. diss, University of Virginia, Charlottesville, Virginia, 2010.

Treib, Marc. "Mapping Experience." Design Quarterly 115 (1980): 1-32.

—. Space Calculated in Seconds. Princeton: Princeton University Press, 1996.

Truax, Barry. Acoustic Communication. Westport, CT: Ablex Publishing, 2001.

- Handbook for Acoustic Ecology. CD-ROM. Vancouver: Cambridge Street Publishing, 1999.

United States Gypsum. Sound Control in Design. 1959.

Vaidhyanathan, Siva. The Googlization of Everything (And Why We Should Worry). Berkeley: University of California Press, 2011.

Waldock, Jacqueline. "Soundmapping: Critiques and Reflections on this New Publicly Engaging Medium." Journal of Sonic Studies 1, no. 1 (October 2011). http:// journal.sonicstudies.org/vol01/nr01/a08. Accessed 23 April 2012.

Walker Art Center. "Art and Civic Engagement: Mapping the Connections." http:// learn.walkerart.org/resource.wac?id=2029. Accessed 16 October 2010.

Weibel, Peter. Beyond Art: A Third Culture. New York: Springer, 2005.

Westerkamp, Hildegard. "Soundwalking." Sound Heritage 3, no. 4 (1974). http:// www.sfu.ca/\%7Ewesterka/writings\%20page/articles\%20pages/ soundwalking.html. Accessed 12 May 2010.

World Health Organization. Guidelines for Community Noise. Edited by Birgitta Berglund, Thomas Lindvall, Dietrich H Schwela. www.who.intdocstore/peh/ noise/guidelines $2 . \mathrm{html}$. Accessed 16 January 2010.

Wurman, Richard Saul. "Making the City Observable." Design Quarterly 80 (1971): 1-3, 5-96. 
Xenakis, Iannis. Arts-Sciences, Alloys. Translated by Sharon Kanach. New York: Pendragon Press, 1985.

—. Musique, architecture. Paris: Casterman, 1976.

Polytope. London: Boosey and Hawkes, 1969.

Terretektorh: Pour Orchestre. Paris: Editions Salabert, 1969.

Zardini, Mirko. Sense of the City: An Alternate Approach to Urbanism. Montréal: Canadian Centre for Architecture, 2005.

Žižek, Slavoj. Interrogating the Real. Edited by Rex Butler and Scott Stephens. London and New York: Continuum, 2005.

- Welcome to the Desert of the Real: Five Essays on September 11 and Related Dates. New York: Verso, 2002.

Zorn, Jonathan. Interview by author. Questionnaire sent and received by email, Charlottesville, VA, 11 August 2010. Copy held in the author's possession.

Zorn, Jonathan, Rachel Thompson, et al. 466 Decibel Readings and 50 Sound Stories. Map created for the Twin Cities Design Festival in 2003, organized by the Walker Art Museum. Copy held in the author's possession. 